\title{
Hypoxia-induced metastasis : the role of the unfolded protein response
}

Citation for published version (APA):

Mujcic, H. (2013). Hypoxia-induced metastasis : the role of the unfolded protein response. [Doctoral Thesis, Maastricht University]. Datawyse / Universitaire Pers Maastricht.

https://doi.org/10.26481/dis.20130912hm

Document status and date:

Published: 01/01/2013

DOI:

10.26481/dis.20130912hm

Document Version:

Publisher's PDF, also known as Version of record

\section{Please check the document version of this publication:}

- A submitted manuscript is the version of the article upon submission and before peer-review. There can be important differences between the submitted version and the official published version of record.

People interested in the research are advised to contact the author for the final version of the publication, or visit the DOI to the publisher's website.

- The final author version and the galley proof are versions of the publication after peer review.

- The final published version features the final layout of the paper including the volume, issue and page numbers.

Link to publication

\footnotetext{
General rights rights.

- You may freely distribute the URL identifying the publication in the public portal. please follow below link for the End User Agreement:

www.umlib.nl/taverne-license

Take down policy

If you believe that this document breaches copyright please contact us at:

repository@maastrichtuniversity.nl

providing details and we will investigate your claim.
}

Copyright and moral rights for the publications made accessible in the public portal are retained by the authors and/or other copyright owners and it is a condition of accessing publications that users recognise and abide by the legal requirements associated with these

- Users may download and print one copy of any publication from the public portal for the purpose of private study or research.

- You may not further distribute the material or use it for any profit-making activity or commercial gain

If the publication is distributed under the terms of Article $25 \mathrm{fa}$ of the Dutch Copyright Act, indicated by the "Taverne" license above, 


\section{Hypoxia-Induced Metastasis:}

The Role of the Unfolded Protein Response 
(C) Copyright H Mujcic, Maastricht 2013

Universitaire Pers Maastricht

ISBN: 9789461592460 


\title{
Hypoxia-Induced Metastasis:
}

\section{The Role of the Unfolded Protein Response}

\author{
DISSERTATION
}

to obtain the degree of Doctor at Maastricht University, on the authority of the Rector Magnificus, Prof.dr. L.L.G. Soete in accordance with the decision of the Board of Deans, to be defended in public on Thursday 12 September 2013, at 12.00 hours

by

Hilda Mujcic

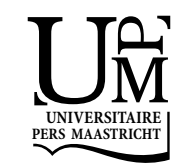




\section{Supervisors/promotores}

Prof. dr. B.G. Wouters

Prof. dr. P. Lambin

\section{Co-supervisors/copromotores}

Dr. M. Koritzinsky (University of Toronto, Canada)

Dr. K.M.A. Rouschop

\section{Assessment Committee/Beoordelingscommissie}

Prof. dr. F.C.S. Ramaekers (chairman/voorzitter)

Dr. J. Bussink (Universitair Medisch Centrum St. Radboud Nijmegen)

Prof. dr. R.P. Coppes (Universitair Medisch Centrum Groningen)

Prof. dr. M.A.G.G. Vooijs 


\section{Content}

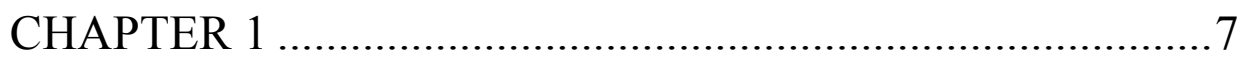

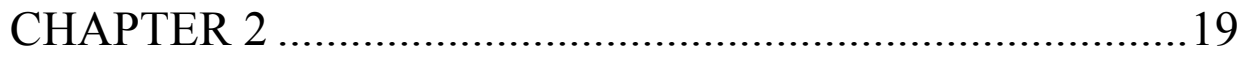

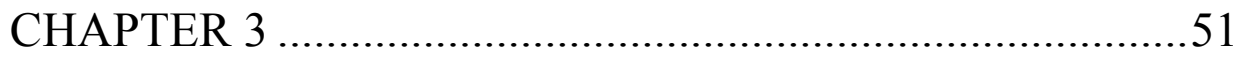

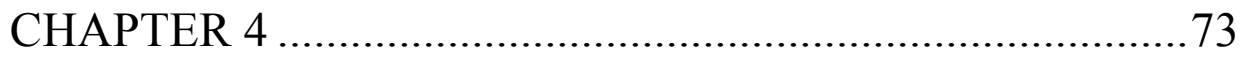

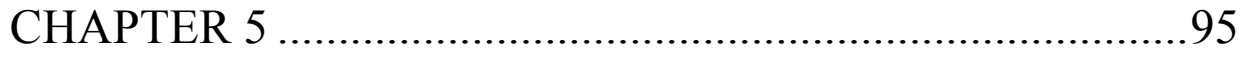

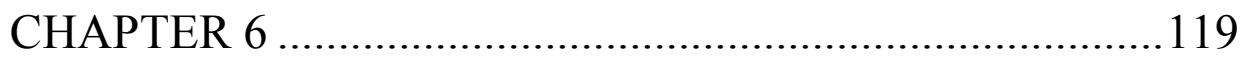

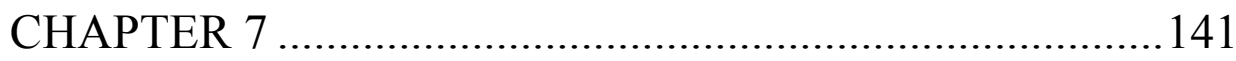

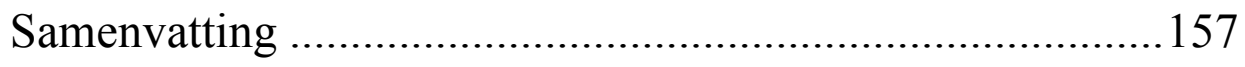

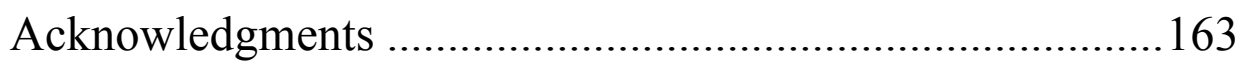

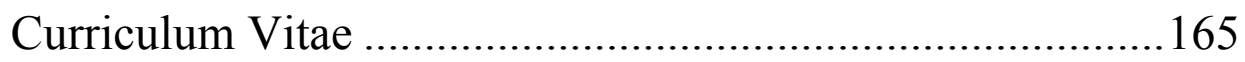

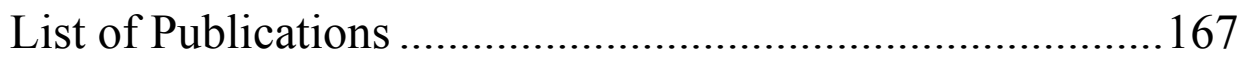



CHAPTER 1

General Introduction 


\section{Cancer and Metastasis}

Cancer is a highly prevalent disease worldwide and one of the leading causes of death. In 2008, 7.6 million deaths (approximately 13\% of total worldwide deaths) were due to cancer (1). Moreover, 12.7 million new cancer cases were diagnosed in that same year (1). Cancer comprises a wide variety of diseases that share a number of characteristics that include uncontrolled division of abnormal cells in the body and the ability of these cells to invade surrounding tissues and spread to other organs - a process referred to as metastasis. The three most common cancer treatment modalities are surgery, radiotherapy and chemotherapy. Treatment choice is dependent on a number of factors, including those specific to the tumor (such as cancer type and disease stage) as well as those of the patient (age, health status). Often, patients receive a combination of treatments to achieve the highest treatment efficacy. When cancer is detected early, meaning before it has metastasized, the cure rate is high. However, most cancers are considered incurable after they have spread to one or more distant sites. For example, the overall 5-year survival for localized (confined to the primary site) uterine cervix cancer disease, is $90.7 \%$, whereas this number is only $16.2 \%$ for cancers with distant metastases (2). Consequently, the vast majority of cancer-related deaths are either directly or indirectly attributable to metastasis.

The presence of clinically detectable metastases often implies that the patient has many more undetectable metastases. Therefore, local therapies (radiation or surgery) are largely ineffective in treating metastatic disease, and systemic therapy is administered instead. Chemotherapy is the standard form of systemic therapy for most metastatic cancers, but in some cases patients can receive hormonal therapy (e.g. breast cancer) or immunotherapy (e.g. melanoma and renal cancer). Unfortunately, systemic therapies are generally not curative. One of the very few exceptions is metastatic testicular germ-cell cancer, which has a cure rate of approximately $80 \%$ (3).

\section{The Metastatic Cascade}

Given its therapeutic relevance, it is important to determine what drives metastasis and why certain tumors are more aggressive and more likely to metastasize than others. To address these questions there is a need to understand how metastasis occurs and the underlying contributing factors. This understanding could potentially lead to new ways to treat patients to prevent 
metastasis (in those who are treated before metastasis has occurred), or even to target novel vulnerabilities in metastatic cells not present in the primary tumor.

Despite almost 200 years of research, the molecular and cellular mechanisms underlying the metastatic process still remain relatively poorly understood. However, during this period - and especially in the last 30 years - some crucial discoveries have been made that have vastly improved our knowledge on the properties of metastatic cells and the biological events that occur during this process. Metastasis is a complex, multi-step process. In the case of solid tumors, the tumor cells must first invade the host interstitial stroma to gain access to the blood circulatory system that will take them to other parts of the body. Tumor cells can also enter the blood circulation indirectly via the lymphatic system, which is connected with the blood vasculature at the subclavian veins (4). The presence of tumor cells in draining lymph nodes (lymph node status) is an important prognostic indicator for many carcinomas, including cervix tumors $(5,6)$.

It is estimated that more than a million cells per gram of tumor can be shed into the bloodstream daily (7). Thus, a $1 \mathrm{~cm}$ tumor that has $\approx 10^{9}$ cells can release about 10 million cells into the bloodstream each day. Soon after entering, tumor cells arrest in capillary beds of secondary organs and those that have survived within the bloodstream may then extravasate and migrate into the surrounding tissue. Tumor cells must subsequently initiate growth within the organ parenchyma to form a micrometastasis. As is the case for the primary tumor, continued growth and development of overt metastases requires stimulation of angiogenesis (8). Only those cancer cells that successfully complete all of these steps can seed distant tumors; metastasis is therefore considered a highly inefficient process. Studies have estimated less than $0.01 \%$ of tumor cells that reach the blood circulation actually form macroscopic metastases (9-11). Tumor cells are relatively proficient in completing the earlier steps, from entering the bloodstream until extravasation into secondary organs. The rate-limiting step of the metastatic cascade is the initiation and maintenance of growth at the secondary site (organ colonization) $(11,12)$. One of the experimental studies in which the metastatic efficiency of the B16F1 murine melanoma cell line was determined using in vivo videomicroscopy, revealed that only $2 \%$ of intraportally injected cells had formed liver micrometastases by day 3 . Few of these micrometastases survived or continued to grow, with only $0.02 \%$ of injected cells eventually contributing to macroscopic metastases by day 13 (10). Similar conclusions about the low frequency of metastatic colonization were drawn from a clinical study involving patients with incurable abdominal cancer that underwent palliative peritoneovenous shunting, a procedure in which ascites (containing cancer cells) is returned to the blood circulation via an anastomosis (13). In 8 out of 15 autopsied patients no micro- or macroscopic hematogenous metastases could be detected, even though patients were infused 
with several million cancer cells per week. In the patients that did develop hematogenous metastatic spread, the metastases were often microscopic and asymptomatic (13).

What factors determine whether a cancer cell will be successful at seeding distant metastases? In 1889, Stephen Paget introduced the "seed-and-soil" hypothesis (14). He was a surgeon who studied the metastatic patterns of cancers and from his studies he concluded that the distribution of metastatic sites is not a random event, but rather the result of an interaction between metastatic cancer cells (the seed) and the site of metastasis (the soil) (14). Thus, according to the seed-and-soil hypothesis, the growth of distant metastases is determined not only by the intrinsic properties of the tumor cells; tumor-host interactions are an equally important determinant of successful completion of metastasis. The seed-and-soil hypothesis is still supported today, and through extensive research we now have a better understanding of the interactions that take place between disseminated tumor cells and the local microenvironment at the secondary site, which consists of a variety of cells, such as bone marrowderived cells, myeloid cells and stromal cells (e.g. fibroblasts), extracellular matrix proteins as well as secreted growth factors $(15,16)$. Even though the emphasis of the seed-and-soil theory is on the metastatic site (foreign soil), we now know that the primary tumor microenvironment (original or native soil) can also be a driver of metastasis. Several non-tumor cells within the primary tumor (e.g. fibroblasts, immune cells, endothelial) can influence the metastatic phenotype of tumor cells (17-20). The same is true for the unique microenvironmental conditions found within the microenvironment of the primary tumor, such as low oxygen (hypoxia) (21-23). In this thesis we investigate mechanisms through which hypoxia regulates metastasis.

\section{Hypoxia and Cancer}

Poorly oxygenated (hypoxic) regions are highly prevalent in most types of advanced solid tumors. Oxygen concentrations experienced by most normal tissues range from $5-7 \%$, whereas hypoxia is often defined as $<3 \% \mathrm{O}_{2}(24)$. Intratumoral hypoxia arises in part from the uncontrolled proliferation of tumor cells, which causes solid tumors to quickly outgrow the nutrient and oxygen supply capacity of the tumor vasculature. Two types of hypoxia can be distinguished within tumors: diffusion-limited hypoxia (also referred to as chronic hypoxia) and perfusion-limited (acute) hypoxia. Chronic hypoxia arises as a result of the limited diffusion of oxygen from perfused vessels. A functional blood vessel can only supply a limited number of cell layers (on average extending $\sim 150 \mu \mathrm{m}$ away from the vessel) with sufficient oxygen. Oxygen consumption by tumor cells results in a gradient of oxygenation 
surrounding the vessel, ranging from normal values at the vessel wall to complete anoxia at the borders of necrosis. Tumors attempt to improve their oxygenation by stimulating growth of new blood vessels from existing ones, a process referred to as angiogenesis. However, the newly formed vasculature often falls short of providing sufficient oxygen for the entire tumor. In addition, these blood vessels are often underdeveloped and exhibit a wide variety of abnormalities that compromise their function - the basis for perfusion-limited hypoxia. These abnormal vessels are prone to temporary closure or obstruction, which can acutely reduce oxygen supply to its surrounding tumor cells, causing a rapid and often severe drop in oxygen concentration.

In 1955, Thomlinson and Gray indirectly demonstrated the existence of hypoxic regions in human tumors (25). They examined clinical specimens of bronchial carcinoma characterized by circular tumor areas surrounded by vascular stroma. The tumor areas were often composed of a necrotic center surrounded by a thin sheet of viable tumor cells, whose thickness was independent of the size of the tumor area. In fact, the thickness of this 'rim' of viable cells was similar to the theoretical oxygen diffusion distance based on oxygen consumption rates that they had calculated. They reasoned that necrosis observed beyond this distance was the result of insufficient oxygen delivery to cells beyond the diffusion limit of oxygen, and therefore that an oxygen gradient must exist between the center and periphery of such a necrotic area.

At the time of Thomlinson and Gray's discovery, it was already known that hypoxic cells are less sensitive to radiotherapy than well-oxygenated cells (26). Hence, the presence of hypoxia within tumors was expected to have negative implications for their radiocurability (25). However, the clinical relevance of hypoxia in human tumors was controversial for many years because clinical attempts to overcome hypoxia-mediated radioresistance using hyperbaric oxygen therapy, chemical radiosensitizers or blood transfusions, did not demonstrate significant benefits over radiotherapy alone $(27,28)$. This changed with the introduction of the computerized Eppendorf $\mathrm{pO}_{2}$ histography system in the late 1980s, which allowed direct measurement of tumor oxygenation in patients $(29,30)$. Multiple clinical studies using the Eppendorf oxygen electrode to measure intratumoral oxygen levels have demonstrated that hypoxia has a negative impact on patient outcome after radiotherapy in different types of tumors, including cervix, prostate, and head and neck tumors (31-34). However, these studies have also revealed that the clinical importance of tumor hypoxia stretches beyond its impact on treatment sensitivity. In 1996, an influential cervical cancer study showed that patients carrying more hypoxic tumors had significantly reduced disease-free and overall survival compared to patients with less hypoxic tumors (35). Importantly, when patients with radiation or surgery as primary mode of treatment were analyzed separately, the association between tumor hypoxia and poor survival remained in both groups. Based on 
this study, it was concluded that hypoxic tumors are characterized by more aggressive disease, suggesting that hypoxia itself may be a direct driving force of malignant phenotypes, such as increased invasion and metastasis. Since that time, numerous clinical studies have revealed a strong association between tumor hypoxia and distant metastasis in cervical cancer (36-38), soft tissue sarcoma (39) and prostate cancer (34).

Laboratory studies investigating the biological changes induced by hypoxia have also suggested its role in malignancy and metastasis (40-46). The first such study was conducted by Hill and colleagues, and showed that exposure of tumor cells to in vitro hypoxia increases their capacity to seed pulmonary metastases following tail-vein injection (40). Induction of hypoxia in vivo via exposure of tumor-bearing animals to low-oxygen inhalation gas has also been shown to increase metastasis in several xenograft models $(42,43,45)$. Tumor cells respond to hypoxia by activating several oxygen-sensitive signaling pathways that allow for adaptation and survival during hypoxic conditions (47). Adaptation is achieved through activation of processes that increase the amount of oxygen that is available to tumor cells, and include angiogenesis and the metabolic switch to anaerobic glycolysis. These processes are mainly regulated by the hypoxia-inducible factor family of transcription factors (HIFs). However, the HIF signaling pathway also regulates the expression of several genes that are more directly involved in the metastasic process (reviewed in chapter 2).

Recently, it has become clear that HIF is not the only, or even the most important, pathway that mediates adaptation to tumor hypoxia. The highly conserved endoplasmic reticulum (ER) stress signaling program known as the unfolded protein response (UPR), is also activated in response to low oxygen levels and is required for cellular adaptation to hypoxia in both normal and transformed cells (10). Several experimental studies have identified the UPR as an important mediator of hypoxia tolerance in vivo and tumor growth in vivo (48-52). Hypoxia causes accumulation of unfolded and misfolded proteins in the ER and triggers activation of the UPR, which promotes adaptation and cell survival during conditions of ER stress. Through inhibition of global protein translation and upregulation of genes involved in protein folding and maturation, further accumulation of unfolded proteins in the ER is prevented. Furthermore, signaling through the UPR stimulates ER-associated degradation (ERAD) and autophagy to remove already accumulated misfolded proteins or protein aggregates (reviewed in (47)). Besides promoting cell survival, these oxygen sensitive signaling pathways can lead to changes in gene expression and cellular phenotype that influence the potential of cancer cells to metastasize. However, hypoxia-induced signaling events that promote tumor metastasis are still relatively poorly understood and involvement of the UPR has not been addressed. 


\section{Research Question and Thesis Outline}

Previous studies aimed at understanding the relationship between hypoxia and metastasis have focused largely on the HIF signaling pathway. Despite being recognized as an important pro-survival pathway during hypoxia, the contribution of UPR signaling to hypoxia-induced metastasis has not yet been examined. As result, in this thesis we aimed to address the following research question: Does hypoxic activation of the UPR influence metastasis, and if so, how does this occur and what is its importance in human cancer?

In Chapter 2 we provide a comprehensive literature review of both clinical and experimental evidence of hypoxia-driven metastasis, and the current knowledge of the molecular mechanisms underlying this process. Previous studies have identified a number of candidate genes that contribute to hypoxia-induced metastasis, the majority of which are regulated by the HIF pathway. In addition, we introduce work from this thesis demonstrating that the UPR is also an important driver of metastasis during hypoxia. In Chapter 3, we report the novel discovery of the first metastasis-associated gene regulated by the UPR in response to severe hypoxia, LAMP3 (lysosomal associated membrane protein $3)$. Overexpression of LAMP3 has previously been shown to promote metastasis in a xenograft model of cervical carcinoma (53), but the mechanisms underlying its metastasis-promoting effects have not been investigated in much detail. Similarly, there are no previous studies reporting on the regulation of LAMP3 gene expression. We identified LAMP3 as part of a microarray screen for novel hypoxia-regulated genes. We measured LAMP3 expression in different cancer cell lines to investigate whether the hypoxia-mediated induction of LAMP3 is cancer specific or common to multiple cancer types. In Chapter 3 we also characterized the transcriptional regulation of LAMP3 during hypoxia, using cells defective in hypoxia signaling through HIF1 or the UPR, as well as chemical agents known to stimulate signaling activity of these pathways. We also examined LAMP3 expression in vivo in both tumor xenografts and breast cancer patient samples. Finally, the relationship between LAMP3 and hypoxia was investigated in glioblastoma xenografts treated with Avastin, an angiogenic inhibitor known to induce tumor hypoxia.

Since little is known about the functional role of LAMP3 in metastasis, we next decided to investigate its involvement in hypoxia-induced cell migration and invasion, two processes critical for metastasis (Chapter 4). Using knockdown experiments in combination with in vitro metastasis assays, the involvement of LAMP3 and its upstream regulators PERK and ATF4 in cell migration was assessed. To study cell migration during hypoxia, the assays were performed 
under low oxygen conditions. As an alternative in vitro model of tumor hypoxia we used spheroid cultures, which spontaneously develop hypoxic cores once they reach a certain size. Invasion of LAMP3 knockdown and control spheroid cultures cells was assessed using the three-dimensional collagen spheroid invasion assays. In Chapter 5 we directly assessed the requirement for UPR signaling and LAMP3 in hypoxia-induced metastasis. We focused on cervix cancer, where evidence from clinical studies is the strongest showing a direct association between tumor hypoxia and metastasis $(36,38)$. First, we constructed a series of isogenic and inducible cell lines to interfere with UPR and/or LAMP3 activation during hypoxia and used these in a xenograft model of hypoxia-driven metastatic cervix carcinoma. We demonstrated that hypoxic activation of the UPR promotes metastasis, and we addressed the individual contribution of both LAMP3 and hypoxia tolerance to this phenotype. To evaluate the potential clinical relevance of these results we investigated whether hypoxia influences LAMP3 in patients with cervical cancer. LAMP3 expression was therefore determined in a set of human cervix tumors for which measurements of tumor oxygenation were available. However, since genetic amplification of LAMP3 has been reported in cervical carcinoma (54), we also determined LAMP3 gene copy numbers using FISH analysis.

Finally, we investigated the clinical relevance of LAMP3 expression in a second type of cancer. For this purpose we measured LAMP3 expression in a set of samples derived from breast carcinoma patients previously treated with surgery and in some cases with the addition of radiotherapy, and tested the prognostic value of LAMP3. This study is described in Chapter 6. In addition, we assessed the evidence for hypoxic regulation of LAMP3 in breast cancer using experimental models, including breast cancer cell lines and xenografts.

\section{References}

1. Ferlay J, Shin HR, Bray F, Forman D, Mathers C, Parkin DM. GLOBOCAN 2008 v2.0, Cancer Incidence and Mortality Worldwide: IARC CancerBase No. 10. [internet]. 2010; Available from: http://globocan.iarc.fr,

2. Howlader N, Noone AM, Krapcho M, Neyman N, Aminou R, Waldron W, et al. SEER Cancer Statistics Review, 1975-2009 (Vintage 2009 Populations), National Cancer Institute. Bethesda, MD. based on November 2011 SEER data submission, posted to the SEER website, April 2012; Available from: http://seer.cancer.gov/csr/1975_2009_pops09/

3. Masters JR, Koberle B. Curing metastatic cancer: lessons from testicular germ-cell tumours. Nature reviews Cancer. 2003;3:517-25.

4. Albrecht I, Christofori G. Molecular mechanisms of lymphangiogenesis in development and cancer. Int J Dev Biol. 2011;55:483-94. 
5. Stehman FB, Bundy BN, DiSaia PJ, Keys HM, Larson JE, Fowler WC. Carcinoma of the cervix treated with radiation therapy. I. A multi-variate analysis of prognostic variables in the Gynecologic Oncology Group. Cancer. 1991;67:2776-85.

6. Tseng JY, Yen MS, Twu NF, Lai CR, Horng HC, Tseng CC, et al. Prognostic nomogram for overall survival in stage IIB-IVA cervical cancer patients treated with concurrent chemoradiotherapy. Am J Obstet Gynecol. 2010;202:174 e1-7.

7. Butler TP, Gullino PM. Quantitation of cell shedding into efferent blood of mammary adenocarcinoma. Cancer research. 1975;35:512-6.

8. Gupta GP, Massague J. Cancer metastasis: building a framework. Cell. 2006;127:679-95.

9. Fidler IJ. Metastasis: guantitative analysis of distribution and fate of tumor embolilabeled with 125 I-5-iodo-2'-deoxyuridine. Journal of the National Cancer Institute. 1970;45:77382.

10. Luzzi KJ, MacDonald IC, Schmidt EE, Kerkvliet N, Morris VL, Chambers AF, et al. Multistep nature of metastatic inefficiency: dormancy of solitary cells after successful extravasation and limited survival of early micrometastases. The American journal of pathology. 1998;153:865-73.

11. Cameron MD, Schmidt EE, Kerkvliet N, Nadkarni KV, Morris VL, Groom AC, et al. Temporal progression of metastasis in lung: cell survival, dormancy, and location dependence of metastatic inefficiency. Cancer research. 2000;60:2541-6.

12. Chambers AF, Groom AC, MacDonald IC. Dissemination and growth of cancer cells in metastatic sites. Nature reviews Cancer. 2002;2:563-72.

13. Tarin D, Price JE, Kettlewell MG, Souter RG, Vass AC, Crossley B. Mechanisms of human tumor metastasis studied in patients with peritoneovenous shunts. Cancer research. 1984;44:3584-92.

14. Paget S. The distribution of secondary growths in cancer of the breast. 1889. Cancer metastasis reviews. 1989;8:98-101.

15. Peinado H, Lavotshkin S, Lyden D. The secreted factors responsible for pre-metastatic niche formation: old sayings and new thoughts. Semin Cancer Biol. 2011;21:139-46.

16. Psaila B, Lyden D. The metastatic niche: adapting the foreign soil. Nature reviews Cancer. 2009;9:285-93.

17. Luo Y, Zhou H, Krueger J, Kaplan C, Lee SH, Dolman C, et al. Targeting tumorassociated macrophages as a novel strategy against breast cancer. The Journal of clinical investigation. 2006;116:2132-41.

18. Pollard JW. Macrophages define the invasive microenvironment in breast cancer. J Leukoc Biol. 2008;84:623-30.

19. Shimoda M, Mellody KT, Orimo A. Carcinoma-associated fibroblasts are a rate-limiting determinant for tumour progression. Semin Cell Dev Biol. 2010;21:19-25.

20. Branco-Price C, Zhang N, Schnelle M, Evans C, Katschinski DM, Liao D, et al. Endothelial cell HIF-1alpha and HIF-2alpha differentially regulate metastatic success. Cancer Cell. 2012;21:52-65.

21. Chaudary N, Hill RP. Hypoxia and metastasis. Clinical cancer research : an official journal of the American Association for Cancer Research. 2007;13:1947-9.

22. Le QT, Denko NC, Giaccia AJ. Hypoxic gene expression and metastasis. Cancer metastasis reviews. 2004;23:293-310.

23. Sullivan R, Graham CH. Hypoxia-driven selection of the metastatic phenotype. Cancer Metastasis Rev. 2007;26:319-31. 
24. Joiner M, Kogel Avd. Basic clinical radiobiology. 4th ed. London: Hodder Arnold; 2009.

25. Thomlinson RH, Gray LH. The histological structure of some human lung cancers and the possible implications for radiotherapy. British journal of cancer. 1955;9:539-49.

26. Gray LH, Conger AD, Ebert M, Hornsey S, Scott OC. The concentration of oxygen dissolved in tissues at the time of irradiation as a factor in radiotherapy. Br J Radiol. 1953;26:638-48.

27. Overgaard J. Hypoxic radiosensitization: adored and ignored. Journal of clinical oncology : official journal of the American Society of Clinical Oncology. 2007;25:4066-74.

28. Brown JM, Wilson WR. Exploiting tumour hypoxia in cancer treatment. Nature reviews Cancer. 2004;4:437-47.

29. Kallinowski F, Zander R, Hoeckel M, Vaupel P. Tumor tissue oxygenation as evaluated by computerized-pO2-histography. International journal of radiation oncology, biology, physics. 1990;19:953-61.

30. Vaupel P, Schlenger K, Knoop C, Hockel M. Oxygenation of human tumors: evaluation of tissue oxygen distribution in breast cancers by computerized $\mathrm{O} 2$ tension measurements. Cancer research. 1991;51:3316-22.

31. Brizel DM, Sibley GS, Prosnitz LR, Scher RL, Dewhirst MW. Tumor hypoxia adversely affects the prognosis of carcinoma of the head and neck. International journal of radiation oncology, biology, physics. 1997;38:285-9.

32. Nordsmark M, Overgaard J. A confirmatory prognostic study on oxygenation status and loco-regional control in advanced head and neck squamous cell carcinoma treated by radiation therapy. Radiother Oncol. 2000;57:39-43.

33. Vaupel P, Hockel M, Mayer A. Detection and characterization of tumor hypoxia using pO2 histography. Antioxidants \& redox signaling. 2007;9:1221-35.

34. Milosevic M, Warde P, Menard C, Chung P, Toi A, Ishkanian A, et al. Tumor hypoxia predicts biochemical failure following radiotherapy for clinically localized prostate cancer. Clin Cancer Res. 2012;18:2108-14.

35. Hockel M, Schlenger K, Aral B, Mitze M, Schaffer U, Vaupel P. Association between tumor hypoxia and malignant progression in advanced cancer of the uterine cervix. Cancer research. 1996;56:4509-15.

36. Sundfor K, Lyng H, Rofstad EK. Tumour hypoxia and vascular density as predictors of metastasis in squamous cell carcinoma of the uterine cervix. British journal of cancer. 1998;78:822-7.

37. Pitson G, Fyles A, Milosevic M, Wylie J, Pintilie M, Hill R. Tumor size and oxygenation are independent predictors of nodal diseases in patients with cervix cancer. International journal of radiation oncology, biology, physics. 2001;51:699-703.

38. Fyles A, Milosevic M, Hedley D, Pintilie M, Levin W, Manchul L, et al. Tumor hypoxia has independent predictor impact only in patients with node-negative cervix cancer. J Clin Oncol. 2002;20:680-7.

39. Brizel DM, Scully SP, Harrelson JM, Layfield LJ, Bean JM, Prosnitz LR, et al. Tumor oxygenation predicts for the likelihood of distant metastases in human soft tissue sarcoma. Cancer research. 1996;56:941-3.

40. Young SD, Marshall RS, Hill RP. Hypoxia induces DNA overreplication and enhances metastatic potential of murine tumor cells. Proceedings of the National Academy of Sciences of the United States of America. 1988;85:9533-7. 
41. Young SD, Hill RP. Effects of reoxygenation on cells from hypoxic regions of solid tumors: anticancer drug sensitivity and metastatic potential. J Natl Cancer Inst. 1990;82:371-80.

42. Cairns RA, Hill RP. Acute hypoxia enhances spontaneous lymph node metastasis in an orthotopic murine model of human cervical carcinoma. Cancer research. 2004;64:205461.

43. Cairns RA, Kalliomaki T, Hill RP. Acute (cyclic) hypoxia enhances spontaneous metastasis of KHT murine tumors. Cancer research. 2001;61:8903-8.

44. Rofstad EK. Microenvironment-induced cancer metastasis. International journal of radiation biology. 2000;76:589-605.

45. Rofstad EK, Gaustad JV, Egeland TA, Mathiesen B, Galappathi K. Tumors exposed to acute cyclic hypoxic stress show enhanced angiogenesis, perfusion and metastatic dissemination. International journal of cancer. 2010;127:1535-46.

46. Lunt SJ, Chaudary N, Hill RP. The tumor microenvironment and metastatic disease. Clinical \& experimental metastasis. 2009;26:19-34.

47. Wouters BG, Koritzinsky M. Hypoxia signalling through mTOR and the unfolded protein response in cancer. Nature reviews Cancer. 2008;8:851-64.

48. Bi M, Naczki C, Koritzinsky M, Fels D, Blais J, Hu N, et al. ER stress-regulated translation increases tolerance to extreme hypoxia and promotes tumor growth. The EMBO journal. 2005;24:3470-81.

49. Blais JD, Addison CL, Edge R, Falls T, Zhao H, Wary K, et al. Perk-dependent translational regulation promotes tumor cell adaptation and angiogenesis in response to hypoxic stress. Molecular and cellular biology. 2006;26:9517-32.

50. Romero-Ramirez L, Cao H, Nelson D, Hammond E, Lee AH, Yoshida H, et al. XBP1 is essential for survival under hypoxic conditions and is required for tumor growth. Cancer research. 2004;64:5943-7.

51. Rouschop KM, Dubois LJ, Keulers TG, van den Beucken T, Lambin P, Bussink J, et al. PERK/eIF2alpha signaling protects therapy resistant hypoxic cells through induction of glutathione synthesis and protection against ROS. Proceedings of the National Academy of Sciences of the United States of America. 2013;110:4622-7.

52. Rouschop KM, van den Beucken T, Dubois L, Niessen H, Bussink J, Savelkouls K, et al. The unfolded protein response protects human tumor cells during hypoxia through regulation of the autophagy genes MAP1LC3B and ATG5. J Clin Invest. 2010;120:127-41.

53. Kanao H, Enomoto T, Kimura T, Fujita M, Nakashima R, Ueda Y, et al. Overexpression of LAMP3/TSC403/DC-LAMP promotes metastasis in uterine cervical cancer. Cancer research. 2005;65:8640-5.

54. Wangsa D, Heselmeyer-Haddad K, Ried P, Eriksson E, Schaffer AA, Morrison LE, et al. Fluorescence in situ hybridization markers for prediction of cervical lymph node metastases. Am J Pathol. 2009;175:2637-45. 



\section{CHAPTER 2}

\section{Hypoxia Signaling and the Metastatic Phenotype}

H. Mujcic

R.P. Hill

M. Koritzinsky

B.G. Wouters

In Preparation 


\begin{abstract}
Conditions of poor oxygenation (hypoxia) are present in the majority of solid human tumors and are associated with poor patient prognosis due to both hypoxia-mediated resistance to treatment, and to hypoxia-induced biological changes that promote increased malignancy, including metastasis. Tumor cells respond to hypoxia by activating several oxygen-sensitive signaling pathways that include the hypoxia inducible factor $1 / 2$ (HIF1/2) signaling pathways and the unfolded protein response (UPR), which alter gene expression to promote adaptation and survival during hypoxic conditions. Furthermore, these hypoxia responsive pathways can lead to changes in gene expression and cellular phenotype that influence the potential of cancer cells to metastasize. However, the hypoxia-induced signaling events that promote tumor metastasis are still relatively poorly understood. Previous studies have largely focused of the contribution the HIF signaling pathway to hypoxia-mediated metastasis. However, recent evidence demonstrates that hypoxic activation of the unfolded protein response (UPR) is also an important mediator of metastasis.
\end{abstract}




\section{Introduction}

Nearly all solid tumors develop some level of poorly oxygenated (hypoxic) areas. High levels of tumor hypoxia are associated with an unfavorable prognosis in many types of cancer. This is due in part to the intrinsic treatment resistance of hypoxic cells, as well as to hypoxia-mediated biological changes that promote more aggressive disease, including metastasis. Substantial evidence from both clinical and experimental studies supports a role for hypoxia in tumor metastasis. Over the last two decades significant progress has been made in understanding the molecular mechanisms underlying hypoxia-driven metastasis, although much remains to be learned. Hypoxia affects multiple metastasis-associated processes, including the epithelial-mesenchymal transition (EMT), invasive migration and (lymph)angiogenesis (figure 1), but the relative contribution of these individual processes to hypoxia-induced metastasis is unclear. Hypoxia has also been implicated in the establishment of the premetastatic niche and subsequent metastatic growth. In addition, recent evidence suggests that hypoxic regulation of the cancer stem cell phenotype contributes to the pool of metastatic cells in the primary tumor. Hypoxia influences these cellular phenotypes through multiple oxygen sensitive signaling pathways that individually influence many changes in gene expression. Importantly, these same hypoxia response pathways also promote tumor cell survival under low-oxygen conditions. Increased tolerance to hypoxia per se, induced prior to, or during the metastatic process, influences the proportion of viable hypoxic cells and is thus also an important contributor to metastatic potential. The best understood hypoxia response pathway is mediated by the hypoxia-inducible factor $1 / 2$ (HIF $1 / 2)$ family of transcription factors. However, emerging evidence suggest that additional pathways, and in particular, the unfolded protein response (UPR), also plays key roles in hypoxia tolerance and metastatic phenotypes. 


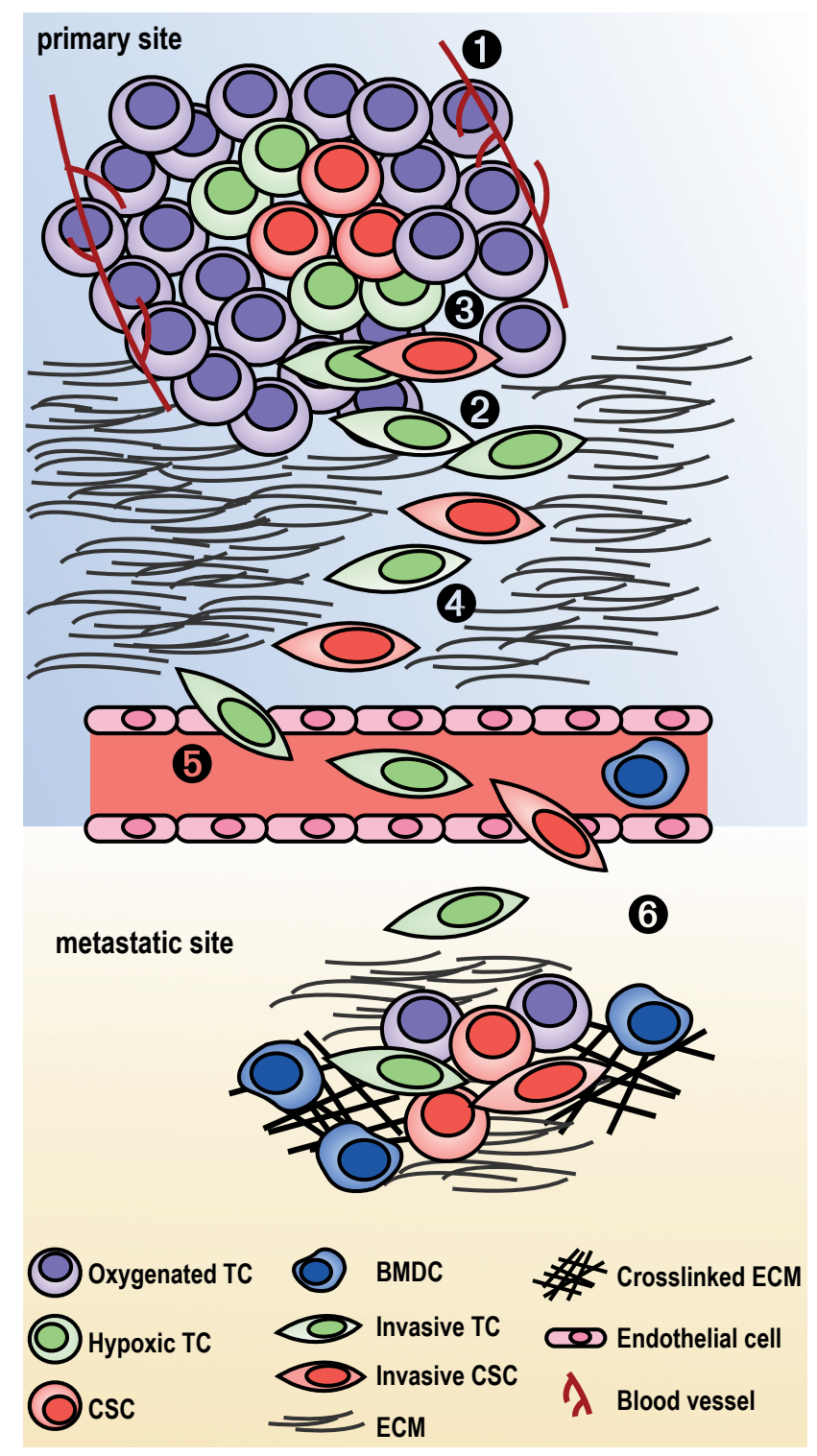

Figure 1. Hypoxic involvement in the metastatic cascade. Hypoxia in the primary tumor promotes angiogenesis (1), which enables tumor expansion and provides a potential route for dissemination. Hypoxia also initiates changes in cell signaling and gene expression that promotes invasiveness through induction of EMT (2) as well as upregulation of cell-matrix adhesion molecules and proteins involved in ECM remodeling and degradation (4). Moreover, hypoxiainduced genes facilitate intra- and extravasation (5), and the recruitment of BMDCs that prepare the metastatic site for tumor cell colonization (6). Cancer stem cells are considered as a potential source of metastasis-initiating cells (3). Cells that have undergone an EMT share many properties with CSCs, including tumor-initiating capacity. Hypoxia directly promotes the expansion of existing cancer stem cells. 


\section{Clinical evidence for hypoxia-induced metastasis}

The presence of poorly oxygenated regions in human tumors was first proposed by Thomlinson and Gray back in 1955 (1). After examining the histological structure of bronchial carcinoma they often observed the presence of tumor areas composed of a necrotic center surrounded by a thin sheet of viable tumor cells. They reasoned that necrosis was the result of insufficient oxygen delivery to cells beyond the diffusion limit of oxygen, and that cells exposed to lower oxygen concentration at the time of irradiation are more radioresistant and would eventually be responsible for repopulation of the tumor. The actual existence of viable hypoxic cells and their contribution to radiotherapy resistance was later demonstrated in rodent tumors and xenografted human tumors $(2,3)$. A number of experimental techniques, including the paired survival curve assay and the clamped tumor growth delay assay (4), allowed direct and repeatable measurement of the proportion of clonogenic radiation resistant hypoxic cells within a tumor.

Evidence that hypoxia similarly drives radioresistance in human tumors arose rapidly with the introduction of the computerized Eppendorf $\mathrm{pO}_{2}$ histography system in the late $1980 \mathrm{~s}(5,6)$. Multiple prospective trials were initiated in different types of easily accessible cancers, including cervix, soft tissue sarcoma and head and neck. The first such study to report the prognostic value of tumor hypoxia was published in 1993 and was carried out in 31 cervix cancer patients treated with radiation alone or combination therapy including radiation (7). Patients harboring tumors with higher levels of hypoxia (defined as a median $\mathrm{pO}_{2} \leq 10 \mathrm{mmHg}$ ) had both a reduced overall and recurrence-free survival compared to patients with less hypoxic tumors $\left(\mathrm{pO}_{2}>10 \mathrm{mmHg}\right)$. The vast majority of patients in this study had been treated with radiation; consistent with the notion that poor outcome was associated with hypoxia mediated radiation resistance. A second study with a longer follow-up time and more patients confirmed the prognostic value of tumor hypoxia (8). However, when patients treated with radiation or surgery as primary mode of treatment were analyzed separately, the positive association between tumor hypoxia and poor survival remained in both groups. Furthermore, histopathological evaluation of the resected tumors revealed increased invasiveness of the hypoxic tumors. This seminal clinical study indicated the clinical importance of tumor hypoxia extends beyond its role in radioresistance.

Since this time, it has become clear that hypoxia itself may be a direct contributor to adverse malignant phenotypes, such as invasion and metastasis. A direct association between tumor hypoxia and distant metastasis has been 
demonstrated in soft tissue sarcoma (9) as well in cervical cancer (10-12). A large study by Fyles et al. involving 106 cervix cancer patients treated with radiotherapy at Princess Margaret Cancer Centre in Toronto identified tumor hypoxia as an independent predictor of treatment outcome, but only in those patients that did not present with lymph node metastases at the time of diagnosis (12). They continued to show that hypoxic tumors were associated with worse outcome because they are more likely to develop distant metastases. Likewise, Milosevic et al. recently demonstrated that hypoxia is associated with early biochemical relapse following radiotherapy in patients with prostate cancer, but only within the first 48 months of completing treatment (13), suggesting the presence of subclinical metastatic disease at time of treatment in patients with hypoxic tumors.

\section{Hypoxia and metastasis: experimental evidence}

Young and Hill were the first to recognize a potential relationship between tumor hypoxia and metastasis in the late 1980s (14). At the time, several studies had provided indirect evidence for a role of gene amplification in cancer metastasis $(15,16)$. In addition, it was known that hypoxic conditions in tumors could cause gene amplification and DNA overreplication $(17,18)$. These findings prompted Young and Hill to hypothesize that hypoxia-induced DNA overreplication could enhance the metastatic potential of cancer cells through amplification of metastasis-associated genes (14). Although their observations were not supportive of a role for DNA amplification in hypoxia induced metastasis $(19,20)$, they did find that in vitro exposure to hypoxia significantly increased the ability of multiple murine cancer cell lines to form lung metastases upon tail-vein injection into mice (14). These observations were later confirmed in several independent studies (21-23).

Exposure of tumor-bearing animals to low-oxygen gas breathing with the purpose to increase tumor hypoxia has also been shown to enhance spontaneous metastasis of murine KHT fibrosarcoma tumors (24) as well as two different human xenograft models $(25,26)$. In this approach, tumor-bearing mice are exposed to additional transient hypoxia by altering the oxygen content of the inhalation gas. Repeated cycles of 'acute' cyclic hypoxia (12 cycles of 10 minutes of $5-7 \% \mathrm{O}_{2}$ per day) have been shown to be more effective at stimulating metastasis than daily exposure to 'chronic' hypoxia $\left(5-7 \% \mathrm{O}_{2}\right.$ for $2 \mathrm{~h} /$ day) (24). A particularly elegant model to study hypoxia-induced metastasis in cervical cancer was established by the Hill group. In this model, ME180 human cervical cancer cells are implanted into the cervix and metastasize to a series of 4 pairs of lymph nodes in a manner similar to that observed in human patients (27). Importantly, this model enables quantification of metastatic 
burden by assessing the number and position of lymph-node metastases. In this model acute hypoxic exposure approximately doubled the number of metastases even though primary tumors were smaller in size (25). Similar results have been observed with the human A-07 melanoma xenografts, which demonstrates increased incidence of pulmonary metastases when exposed to the acute hypoxia regimen (26). The effects of hypoxia on tumor cell invasion and metastasis have been demonstrated with other models as well. The in vivo chick embryo model has been used to show that hypoxia induces tumor cell migration and invasion of the extra-embryonic membranes $(28,29)$. Similarly, hypoxia enhances tumor cell invasion and metastasis in an embryonic zebrafish metastasis model (30).

\section{Hypoxia-inducible factor family of transcription factors (HIFs)}

Tumor cells respond to hypoxia through several adaptive oxygen-sensitive signaling pathways. The best-characterized response is mediated by the hypoxia-inducible factor family of transcription factors (HIFs). Functionally active HIFs are heterodimers composed of an oxygen-regulated $\alpha$-subunit and a constitutively expressed $\beta$-subunit (31). Three different HIF $\alpha$-subunits have been identified, HIF $1 \alpha$, HIF $2 \alpha$ and HIF $3 \alpha$, of which HIF $1 \alpha$ is the most widely expressed. HIF1 regulates the expression of genes involved in many different processes, including metabolism, angiogenesis and also metastasis (32). Oxygen-dependent regulation of HIF1 $\alpha$ expression occurs at the posttranslational level. In the presence of oxygen, HIF $\alpha$ subunits are targeted for ubiquitination and proteasomal degradation following hydroxylation of two of their proline residues by HIF prolyl hydroxylases (PHDs) and subsequent binding of the E3 ubiquitin ligase von Hippel-Lindau (pVHL). Since PHDs are reliant on oxygen for their activity, HIF $\alpha$ proteins escape degradation in a hypoxic environment allowing HIF $\alpha$-HIF $\beta$ complex formation and activation of its target genes (reviewed in (33)).

\section{HIFs and metastasis}

Previous studies have established HIF 1 as an important mediator of metastasis by inhibiting HIF1 itself or one of its downstream genes. In a transgenic mouse model of metastatic breast cancer, conditional deletion of HIF $1 \alpha$ in the mammary epithelium resulted in delayed tumor onset and inhibition of tumor growth (34). Importantly, end-point HIF $1 \alpha^{-/-}$tumors also showed reduced ability to seed pulmonary metastases (34). Studies using xenograft models support a role for HIF in hypoxia driven metastasis $(35,36)$. HIF1 is thought to promote 
metastatic disease by regulating the expression of a large number of genes involved in metastasis-associated processes such as the EMT, migration, invasion and angiogenesis/lymphangiogenesis.

\section{Epithelial-Mesenchymal Transition}

In order to gain access to the blood and/or lymphatic vasculature located in the interstitial stroma and seed distant metastases, tumor cells within the primary tumor must first acquire a motile and invasive phenotype. Invasion requires altered intercellular and tumor cell-extracellular matrix adhesion, proteolysis of extracellular matrix components and migration (37). Cancer cells employ different types of cell migration, including single-cell mesenchymal or amoeboid migration, and collective cell migration $(38,39)$. The predominant form for most epithelial cancers is collective migration, but carcinoma cells that undergo an epithelial-mesenchymal transition (EMT) can also migrate as single cells. The EMT has received widespread attention over the last few years, but whether it is an essential event in the metastatic cascade still remains controversial. Besides tumor cell invasion and metastasis, the EMT has also been implicated in other cancer-related processes, including apoptosis (40), senescence (41), immune surveillance (42) and responses to radio- and chemotherapy $(43,44)$. Moreover, induction of EMT has been shown to generate cells with stem cell-like properties (45) (see below).

Cells that undergo an EMT acquire a more motile, mesenchymal phenotype that is characterized by loose intercellular contacts and loss of polarity. Molecular changes associated with EMT include downregulation of epithelial markers, Ecadherin in particular, but also claudins, cytokeratins, integrins, mucins, occludin and ZO proteins. This is accompanied by increased expression of mesenchymal genes, including vimentin, $\mathrm{N}$-cadherin and $\alpha$-smooth muscle actin (46). Hypoxia is a strong EMT inducer (47-51), but EMT is also triggered by a variety of other microenvironmental signals such as growth factors, cytokines and hormones. Hypoxia acts on components of EMT-inducing signaling pathways (e.g. TGF $\beta / S m a d$, Notch, Wnt/ $\beta$-catenin and NFKB (reviewed in (52, 53))) as well as on transcription factors that are downstream of these pathways. Key transcription factors involved in the EMT are SNAI1, SNAI2, TWIST1 and ZEB1/2. These factors function as transcriptional repressors of epithelial genes by means of epigenetic silencing, but they can also induce the expression of certain mesenchymal genes (46).

SNAI1 (also known as Snail) belongs to the Snail family of zinc finger transcription factors that also includes SNAI2 (also known as Slug). Hypoxia has been shown to increase SNAI1 expression in extravillous trophoblast cells (54) and in multiple cancer cell lines, including ovarian and breast cancer (5557). Elevated SNAI1 expression coincides with downregulation of E-cadherin 
and induction of EMT as well as enhanced cell migration and invasiveness (5457). Both HIF $1 \alpha$ and HIF $2 \alpha$ activate SNAI1 transcription through direct binding to a hypoxia-response element (HRE) within the SNAI1 promoter (58). Hypoxia also enhances the expression of SNAI2 (56) and an association between SNAI2 and CA9 expression was found in patient-derived breast tumor tissue (59).

Another direct HIF1 $\alpha$ target gene is the basic helix-loop-helix (bHLH) transcription factor TWIST1. Yang et al. (60) demonstrated the presence of a functional HRE in the TWIST proximal promoter and showed that TWIST1 expression is required for hypoxia-induced EMT and experimental metastasis in $\mathrm{FaDu}$ (hypopharyngeal cancer) cells. They also showed that TWIST1 and SNAI1 expression is higher in more hypoxic human head and neck squamous cell carcinoma (HNSCC) tumors compared to less hypoxic tumors, as assessed by HIF $1 \alpha$ and CA9 staining. Moreover, overexpression of HIF $1 \alpha$, TWIST1 or SNAI1 is associated with a shorter metastasis-free period and reduced overall survival. Tumors with triple-positive staining for HIF $1 \alpha$, TWIST1 and SNAI1 showed the shortest metastasis-free period and worst overall survival (60).

HIF also promotes the transcription of E-cadherin repressors ZEB1 and ZEB2 (also known as $\delta E F 1$ and SIP1, respectively) $(50,51)$. In epithelial cells, expression of ZEB factors is repressed by the miR-200 family and miR-205 (61). ZEB factors, however, also function as inhibitors of the miR-200 family $(62,63)$. Hence, when ZEB1/2 levels are increased - in response to hypoxia for example - the miR-200-mediated ZEB repression is relieved, allowing cells to undergo an EMT.

\section{Tissue invasion (and intra-/extravasation)}

In addition to EMT dependent changes in E-cadherin, hypoxia regulates the expression of cell adhesion molecules such as integrins $(64,65)$, CD44 (66) and L1CAM (L1 cell adhesion molecule), a direct HIF1 $\alpha$ target gene that was recently shown to promote tumor cells extravasation by stimulating tumor cell binding to endothelial cells (35). Hypoxia also induces several protease systems, which facilitate cellular invasion through proteolytic degradation of the basement membrane and extracellular matrix as well as enzymatic processing and activation of other proteases, cell surface receptors, growth factors and chemokines (38). These systems include the serine protease urokinase plasminogen activator (uPA) and its receptor uPAR (67), MMPs (metalloproteinases) (48), ADAMs $(68,69)$ and cathepsins (70). Hypoxia mediated induction of UPAR has been shown to increase tumor cell invasion (71) and spontaneous lymph node metastasis in human melanoma xenografts (72). Furthermore, uPAR expression is required for hypoxia-induced EMT in breast cancer cells (57). uPAR binds and activates the pro-enzyme uPA, which 
then catalyzes the conversion of plasminogen into the active protease plasmin. Plasmin can degrade a variety of ECM proteins and also cleave and thereby activate several MMPs (73). Besides their key role in tissue invasion and intravasation through the degradation and remodeling of the ECM, MMPs also promote metastasis by promoting angiogenesis, inflammation and metastatic niche formation (see below) (74).

Another hypoxia-regulated ECM protein that has received much attention is lysyl oxidase (LOX). Numerous experimental studies have shown that secreted LOX enhances tumor cell invasion $(75,76)$ and metastasis $(77-80)$. Erler et al. were the first to demonstrate a direct requirement for LOX in hypoxia-induced metastasis (79). They identified LOX as a direct HIF $1 \alpha$ target gene and showed that hypoxia-induced LOX is essential for the formation of spontaneous metastases in an orthotopic breast cancer model. They also showed that LOX expression correlates with the degree of hypoxia in breast and head and neck cancer. Moreover, patients with high LOX expression had reduced metastasisfree and overall survival (79). Other clinical studies have confirmed the association between LOX expression and metastatic disease in these and additional cancer types $(77,81)$. LOX catalyzes the covalent crosslinking of collagen and elastin in the interstitial space, which leads to a more rigid ECM (82). In a recent report, Erler and co-workers showed that LOX-mediated stiffening of the ECM leads to activation of the FAK/SRC-signaling pathway and increased proliferation and metastasis in a colorectal cancer model (83). LOX-induced ECM stiffening has also been shown to promote tumor progression in a transgenic model of breast cancer (80). In addition to its role in invasive migration, hypoxia-induced LOX also mediates premetastatic niche formation (78) (see below).

Hypoxia regulates the expression of many other genes involved in cell adhesion, motility, chemotaxis, invasion and intra- and extravasion. These have been extensively reviewed previously (84-86).

\section{Angiogenesis/lymphangiogenesis}

Expansion of the existing blood supply is necessary to support continuous growth of the primary tumor as well as to facilitate systemic tumor cell dissemination. Hypoxia is an extremely potent stimulus for tumor angiogenesis. HIFs activate the transcription of various pro-angiogenic genes, including the primary mediator of angiogenesis VEGF-A (87) and its receptors VEGFR1 (FLT1) (88) and VEGFR2 (FLK1) $(89,90)$. Other examples of HIF-regulated angiogenesis-related genes are PDGF-B (platelet-derived growth factor-B), 
angiopoietins (ANGPT1, ANGPT2, ANGPT4) $(35,91)$, plasminogen activator inhibitor-1 (PAI-1) (92) and interleukin-8 (IL-8) (93).

Rofstad and co-workers have demonstrated that acute hypoxia treatment of animals carrying A-07 melanoma tumors results in increased spontaneous metastasis and enhanced perfusion and angiogenesis in the primary tumor, as evidenced by a higher microvascular density and VEGF-A expression (26). Anti-VEGF-A treatment significantly inhibited lung metastasis formation and reduced primary tumor microvascular density, indicating that hypoxia-induced angiogenesis is an important mechanism for metastatic dissemination in A-07 tumors. Likewise, in D-12 melanoma xenografts the degree of hypoxia was associated with the incidence of spontaneous pulmonary metastases as well as microvascular density and IL-8 expression (94). In vivo administration of an anti-IL-8 or anti-VEGF antibody inhibited metastasis. The same group has also shown that prior in vitro exposure of D-12 melanoma cells to hypoxia increases VEGF expression and secretion, and pulmonary metastasis, whereas treatment of animals with neutralizing antibodies against VEGF reduced their metastatic potential (21). However, in this case the enhanced metastatic efficiency is more likely the result of VEGF-mediated vascular permeability rather than increased angiogenesis as angiogenic growth is not required until progression to macrometastases $(95,96)$.

Hypoxia may also stimulate tumor neovascularization and metastatic spread via recruitment of vascular modulatory bone marrow-derived cells (BMDCs) (97). HIF $1 \alpha$-mediated induction of SDF1 $\alpha$ in glioblastoma was shown to attract $\mathrm{CXCR}^{+}{ }^{+}$bone marrow-derived endothelial and pericyte progenitor cells to the tumor site as well as CD45 $5^{+}$myeloid cells expressing MMP-9. MMP-9 activity resulted in increased tumor cell infiltration into the brain parenchyma as well as VEGF release from the ECM and concomitant increase in angiogenesis (97).

As described above, hypoxia also promotes lymphatic spread of cancer cells, which may occur through increased expression of lymphangiogenic genes such as VEGF-C and VEGF-D, and VEGFR3 (Flt-4), the receptor for both (98-101). Using an animal model of metastatic cervical carcinoma, Chaudary et al. recently showed that VEGF-C/VEGFR3 signaling is essential for hypoxiainduced nodal metastasis (98). They exposed tumor-bearing animals to acute hypoxia and observed a significant increase in the number of lymph node metastases. The hypoxia treatment caused an increase in tumor expression of VEGF-C and VEGFR3 as well as the number of lymphatic and blood vessels. Knockdown of VEGF-C or inhibition of VEGFR3 completely abrogated hypoxia-mediated metastasis to the lymph nodes (98). Lymphatic metastasis of hypoxic breast cancer cells has similarly been shown to depend on HIF 1, through its ability to induce PDGF-B expression (102). 


\section{Hypoxia, cancer stem cells and metastasis}

Hypoxia has been implicated in promoting a cancer stem cell (CSC) phenotype. The cancer stem cell population within a tumor represents a limited number of cells that have the unique ability to self-renew and regenerate the tumor, including its phenotypic heterogeneity. Accordingly, CSCs in many aspects resemble metastatic cancer cells, which must be able to initiate tumor formation at distant sites. Indeed, data from several studies suggest that a specific subpopulation of CSCs within a tumor is responsible for the seeding of metastases (103-107). Hermann et al. demonstrated that HIF target gene CXCR4 is crucial for metastatic spread of pancreatic CD133 ${ }^{+} \mathrm{CSCs}$, despite the fact that $\mathrm{CD} 133^{+} \mathrm{CXCR} 4^{+}$and $\mathrm{CD} 133^{+} \mathrm{CXCR} 4^{-} \mathrm{CSC}$ show similar tumorigenic potential (106). Likewise, only CD $26^{+}$patient-derived colorectal CSCs are able to form liver metastases following orthotopic implantation (103).

Most of the evidence linking hypoxia to the regulation of the CSC phenotype is derived from studies in glioblastoma. Hypoxia has been shown to induce the expression of CD133 and other stem markers, including Nestin, OCT4 and SOX2 in patient-derived stem cells cultures (108). Hypoxia exposure of glioma stem cells stimulates their proliferation and self-renewal potential while inhibiting differentiation (108-110).

Recent evidence suggests that hypoxia may also induce a stem-like phenotype in differentiated, non-stem tumor cells. Pahlman and colleagues studied the effects of hypoxia on the differentiation status of neuroblastoma cells and showed that hypoxia induces the expression of stem cell-related genes including c-KIT and NOTCH-1, suggesting a shift to a less differentiated state (111). They observed a similar effect on gene expression in breast cancer and showed that hypoxia was associated with a less differentiated phenotype (112). A more recent study by Heddleston et al. demonstrated that hypoxia promotes selfrenewal of both glioma CSCs and non-CSCs, as reflected by enhanced neurosphere formation (113). In non-CSCs, hypoxia increased the expression of stem cell genes OCT4, NANOG and c-MYC to levels comparable in existing CSCs. They continued to show that the acquisition of the stem-like phenotype was mediated by HIF $2 \alpha$. Overexpression of HIF $2 \alpha$ in non-CSCs recapitulated the effects of hypoxia and increased in vivo tumor growth. Interestingly, Mani et al. showed that induction of the epithelial-mesenchymal transition in immortalized human mammary epithelial cells (HMLEs) gives rise to cells that exhibit stem cell-like behavior, including expression of stem cell markers and increased ability to form mammospheres (45). In addition, transformed HMLEs that were forced to undergo an EMT were more tumorigenic. Since hypoxia is a 
strong trigger for EMT, hypoxic activation of the EMT might represent a potential mechanism through which hypoxia promotes stemness. Furthermore, since CSCs play a crucial role in metastasis, hypoxia-induced changes in EMT and stemness might underlie hypoxia-driven metastasis.

\section{Premetastatic niche formation}

Increasing evidence supports a role for hypoxia in the establishment of a premetastatic niche at secondary sites. The premetastatic niche is a specialized microenvironment that is conducive for the arrival of disseminated tumor cells and the formation of metastases (114). Establishment of such a niche involves preconditioning of the metastatic site by bone marrow-derived cells (BMDCs) that are recruited in response to factors secreted by cancer cells in the primary tumor, including VEGF-A, placental growth factor (PlGF), transforming growth factor- $\beta$ (TGF- $\beta$ ) and tumor necrosis factor- $\alpha$ (TNF- $\alpha$ ) (115), many of which are known hypoxia-responsive genes. Tumor-secreted factors, such as SDF1, simultaneously function as chemotactic attractants for malignant cells in the primary tumor. Once at the metastatic site, the BMDCs secrete a variety of molecules, including cytokines, chemokines, MMPs and fibronectin, which results in remodeling of the ECM and recruitment of additional BMDCs and eventually metastatic tumor cells. Erler et al. have demonstrated that LOX secretion by hypoxic tumor cells plays a key role in the initiation of the premetastatic niche through recruitment of bone marrow-derived $\mathrm{CD} 11 \mathrm{~b}^{+}$ myeloid cells (78). Their study showed that hypoxia-induced LOX accumulates at the premetastatic site where it crosslinks collagen IV in the basement membrane and increases adhesion of $\mathrm{CD} 11 \mathrm{~b}^{+}$BMDC. Binding of $\mathrm{CD} 11 \mathrm{~b}^{+}$cells to the cross-linked basement membrane increased their production of active MMP-2 and resulted in enhanced degradation of collagen IV and BMDC invasion into the lung tissue. Inhibition of LOX suppressed recruitment of BMDCs to the premetastatic site and the formation of metastases (78). LOXL2 and LOXL4 (LOX-like 2-4), two other members of the LOX family and both direct HIF target genes, have also been implicated in the initiation of the premetastatic niche (116). Consistent with a role for HIFs in premetastatic niche formation and metastasis, a recent report by Semenza and co-workers showed that inhibitors of HIF1 block hypoxia-induced expression of LOX and LOXL proteins, collagen cross-linking, $\mathrm{CD}_{1} 1 \mathrm{~b}^{+} \mathrm{BMDC}$ recruitment and lung metastasis in an orthotopic breast cancer model (117).

Among the BMDCs that are recruited to the premetastatic site is a specific subpopulation immunosuppressive myeloid cells, also referred to as myeloidderived suppressor cells (MDSCs, CD1 $\left.1 \mathrm{~b}^{+} / \mathrm{Gr}-1^{+}\right)(118,119)$. MDSCs are a heterogeneous population of cells of myeloid origin that comprises myeloid 
progenitors and precursors of granulocytes, dendritic cells and macrophages (120). Accumulation of MDSCs in the primary tumor promotes tumor progression mainly through their ability to suppress anti-tumor $\mathrm{T}$ cell and NK cell responses (121). Thus, MDSCs most likely contribute to the establishment of the premetastatic niche through their immunosuppressive function $(122,123)$ and their ability to secrete a variety of MMPs and chemokines $(118,119)$. A recent report demonstrated that secretion of monocyte chemotactic protein-1 (MCP-1/CCL2) by hypoxic cells in primary breast tumors mobilizes a specific subpopulation of MDSCs $\left(\mathrm{CD} 11 \mathrm{~b}^{+} / \mathrm{Ly} 6 \mathrm{C}^{\mathrm{med}} / \mathrm{Ly} 6 \mathrm{G}^{+}\right)$from the bone marrow to the premetastatic lung and increases metastasis formation (123). A BMDC population consisting of less mature NK cells with a reduced cytotoxic activity was also enriched in the lungs of these animals. Depletion of NK cells resulted in a significant increase in the number of lung tumor cells (123). These data suggest that hypoxia promotes premetastatic niche formation in part through recruitment of MDSCs capable of suppressing NK cell anti-tumor activity.

\section{HIF-independent regulation of gene expression during hypoxia}

The unfolded protein response (UPR) was recently identified as a novel hypoxia-responsive pathway that is activated independently of HIF1 $\alpha$ (124). The UPR is a highly conserved response to endoplasmic reticulum (ER) stress consisting of three independent pathways initiated by a unique sensor of ER stress. These include PKR-like ER kinase (PERK, also known as EIF2AK3), inositol-requiring enzyme 1 (IRE1), and activating transcription factor 6 (ATF6) (figure 2). Under physiological conditions the endoplasmic reticulum is responsible for the folding and maturation of secretory and transmembrane proteins. However, certain conditions that include nutrient and redox status imbalance and also hypoxia, cause accumulation of unfolded and misfolded polypeptide chains in the ER and subsequent activation of the UPR. Even though there is substantial evidence demonstrating low oxygen levels are a stimulus for UPR activation, the molecular mechanisms behind this activation are still poorly understood. A previous study in yeast has reported that oxygen is required for proper ER protein maturation by acting as a terminal electron acceptor during disulfide bond formation (125).

During hypoxia or other forms of ER stress, activation of the PERK arm of the UPR results in an immediate inhibition of overall mRNA translation through Ser51 phosphorylation and inhibition of eukaryotic translation initiation factor 2a (eIF2) (124, 126-128). Hypoxia induced phosphorylation of eIF2 $\alpha$ can occur over a range of oxygen concentrations, but the fastest and strongest induction occurs during severe hypoxia $(<0.02 \%)(124,129)$. Although the translation of 
most genes is inhibited during hypoxia, a small subset of genes is selectively translated under these conditions. The UPR transcription factor ATF4 (Activating transcription factor 4) is amongst this group, and is induced by hypoxia. ATF4 activates the transcription of stress-inducible genes that promote restoration of normal ER function, such as ER protein chaperones and genes involved in amino acid metabolism and resistance to oxidative stress (130). ATF4 also induces DNA damage gene 34 (GADD34) (131). GADD34 mediates a negative feedback loop that results in dephosphorylation of eIF2a and relief from translational inhibition $(131,132)$. GADD34 interacts with the catalytic subunit of protein phosphatase 1 (PP1c) to promote dephosphorylation of eIF2 $\alpha$ (133).

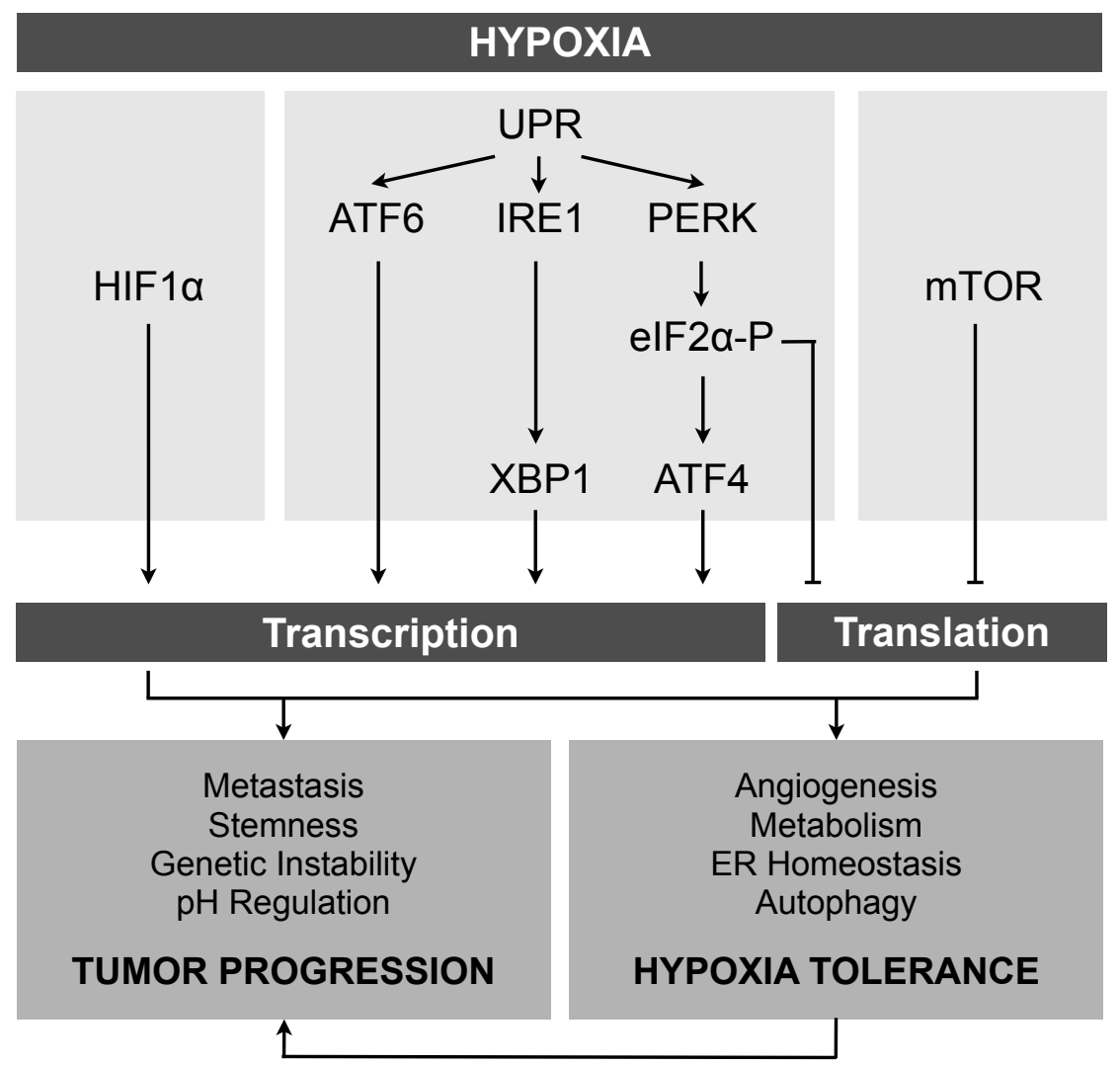

Figure 2. Hypoxia-responsive signaling pathways. Hypoxia activates several oxygen-sensitive pathways, which affect both gene transcription and mRNA translation. The resulting changes in gene expression are responsible for the initiation of diverse biological responses, which either contribute to hypoxia tolerance or to adverse phenotypes, such as metastasis. Furthermore, increased hypoxia tolerance indirectly promotes the emergence of hypoxia-associated adverse phenotypes. 


\section{UPR and metastasis}

Recent evidence suggests that hypoxic activation of the UPR may also contribute to a metastatic phenotype $(134,135)$. Robust activation of the UPR is observed at very low levels of oxygen, which can occur from acute interruptions in blood flow or red cell flux. Several studies have directly assessed the importance of this form of acute hypoxia, and concluded it may be more important for metastasis than hypoxia arising due to limited diffusion from perfused vessels $(24,136)$. Furthermore, tumor cells exposed to acute hypoxia are often located closer to blood vessels compared to chronically hypoxic cells and thus have easier access to the blood circulation (137). UPR signaling is thought to enhance hypoxia-induced metastasis by regulating the expression of metastasis-associated genes as well as by increasing cell survival under hypoxic conditions. Several hypoxia-responsive genes involved in the metastatic process are dependent on the UPR for their expression. These include the recently identified hypoxia target gene lysosomal associated membrane protein 3 (LAMP3)(138), VEGF-A and carbonic anhydrase 9 (CA9).

\section{Lysosomal associated membrane protein 3 (LAMP3)}

We have recently identified LAMP3 as a novel hypoxia-inducible gene that is transcriptionally regulated through the PERK/eIF2 $\alpha /$ ATF4 arm of the UPR (138). LAMP3 induction during hypoxia does not require HIF $1 \alpha$ activity (138). We have also shown that LAMP3 expression is necessary for hypoxia-induced metastasis using the previously described animal model of metastatic cervix carcinoma $(25,134)$. Knockdown of LAMP3 significantly inhibits lymph node metastasis in animals exposed to acute hypoxia, without affecting primary tumor growth. LAMP3 promotes tumor cell migration and invasion during hypoxia, but the underlying molecular mechanisms remain unknown $(134,135)$.

LAMP3 is overexpressed in breast cancer (138) and Nagelkerke et al. recently identified LAMP3 mRNA expression as an independent prognostic factor for locoregional control in a subgroup of breast cancer patients treated with radiotherapy (139). Moreover, we have also shown that LAMP3 protein expression correlates with the level of tumor hypoxia in human cervix cancer (134). Tumor hypoxia has previously been identified as an independent predictor of metastasis in a similar group of patients taking part in the same clinical trial (12), suggesting an involvement of LAMP3 in metastasis in these patients. 


\section{Angiogenesis}

Both PERK and IRE1 arms of the UPR have been directly implicated in tumor angiogenesis $(140,141)$. Blais et al. showed that PERK is required for proper vessel formation and maturation in tumors (140). Consistent with this finding, PERK $^{-/-}$tumors were smaller and poorly vascularized compared with PERK ${ }^{+/}$ tumors. PERK regulates the transcription and/or translation of several proangiogenic genes during hypoxia. VCIP (VEGF and type I collagen inducible protein) is a proangiogenic transcript preferentially translated during hypoxia in a PERK-dependent manner (140). Similarly, multiple angiogenesisrelated genes remain efficiently translated in DU145 prostate carcinoma cells exposed to 4 hours of severe hypoxia (142). UPR activation also increases expression of VEGF-A through an effect on both transcription and mRNA stability (143-146).

\section{Carbonic anhydrase 9 (CA9)}

CA9 is a well-characterized hypoxia-regulated gene that is often used as a surrogate marker for tumor hypoxia. CA9 plays a vital role in the regulation of tumor $\mathrm{pH}$ during hypoxia. Full transcriptional induction of CA9 during hypoxia is dependent on both HIF $1 \alpha$ and the UPR transcription factor ATF4 $(147,148)$. High CA9 expression correlates with poor patient prognosis in multiple cancer types (149-151). Furthermore, an association between CA9 expression and distant metastasis has been identified in breast and cervix cancer (152-154). A direct role for CA9 in metastasis is supported by data from several experimental studies (154-156). Lou et al. demonstrated that shRNA-mediated or pharmacologic inhibition of CA9 inhibits metastasis in two different tumor models of metastatic breast cancer (154). CA9 is thought to promote metastasis by increasing both tumor cell survival during hypoxia, and cell migration and invasion (157). By catalyzing the reversible conversion of carbon dioxide to bicarbonate and protons, $\mathrm{CA} 9$ aids in the maintenance of the intracellular $\mathrm{pH}$, while at the same time promoting acidification of the extracellular space. An acidic tumor microenvironment has been associated with increased breakdown of extracellular matrix, invasion and metastasis (158-160). CA9 may also regulate tumor cell migration (161-163). Svastova et al. showed that CA9 relocalizes to lamellipodia of migrating cells where it interacts with bicarbonate transporters and promotes cell migration (163). Furthermore, a recent study suggests a role for CA9 in the expansion of cancer stem cells residing in hypoxic niches (164). 


\section{Hypoxia tolerance and metastasis}

The ability to survive low-oxygen conditions within the primary tumor is a prerequisite for metastasis of hypoxic cells. Consequently, tumor cells with a higher level of tolerance to hypoxia will, by definition, have a higher probability to seed distant metastases. Hill and co-workers have shown that hypoxia can enhance metastatic efficiency of murine KHT and human HT1080 fibrosarcoma cells by increasing cell survival at the metastatic site without affecting their adhesive and invasive properties $(23,165)$. In KHT cells, the increased metastatic efficiency was, at least in part, due to hypoxic upregulation of $\mathrm{Mdm} 2$ expression and consequent inhibition of p53-mediated apoptosis (165). In fact, hypoxia can act as a selective pressure for tumor cells that have lost p53 and therefore show increased resistance to apoptosis (166). The molecular mechanisms behind the increased survival of lung-arrested HT1080 cells remained unresolved, but likely also involve apoptosis (23).

Both the HIF and UPR pathways described earlier, are also important mediators of hypoxia tolerance. HIF is thought to promote tolerance mainly through its regulation of metabolic genes $(32,167)$. UPR activation alleviates ER stress and promotes hypoxia tolerance by on one hand preventing further accumulation of unfolded proteins in the ER through inhibition of protein translation, and on the other hand by stimulating gene expression through activation of the ATF4, XBP1, and ATF6 transcription factors. There is so far no evidence of ATF6 mediating tolerance. However, numerous studies have demonstrated that signaling through XBP1 and ATF4 promotes hypoxia tolerance and tumor growth $(124,129,134,140,168-171)$. ATF4 can promote survival of hypoxic cells in multiple ways. Transcriptional induction of the autophagy related genes MAP1LC3B and ATG5 by ATF4 and CHOP functions to maintain high rates of autophagy during hypoxia (171). Inhibition of autophagy sensitizes cells to hypoxia-induced cell death in vitro and similarly, radiosensitizes tumors (171), indicating that PERK/ATF4-dependent regulation of autophagy represent an important cell survival mechanism during conditions of hypoxia. Furthermore, ATF4 signaling protects hypoxic cells against oxidative stress by increasing intracellular cysteine levels and glutathione synthesis (170). This protection is especially important in cells experiencing cyclic hypoxia, during which reoxygenation-induced accumulation of reactive oxygen species (ROS) occurs. Both HIF and PERK/eIF2 $\alpha$ signaling were found to be important for hypoxic cell survival, but only PERK/eIF $2 \alpha$ contributed to the survival of radiationresistant cells in tumor xenografts that arise as a consequence of transient changes in oxygenation (170). Similarly, XBP $1^{-/-} \mathrm{MEFs}$ display lower survival rates during hypoxia and are unable to form tumors, whereas tumors derived 
from XBP1-knockdown cells grow significantly slower compared to XBP1 wild type tumors (169).

\section{Antiangiogenic therapy-induced hypoxia and metastasis}

Hypoxia induced metastasis may also be important in the context of treatment, and particularly in tumors treated with antiangiogenic agents that result in tumor vessel destruction. Targeting angiogenesis is effective at reducing primary tumor growth but can promote invasiveness and metastasis in several tumor models (172-177). Hypoxia resulting from the disruption of vasculature in this setting has been proposed to be a major contributor to antiangiogenic therapy resistance as well as the driving force for the increased malignancy observed in preclinical models. Multiple experimental studies have demonstrated that antiangiogenic drugs increase tumor hypoxia (138, 173, 175-181). The antiangiogenic agent bevacizumab was similarly shown to reduce tumor perfusion in patients (182). Paez-Ribes et al. demonstrated that genetic or pharmacological inhibition of VEGF/VEGFR signaling increases lymphatic and distant metastasis in a mouse model of pancreatic neuroendocrine carcinoma (173). They also showed that the treated tumors exhibited a higher degree of hypoxia compared to the untreated tumors, implicating therapy-induced hypoxia in the observed metastatic phenotype. Using the same tumor model of pancreatic neuroendocrine carcinoma, Sennino et al. investigated the contribution of c-Met signaling to the increase in metastasis following antiangiogenic therapy (176). C-Met, the Hepatocyte growth factor (HGF) receptor, is a direct HIF1 $\alpha$ target gene (183) that stimulates many cellular processes, including migration, invasion and metastasis (184). Combined inhibition of c-Met and VEGF/VEGFR signaling using either a selective inhibitor or an agent that targets both pathways, reduced tumor invasion and metastasis and prolonged overall survival (176). These findings are in agreement with two previous reports in which two small-molecule inhibitors (XL880/foretinib and XL184/cabozantinib) were used that potently block multiple receptor tyrosine kinases, including VEGFR and c-Met $(185,186)$.

\section{Conclusion}

The poor prognosis of patients with hypoxic tumors is only partly explained by their increased resistance to common treatment modalities that include radiation and chemotherapy. Hypoxia can directly promote tumor malignancy through activation of oxygen sensitive signaling pathways that increase hypoxia tolerance and promote tumor progression, including metastasis (figure 2). Previous studies aimed at understanding the relationship between hypoxia and 
metastasis have focused largely on the HIF signaling pathway. However, recent evidence demonstrates that the unfolded protein response (UPR), a pro-survival pathway that is activated during hypoxia, is also an important mediator of metastasis. Therefore, targeting HIF and/or UPR signaling presents a potential therapeutic strategy to prevent development of metastases. Strategies to target hypoxic cells should be combined with radiotherapy and chemotherapy, which are aimed at eliminating well-oxygenated tumor cells, including those with increased metastatic potential. Furthermore, recent data from experimental studies suggest that simultaneous inhibition of tumor angiogenesis and hypoxia signaling might improve the clinical efficiency of antiangiogenic therapy by increasing its anti-tumor activity, and by preventing hypoxia-induced metastasis that has been observed in several experimental settings. Combinations of antiangiogenic drugs with inhibitors of HIF1, the UPR, or their downstream effectors, should therefore similarly be evaluated in more detail.

\section{References}

1. Thomlinson RH, Gray LH. The histological structure of some human lung cancers and the possible implications for radiotherapy. British journal of cancer. 1955;9:539-49.

2. Powers WE, Tolmach LJ. A multicomponent x-ray survival curve for mouse lymphosarcoma cells irradiated in vivo. Nature. 1963;197:710-1.

3. Rockwell S, Moulder JE. Hypoxic fractions of human tumors xenografted into mice: a review. International journal of radiation oncology, biology, physics. 1990;19:197-202.

4. Moulder JE, Rockwell S. Hypoxic fractions of solid tumors: experimental techniques, methods of analysis, and a survey of existing data. International journal of radiation oncology, biology, physics. 1984;10:695-712.

5. Kallinowski F, Zander R, Hoeckel M, Vaupel P. Tumor tissue oxygenation as evaluated by computerized-pO2-histography. International journal of radiation oncology, biology, physics. 1990;19:953-61.

6. Vaupel P, Schlenger K, Knoop C, Hockel M. Oxygenation of human tumors: evaluation of tissue oxygen distribution in breast cancers by computerized $\mathrm{O} 2$ tension measurements. Cancer research. 1991;51:3316-22.

7. Hockel M, Knoop C, Schlenger K, Vorndran B, Baussmann E, Mitze M, et al. Intratumoral pO2 predicts survival in advanced cancer of the uterine cervix. Radiother Oncol. 1993;26:45-50.

8. Hockel M, Schlenger K, Aral B, Mitze M, Schaffer U, Vaupel P. Association between tumor hypoxia and malignant progression in advanced cancer of the uterine cervix. Cancer research. 1996;56:4509-15.

9. Brizel DM, Scully SP, Harrelson JM, Layfield LJ, Bean JM, Prosnitz LR, et al. Tumor oxygenation predicts for the likelihood of distant metastases in human soft tissue sarcoma. Cancer research. 1996;56:941-3.

10. Sundfor K, Lyng H, Rofstad EK. Tumour hypoxia and vascular density as predictors of metastasis in squamous cell carcinoma of the uterine cervix. British journal of cancer. 1998;78:822-7. 


\section{Hypoxia Signaling and the Metastatic Phenotype}

11. Pitson G, Fyles A, Milosevic M, Wylie J, Pintilie M, Hill R. Tumor size and oxygenation are independent predictors of nodal diseases in patients with cervix cancer. International journal of radiation oncology, biology, physics. 2001;51:699-703.

12. Fyles A, Milosevic M, Hedley D, Pintilie M, Levin W, Manchul L, et al. Tumor hypoxia has independent predictor impact only in patients with node-negative cervix cancer. J Clin Oncol. 2002;20:680-7.

13. Milosevic M, Warde P, Menard C, Chung P, Toi A, Ishkanian A, et al. Tumor hypoxia predicts biochemical failure following radiotherapy for clinically localized prostate cancer. Clin Cancer Res. 2012;18:2108-14.

14. Young SD, Marshall RS, Hill RP. Hypoxia induces DNA overreplication and enhances metastatic potential of murine tumor cells. Proceedings of the National Academy of Sciences of the United States of America. 1988;85:9533-7.

15. Hill RP. Tumor progression: potential role of unstable genomic changes. Cancer metastasis reviews. 1990;9:137-47.

16. Gitelman I, Dexter DF, Roder JC. DNA amplification and metastasis of the human melanoma cell line MeWo. Cancer research. 1987;47:3851-5.

17. Rice GC, Hoy C, Schimke RT. Transient hypoxia enhances the frequency of dihydrofolate reductase gene amplification in Chinese hamster ovary cells. Proceedings of the National Academy of Sciences of the United States of America. 1986;83:5978-82.

18. Loffler M. Restimulation of cell cycle progression by hypoxic tumour cells with deoxynucleosides requires ppm oxygen tension. Experimental cell research. 1987;169:255-61.

19. Young SD, Hill RP. Effects of reoxygenation on cells from hypoxic regions of solid tumors: analysis of transplanted murine tumors for evidence of DNA overreplication. Cancer research. 1990;50:5031-8.

20. Young SD, Hill RP. Effects of reoxygenation on cells from hypoxic regions of solid tumors: anticancer drug sensitivity and metastatic potential. Journal of the National Cancer Institute. 1990;82:371-80.

21. Rofstad EK, Danielsen T. Hypoxia-induced metastasis of human melanoma cells: involvement of vascular endothelial growth factor-mediated angiogenesis. British journal of cancer. 1999;80:1697-707.

22. Stackpole CW, Groszek L, Kalbag SS. Benign-to-malignant B16 melanoma progression induced in two stages in vitro by exposure to hypoxia. Journal of the National Cancer Institute. 1994;86:361-7.

23. Zhang L, Hill RP. Hypoxia enhances metastatic efficiency in HT1080 fibrosarcoma cells by increasing cell survival in lungs, not cell adhesion and invasion. Cancer research. 2007;67:7789-97.

24. Cairns RA, Kalliomaki T, Hill RP. Acute (cyclic) hypoxia enhances spontaneous metastasis of KHT murine tumors. Cancer research. 2001;61:8903-8.

25. Cairns RA, Hill RP. Acute hypoxia enhances spontaneous lymph node metastasis in an orthotopic murine model of human cervical carcinoma. Cancer research. 2004;64:205461.

26. Rofstad EK, Gaustad JV, Egeland TA, Mathiesen B, Galappathi K. Tumors exposed to acute cyclic hypoxic stress show enhanced angiogenesis, perfusion and metastatic dissemination. International journal of cancer. 2010;127:1535-46. 
27. Cairns RA, Hill RP. A fluorescent orthotopic model of metastatic cervical carcinoma. Clinical \& experimental metastasis. 2004;21:275-81.

28. Plasswilm L, Tannapfel A, Cordes N, Demir R, Hoper K, Bauer J, et al. Hypoxia-induced tumour cell migration in an in vivo chicken model. Pathobiology. 2000;68:99-105.

29. Demir R, Naschberger L, Demir I, Melling N, Dimmler A, Papadopoulus T, et al. Hypoxia generates a more invasive phenotype of tumour cells: an in vivo experimental setup based on the chorioallantoic membrane. Pathol Oncol Res. 2009;15:417-22.

30. Lee SL, Rouhi P, Dahl Jensen L, Zhang D, Ji H, Hauptmann G, et al. Hypoxia-induced pathological angiogenesis mediates tumor cell dissemination, invasion, and metastasis in a zebrafish tumor model. Proceedings of the National Academy of Sciences of the United States of America. 2009;106:19485-90.

31. Wang GL, Jiang BH, Rue EA, Semenza GL. Hypoxia-inducible factor 1 is a basic-helixloop-helix-PAS heterodimer regulated by cellular O2 tension. Proceedings of the National Academy of Sciences of the United States of America. 1995;92:5510-4.

32. Harris AL. Hypoxia--a key regulatory factor in tumour growth. Nature reviews Cancer. 2002;2:38-47.

33. Kaelin WG, Jr., Ratcliffe PJ. Oxygen sensing by metazoans: the central role of the HIF hydroxylase pathway. Molecular cell. 2008;30:393-402.

34. Liao D, Corle C, Seagroves TN, Johnson RS. Hypoxia-inducible factor-1alpha is a key regulator of metastasis in a transgenic model of cancer initiation and progression. Cancer research. 2007;67:563-72.

35. Zhang H, Wong CC, Wei H, Gilkes DM, Korangath P, Chaturvedi P, et al. HIF-1dependent expression of angiopoietin-like 4 and L1CAM mediates vascular metastasis of hypoxic breast cancer cells to the lungs. Oncogene. 2012;31:1757-70.

36. Hiraga T, Kizaka-Kondoh S, Hirota K, Hiraoka M, Yoneda T. Hypoxia and hypoxiainducible factor- 1 expression enhance osteolytic bone metastases of breast cancer. Cancer research. 2007;67:4157-63.

37. Friedl P, Wolf K. Tumour-cell invasion and migration: diversity and escape mechanisms. Nature reviews Cancer. 2003;3:362-74.

38. Friedl P, Alexander S. Cancer invasion and the microenvironment: plasticity and reciprocity. Cell. 2011;147:992-1009.

39. Yilmaz M, Christofori G. Mechanisms of motility in metastasizing cells. Molecular cancer research : MCR. 2010;8:629-42.

40. Gal A, Sjoblom T, Fedorova L, Imreh S, Beug H, Moustakas A. Sustained TGF beta exposure suppresses Smad and non-Smad signalling in mammary epithelial cells, leading to EMT and inhibition of growth arrest and apoptosis. Oncogene. 2008;27:1218-30.

41. Ansieau S, Bastid J, Doreau A, Morel AP, Bouchet BP, Thomas C, et al. Induction of EMT by twist proteins as a collateral effect of tumor-promoting inactivation of premature senescence. Cancer Cell. 2008;14:79-89.

42. Knutson KL, Lu H, Stone B, Reiman JM, Behrens MD, Prosperi CM, et al. Immunoediting of cancers may lead to epithelial to mesenchymal transition. Journal of immunology. 2006;177:1526-33.

43. Yang AD, Fan F, Camp ER, van Buren G, Liu W, Somcio R, et al. Chronic oxaliplatin resistance induces epithelial-to-mesenchymal transition in colorectal cancer cell lines. Clinical cancer research : an official journal of the American Association for Cancer Research. 2006;12:4147-53. 


\section{Hypoxia Signaling and the Metastatic Phenotype}

44. Kurrey NK, Jalgaonkar SP, Joglekar AV, Ghanate AD, Chaskar PD, Doiphode RY, et al. Snail and slug mediate radioresistance and chemoresistance by antagonizing p53mediated apoptosis and acquiring a stem-like phenotype in ovarian cancer cells. Stem Cells. 2009;27:2059-68.

45. Mani SA, Guo W, Liao MJ, Eaton EN, Ayyanan A, Zhou AY, et al. The epithelial-mesenchymal transition generates cells with properties of stem cells. Cell. 2008;133:704-15.

46. Peinado H, Olmeda D, Cano A. Snail, Zeb and bHLH factors in tumour progression: an alliance against the epithelial phenotype? Nature reviews Cancer. 2007;7:415-28.

47. Kokura $\mathrm{S}$, Yoshida $\mathrm{N}$, Imamoto $\mathrm{E}$, Ueda $\mathrm{M}$, Ishikawa $\mathrm{T}$, Uchiyama $\mathrm{K}$, et al. Anoxia/reoxygenation down-regulates the expression of E-cadherin in human colon cancer cell lines. Cancer letters. 2004;211:79-87.

48. Krishnamachary B, Berg-Dixon S, Kelly B, Agani F, Feldser D, Ferreira G, et al. Regulation of colon carcinoma cell invasion by hypoxia-inducible factor 1 . Cancer research. 2003;63:1138-43.

49. Esteban MA, Tran MG, Harten SK, Hill P, Castellanos MC, Chandra A, et al. Regulation of E-cadherin expression by VHL and hypoxia-inducible factor. Cancer research. 2006;66:3567-75.

50. Evans AJ, Russell RC, Roche O, Burry TN, Fish JE, Chow VW, et al. VHL promotes E2 box-dependent E-cadherin transcription by HIF-mediated regulation of SIP1 and snail. Molecular and cellular biology. 2007;27:157-69.

51. Krishnamachary B, Zagzag D, Nagasawa H, Rainey K, Okuyama H, Baek JH, et al. Hypoxia-inducible factor-1-dependent repression of E-cadherin in von Hippel-Lindau tumor suppressor-null renal cell carcinoma mediated by TCF3, ZFHX1A, and ZFHX1B. Cancer research. 2006;66:2725-31.

52. Haase VH. Oxygen regulates epithelial-to-mesenchymal transition: insights into molecular mechanisms and relevance to disease. Kidney international. 2009;76:492-9.

53. Jiang J, Tang YL, Liang XH. EMT: a new vision of hypoxia promoting cancer progression. Cancer biology \& therapy. 2011;11:714-23.

54. Arimoto-Ishida E, Sakata M, Sawada K, Nakayama M, Nishimoto F, Mabuchi S, et al. Up-regulation of alpha5-integrin by E-cadherin loss in hypoxia and its key role in the migration of extravillous trophoblast cells during early implantation. Endocrinology. 2009;150:4306-15.

55. Imai T, Horiuchi A, Wang C, Oka K, Ohira S, Nikaido T, et al. Hypoxia attenuates the expression of E-cadherin via up-regulation of SNAIL in ovarian carcinoma cells. The American journal of pathology. 2003;163:1437-47.

56. Kurrey NK, K A, Bapat SA. Snail and Slug are major determinants of ovarian cancer invasiveness at the transcription level. Gynecologic oncology. 2005;97:155-65.

57. Lester RD, Jo M, Montel V, Takimoto S, Gonias SL. uPAR induces epithelialmesenchymal transition in hypoxic breast cancer cells. The Journal of cell biology. 2007; 178:425-36.

58. Luo D, Wang J, Li J, Post M. Mouse snail is a target gene for HIF. Molecular cancer research : MCR. 2011;9:234-45.

59. Storci G, Sansone P, Trere D, Tavolari S, Taffurelli M, Ceccarelli C, et al. The basal-like breast carcinoma phenotype is regulated by SLUG gene expression. The Journal of pathology. 2008;214:25-37. 
60. Yang MH, Wu MZ, Chiou SH, Chen PM, Chang SY, Liu CJ, et al. Direct regulation of TWIST by HIF-1alpha promotes metastasis. Nat Cell Biol. 2008;10:295-305.

61. Gregory PA, Bert AG, Paterson EL, Barry SC, Tsykin A, Farshid G, et al. The miR-200 family and miR-205 regulate epithelial to mesenchymal transition by targeting ZEB1 and SIP1. Nat Cell Biol. 2008;10:593-601.

62. Bracken CP, Gregory PA, Kolesnikoff N, Bert AG, Wang J, Shannon MF, et al. A double-negative feedback loop between ZEB1-SIP1 and the microRNA-200 family regulates epithelial-mesenchymal transition. Cancer research. 2008;68:7846-54.

63. Burk U, Schubert J, Wellner U, Schmalhofer O, Vincan E, Spaderna S, et al. A reciprocal repression between ZEB1 and members of the miR-200 family promotes EMT and invasion in cancer cells. EMBO Rep. 2008;9:582-9.

64. Cowden Dahl KD, Robertson SE, Weaver VM, Simon MC. Hypoxia-inducible factor regulates alphavbeta3 integrin cell surface expression. Mol Biol Cell. 2005;16:1901-12.

65. Yoon SO, Shin S, Mercurio AM. Ras stimulation of E2F activity and a consequent E2F regulation of integrin alpha6beta4 promote the invasion of breast carcinoma cells. Cancer research. 2006;66:6288-95.

66. Krishnamachary B, Penet MF, Nimmagadda S, Mironchik Y, Raman V, Solaiyappan M, et al. Hypoxia regulates CD44 and its variant isoforms through HIF-1alpha in triple negative breast cancer. PLoS One. 2012;7:e44078.

67. Buchler P, Reber HA, Tomlinson JS, Hankinson O, Kallifatidis G, Friess H, et al. Transcriptional regulation of urokinase-type plasminogen activator receptor by hypoxiainducible factor 1 is crucial for invasion of pancreatic and liver cancer. Neoplasia. 2009;11:196-206.

68. Zheng X, Jiang F, Katakowski M, Kalkanis SN, Hong X, Zhang X, et al. Inhibition of ADAM17 reduces hypoxia-induced brain tumor cell invasiveness. Cancer science. 2007;98:674-84.

69. Rzymski T, Petry A, Kracun D, Riess F, Pike L, Harris AL, et al. The unfolded protein response controls induction and activation of ADAM17/TACE by severe hypoxia and ER stress. Oncogene. 2012;31:3621-34.

70. Cuvier C, Jang A, Hill RP. Exposure to hypoxia, glucose starvation and acidosis: effect on invasive capacity of murine tumor cells and correlation with cathepsin $(\mathrm{L}+\mathrm{B})$ secretion. Clinical \& experimental metastasis. 1997;15:19-25.

71. Graham CH, Forsdike J, Fitzgerald CJ, Macdonald-Goodfellow S. Hypoxia-mediated stimulation of carcinoma cell invasiveness via upregulation of urokinase receptor expression. International journal of cancer Journal international du cancer. 1999;80:617-23.

72. Rofstad EK, Rasmussen H, Galappathi K, Mathiesen B, Nilsen K, Graff BA. Hypoxia promotes lymph node metastasis in human melanoma xenografts by up-regulating the urokinase-type plasminogen activator receptor. Cancer research. 2002;62:1847-53.

73. Carmeliet P, Moons L, Lijnen R, Baes M, Lemaitre V, Tipping P, et al. Urokinasegenerated plasmin activates matrix metalloproteinases during aneurysm formation. Nat Genet. 1997;17:439-44.

74. Kessenbrock K, Plaks V, Werb Z. Matrix metalloproteinases: regulators of the tumor microenvironment. Cell. 2010;141:52-67.

75. Kirschmann DA, Seftor EA, Fong SF, Nieva DR, Sullivan CM, Edwards EM, et al. A mole-cular role for lysyl oxidase in breast cancer invasion. Cancer research. 2002;62:4478-83. 


\section{Hypoxia Signaling and the Metastatic Phenotype}

76. Payne SL, Fogelgren B, Hess AR, Seftor EA, Wiley EL, Fong SF, et al. Lysyl oxidase regulates breast cancer cell migration and adhesion through a hydrogen peroxidemediated mechanism. Cancer research. 2005;65:11429-36.

77. Baker AM, Cox TR, Bird D, Lang G, Murray GI, Sun XF, et al. The role of lysyl oxidase in SRC-dependent proliferation and metastasis of colorectal cancer. Journal of the National Cancer Institute. 2011;103:407-24.

78. Erler JT, Bennewith KL, Cox TR, Lang G, Bird D, Koong A, et al. Hypoxia-induced lysyl oxidase is a critical mediator of bone marrow cell recruitment to form the premetastatic niche. Cancer Cell. 2009;15:35-44.

79. Erler JT, Bennewith KL, Nicolau M, Dornhofer N, Kong C, Le QT, et al. Lysyl oxidase is essential for hypoxia-induced metastasis. Nature. 2006;440:1222-6.

80. Levental KR, Yu H, Kass L, Lakins JN, Egeblad M, Erler JT, et al. Matrix crosslinking forces tumor progression by enhancing integrin signaling. Cell. 2009;139:891-906.

81. Le QT, Harris J, Magliocco AM, Kong CS, Diaz R, Shin B, et al. Validation of lysyl oxidase as a prognostic marker for metastasis and survival in head and neck squamous cell carcinoma: Radiation Therapy Oncology Group trial 90-03. Journal of clinical oncology : official journal of the American Society of Clinical Oncology. 2009;27:4281-6.

82. Kagan HM, Li W. Lysyl oxidase: properties, specificity, and biological roles inside and outside of the cell. Journal of cellular biochemistry. 2003;88:660-72.

83. Baker AM, Bird D, Lang G, Cox TR, Erler JT. Lysyl oxidase enzymatic function increases stiffness to drive colorectal cancer progression through FAK. Oncogene. 2012.

84. Chan DA, Giaccia AJ. Hypoxia, gene expression, and metastasis. Cancer Metastasis Rev. 2007;26:333-9.

85. Sullivan R, Graham CH. Hypoxia-driven selection of the metastatic phenotype. Cancer Metastasis Rev. 2007;26:319-31.

86. Lunt SJ, Chaudary N, Hill RP. The tumor microenvironment and metastatic disease. Clinical \& experimental metastasis. 2009;26:19-34.

87. Forsythe JA, Jiang BH, Iyer NV, Agani F, Leung SW, Koos RD, et al. Activation of vascular endothelial growth factor gene transcription by hypoxia-inducible factor 1 . Molecular and cellular biology. 1996;16:4604-13.

88. Gerber HP, Condorelli F, Park J, Ferrara N. Differential transcriptional regulation of the two vascular endothelial growth factor receptor genes. Flt-1, but not Flk-1/KDR, is upregulated by hypoxia. The Journal of biological chemistry. 1997;272:23659-67.

89. Elvert G, Kappel A, Heidenreich R, Englmeier U, Lanz S, Acker T, et al. Cooperative interaction of hypoxia-inducible factor-2alpha (HIF-2alpha) and Ets-1 in the transcriptional activation of vascular endothelial growth factor receptor-2 (Flk-1). The Journal of biological chemistry. 2003;278:7520-30.

90. Kappel A, Ronicke V, Damert A, Flamme I, Risau W, Breier G. Identification of vascular endothelial growth factor (VEGF) receptor-2 (Flk-1) promoter/enhancer sequences sufficient for angioblast and endothelial cell-specific transcription in transgenic mice. Blood. 1999;93:4284-92.

91. Kelly BD, Hackett SF, Hirota K, Oshima Y, Cai Z, Berg-Dixon S, et al. Cell type-specific regulation of angiogenic growth factor gene expression and induction of angiogenesis in nonischemic tissue by a constitutively active form of hypoxia-inducible factor 1 . Circ Res. 2003;93:1074-81. 
92. Kietzmann T, Roth U, Jungermann K. Induction of the plasminogen activator inhibitor-1 gene expression by mild hypoxia via a hypoxia response element binding the hypoxiainducible factor-1 in rat hepatocytes. Blood. 1999;94:4177-85.

93. Kim KS, Rajagopal V, Gonsalves C, Johnson C, Kalra VK. A novel role of hypoxiainducible factor in cobalt chloride- and hypoxia-mediated expression of IL-8 chemokine in human endothelial cells. Journal of immunology. 2006;177:7211-24.

94. Rofstad EK, Halsor EF. Hypoxia-associated spontaneous pulmonary metastasis in human melanoma xenografts: involvement of microvascular hot spots induced in hypoxic foci by interleukin 8. British journal of cancer. 2002;86:301-8.

95. Holmgren L, O'Reilly MS, Folkman J. Dormancy of micrometastases: balanced proliferation and apoptosis in the presence of angiogenesis suppression. Nat Med. 1995;1:149-53.

96. Bergers G, Benjamin LE. Tumorigenesis and the angiogenic switch. Nature reviews Cancer. 2003;3:401-10.

97. Du R, Lu KV, Petritsch C, Liu P, Ganss R, Passegue E, et al. HIF1alpha induces the recruitment of bone marrow-derived vascular modulatory cells to regulate tumor angiogenesis and invasion. Cancer Cell. 2008;13:206-20.

98. Chaudary N, Milosevic M, Hill RP. Suppression of vascular endothelial growth factor receptor 3 (VEGFR3) and vascular endothelial growth factor C (VEGFC) inhibits hypoxia-induced lymph node metastases in cervix cancer. Gynecologic oncology. 2011;123:393-400.

99. Currie MJ, Hanrahan V, Gunningham SP, Morrin HR, Frampton C, Han C, et al. Expression of vascular endothelial growth factor $\mathrm{D}$ is associated with hypoxia inducible factor (HIF-1alpha) and the HIF-1alpha target gene DEC1, but not lymph node metastasis in primary human breast carcinomas. Journal of clinical pathology. 2004;57:829-34.

100. Schoppmann SF, Fenzl A, Schindl M, Bachleitner-Hofmann T, Nagy K, Gnant M, et al. Hypoxia inducible factor-1alpha correlates with VEGF-C expression and lymphangiogenesis in breast cancer. Breast Cancer Res Treat. 2006;99:135-41.

101. Simiantonaki N, Jayasinghe C, Michel-Schmidt R, Peters K, Hermanns MI, Kirkpatrick CJ. Hypoxia-induced epithelial VEGF-C/VEGFR-3 upregulation in carcinoma cell lines. International journal of oncology. 2008;32:585-92.

102. Schito L, Rey S, Tafani M, Zhang H, Wong CC, Russo A, et al. Hypoxia-inducible factor 1-dependent expression of platelet-derived growth factor B promotes lymphatic metastasis of hypoxic breast cancer cells. Proceedings of the National Academy of Sciences of the United States of America. 2012;109:E2707-16.

103. Pang R, Law WL, Chu AC, Poon JT, Lam CS, Chow AK, et al. A subpopulation of CD26+ cancer stem cells with metastatic capacity in human colorectal cancer. Cell Stem Cell. 2010;6:603-15.

104. Liu H, Patel MR, Prescher JA, Patsialou A, Qian D, Lin J, et al. Cancer stem cells from human breast tumors are involved in spontaneous metastases in orthotopic mouse models. Proceedings of the National Academy of Sciences of the United States of America. 2010;107:18115-20.

105. Dieter SM, Ball CR, Hoffmann CM, Nowrouzi A, Herbst F, Zavidij O, et al. Distinct types of tumor-initiating cells form human colon cancer tumors and metastases. Cell Stem Cell. 2011;9:357-65. 


\section{Hypoxia Signaling and the Metastatic Phenotype}

106. Hermann PC, Huber SL, Herrler T, Aicher A, Ellwart JW, Guba M, et al. Distinct populations of cancer stem cells determine tumor growth and metastatic activity in human pancreatic cancer. Cell Stem Cell. 2007;1:313-23.

107. Charafe-Jauffret E, Ginestier C, Iovino F, Wicinski J, Cervera N, Finetti P, et al. Breast cancer cell lines contain functional cancer stem cells with metastatic capacity and a distinct molecular signature. Cancer research. 2009;69:1302-13.

108. McCord AM, Jamal M, Shankavaram UT, Lang FF, Camphausen K, Tofilon PJ. Physiologic oxygen concentration enhances the stem-like properties of CD133+ human glioblastoma cells in vitro. Molecular cancer research : MCR. 2009;7:489-97.

109. Seidel S, Garvalov BK, Wirta V, von Stechow L, Schanzer A, Meletis K, et al. A hypoxic niche regulates glioblastoma stem cells through hypoxia inducible factor 2 alpha. Brain : a journal of neurology. 2010;133:983-95.

110. Soeda A, Park M, Lee D, Mintz A, Androutsellis-Theotokis A, McKay RD, et al. Hypoxia promotes expansion of the CD133-positive glioma stem cells through activation of HIF1alpha. Oncogene. 2009;28:3949-59.

111. Jogi A, Ora I, Nilsson H, Lindeheim A, Makino Y, Poellinger L, et al. Hypoxia alters gene expression in human neuroblastoma cells toward an immature and neural crest-like phenotype. Proceedings of the National Academy of Sciences of the United States of America. 2002;99:7021-6.

112. Helczynska K, Kronblad A, Jogi A, Nilsson E, Beckman S, Landberg G, et al. Hypoxia promotes a dedifferentiated phenotype in ductal breast carcinoma in situ. Cancer research. 2003;63:1441-4.

113. Heddleston JM, Li Z, McLendon RE, Hjelmeland AB, Rich JN. The hypoxic microenvironment maintains glioblastoma stem cells and promotes reprogramming towards a cancer stem cell phenotype. Cell Cycle. 2009;8:3274-84.

114. Psaila B, Lyden D. The metastatic niche: adapting the foreign soil. Nature reviews Cancer. 2009;9:285-93.

115. Peinado H, Lavotshkin S, Lyden D. The secreted factors responsible for pre-metastatic niche formation: old sayings and new thoughts. Semin Cancer Biol. 2011;21:139-46.

116. Wong CC, Gilkes DM, Zhang H, Chen J, Wei H, Chaturvedi P, et al. Hypoxia-inducible factor 1 is a master regulator of breast cancer metastatic niche formation. Proceedings of the National Academy of Sciences of the United States of America. 2011;108:16369-74.

117. Wong CC, Zhang H, Gilkes DM, Chen J, Wei H, Chaturvedi P, et al. Inhibitors of hypoxia-inducible factor 1 block breast cancer metastatic niche formation and lung metastasis. Journal of molecular medicine. 2012;90:803-15.

118. Hiratsuka S, Watanabe A, Aburatani H, Maru Y. Tumour-mediated upregulation of chemoattractants and recruitment of myeloid cells predetermines lung metastasis. Nat Cell Biol. 2006;8:1369-75.

119. Yang L, Huang J, Ren X, Gorska AE, Chytil A, Aakre M, et al. Abrogation of TGF beta signaling in mammary carcinomas recruits $\mathrm{Gr}-1+\mathrm{CD} 11 \mathrm{~b}+$ myeloid cells that promote metastasis. Cancer Cell. 2008;13:23-35.

120. Gabrilovich DI, Nagaraj S. Myeloid-derived suppressor cells as regulators of the immune system. Nat Rev Immunol. 2009;9:162-74.

121. Dolcetti L, Marigo I, Mantelli B, Peranzoni E, Zanovello P, Bronte V. Myeloid-derived suppressor cell role in tumor-related inflammation. Cancer letters. 2008;267:216-25. 
122. Mauti LA, Le Bitoux MA, Baumer K, Stehle JC, Golshayan D, Provero P, et al. Myeloidderived suppressor cells are implicated in regulating permissiveness for tumor metastasis during mouse gestation. The Journal of clinical investigation. 2011;121:2794-807.

123. Sceneay J, Chow MT, Chen A, Halse HM, Wong CS, Andrews DM, et al. Primary tumor hypoxia recruits $\mathrm{CD} 11 \mathrm{~b}+/ \mathrm{Ly} 6 \mathrm{Cmed} / \mathrm{Ly} 6 \mathrm{G}+$ immune suppressor cells and compromises NK cell cytotoxicity in the premetastatic niche. Cancer research. 2012;72:3906-11.

124. Koumenis C, Naczki C, Koritzinsky M, Rastani S, Diehl A, Sonenberg N, et al. Regulation of protein synthesis by hypoxia via activation of the endoplasmic reticulum kinase PERK and phosphorylation of the translation initiation factor eIF2alpha. Molecular and cellular biology. 2002;22:7405-16.

125. Tu BP, Weissman JS. The FAD- and O(2)-dependent reaction cycle of Ero1-mediated oxidative protein folding in the endoplasmic reticulum. Molecular cell. 2002;10:983-94.

126. Harding HP, Zhang Y, Bertolotti A, Zeng H, Ron D. Perk is essential for translational regulation and cell survival during the unfolded protein response. Molecular cell. 2000;5:897-904.

127. Harding HP, Zhang Y, Ron D. Protein translation and folding are coupled by an endoplasmic-reticulum-resident kinase. Nature. 1999;397:271-4.

128. Shi Y, Vattem KM, Sood R, An J, Liang J, Stramm L, et al. Identification and characterization of pancreatic eukaryotic initiation factor 2 alpha-subunit kinase, PEK, involved in translational control. Molecular and cellular biology. 1998;18:7499-509.

129. Koritzinsky M, Rouschop KM, van den Beucken T, Magagnin MG, Savelkouls K, Lambin P, et al. Phosphorylation of eIF2alpha is required for mRNA translation inhibition and survival during moderate hypoxia. Radiother Oncol. 2007;83:353-61.

130. Harding HP, Zhang Y, Zeng H, Novoa I, Lu PD, Calfon M, et al. An integrated stress response regulates amino acid metabolism and resistance to oxidative stress. Molecular cell. 2003;11:619-33.

131. Ma Y, Hendershot LM. Delineation of a negative feedback regulatory loop that controls protein translation during endoplasmic reticulum stress. J Biol Chem. 2003;278:34864-73.

132. Novoa I, Zeng H, Harding HP, Ron D. Feedback inhibition of the unfolded protein response by GADD34-mediated dephosphorylation of eIF2alpha. The Journal of cell biology. 2001;153:1011-22.

133. He B, Gross M, Roizman B. The gamma(1)34.5 protein of herpes simplex virus 1 complexes with protein phosphatase 1alpha to dephosphorylate the alpha subunit of the eukaryotic translation initiation factor 2 and preclude the shutoff of protein synthesis by double-stranded RNA-activated protein kinase. Proceedings of the National Academy of Sciences of the United States of America. 1997;94:843-8.

134. Mujcic H, Nagelkerke A, Rouschop K, Chung S, Chaudary N, Span PN, et al. Hypoxic Activation of the PERK/eIF2 $\alpha$ arm of the Unfolded Protein Response Promotes Metastasis through Induction of LAMP3. Submitted.

135. Nagelkerke A, Bussink J, Mujcic H, Wouters BG, Lehmann S, Sweep FC, et al. Hypoxia stimulates migration of breast cancer cells via the PERK/ATF4/LAMP3-arm of the unfolded protein response. Breast cancer research : BCR. 2013;15:R2.

136. Rofstad EK, Galappathi K, Mathiesen B, Ruud EB. Fluctuating and diffusion-limited hypoxia in hypoxia-induced metastasis. Clinical cancer research : an official journal of the American Association for Cancer Research. 2007;13:1971-8. 


\section{Hypoxia Signaling and the Metastatic Phenotype}

137. Chaudary N, Hill RP. Hypoxia and metastasis. Clinical cancer research : an official journal of the American Association for Cancer Research. 2007;13:1947-9.

138. Mujcic H, Rzymski T, Rouschop KM, Koritzinsky M, Milani M, Harris AL, et al. Hypoxic activation of the unfolded protein response (UPR) induces expression of the metastasis-associated gene LAMP3. Radiother Oncol. 2009;92:450-9.

139. Nagelkerke A, Mujcic H, Bussink J, Wouters BG, van Laarhoven HW, Sweep FC, et al. Hypoxic regulation and prognostic value of LAMP3 expression in breast cancer. Cancer. 2011;117:3670-81.

140. Blais JD, Addison CL, Edge R, Falls T, Zhao H, Wary K, et al. Perk-dependent translational regulation promotes tumor cell adaptation and angiogenesis in response to hypoxic stress. Molecular and cellular biology. 2006;26:9517-32.

141. Romero-Ramirez L, Cao H, Regalado MP, Kambham N, Siemann D, Kim JJ, et al. X box-binding protein 1 regulates angiogenesis in human pancreatic adenocarcinomas. Transl Oncol. 2009;2:31-8.

142. Koritzinsky M, Seigneuric R, Magagnin MG, van den Beucken T, Lambin P, Wouters BG. The hypoxic proteome is influenced by gene-specific changes in mRNA translation. Radiotherapy and oncology : journal of the European Society for Therapeutic Radiology and Oncology. 2005;76:177-86.

143. Pereira ER, Liao N, Neale GA, Hendershot LM. Transcriptional and post-transcriptional regulation of proangiogenic factors by the unfolded protein response. PLoS One. 2010;5.

144. Ghosh R, Lipson KL, Sargent KE, Mercurio AM, Hunt JS, Ron D, et al. Transcriptional regulation of VEGF-A by the unfolded protein response pathway. PLoS One. 2010;5:e9575.

145. Roybal CN, Yang S, Sun CW, Hurtado D, Vander Jagt DL, Townes TM, et al. Homocysteine increases the expression of vascular endothelial growth factor by a mechanism involving endoplasmic reticulum stress and transcription factor ATF4. The Journal of biological chemistry. 2004;279:14844-52.

146. Drogat B, Auguste P, Nguyen DT, Bouchecareilh M, Pineau R, Nalbantoglu J, et al. IRE1 signaling is essential for ischemia-induced vascular endothelial growth factor-A expression and contributes to angiogenesis and tumor growth in vivo. Cancer research. 2007;67:6700-7.

147. van den Beucken T, Koritzinsky M, Niessen H, Dubois L, Savelkouls K, Mujcic H, et al. Hypoxia-induced expression of carbonic anhydrase 9 is dependent on the unfolded protein response. The Journal of biological chemistry. 2009;284:24204-12.

148. Wykoff CC, Beasley NJ, Watson PH, Turner KJ, Pastorek J, Sibtain A, et al. Hypoxiainducible expression of tumor-associated carbonic anhydrases. Cancer research. 2000;60:7075-83.

149. Swinson DE, Jones JL, Richardson D, Wykoff C, Turley H, Pastorek J, et al. Carbonic anhydrase IX expression, a novel surrogate marker of tumor hypoxia, is associated with a poor prognosis in non-small-cell lung cancer. Journal of clinical oncology : official journal of the American Society of Clinical Oncology. 2003;21:473-82.

150. Korkeila E, Talvinen K, Jaakkola PM, Minn H, Syrjanen K, Sundstrom J, et al. Expression of carbonic anhydrase IX suggests poor outcome in rectal cancer. British journal of cancer. 2009;100:874-80. 
151. Eckert AW, Lautner MH, Schutze A, Bolte K, Bache M, Kappler M, et al. Co-expression of Hiflalpha and CAIX is associated with poor prognosis in oral squamous cell carcinoma patients. J Oral Pathol Med. 2010;39:313-7.

152. Kim JY, Shin HJ, Kim TH, Cho KH, Shin KH, Kim BK, et al. Tumor-associated carbonic anhydrases are linked to metastases in primary cervical cancer. J Cancer Res Clin Oncol. 2006;132:302-8.

153. Loncaster JA, Harris AL, Davidson SE, Logue JP, Hunter RD, Wycoff CC, et al. Carbonic anhydrase (CA IX) expression, a potential new intrinsic marker of hypoxia: correlations with tumor oxygen measurements and prognosis in locally advanced carcinoma of the cervix. Cancer research. 2001;61:6394-9.

154. Lou Y, McDonald PC, Oloumi A, Chia S, Ostlund C, Ahmadi A, et al. Targeting tumor hypoxia: suppression of breast tumor growth and metastasis by novel carbonic anhydrase IX inhibitors. Cancer research. 2011;71:3364-76.

155. Gieling RG, Babur M, Mamnani L, Burrows N, Telfer BA, Carta F, et al. Antimetastatic effect of sulfamate carbonic anhydrase IX inhibitors in breast carcinoma xenografts. Journal of medicinal chemistry. 2012;55:5591-600.

156. Pacchiano F, Carta F, McDonald PC, Lou Y, Vullo D, Scozzafava A, et al. Ureidosubstituted benzenesulfonamides potently inhibit carbonic anhydrase IX and show antimetastatic activity in a model of breast cancer metastasis. Journal of medicinal chemistry. 2011;54:1896-902.

157. Robertson N, Potter C, Harris AL. Role of carbonic anhydrase IX in human tumor cell growth, survival, and invasion. Cancer research. 2004;64:6160-5.

158. Gatenby RA, Gawlinski ET, Gmitro AF, Kaylor B, Gillies RJ. Acid-mediated tumor invasion: a multidisciplinary study. Cancer research. 2006;66:5216-23.

159. Gatenby RA, Gillies RJ. A microenvironmental model of carcinogenesis. Nature reviews Cancer. 2008;8:56-61.

160. Moellering RE, Black KC, Krishnamurty C, Baggett BK, Stafford P, Rain M, et al. Acid treatment of melanoma cells selects for invasive phenotypes. Clinical \& experimental metastasis. 2008;25:411-25.

161. Shin HJ, Rho SB, Jung DC, Han IO, Oh ES, Kim JY. Carbonic anhydrase IX (CA9) modulates tumor-associated cell migration and invasion. J Cell Sci. 2011;124:1077-87.

162. Svastova E, Zilka N, Zat'ovicova M, Gibadulinova A, Ciampor F, Pastorek J, et al. Carbonic anhydrase IX reduces E-cadherin-mediated adhesion of MDCK cells via interaction with beta-catenin. Experimental cell research. 2003;290:332-45.

163. Svastova E, Witarski W, Csaderova L, Kosik I, Skvarkova L, Hulikova A, et al. Carbonic anhydrase IX interacts with bicarbonate transporters in lamellipodia and increases cell migration via its catalytic domain. The Journal of biological chemistry. 2012;287:3392-402.

164. Lock FE, McDonald PC, Lou Y, Serrano I, Chafe SC, Ostlund C, et al. Targeting carbonic anhydrase IX depletes breast cancer stem cells within the hypoxic niche. Oncogene. 2012.

165. Zhang L, Hill RP. Hypoxia enhances metastatic efficiency by up-regulating Mdm2 in KHT cells and increasing resistance to apoptosis. Cancer research. 2004;64:4180-9.

166. Graeber TG, Osmanian C, Jacks T, Housman DE, Koch CJ, Lowe SW, et al. Hypoxiamediated selection of cells with diminished apoptotic potential in solid tumours. Nature. 1996;379:88-91.

167. Majmundar AJ, Wong WJ, Simon MC. Hypoxia-inducible factors and the response to hypoxic stress. Molecular cell. 2010;40:294-309. 


\section{Hypoxia Signaling and the Metastatic Phenotype}

168. Bi M, Naczki C, Koritzinsky M, Fels D, Blais J, Hu N, et al. ER stress-regulated translation increases tolerance to extreme hypoxia and promotes tumor growth. The EMBO journal. 2005;24:3470-81.

169. Romero-Ramirez L, Cao H, Nelson D, Hammond E, Lee AH, Yoshida H, et al. XBP1 is essential for survival under hypoxic conditions and is required for tumor growth. Cancer research. 2004;64:5943-7.

170. Rouschop KM, Dubois LJ, Keulers TG, van den Beucken T, Lambin P, Bussink J, et al. PERK/eIF2alpha signaling protects therapy resistant hypoxic cells through induction of glutathione synthesis and protection against ROS. Proceedings of the National Academy of Sciences of the United States of America. 2013;110:4622-7.

171. Rouschop KM, van den Beucken T, Dubois L, Niessen H, Bussink J, Savelkouls K, et al. The unfolded protein response protects human tumor cells during hypoxia through regulation of the autophagy genes MAP1LC3B and ATG5. J Clin Invest. 2010;120:127-41.

172. Ebos JM, Lee CR, Cruz-Munoz W, Bjarnason GA, Christensen JG, Kerbel RS. Accelerated metastasis after short-term treatment with a potent inhibitor of tumor angiogenesis. Cancer Cell. 2009;15:232-9.

173. Paez-Ribes M, Allen E, Hudock J, Takeda T, Okuyama H, Vinals F, et al. Antiangiogenic therapy elicits malignant progression of tumors to increased local invasion and distant metastasis. Cancer Cell. 2009;15:220-31.

174. Rubenstein JL, Kim J, Ozawa T, Zhang M, Westphal M, Deen DF, et al. Anti-VEGF antibody treatment of glioblastoma prolongs survival but results in increased vascular cooption. Neoplasia. 2000;2:306-14.

175. Casanovas O, Hicklin DJ, Bergers G, Hanahan D. Drug resistance by evasion of antiangiogenic targeting of VEGF signaling in late-stage pancreatic islet tumors. Cancer Cell. 2005;8:299-309.

176. Sennino B, Ishiguro-Oonuma T, Wei Y, Naylor RM, Williamson CW, Bhagwandin V, et al. Suppression of tumor invasion and metastasis by concurrent inhibition of c-Met and VEGF signaling in pancreatic neuroendocrine tumors. Cancer Discov. 2012;2:270-87.

177. Cooke VG, LeBleu VS, Keskin D, Khan Z, O'Connell JT, Teng Y, et al. Pericyte depletion results in hypoxia-associated epithelial-to-mesenchymal transition and metastasis mediated by met signaling pathway. Cancer Cell. 2012;21:66-81.

178. Conley SJ, Gheordunescu E, Kakarala P, Newman B, Korkaya H, Heath AN, et al. Antiangiogenic agents increase breast cancer stem cells via the generation of tumor hypoxia. Proceedings of the National Academy of Sciences of the United States of America. 2012;109:2784-9.

179. Franco M, Man S, Chen L, Emmenegger U, Shaked Y, Cheung AM, et al. Targeted antivascular endothelial growth factor receptor-2 therapy leads to short-term and long-term impairment of vascular function and increase in tumor hypoxia. Cancer research. 2006;66:3639-48.

180. Keunen O, Johansson M, Oudin A, Sanzey M, Rahim SA, Fack F, et al. Anti-VEGF treatment reduces blood supply and increases tumor cell invasion in glioblastoma. Proceedings of the National Academy of Sciences of the United States of America. 2011;108:3749-54.

181. Ren Y, Fleischmann D, Foygel K, Molvin L, Lutz AM, Koong AC, et al. Antiangiogenic and radiation therapy: early effects on in vivo computed tomography perfusion parameters in human colon cancer xenografts in mice. Invest Radiol. 2012;47:25-32. 
182. Yopp AC, Schwartz LH, Kemeny N, Gultekin DH, Gonen M, Bamboat Z, et al. Antiangiogenic therapy for primary liver cancer: correlation of changes in dynamic contrast-enhanced magnetic resonance imaging with tissue hypoxia markers and clinical response. Ann Surg Oncol. 2011;18:2192-9.

183. Pennacchietti S, Michieli P, Galluzzo M, Mazzone M, Giordano S, Comoglio PM. Hypoxia promotes invasive growth by transcriptional activation of the met protooncogene. Cancer Cell. 2003;3:347-61.

184. Stella GM, Benvenuti S, Comoglio PM. Targeting the MET oncogene in cancer and metastases. Expert Opin Investig Drugs. 2010;19:1381-94.

185. You WK, Sennino B, Williamson CW, Falcon B, Hashizume H, Yao LC, et al. VEGF and c-Met blockade amplify angiogenesis inhibition in pancreatic islet cancer. Cancer research. 2011;71:4758-68.

186. Qian F, Engst S, Yamaguchi K, Yu P, Won KA, Mock L, et al. Inhibition of tumor cell growth, invasion, and metastasis by EXEL-2880 (XL880, GSK1363089), a novel inhibitor of HGF and VEGF receptor tyrosine kinases. Cancer research. 2009;69:8009-16. 


\section{CHAPTER 3}

\section{Hypoxic Activation of the Unfolded Protein Response (UPR) Induces Expression of the Metastasis-Associated Gene LAMP3}

H. Mujcic ${ }^{*}$

T. Rzymski*

K.M.A. Rouschop

M. Koritzinsky

M. Milani

A.L. Harris

B.G. Wouters

Radiother Oncol. 2009;(92):450-459

\footnotetext{
*These authors contributed equally
} 


\begin{abstract}
Background and Purpose: Tumor hypoxia contributes to failure of cancer treatment through its ability to protect against therapy and adversely influence tumor biology. In particular, several studies suggest that hypoxia promotes metastasis. Hypoxia-induced cellular changes are mediated by oxygen-sensitive signaling pathways that activate downstream transcription factors. We have investigated the induction and transcriptional regulation of a novel metastasisassociated gene, LAMP3 during hypoxia.
\end{abstract}

Materials and Methods: Microarray, quantitative PCR, Western blot analysis and immunohistochemistry were used to investigate hypoxic regulation of LAMP3. The mechanism for LAMP3 induction was investigated using transient RNAi and stable shRNA targeting components of the hypoxic response. Endoplasmic reticulum stress inducing agents, including proteasome inhibitors were assessed for their ability to regulate LAMP3.

Results: LAMP3 is strongly induced by hypoxia at both the mRNA and protein levels in a large panel of human tumor cell lines. Induction of LAMP3 occurs as a consequence of the activation of the PERK/eIF2 $\alpha /$ ATF 4 arm of the unfolded protein response (UPR) and is independent of HIF $1 \alpha$. LAMP3 is expressed heterogeneously within the microenvironment of tumors, is overexpressed in breast cancer, and increases in tumors treated with Avastin.

Conclusions: These data identify LAMP3 as a novel hypoxia-inducible gene regulated by the UPR. LAMP3 is a new candidate biomarker of UPR activation by hypoxia in tumors and is a potential mediator of hypoxia-induced metastasis. 


\section{Introduction}

Numerous clinical studies have demonstrated that the majority of solid tumors contain regions of poor oxygenation or hypoxia (1). Hypoxic cells are considerably more resistant to radiotherapy than well-oxygenated cells, and also compromise the effectiveness of other forms of treatment $(2,3)$. Moreover, hypoxia contributes to the development of a more malignant tumor phenotype (4-6). Various clinical studies have demonstrated an association between hypoxia and poor patient prognosis $(7,8)$ as well as hypoxia and metastasis $(9$ 11). Data from experimental studies support a functional role for hypoxia underlying this clinical association, as exposure of tumor cells or tumor bearing mice to hypoxic environments can directly promote metastasis (12-15).

Changes in cell biology that occur in response to hypoxia are attributed largely to the activation of oxygen-sensing pathways that influence gene expression. Hypoxic exposure elicits a substantial transcriptional response due in part to the activation of the hypoxia inducible factor (HIF) family of transcription factors. HIF1 and HIF2 induce genes involved in angiogenesis, glycolysis, erythropoiesis and cell survival $(16,17)$. Recently, the unfolded protein response (UPR) has also been demonstrated to contribute to hypoxic adaptation in tumors (reviewed in (4)). In comparison to HIF, which is activated over a wide range of oxygen concentrations below $2 \%$, maximum activation of the UPR requires exposure to more severe hypoxia $\left(<0.02 \% \mathrm{O}_{2}\right)$ (reviewed in (18)). Nevertheless, activation of the UPR has been shown to protect tumor cells against hypoxia-induced cell death both in vitro and in vivo over a range of oxygen concentrations (19-21).

The UPR is activated in response to endoplasmic reticulum (ER) stress during hypoxia, and results in the downstream activation of numerous adaptive mechanisms. The UPR is initiated by three independent ER transmembrane proteins: inositol-requiring enzyme 1 (IRE1), PKR-like ER kinase (PERK) and activating transcription factor 6 (ATF6) (22). Exposure to severe hypoxia causes rapid activation of PERK and phosphorylation of its substrate eIF2 $\alpha$ on Serine 51, which leads to a reduction in overall protein synthesis (23). Although translation of most genes is inhibited under these conditions, certain gene transcripts are able to escape this inhibition due to the presence of regulatory sequences in their 5' untranslated regions. This change in translation efficiency contributes to changes in differential protein expression during hypoxia (23, 24). Translation of the transcription factor ATF4 is strongly stimulated under hypoxic conditions in response to PERK activation (25) due to the presence of two upstream open reading frames in its 5' UTR (26). ATF4 activates various 
UPR-target genes that promote restoration of normal ER function and protection against reactive oxygen species (27). The IRE1 and ATF6 arms of the UPR are also responsible for eliciting transcriptional activation of a large number of target genes during hypoxia. Consequently, the UPR mediates both translational (via PERK) and transcriptional responses (via PERK, IRE1, and ATF6) during hypoxia.

In an ongoing effort to characterize the biological response to hypoxia we report here the identification of a novel hypoxia-regulated gene, lysosomal-associated membrane protein 3 (LAMP3) that previously has been implicated in metastasis. LAMP3 (also known as TSC403, DC-LAMP and CD208) is a member of the LAMP family of highly glycosylated proteins that reside predominantly in the lysosomal membrane. LAMP3 was first identified as a lung-specific gene (28), but is also a well-established cell surface marker of mature dendritic cells. Although its precise function in both cell types is unknown, LAMP3 is most likely involved in MHC II-associated antigen presentation in dendritic cells (29). LAMP3 is overexpressed in several human cancers, including lung, colon, esophagus, breast and ovary cancer (28), and high LAMP3 expression predicted for poor survival in a small cohort of patients with cancer of the uterine cervix (30). Although the functional role of this protein in carcinogenesis and tumor progression remains largely unknown, overexpression of LAMP3 has been shown to stimulate metastasis from subcutaneously growing tumor xenografts (30). Here it is shown that LAMP3 is transcriptionally induced during hypoxia in a PERK/ATF4 dependent manner. Furthermore, LAMP3 expression is increased in breast cancer and in tumors treated with the anti-angiogenic agent Avastin.

\section{Materials and methods}

\section{Cell culture, hypoxic exposure and drug treatment}

This study included the following human cancer cell lines: HT-29 (colon adenocarcinoma), MCF7 (breast adenocarcinoma), DU 145 (prostate carcinoma), A549 (lung carcinoma), ME180 (cervix carcinoma) and U-373 MG (glioblastoma-astrocytoma), HCT116 (colon carcinoma), HeLa (cervical carcinoma), and MDA-MB-231 (breast adenocarcinoma). The cells were grown in DMEM (HT-29, A549, MDA-MB-231), RPMI (MCF7), McCoy's 5A (DU145) or MEM-alpha (ME180 and U-373 MG) media supplemented with $10 \%$ fetal bovine serum. MCF7 cells used for experiments with gradual hypoxia (see below) were cultured in DMEM. U-373 MG cells expressing the Cterminal active part of GADD34 (31), eIF2 $\alpha$ (S51A) and the shRNA against PERK (targeting sequence 5'-AGCGCGGCAGGTCATTAGTAA-3') were generated as described previously (20). 
Exposure to hypoxia was done in two different ways. The first was an acute shift to severe hypoxia $\left(<0.02 \% \mathrm{O}_{2}\right)$ and was established by culturing cells on glass dishes. This enables rapid equilibration of the cellular media with the environment when the dishes are placed into the hypoxic chamber. The second was a more gradual shift to severe hypoxia $\left(<0.02 \% \mathrm{O}_{2}\right)$ and was accomplished by culturing cells on plastic dishes. In the latter experiments, oxygen dissolved in the plastic dishes delays the establishment of severe hypoxic conditions for the cells when switched to the hypoxic atmosphere. In the manuscript we refer to these two types of hypoxic treatment as rapid hypoxia and gradual hypoxia. All hypoxic exposures were carried out in the same hypoxic culture chamber (MACS VA500 microaerophilic workstation, Don Whitley Scientific, Shipley, UK). The composition of the atmosphere in the chamber consisted of $5 \% \mathrm{H}_{2}$, $5 \% \mathrm{CO}_{2}, 0.0 \% \mathrm{O}_{2}$ and residual $\mathrm{N}_{2}$.

For experiments involving exposure to stress inducing agents, MCF7 and MDA-MB-231 cells were exposed for $24 \mathrm{~h}$ to desferoxamine (dfo) $40 \mu \mathrm{M}$, $\mathrm{CoCl}_{2} 100 \mu \mathrm{M}$, arsenite (ars) $5 \mu \mathrm{M}, \mathrm{MG} 132-10 \mu \mathrm{M}$, thapsigargin (thaps) 300 $\mathrm{nM}, \mathrm{MG} 115-5 \mu \mathrm{M}, 5 \mu \mathrm{g} / \mathrm{ml}$ tunicamycin (tunic) and bortezomib (velc) $100 \mathrm{nM}$. Bortezomib was a gift from Millennium Pharmaceuticals Inc. (Cambridge, MA). MG115, MG132, thapsigargin and tunicamycin were from Calbiochem.

\section{Microarray experiments}

Microarray experiments were performed as previously described (24). Briefly, DU145, HT-29 and MCF7 cells were grown on glass dishes and exposed to various periods of hypoxia $\left(<0.02 \% \mathrm{O}_{2}\right)$, respectively, $0,1,2,4,8,16$ or $24 \mathrm{~h}$. Equal amounts of total RNA from three different experiments were pooled before hybridization to the arrays. The pooled RNA samples were hybridized to Human Genome U133 Plus 2.0 Arrays from Affymetrix, which comprises a total of 54.675 probe sets. Genes whose signal intensity was below 100 for one or more total RNA samples were removed from the analysis.

\section{RNA isolation and quantitative PCR analysis}

Total RNA was extracted using the Promega SV Total RNA Isolation kit (Promega). RNA was reverse transcribed using iScript cDNA Synthesis Kit (BioRad), both according to the manufacturers' instructions. Quantitative RTPCR was performed in ABI 7700 (Applied Biosystems). The abundance of the following genes was detected with SYBR ${ }^{\circledR}$ Green I (Eurogentec/Applied Biosystems) using the indicated forward and reverse primers: 18S: Fagtccetgccetttgtacaca and R-gatccgagggcctcactaaac; LAMP3: F-tgaaaacaaccgatgtccaa and R-tcagacgagcactcatccac; ATF4: F-tggccaagcacttcaaacct and Rgttgttggagggactgaccaa; ATF6: F-agactgaagagcaggtgagcaaa and R-gatgatgaaaaatggagcagctt; CHOP: F-cagagctggaacctgaggag and R-tggatcagtctg- 
gaaaagca. The abundance of HIF1 $\alpha$ was detected with Taqman Gene Expression Assay (Applied Biosystems) hs00153153_m1. All samples were normalized by 18S rRNA signal.

\section{Western blotting}

Cells were lysed in RIPA buffer $(150 \mathrm{mM} \mathrm{NaCl}, 1.0 \%$ IGEPAL CA-630, 0.5\% sodium deoxycholate, $0.1 \%$ SDS, $50 \mathrm{mM}$ Tris and CompleteTM (Roche) protease inhibitor cocktail). Protein concentrations were determined using Bradford measurement (BioRad). For denaturation, equal amounts of protein were boiled in 6x SDS sample buffer (Laemmli) and polypeptides were resolved by SDS-PAGE and transferred onto a $0.2 \mu \mathrm{m}$ nitrocellulose membrane (Amersham Corp.). Blots were probed with anti-LAMP3 goat polyclonal antibody (AF4087, R\&D Systems), anti-ATF4 (SC-200, Santa Cruz), antiphospho-eIF2 $\alpha$ rabbit monoclonal antibody (Cell Signaling), anti-phosphoPERK (T980) rabbit polyclonal antibody (Biolegend), or anti-actin mouse monoclonal antibody (Sigma). Bound antibodies were visualized using HRPlinked secondary antibodies (anti-goat (Santa Cruz Biotechnology) and antimouse (Sigma)) and ECL luminescence (Pierce).

\section{siRNA transfections}

U-373 MG and A549 cells were seeded at $15 \%$ confluence the day before transfection. Transfection was performed by incubating the cells for $16 \mathrm{~h}$ in a transfection mixture containing $250 \mathrm{pmol}$ siRNA and $5 \mu \mathrm{l}$ of Lipofectamine 2000 Transfection Reagent (Invitrogen) in $2.5 \mathrm{ml}$ of serum-free DMEM. All siRNAs were purchased either from Ambion: (HIF1 $\alpha$ ID: 42840; ATF4_ID: 122372; ATF6_ID: 115889 and Silencer Negative Control \#1) or from Eurogentec: ATTF4 sense, 5'-CCACGUUGGAUGACACUUGdTdT; ATF4 antisense, 5'-CAAGUGUCAUCCAACGUGGdTdT. Transfected cells were subcultured $24 \mathrm{~h}$ after transfection and harvested $72 \mathrm{~h}$ after transfection.

\section{Immunohistochemistry}

Cells were grown as monolayers on cover slips. Cells were fixed in $-20^{\circ} \mathrm{C}$ cold methanol for $15 \mathrm{~min}$, washed three times with PBS and blocked with $1 \%$ bovine serum in PBS, $\mathrm{pH} 7.5$, for 30 min followed by overnight incubation with antiLAMP3 goat polyclonal antibody (AF4087, R\&D Systems) at a 50-fold dilution at $4{ }^{\circ} \mathrm{C}$. Secondary fluorescent Alexa 594 (Invitrogen) was used at dilution 1:500 in blocking buffer for $1 \mathrm{~h}$. Cells were visualized by using a Nikon microscope fitted with the appropriate filters.

The expression of LAMP3 was investigated in vivo within ME180 xenografts grown orthotopically in the cervix (32). Frozen sections $(5 \mu \mathrm{m})$ were fixed for 20 min with $2 \%$ paraformaldehyde, rinsed $3 \times 5$ min each with PBS and then 
incubated with anti-LAMP3 goat polyclonal antibody (AF4087, R\&D Systems) at a 50-fold dilution overnight at room temperature in a humidity chamber. Slides were rinsed $3 \times 5$ min each with PBS and incubated with Jackson ImmunoResearch Donkey anti-Goat at a 200 -fold dilution for $1 \mathrm{~h}$ at room temperature. Slides were then rinsed $3 \times 5 \mathrm{~min}$ each with $\mathrm{PBS}$ and counterstained with DAPI at a concentration of $1 \mu \mathrm{g} / \mathrm{ml}$ for $5 \mathrm{~min}$. Samples were then rinsed $3 \times 5$ min each with PBS. Images were acquired with a Photometrics Quantix cooled CCD camera mounted on Olympus BX50 using a 20x objective.

\section{LAMP3 expression in U-87MG xenografts and breast cancer patients}

Six- to eight-week-old female BALB/c severe combined immunodeficiency (SCID) mice (Harlan Sprague-Dawley, Inc.) were implanted s.c. with $100 \mu$ of cell suspension with an equal volume of Matrigel (BD Bioscience). U-87 MG cells $\left(10^{7}\right)$ were injected into each mouse. Each group consisted of five mice. Tumor growth was monitored twice to three times every week by measuring the length, width, and height of each tumor using callipers. Tumor volumes were calculated from the formula $\mathrm{L} \times \mathrm{W} \times \mathrm{H} / 0.52$. When a tumor reached the maximum size $\left(1.44 \mathrm{~cm}^{2}\right.$ surface area) permitted by the Home Office license, the mouse was sacrificed, and the tumor was excised. Where appropriate, Avastin (Bevacizumab) was given i.p. (10 mg/kg every 3 days) for a total of five injections (U-87 MG) starting from day 0 when the tumor cells were implanted.

Thirty RNA samples extracted from surgically resected tumors from unselected patients with different stages and grades of epithelial breast carcinoma and 11 samples from surrounding normal tissue were retrieved from the archives of the John Radcliffe Hospital, Oxford, United Kingdom.

\section{Results}

Hypoxic induction of LAMP3 was identified in an ongoing screen for hypoxiaregulated genes utilizing microarray datasets carried out in HT-29, DU145 and MCF7 cell lines exposed to different durations of rapid or gradual severe hypoxia $(<0.02 \%)$. Establishment of rapid hypoxia resulted in robust induction of LAMP 3 mRNA levels in two of the three lines investigated, rising steadily to $\sim 90$-fold in HT-29 cells by $12 \mathrm{~h}$ and $\sim 10$-fold in MCF7 cells by $24 \mathrm{~h}$ (Fig. 1A). Induction of LAMP3 mRNA was validated in these and two additional cell lines (A549 and ME180) exposed to rapid hypoxia for 4,8 and $24 \mathrm{~h}$ using quantitative RT-PCR (Fig. 1B). Each of the cell lines shows a substantial induction of LAMP3 ranging from 5- to 80-fold, similar to that observed in the microarray data. MCF7 cells were also exposed to severe hypoxia in a more 
gradual way by culturing cells on plastic. These conditions also result in strong induction of LAMP3 but with slower kinetics, with a $\sim 10$-fold induction at $24 \mathrm{~h}$ and 400 -fold induction at $48 \mathrm{~h}$ (Fig. 1C). These data demonstrate that LAMP3 is substantially induced by severe hypoxia, regardless of whether the onset of hypoxia is rapid or gradual.

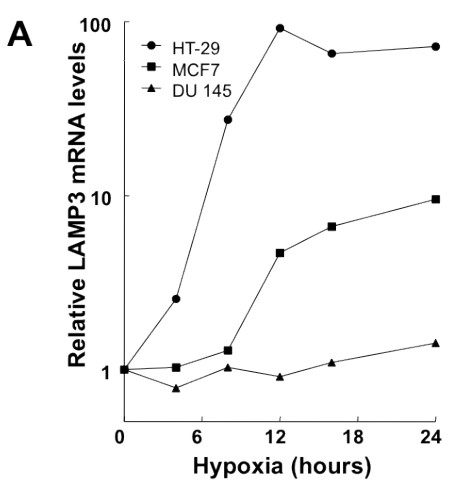

B

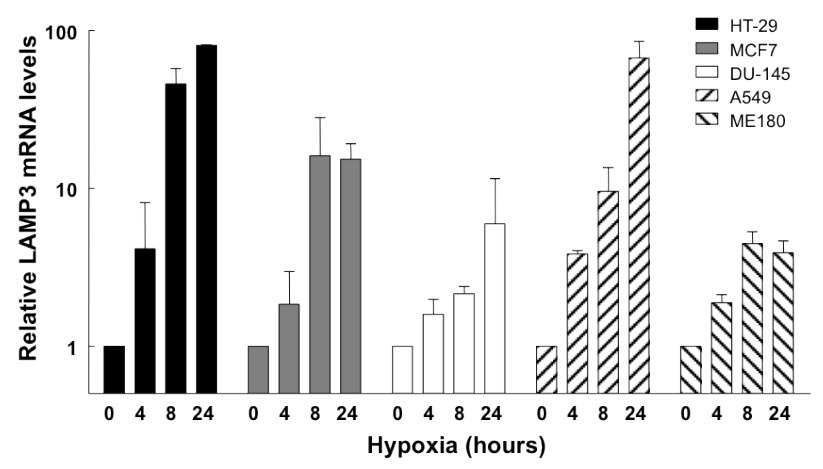

Figure 1. Hypoxia induces expression of LAMP3 mRNA. (A) LAMP3 gene expression in response to rapid hypoxia as measured by microarray analysis in the HT-29, MCF7 and DU-145 cancer cell lines. Gene expression levels are shown relative to the aerobic control. (B) Validation of microarray gene expression data by qRT-PCR. LAMP3 expression was quantified in five different cancer cell lines exposed to rapid hypoxia for the indicated period of time. (C) LAMP3 mRNA expression in response to gradual hypoxia. LAMP3 expression was quantified by qRTPCR in MCF7 cultured on plastic dishes as a function of time following exposure to severe hypoxia $(<0.02 \%)$.

Hypoxic induction of LAMP3 was also investigated at the protein level (Fig. 2). Exposure to both rapid (Fig. 2A and B) or gradual (Fig. 2C and B) hypoxia resulted in a pronounced increase in LAMP3 protein levels in each of the five cell lines investigated. The LAMP proteins, including LAMP3, are known to be highly glycosylated, containing multiple $\mathrm{N}$ - and O-linked glycans (33). As a result, immunoblotting with anti-LAMP3 produces multiple reactive bands of 
different molecular weight most likely reflecting the various glycosylated forms of the LAMP3 protein under hypoxic conditions. Hypoxia resulted in substantial increases in all forms of the protein. Treatment of extracts with an endoglycosidase that specifically cleaves $\mathrm{N}$-linked glycans from glycoproteins resulted in the loss of higher MW immunoreactive bands, confirming the glycosylation of LAMP3 (data not shown). Furthermore, exposure of cells to tunicamycin, an inhibitor of $\mathrm{N}$-linked protein glycosylation, prevented the appearance of higher MW bands (see Fig. 4B). LAMP3 protein expression and subcellular localization were also examined using immunohistochemistry (Fig. 2E). These experiments demonstrated increased expression of LAMP3 on the cell membrane and within cytoplasmic punctuate vesicles (presumably lysosomes).

The mechanistic regulation of LAMP3 was investigated using knockdown experiments against the hypoxia-regulated transcription factors, including HIF1, ATF4 and ATF6. Preliminary analysis of the putative promoter region of LAMP3 suggested potential binding sites for each of these transcription factors. A549 cells, which demonstrate strong induction of LAMP3, were transfected with siRNA targeting HIF1 $\alpha$, ATF4, or ATF6 and subsequently exposed to normoxia or rapid hypoxia for $24 \mathrm{~h}$. A knockdown efficiency between $60 \%$ and $85 \%$ was achieved for each (Fig. 3A). No significant differences in LAMP3 mRNA expression were observed between the HIF1 $\alpha$ or ATF6 knockdown cells and the SCR controls under normoxic or hypoxic conditions (Fig. 3B). In contrast, knockdown of ATF4 strongly suppressed LAMP3 induction during exposure to rapid hypoxia. Similar results were observed in U-373 MG cells exposed to rapid hypoxia (Fig. 3A and B) and in MCF7 cells cultured under conditions of more gradual exposure to hypoxia at both the mRNA (Fig. 3D) and protein levels (Fig. 3E).

To confirm the requirement of the UPR signaling pathway for the transcriptional regulation of LAMP3 during hypoxia, a set of inducible isogenic U-373 MG cell lines engineered to have distinct defects in the PERK/eIF2 $\alpha /$ ATF 4 arm of the UPR was used. These cells express either a dominant negative eIF $2 \alpha$ mutant (S51A) that cannot be phosphorylated, a Cterminal truncated active GADD34 protein which directs phosphatase activity against eIF2 $\alpha$, or a short-hairpin interfering RNA (shRNA) against PERK (20, $34,35)$. Each of these stable cell lines is unable to maintain phosphorylation of eIF2 $\alpha$, and thus unable to induce ATF4 $(20,34,35)$. Consistent with the transient siRNA knockdown experiments (Fig. 3B), each of the three cell lines with defective PERK signaling demonstrated a substantial reduction in LAMP3 mRNA induction during hypoxia (Fig. 3C). Together these data indicate that LAMP3 induction during hypoxia occurs as a result of PERK-dependent activation of the transcription factor ATF4. 

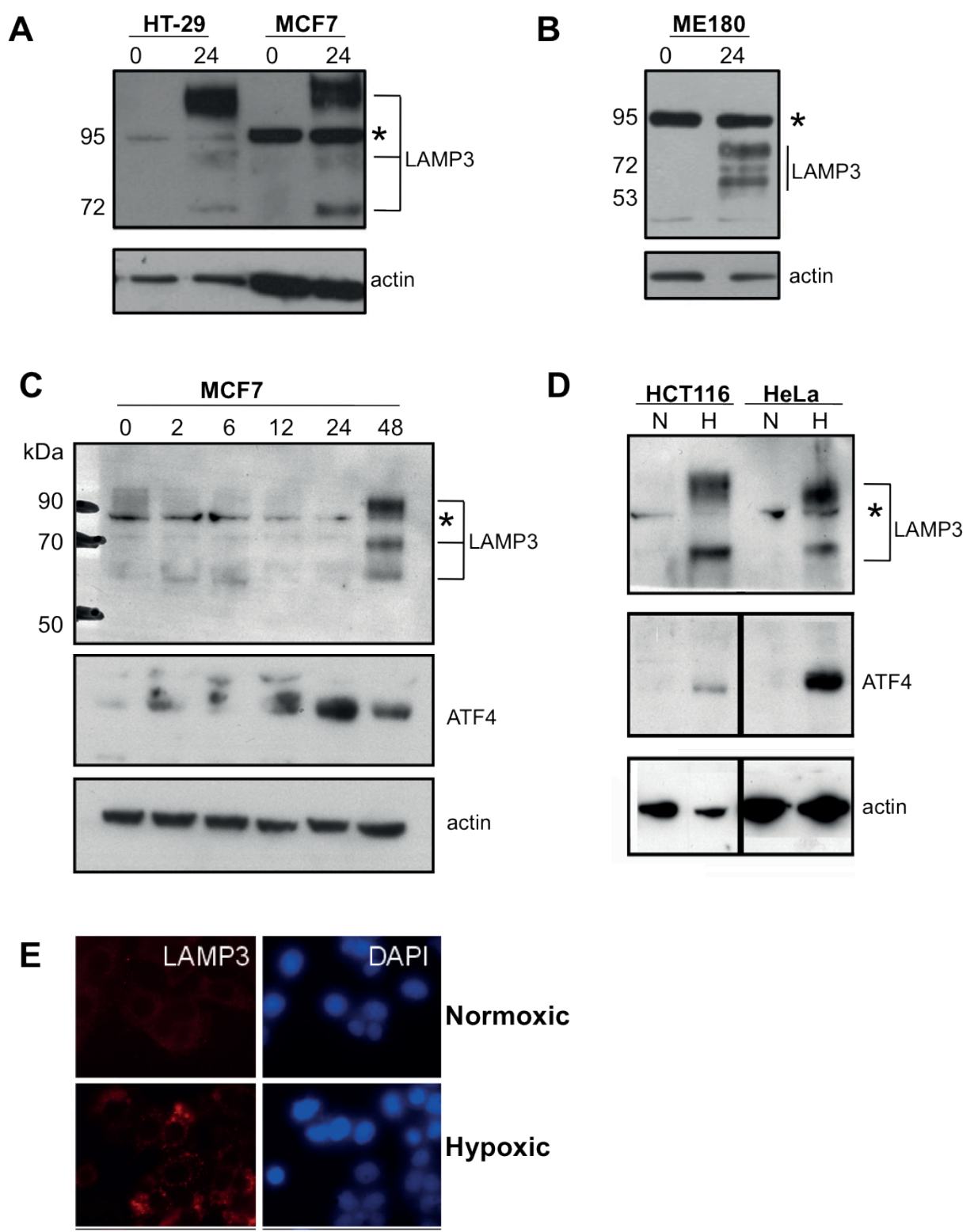

Figure 2. Hypoxia induces expression of LAMP3 protein. LAMP3 protein levels in (A) HT-29, MCF7 and (B) ME180 cells exposed to rapid hypoxia for the indicated period of time were measured by immunoblotting. (C) Protein levels of LAMP3, ATF4 and actin in MCF7 cultured on plastic dishes exposed to hypoxia for the indicated period of time were measured by immunoblotting. (D) Protein levels of LAMP3, ATF4 and actin in HCT116 and HeLa cells cultured on plastic dishes exposed to normoxia or hypoxia for $24 \mathrm{~h}$ were assessed by immunoblotting. Asterisk indicates non-specific protein band. (E) MCF7 cells cultured on plastic were exposed to normoxia hypoxia for $48 \mathrm{~h}$. Cells were observed by the fluorescent microscopy; images with LAMP3-Alexa Fluor 594 and DAPI staining are shown. 
A A549
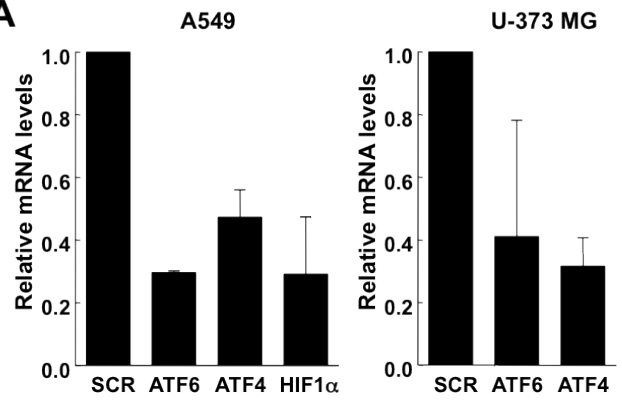

B
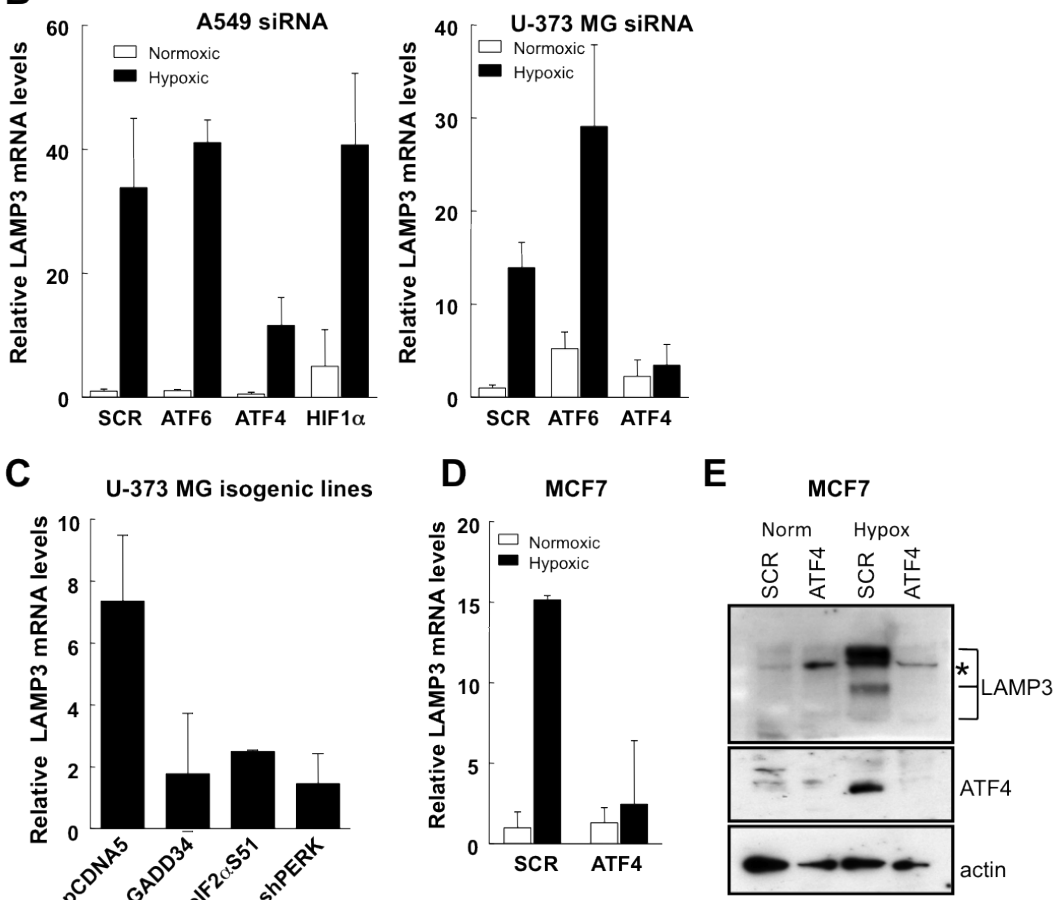

Figure 3. Hypoxia induces LAMP3 via the PERK/eIF2 $\alpha /$ ATF4 arm of the UPR. ATF6, ATF4 and HIF $1 \alpha$ were transiently knocked down in either A549 or U-373 MG cells using siRNA. Following knockdown, cells were exposed to $24 \mathrm{~h}$ of rapid hypoxia. (A) Gene-specific knockdown efficiency was determined using qRT-PCR. Expression levels are shown relative to the mRNA levels in cells transfected with control siRNA (SCR). (B) Relative LAMP3 mRNA expression levels in the siRNA knockdown cells following $24 \mathrm{~h}$ of exposure to rapid hypoxia. (C) Isogenic U-373 MG cells expressing either a dominant negative mutant of eIF2 $\alpha$ (S51A), truncated GADD34 or a short-hairpin targeting PERK were exposed to $24 \mathrm{~h}$ of rapid hypoxia. LAMP3 mRNA levels were quantified using qRT-PCR. (D) Relative LAMP3 mRNA levels were measured using qRT-PCR assessed in ATF4 siRNA knockdown and control (SCR) MCF7 cells cultured on plastic dishes and exposed to normoxia or hypoxia for $48 \mathrm{~h}$. Error bars represent standard deviations. (E) Protein levels of LAMP3, ATF4 and actin in ATF4 siRNA knockdown MCF7 cells cultured on plastic and exposed to normoxia or $48 \mathrm{~h}$ of hypoxia were measured by immunoblotting. Asterisk indicates non-specific protein band. 
The ability of the UPR to transcriptionally regulate LAMP3 was further investigated in MCF7 and MDA-MB-231 cell lines using a series of agents known to cause ER and other forms of cell stress. The two most well-studied ER stress-inducing compounds are thapsigargin, which disrupts calcium stores in the ER and tunicamycin, which prevents N-linked protein glycosylation in the ER (36). Exposure to either of these agents resulted in robust induction of LAMP3 mRNA (Fig. 4A) and protein (Fig. 4B) to levels similar to that observed with hypoxia. Each of these agents also resulted in activation of PERK, phosphorylation of eIF $2 \alpha$ and induction of ATF4, but had little to no effect on HIF1 $\alpha$ (Fig. 4B). Furthermore, knockdown of ATF4 using siRNA prevented LAMP3 induction in response to thapsigargin treatment, confirming the role of the UPR in its regulation (Fig. 4C).

Proteasome inhibitors have also been shown to induce ER stress and to potentiate hypoxia-induced cell death through this pathway (37-40). In MCF7 cells, exposure to the proteasome inhibitors velcade, MG115 and MG132 each led to a substantial increase in LAMP3 mRNA and protein levels (Fig. 4A and B). These agents also led to PERK activation, eIF2 $\alpha$ phosphorylation and ATF4 induction. As a consequence of proteasome inhibition, these agents also cause HIF $1 \alpha$ protein stabilization (Fig. 4B). However, knockdown of ATF4 using siRNA largely prevented LAMP3 induction in response to velcade suggesting that the UPR is also primarily responsible for its induction during proteasome inhibition.

Exposure to cobalt chloride, which increases HIF1 $\alpha$ (Fig. 4B) or arsenite (an inducer of oxidative stress), had no effect on LAMP3 or ATF4. Interestingly, desferrioxamine (DFO), an iron chelator that also induces HIF $1 \alpha$ levels, did cause a small induction of LAMP3 mRNA in both MCF7 and MDA-MB-231 cell lines (Fig. 4A). However, DFO is also reported to cause ER stress (41), and in MCF7 cells resulted in noticeable eIF2 $\alpha$ phosphorylation and ATF4 induction (Fig. 4B). Thus, the results with DFO are consistent with each of the tested agents and suggest that induction of ER stress and activation of ATF4 directly lead to LAMP3 induction. 

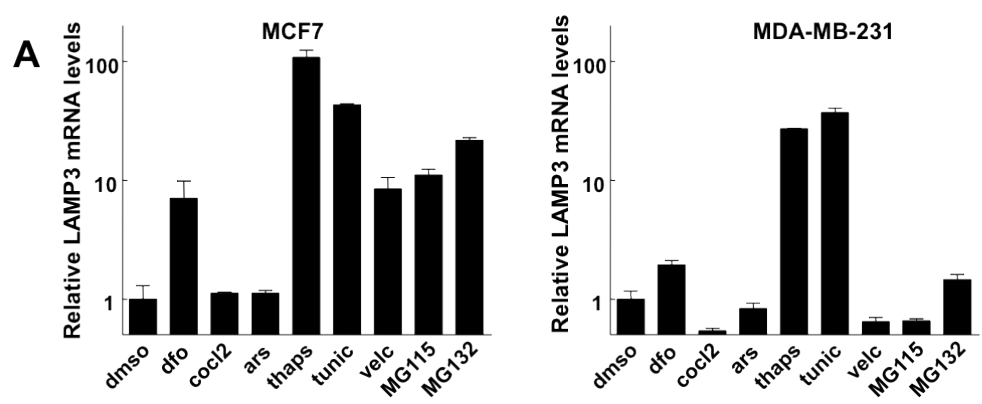

B
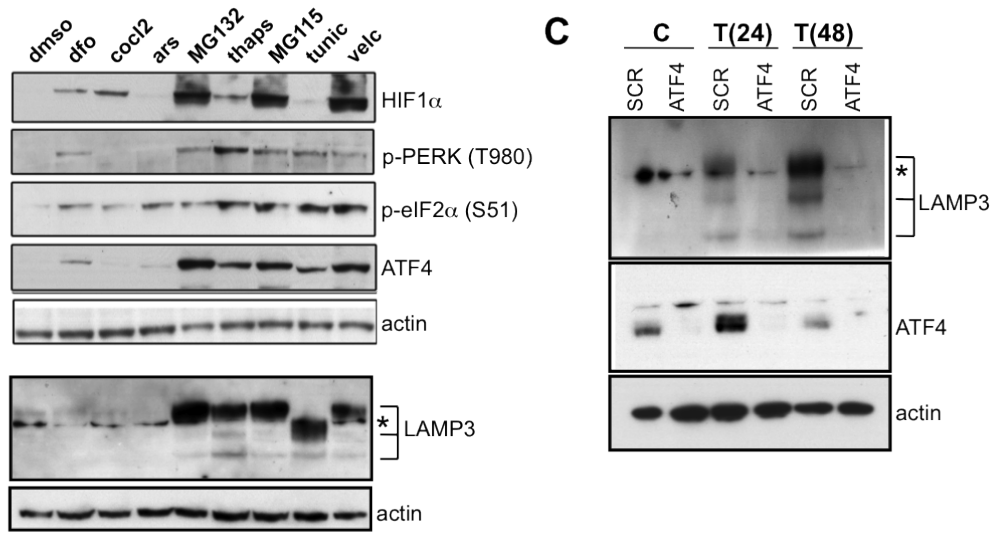

D

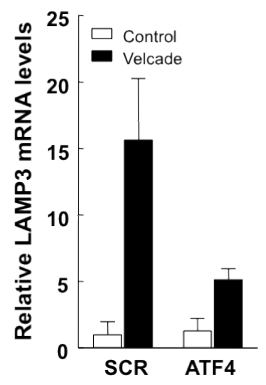

Figure 4. ER stress inducing agents induce LAMP3 via the PERK/eIF2 $\alpha /$ ATF4 arm of the UPR. (A) MCF7 (left panel) and MDA-MB-231 cells (right panel) were treated for $24 \mathrm{~h}$ with desferoxamine (dfo) $40 \mu \mathrm{M}$, CoCl2 $100 \mu \mathrm{M}$, arsenite (ars) $5 \mu \mathrm{M}$, MG132 $10 \mu \mathrm{M}$, thapsigargin (thaps) $300 \mathrm{nM}$, MG115 $5 \mu \mathrm{M}, 5 \mu \mathrm{g} / \mathrm{ml}$ tunicamycin (tunic) and bortezomib (velc) $100 \mathrm{nM}$. LAMP3 mRNA levels were measured by qRT-PCR. Error bars represent standard deviations. (B) Protein levels of HIF1 $\alpha$, phospho-PERK (Thr980), phospho-eIF2 $\alpha$ (Ser51), ATF4, LAMP3 and actin were measured by immunoblot analysis on samples from (A). (C) LAMP3 and ATF4 protein levels were measured in ATF4 knockdown (ATF4 lanes) and control (SCR lanes) MCF7 cells. Cells were either untreated (C) or exposed to thapsigargin (300 nM) for $24 \mathrm{~h}(\mathrm{~T}(24))$ or $48 \mathrm{~h}$ (T(48)). Levels of protein expression were measured by immunoblotting. Asterisk indicates nonspecific protein band. (D) ATF4 siRNA knockdown and control (SCR) MCF7 cells were treated with $100 \mathrm{nM}$ velcade (bortezomib) for $24 \mathrm{~h}$. Relative mRNA levels for LAMP3 were measured by qRT-PCR. Error bars represent standard deviations. 
Finally, the expression of LAMP3 was investigated in vivo in both tumor xenografts and breast cancer patient samples. Immunohistochemical analysis demonstrated that LAMP3 protein is present primarily on the membrane in ME180 tumor xenografts grown orthotopically in the cervix of immune deficient mice (Fig. 5A). Furthermore, the intensity of LAMP3 staining was highly heterogeneous within the two xenografts investigated, suggesting that its expression was subject to microenvironmental regulation. LAMP3 mRNA levels were also evaluated in a series of 11 samples from normal breast tissue and 30 samples from breast cancer patients (Fig. 5A). The expression in tumor tissue was significantly higher $(\mathrm{p}<.002)$ than that in normal tissue and its range in expression was also greatly enhanced.

Finally, the expression of LAMP3 mRNA was measured within a series of U-87 MG tumor xenografts that had previously been treated with or without Avastin, an angiogenic inhibitor that affects tumor vasculature and can induce tumor hypoxia. The Avastin-treated tumors showed significantly increased expression of the UPR-target gene CHOP $(\mathrm{p}=0.0004)$ and LAMP3 $(\mathrm{p}=0.0415)$ (Fig. 5C). 


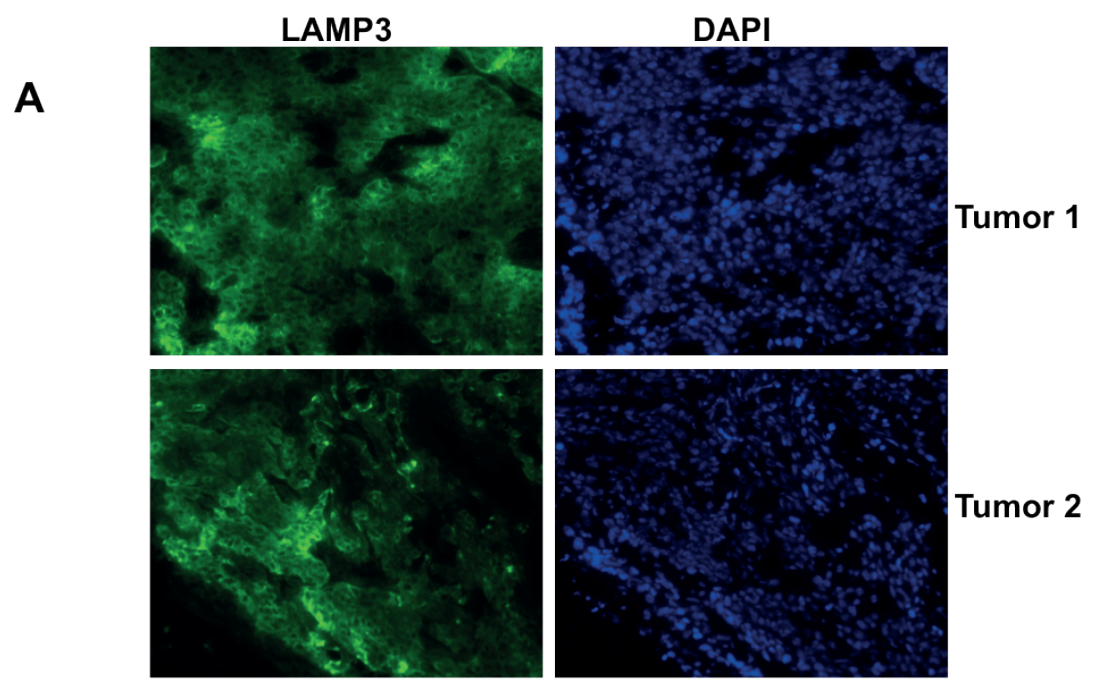

B

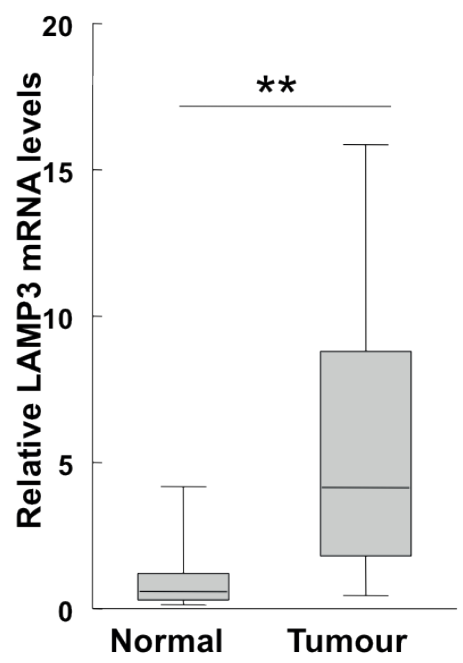

C

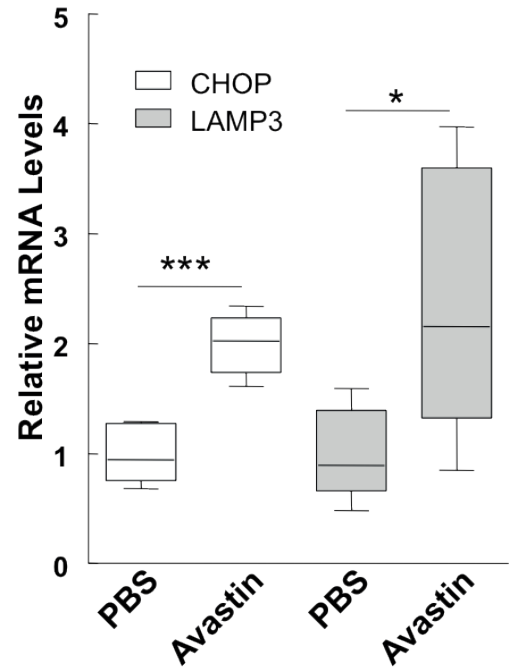

Figure 5. LAMP3 expression in tumors. (A) The intensity and distribution of LAMP3 was assessed by immunohistochemistry in two different ME180 orthotopic xenografts. Left panel shows heterogeneous membrane staining of LAMP3. Right panels show DAPI stained nuclei. (B) Box-and-whisker plot of LAMP3 expression in 30 RNA tumor samples from unselected patients with different stages and grades of epithelial breast carcinoma and 11 samples from surrounding normal tissue as determined by qRT-PCR. Data are normalized to the mean level in normal tissue. Stars indicate significance in two tailed Student's t-test $* * p<0.005$. (C) Box-and-whisker plot of LAMP3 and CHOP expression in RNA samples extracted from xenograft tumors as measured by qRT-PCR. $\mathrm{N}=5$, stars indicate significance in two tailed Student's t-test $* \mathrm{p}<0.05$. 


\section{Discussion}

The data presented here identify LAMP3 as a novel hypoxia-inducible gene. Induction of LAMP3 occurred in response to severe hypoxia $(<0.02 \%)$ and was observed in each of the eight human tumor cell lines investigated. Several lines of evidence indicate that unlike many hypoxia-induced genes, LAMP3 is not regulated by HIF-1, but instead is induced by the UPR in a PERK, eIF $2 \alpha$, and ATF4-dependent manner. First, the kinetics of LAMP3 induction correlate with that of PERK activation and ATF4 induction. LAMP3 mRNA and protein induction occurred rapidly when the cells were cultured on glass, and more slowly when cultured on plastic (Figs. 1 and 2). This correlates well with the activation kinetics of the PERK/eIF2 $\alpha / \mathrm{ATF} 4$ arm of the UPR under these different conditions $(23,42)$, which arise due to the dissolved oxygen present within the plastic. More importantly, knockdown of ATF4 using siRNA or disruption of PERK-mediated eIF2 $\alpha$ phosphorylation through three different approaches prevented LAMP3 induction during hypoxia in all cases (Fig. 3). Furthermore, LAMP3 was induced by several other agents known to cause ER stress and activate the UPR, including proteasome inhibitors, which are currently being used in the clinic to treat certain types of cancer.

Several recent studies have indicated that the UPR is an important adaptive mechanism that promotes hypoxia tolerance and tumor growth (reviewed in (4)). The UPR may facilitate cell survival through multiple mechanisms including regulation of autophagy, $\mathrm{pH}$ control, angiogenesis, and others $(19,34$, $37,43,44)$. However, the clinical relevance and frequency of UPR activation in tumors is still largely unknown. In spite of the fact that the UPR is most strongly induced under conditions of severe hypoxia (which we define as less than $0.02 \%$ ), activation of UPR signaling pathway can also be observed at higher oxygen concentrations $(0.2 \%, 2 \%)$ although this requires longer duration $(20,45)$. More importantly, we and others have previously shown that conditions of hypoxia are severe enough in tumors to activate the UPR and that disruption of the PERK/eIF2 $\alpha$-dependent arm of the UPR (19) as well as the IRE1-dependent arm (21) results in reduced cell survival and tumor growth. Identification of LAMP3 as a novel UPR and hypoxia-regulated gene presents a new clinical opportunity to test the importance of this pathway in human cancers. The data presented here indicate that LAMP3 staining intensity varies significantly within tumor sections consistent with its regulation by microenvironmental stress. LAMP3 has previously been reported to be overexpressed in several tumor types (28) and this was also observed in this study in a series of unselected breast cancer patients (Fig. 5). Furthermore, treatment of tumor xenografts with the anti-angiogenic agent Avastin, which is thought to induce hypoxia through disruption of tumor vasculature, increased the expression of 
both LAMP3 and the UPR-target gene CHOP. It will be interesting to evaluate the potential prognostic value of LAMP3 in patients treated with radiotherapy and chemotherapies where hypoxia is known to be important.

The biologic importance of LAMP3 regulation by hypoxia remains to be investigated. However, a previous study using xenografts engineered to overexpress LAMP3 indicated that it can stimulate metastasis (30). Thus, it is tempting to speculate that induction of LAMP3 may contribute to hypoxiainduced metastasis, a phenomenon that underlies at least part of the adverse clinical outcome of patients with hypoxic tumors. The fact that hypoxia can stimulate metastasis represents a paradox, as chronically hypoxic cells are typically located at large distances away from vessels and thus do not have an easy route to the circulation. However, tumor hypoxia can arise directly around or near to vessels due to transient changes in blood perfusion (46). The temporary collapse or occlusion of a vessel results in rapid and severe oxygen deprivation to a large number of tumor cells surrounding the affected vessel, similar to the conditions of severe hypoxia used in this study. These acutely hypoxic cells would be expected to show robust activation of the UPR and their proximity to vessels makes them good candidates for hypoxia-induced metastasis. Indeed, exposure of tumor bearing mice to transient hypoxia exposures over many days results in a significant stimulation of metastasis (12). Several recent reports suggest that hypoxia-mediated metastasis may also be important in tumors treated with agents that directly or indirectly damage tumor vessels. Short-term treatment with anti-angiogenic agents that target VEGF signaling is effective at reducing tumor size but promotes metastasis in several tumor models $(47,48)$. Disruption of tumor vasculature in this setting may contribute to the induction of severe hypoxia and UPR activation as observed here in xenografts treated with Avastin (Fig. 5).

Previous studies have identified a number of candidate genes that contribute to hypoxia-induced metastasis, the majority of which are regulated by HIF. These include LOX, CXCR4, uPAR, VEGF-C, Mdm2, and OPN (15, 49-54). LAMP3 represents the first metastasis-associated gene regulated by the UPR in response to severe hypoxia and is thus an interesting candidate to explore further in tumor models of metastasis. The fact that LAMP3 is predominantly expressed on the cell surface also makes it an attractive potential therapeutic target and/or biomarker for molecular imaging approaches to treat or characterize aggressive hypoxic tumors. 


\section{Acknowledgements}

The authors would like to thank David Hedley, Dick Hill and Trudey Nicklee for providing frozen sections of ME-180 tumor xenografts and for advice and technical assistance on the immunohistochemical staining of LAMP3 in these samples. This work was financially supported by Dutch Science Organization (ZonMW VENI Grants 916.76.158 to K.R. and 016.056.015 to M.K.), the Dutch Cancer Society (KWF Grant UM 2003-2821 to B.W.), the EU 7th framework program grant 222741 (Metoxia) to B.W. and T.R. and Cancer Research UK to A.H.

\section{References}

1. Brown JM, Wilson WR. Exploiting tumour hypoxia in cancer treatment. Nature reviews Cancer. 2004;4:437-47.

2. Grau C, Overgaard J. Effect of etoposide, carmustine, vincristine, 5-fluorouracil, or methotrexate on radiobiologically oxic and hypoxic cells in a $\mathrm{C} 3 \mathrm{H}$ mouse mammary carcinoma in situ. Cancer Chemother Pharmacol. 1992;30:277-80.

3. Nordsmark M, Bentzen SM, Rudat V, Brizel D, Lartigau E, Stadler P, et al. Prognostic value of tumor oxygenation in 397 head and neck tumors after primary radiation therapy. An international multi-center study. Radiotherapy and oncology : journal of the European Society for Therapeutic Radiology and Oncology. 2005;77:18-24.

4. Wouters BG, Koritzinsky M. Hypoxia signaling through mTOR and the unfolded protein response in cancer. Nature reviews Cancer. 2008;8:851-64.

5. Graeber TG, Osmanian C, Jacks T, Housman DE, Koch CJ, Lowe SW, et al. Hypoxiamediated selection of cells with diminished apoptotic potential in solid tumours. Nature. 1996;379:88-91.

6. Huang LE, Bindra RS, Glazer PM, Harris AL. Hypoxia-induced genetic instability--a calculated mechanism underlying tumor progression. Journal of molecular medicine. 2007;85:139-48.

7. Hockel M, Schlenger K, Aral B, Mitze M, Schaffer U, Vaupel P. Association between tumor hypoxia and malignant progression in advanced cancer of the uterine cervix. Cancer research. 1996;56:4509-15.

8. Fyles AW, Milosevic M, Wong R, Kavanagh MC, Pintilie M, Sun A, et al. Oxygenation predicts radiation response and survival in patients with cervix cancer. Radiotherapy and oncology : journal of the European Society for Therapeutic Radiology and Oncology. 1998;48:149-56.

9. Brizel DM, Scully SP, Harrelson JM, Layfield LJ, Bean JM, Prosnitz LR, et al. Tumor oxygenation predicts for the likelihood of distant metastases in human soft tissue sarcoma. Cancer research. 1996;56:941-3. 
10. Fyles A, Milosevic M, Hedley D, Pintilie M, Levin W, Manchul L, et al. Tumor hypoxia has independent predictor impact only in patients with node-negative cervix cancer. J Clin Oncol. 2002;20:680-7.

11. Nordsmark M, Hoyer M, Keller J, Nielsen OS, Jensen OM, Overgaard J. The relationship between tumor oxygenation and cell proliferation in human soft tissue sarcomas. International journal of radiation oncology, biology, physics. 1996;35:701-8.

12. Cairns RA, Hill RP. Acute hypoxia enhances spontaneous lymph node metastasis in an orthotopic murine model of human cervical carcinoma. Cancer research. 2004;64:205461.

13. Cairns RA, Kalliomaki T, Hill RP. Acute (cyclic) hypoxia enhances spontaneous metastasis of KHT murine tumors. Cancer research. 2001;61:8903-8.

14. Rofstad EK, Rasmussen H, Galappathi K, Mathiesen B, Nilsen K, Graff BA. Hypoxia promotes lymph node metastasis in human melanoma xenografts by up-regulating the urokinase-type plasminogen activator receptor. Cancer research. 2002;62:1847-53.

15. Zhang L, Hill RP. Hypoxia enhances metastatic efficiency by up-regulating Mdm2 in KHT cells and increasing resistance to apoptosis. Cancer research. 2004;64:4180-9.

16. Harris AL. Hypoxia--a key regulatory factor in tumour growth. Nature reviews Cancer. 2002;2:38-47.

17. Semenza GL. Hypoxia-inducible factor 1: oxygen homeostasis and disease pathophysiology. Trends Mol Med. 2001;7:345-50.

18. Koumenis C, Wouters BG. "Translating" tumor hypoxia: unfolded protein response (UPR)-dependent and UPR-independent pathways. Molecular cancer research : MCR. 2006;4:423-36.

19. Bi M, Naczki C, Koritzinsky M, Fels D, Blais J, Hu N, et al. ER stress-regulated translation increases tolerance to extreme hypoxia and promotes tumor growth. The EMBO journal. 2005;24:3470-81.

20. Koritzinsky M, Rouschop KM, van den Beucken T, Magagnin MG, Savelkouls K, Lambin P, et al. Phosphorylation of eIF2alpha is required for mRNA translation inhibition and survival during moderate hypoxia. Radiother Oncol. 2007;83:353-61.

21. Romero-Ramirez L, Cao H, Nelson D, Hammond E, Lee AH, Yoshida H, et al. XBP1 is essential for survival under hypoxic conditions and is required for tumor growth. Cancer research. 2004;64:5943-7.

22. Ron D, Walter P. Signal integration in the endoplasmic reticulum unfolded protein response. Nat Rev Mol Cell Biol. 2007;8:519-29.

23. Koritzinsky M, Magagnin MG, van den Beucken T, Seigneuric R, Savelkouls K, Dostie J, et al. Gene expression during acute and prolonged hypoxia is regulated by distinct mechanisms of translational control. The EMBO journal. 2006;25:1114-25.

24. Koritzinsky M, Seigneuric R, Magagnin MG, van den Beucken T, Lambin P, Wouters BG. The hypoxic proteome is influenced by gene-specific changes in mRNA translation. Radiotherapy and oncology : journal of the European Society for Therapeutic Radiology and Oncology. 2005;76:177-86.

25. Blais JD, Filipenko V, Bi M, Harding HP, Ron D, Koumenis C, et al. Activating transcription factor 4 is translationally regulated by hypoxic stress. Molecular and cellular biology. 2004;24:7469-82. 
26. Lu PD, Harding HP, Ron D. Translation reinitiation at alternative open reading frames regulates gene expression in an integrated stress response. The Journal of cell biology. 2004; 167:27-33.

27. Harding HP, Zhang Y, Zeng H, Novoa I, Lu PD, Calfon M, et al. An integrated stress response regulates amino acid metabolism and resistance to oxidative stress. Molecular cell. 2003;11:619-33.

28. Ozaki K, Nagata M, Suzuki M, Fujiwara T, Ueda K, Miyoshi Y, et al. Isolation and characterization of a novel human lung-specific gene homologous to lysosomal membrane glycoproteins 1 and 2: significantly increased expression in cancers of various tissues. Cancer research. 1998;58:3499-503.

29. de Saint-Vis B, Vincent J, Vandenabeele S, Vanbervliet B, Pin JJ, Ait-Yahia S, et al. A novel lysosome-associated membrane glycoprotein, DC-LAMP, induced upon DC maturation, is transiently expressed in MHC class II compartment. Immunity. 1998;9:32536.

30. Kanao H, Enomoto T, Kimura T, Fujita M, Nakashima R, Ueda Y, et al. Overexpression of LAMP3/TSC403/DC-LAMP promotes metastasis in uterine cervical cancer. Cancer research. 2005;65:8640-5.

31. Novoa I, Zeng H, Harding HP, Ron D. Feedback inhibition of the unfolded protein response by GADD34-mediated dephosphorylation of eIF2alpha. The Journal of cell biology. 2001;153:1011-22.

32. Pham NA, Magalhaes JM, Do T, Schwock J, Dhani N, Cao PJ, et al. Activation of Src and Src-associated signaling pathways in relation to hypoxia in human cancer xenograft models. International journal of cancer Journal international du cancer. 2009;124:280-6.

33. Fukuda M. [Lysosomal membrane glycoproteins; structure, biosynthesis, and trafficking to lysosome]. Seikagaku. 1990;62:1225-40.

34. van den Beucken T, Koritzinsky M, Niessen H, Dubois L, Savelkouls K, Mujcic H, et al. Hypoxia-induced expression of carbonic anhydrase 9 is dependent on the unfolded protein response. The Journal of biological chemistry. 2009;284:24204-12.

35. Yang J, Ahmed A, Poon E, Perusinghe N, de Haven Brandon A, Box G, et al. Smallmolecule activation of p53 blocks hypoxia-inducible factor 1alpha and vascular endothelial growth factor expression in vivo and leads to tumor cell apoptosis in normoxia and hypoxia. Molecular and cellular biology. 2009;29:2243-53.

36. Lu PD, Jousse C, Marciniak SJ, Zhang Y, Novoa I, Scheuner D, et al. Cytoprotection by pre-emptive conditional phosphorylation of translation initiation factor 2. The EMBO journal. 2004;23:169-79.

37. Milani M, Rzymski T, Mellor HR, Pike L, Bottini A, Generali D, et al. The role of ATF4 stabilization and autophagy in resistance of breast cancer cells treated with Bortezomib. Cancer research. 2009;69:4415-23.

38. Fels DR, Ye J, Segan AT, Kridel SJ, Spiotto M, Olson M, et al. Preferential cytotoxicity of bortezomib toward hypoxic tumor cells via overactivation of endoplasmic reticulum stress pathways. Cancer research. 2008;68:9323-30.

39. Tan YY, Zhou HY, Wang ZQ, Chen SD. Endoplasmic reticulum stress contributes to the cell death induced by UCH-L1 inhibitor. Molecular and cellular biochemistry. 2008;318:109-15. 
40. Obeng EA, Carlson LM, Gutman DM, Harrington WJ, Jr., Lee KP, Boise LH. Proteasome inhibitors induce a terminal unfolded protein response in multiple myeloma cells. Blood. 2006;107:4907-16.

41. Yoo YB, Lee KR, Kim SW, Kwon K, Goo TW, Kwon OY. Deferoxamine induces endoplasmic reticulum stress in PC12 cells. Z Naturforsch C. 2008;63:308-10.

42. Ameri K, Lewis CE, Raida M, Sowter H, Hai T, Harris AL. Anoxic induction of ATF-4 through HIF-1-independent pathways of protein stabilization in human cancer cells. Blood. 2004;103:1876-82.

43. Rouschop KM, Wouters BG. Regulation of autophagy through multiple independent hypoxic signaling pathways. Current molecular medicine. 2009;9:417-24.

44. Blais JD, Addison CL, Edge R, Falls T, Zhao H, Wary K, et al. Perk-dependent translational regulation promotes tumor cell adaptation and angiogenesis in response to hypoxic stress. Molecular and cellular biology. 2006;26:9517-32.

45. Koumenis C, Naczki C, Koritzinsky M, Rastani S, Diehl A, Sonenberg N, et al. Regulation of protein synthesis by hypoxia via activation of the endoplasmic reticulum kinase PERK and phosphorylation of the translation initiation factor eIF2alpha. Molecular and cellular biology. 2002;22:7405-16.

46. Dewhirst MW, Cao Y, Moeller B. Cycling hypoxia and free radicals regulate angiogenesis and radiotherapy response. Nature reviews Cancer. 2008;8:425-37.

47. Ebos JM, Lee CR, Cruz-Munoz W, Bjarnason GA, Christensen JG, Kerbel RS. Accelerated metastasis after short-term treatment with a potent inhibitor of tumor angiogenesis. Cancer Cell. 2009;15:232-9.

48. Paez-Ribes M, Allen E, Hudock J, Takeda T, Okuyama H, Vinals F, et al. Antiangiogenic therapy elicits malignant progression of tumors to increased local invasion and distant metastasis. Cancer Cell. 2009;15:220-31.

49. Chaudary N, Hill RP. Increased expression of metastasis-related genes in hypoxic cells sorted from cervical and lymph nodal xenograft tumors. Laboratory investigation; a journal of technical methods and pathology. 2009;89:587-96.

50. Zhang L, Hill RP. Hypoxia enhances metastatic efficiency in HT1080 fibrosarcoma cells by increasing cell survival in lungs, not cell adhesion and invasion. Cancer research. 2007;67:7789-97.

51. Le QT, Sutphin PD, Raychaudhuri S, Yu SC, Terris DJ, Lin HS, et al. Identification of osteopontin as a prognostic plasma marker for head and neck squamous cell carcinomas. Clinical cancer research : an official journal of the American Association for Cancer Research. 2003;9:59-67.

52. Said HM, Katzer A, Flentje M, Vordermark D. Response of the plasma hypoxia marker osteopontin to in vitro hypoxia in human tumor cells. Radiotherapy and oncology : journal of the European Society for Therapeutic Radiology and Oncology. 2005;76:200-5.

53. Erler JT, Bennewith KL, Nicolau M, Dornhofer N, Kong C, Le QT, et al. Lysyl oxidase is essential for hypoxia-induced metastasis. Nature. 2006;440:1222-6.

54. Staller P, Sulitkova J, Lisztwan J, Moch H, Oakeley EJ, Krek W. Chemokine receptor CXCR4 downregulated by von Hippel-Lindau tumour suppressor pVHL. Nature. 2003;425:307-11 



\title{
CHAPTER 4
}

Hypoxia Stimulates Migration of Breast Cancer Cells via the PERK/ATF4/LAMP3Arm of the Unfolded Protein Response

\author{
A. Nagelkerke \\ J. Bussink \\ H. Mujcic \\ B.G. Wouters \\ S. Lehmann \\ F.C.G.J. Sweep \\ P.N. Span
}

Breast Cancer Research 2013; 15:R2 


\begin{abstract}
Background and Purpose: The hypoxia-inducible factor (HIF)-1 pathway can stimulate tumor cell migration and metastasis. Furthermore, hypoxic tumors are associated with a poor prognosis. Besides the HIF-1 pathway, the unfolded protein response (UPR) is also induced by hypoxic conditions. The PKR-like ER kinase (PERK)/activating transcription factor 4 (ATF4)-arm of the UPR induces expression of lysosomal-associated membrane protein 3 (LAMP3), a factor that has been linked to metastasis and poor prognosis in solid tumors. In this study the role of UPR-induced LAMP3 in hypoxia-mediated migration of breast cancer cells was examined.
\end{abstract}

Materials and Methods: A number of in vitro metastasis models were used to study the migration and invasion of MDA-MB-231 breast cancer cells under hypoxic conditions. PERK, ATF4 and their downstream factor LAMP3 were knocked down to examine their role in cell migration. In addition, multicellular tumor spheroids were used to study the involvement of the tumor microenvironment in invasion.

Results: Using transwell assays, migration of different breast cancer cell lines was assessed. A direct correlation was found between cell migration and baseline LAMP3 expression. Furthermore, moderate hypoxia $\left(\begin{array}{lll}1 \% & \mathrm{O}_{2}\end{array}\right)$ was found to be optimal in stimulating migration of MDA-MB-231 cells. siRNA mediated knockdown of PERK, ATF4 and LAMP3 reduced migration of cells under these conditions. Using gap closure assays, similar results were found. In a three-dimensional invasion assay into collagen, LAMP3 knockdown cells showed a diminished capacity to invade compared to control cells when collectively grown in multicellular spheroids.

Conclusions: Thus, the PERK/ATF4/LAMP3-arm of the UPR is an additional pathway mediating hypoxia-induced breast cancer cell migration. 


\section{Introduction}

Breast cancer mortality is caused foremost by the spread of cancer cells within the host in a process called metastasis (1). Before tumor cells can metastasize, the tumor will need to invade, seek access to the lymphatic or vascular system and colonize the metastatic site $(2,3)$. Insights in this process will aid in the prevention of cancer metastasis and help improve prognosis.

An important characteristic of most solid tumors is the presence of hypoxic regions (4-6). Absent or inadequate vasculature within the tumor causes disruption of the supply of blood and consequentially an impaired delivery of oxygen and nutrients and an impaired removal of carbon dioxide and waste products. Several studies found low oxygen tension in tumors to be an adverse prognostic marker in different tumor types (7-10). In addition, endogenous hypoxia-related markers, such as carbonic anhydrase-IX, were also shown to negatively influence patient outcome in breast cancer $(11,12)$. Furthermore, hypoxic tumors were found to correlate with metastatic occurrences: patients with hypoxic primary tumors developed more metastases than patients with less hypoxic tumors $(7,13-15)$. Mechanistically, numerous factors have been identified that are induced by hypoxia and that can promote metastasis (reviewed in (16-20)). The common denominator of most, if not all, of these factors is that they are either directly or indirectly influenced by the action of the family of master transcription regulators during hypoxic conditions: the hypoxia-inducible factor (HIF)-family (18).

Recently, a separate pathway from the HIFs was described, which is able to regulate gene expression during hypoxia, namely the unfolded protein response or UPR (21-24). Within this response three distinct arms have been classified: the PKR-like endoplasmic reticulum kinase (PERK)/activating transcription factor 4 (ATF4)-arm, the inositol-requiring protein 1 (IRE1)-arm and the activating transcription factor 6 (ATF6)-arm. These pathways are activated during endoplasmic reticulum stress conditions and enable cell survival by regulating apoptosis, angiogenesis and autophagy (21, 23-25). Thus far, the UPR has not been directly implicated in hypoxia-induced metastasis. However, recently lysosomal-associated membrane protein 3 (LAMP3, also known as DC-LAMP, TSC-403 or CD208) was identified as a factor induced by hypoxia as part of the PERK/ATF4 arm of the UPR $(26,27)$. In addition, we found that LAMP3 has prognostic relevance in breast cancer (28). Two homologs of LAMP3, LAMP1 and LAMP2, have been associated with cancer metastasis previously $(29,30)$. LAMP3 itself was also found to be involved in metastasis: overexpression of LAMP3 in a cervical xenograft model showed an increased 
metastatic potential (31). In what way LAMP3 is involved in breast cancer metastasis and which role hypoxia may have in this process is unknown. Therefore, we set out to determine whether the UPR can influence migration and invasion of breast cancer cells via LAMP3 under hypoxic conditions.

\section{Materials and methods}

\section{Cell culture and hypoxic incubations}

All cell lines used were obtained from LGC Promochem (Teddington, UK) and maintained in Dulbecco's Modified Eagle's Medium (DMEM) supplemented with $10 \%$ (vol/vol) fetal bovine serum (FBS), $20 \mathrm{mM}$ Hepes, 1x nonessential amino acids, $2 \mathrm{mM} \mathrm{L}$-glutamine and $10 \mathrm{U} / \mathrm{ml}$ penicillin, $10 \mu \mathrm{g} / \mathrm{ml}$ streptomycin (all from PAA Laboratories, Cölbe, Germany) at $37^{\circ} \mathrm{C}$ with $5 \% \mathrm{CO}_{2}$. Hypoxic conditions were induced with a H35 Hypoxystation (Don Whitly Scientific Ltd, Shipley, UK).

\section{Cell migration using modified Boyden Chambers}

Membranes with $8 \mu \mathrm{m}$ pores (Greiner Bio-one, Alphen a/d Rijn, The Netherlands) were used in a 24-wells format. A total of 40,000 cells, serumstarved overnight where indicated, were added to the upper compartment. The lower compartment was filled with standard cell culture medium. Cells were allowed to migrate for 24 hours, after which chambers were fixed for 10 minutes in cold $70 \%$ ethanol. Membranes were stained with $0.5 \%(\mathrm{w} / \mathrm{v})$ crystal violet (Sigma-Aldrich, St. Louis, MO, USA) for 30 minutes and subsequently washed thoroughly with tap water. Cells that had not migrated to the lower compartment were removed with a cotton swab. Migrated cells were quantified by solubilizing bound crystal violet in $1 \%(\mathrm{wt} / \mathrm{vol})$ sodium dodecyl sulfate (SDS, Sigma-Aldrich) for 1 hour at $37^{\circ} \mathrm{C}$. Absorbance was measured at $595 \mathrm{~nm}$.

\section{RNA isolation, $c D N A$ synthesis and quantitative polymerase chain reactions (qPCR)}

RNA was isolated with Norgen's total RNA purification kit (Norgen Biotek Corp., Thorold, Canada) and stored at $-80^{\circ} \mathrm{C}$ until further processing. cDNA was synthesized using the iScript cDNA synthesis kit (Bio-Rad Laboratories Inc., Richmond, CA, USA) with $1 \mu \mathrm{g}$ RNA as input. The following primers were used for the qPCR: PERK FW: 5'-CTGATTTTGAGCCAATTC-3' and RV: 5'-CCGGTACTCGCGTCGCTG-3', ATF4 FW: 5'-CCTTCACCTTCTTACAACCT-3' and RV: 5'-GTAGTCTGGCTTCCTATCTC-3', LAMP3 FW: 5'-TGAAAACAACCGATGTCCAA-3' and RV: 5'-TCAGACGAGCACTCATCCAC-3'. qPCR was carried out on a CFX96 real-time PCR detection system (Bio-Rad) with SYBR Green (Applied Biosystems, Foster City, CA, 
USA). As a reference gene, hypoxanthine-guanine phosphoribosyltransferase (HPRT) in a pre-developed assay (Applied Biosystems) was used.

\section{Transient transfection}

Cells were transfected transiently for PERK, ATF4 or LAMP3 using mission siRNAs (Sigma Aldrich): PERK (NM_004836), SASI_Hs01_00096845 and SASI_Hs01_00096846. ATF4 (NM_001675), SASI_Hs02_00332313 and SASI_Hs01_00175197. LAMP3 (NM_014398), SASI_Hs01_00214233 and SASI_Hs02_00345584. Transfections were performed using Saint-Red (Synvolux Therapeutics, Groningen, The Netherlands) according to the manufacturer's instructions.

\section{Generation of stable MDA-MB-231 shLAMP3 pools}

A U6 promoter-driven short hairpin RNA (shRNA) expression vector targeting LAMP3 and a non-targeting control vector (PLKO1_shLAMP3 (TRCN0000148784, number 842) and PLKO.1 control, respectively) were purchased from Sigma-Aldrich. Briefly, pseudotyped lentiviral particles were produced in HEK293FT cells using the ViraPower lentiviral expression system according to the manufacturer's instructions (Invitrogen, Carlsbad, CA, USA). MDA-MB231 cells were infected at a low passage number after which a pool of transfected cells was derived by puromycin $(4 \mu \mathrm{g} / \mathrm{ml})$ selection for approximately 10 days.

\section{Colony-forming assays}

For the colony-forming assays 500 transiently transfected cells were plated in T25 cell culture flasks (Greiner Bio-one) and allowed to adhere overnight. Cells were incubated under hypoxic conditions $\left(1 \% \mathrm{O}_{2}\right)$ for 24 hours after which they were transferred to the normoxic incubator and given time to form colonies. Once colonies in the normoxic controls comprised of at least 50 cells, flasks were fixated in $70 \%$ ethanol for 10 minutes at $4{ }^{\circ} \mathrm{C}$ and stained with $0.5 \%$ crystal violet for 30 minutes. Colonies of at least 50 cells were scored manually.

\section{Gap closure assays}

Monolayer gap closure assays (formerly known as scratch assays) were conducted using silicone cell culture inserts (Ibidi, Martinsried, Germany) attached to culture plates. In short, 30,000 cells were seeded in the inserts and allowed to recover overnight to form a confluent monolayer. Inserts were removed with tweezers, after which cells were rinsed thrice with Hank's buffered saline solution (HBSS, PAA Laboratories) to remove detached cells. Culture medium was re-added and closure of the gap was followed for 24 hours using live imaging (see below). Gap closure was quantified using ImageJ (National Institutes of Health, Bethesda, MD, USA). 


\section{Spheroid culture}

Multicellular tumor spheroids were prepared from conventional monolayer cultures using an adapted liquid overlay technique. In short, V-shaped 96-wells plates (Greiner Bio-one) were coated with $0.5 \%(\mathrm{wt} / \mathrm{vol})$ poly-HEMA (SigmaAldrich). A total of 1,000 cells in $100 \mu$ of standard culture medium with $2.5 \%$ (vol/vol) Matrigel (BD Biosciences, San Jose, CA, USA) were added to each well, after which cells were spun down for 10 minutes at $1,000 \mathrm{x}$ g. Within 24 hours spheroids were formed.

\section{Pimonidazole staining}

After formation, MDA-MB-231 spheroids were incubated for 1 hour with 200 $\mu \mathrm{M}$ of pimonidazole (1-[(2-hydroxy-3-piperidinyl)propyl]-2-nitroimidazole hydrochloride, Natural Pharmacia International Inc., Burlington, MA, USA). Next, spheroids were fixed in 4\% paraformaldehyde (Merck Chemicals, Darmstadt, Germany), and embedded in paraffin. Staining was performed on 5$\mu \mathrm{m}$ sections as previously described (28), using the following antibodies: mouse-anti-pimonidazole (Natural Pharmacia International Inc.) diluted 1:800 and biotin-conjugated donkey-anti-mouse IgG (715-066-150, Jackson ImmunoResearch Laboratories Inc., West Grove, PA, USA) diluted 1:200.

\section{Cell labeling with cell tracker}

To label cells with CellTracker Green (Life Technologies, Carlsbad, CA, USA) or CellTracker Orange (Life Technologies), $0.15 \times 10^{6}$ cells $/ \mathrm{ml}$ were seeded in a T75 cell culture flask (Greiner Bio-one). Cells were allowed to adhere, after which CellTracker was dissolved in DMSO and added at $10 \mu \mathrm{M}$ to the cell culture medium. Flasks were incubated at $37^{\circ} \mathrm{C}$ for 45 minutes. Next, cell culture medium was replenished and cells were allowed to recover for 30 minutes, after which they were ready for further experimentation.

\section{Spheroid invasion assays in collagen}

Twenty-four hours after formation, spheroids were embedded into collagen. Spheroids were collected in a $15 \mathrm{ml}$ tube and allowed to descend to the bottom. Cell culture medium was renewed once. Next, the spheroids were combined with $4 \mathrm{mg} / \mathrm{ml}$ of rat-tail collagen type I (BD Biosciences), according to the manufacturer's instructions. The collagen was allowed to polymerize for 10 minutes at room temperature, after which the mixture was pipetted carefully into a 12-wells plate (Greiner Bio-one). The collagen disk was incubated at $37^{\circ} \mathrm{C}$ until fully solidified, after which standard cell culture medium was added. Spheroids were allowed to invade the collagen for several days, as indicated in the legends to the figures. 


\section{F-actin staining}

After invasion of spheroids into collagen, collagen disks were fixed in $4 \%$ paraformaldehyde for 30 minutes at room temperature. Next, disks were washed with PBS, after which they were incubated with Alexa-488-conjugated Phalloidin (1:100; Life Technologies) for 3 hours at room temperature. After washing once more with PBS images were acquired.

\section{Live imaging and microscopy}

Live imaging of cells was performed using the JULI (Just Unbelievable Live Imaging) system from PAA. All other microscopic images were obtained using a Leica DM 6000 fluorescence microscope in combination with IPLab imaging software (Scanalytics Inc., Fairfax, VA, USA).

\section{Data analysis and statistics}

Unless stated otherwise, all data are presented as mean values \pm standard deviation. Statistical analysis was carried out using Student's t-tests or one-way analysis of variance (ANOVA) with Tukey's post-hoc test where appropriate unless stated otherwise. Two-sided $P$ values $<0.05$ were considered statistically significant. Asterisks indicate statistical significance: $* * *$ is $P<0.001$, ** is $P<$ 0.01 and $*$ is $P<0.05$.

\section{Results}

\section{Breast cancer cell migration in transwell assays}

To study the role of the UPR in the process of breast cancer cell migration, a number of models for in vitro metastasis were used. First, cell migration was studied in a series of six breast cancer cell lines under normoxic conditions using a transwell assay. In this assay cells have to actively migrate through a porous membrane. Cells were serum-deprived overnight and added to the upper compartment of modified Boyden chambers. In the lower compartment serum was added as a chemoattractant. As shown in Figure 1A, vast differences were found in the capability of cells to migrate to the lower compartment. The largest percentage of migrated cells was found in MDA-MB-231 and MDA-MB-468 cells, both triple-negative cell lines (that is, lacking expression of the estrogen receptor, progesterone receptor and human epidermal growth factor receptor 2). In contrast, MCF-7 and MDA- MB-175 cells demonstrated very little migration. A direct comparison between the potential to migrate and the expression of LAMP3 on the mRNA level revealed a moderate correlation in this small group of cell lines (see Figure 1B). All subsequent experiments were performed with 
the MDA-MB-231 cells, a commonly used breast cancer cell line to study cell migration.

A

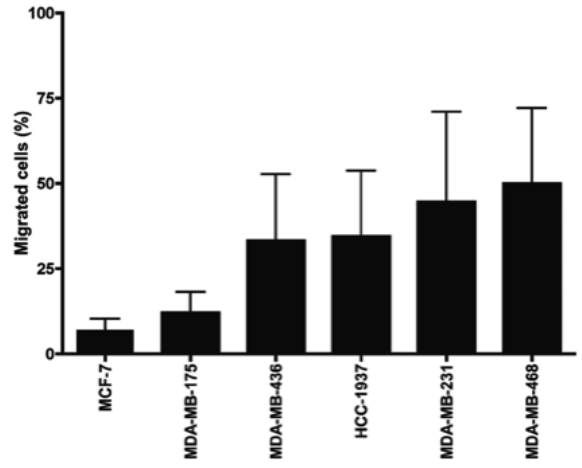

B

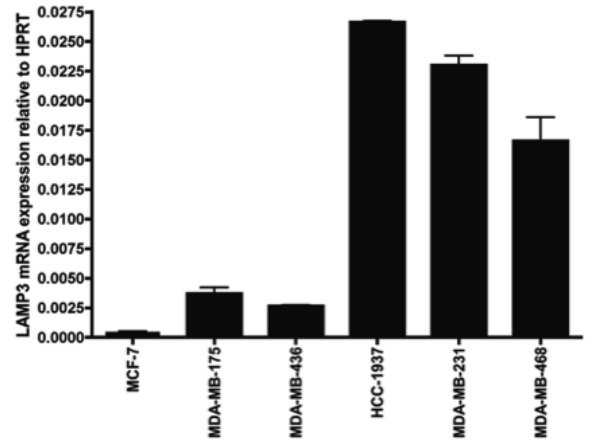

Figure 1. Migration of breast cancer cells correlates with LAMP3 mRNA expression. (A) Migration of six different breast cancer cell lines under normoxic conditions during 24 hours in a transwell assay. (B) mRNA expression of LAMP3 in the same six cell lines. Results are from two representative experiments with three replicates each. LAMP3, lysosomal-associated membrane protein 3 .

\section{Importance of serum deprivation on migration of MDA-MB-231 cells in a transwell assay}

The standard protocol for a transwell assay includes serum deprivation of the cells before the assay. This enables the addition of serum as a chemoattractant to the lower compartment. However, starvation induces the UPR profoundly and could therefore influence cell migration, especially under hypoxic conditions. In the present study, the chemoattractant function of serum was confirmed: overnight starvation of cells led to an increase in migration compared to cells that were not starved and thus allowed to migrate in complete medium (see Figure 2A). Next, this assay was used to establish the optimal percentage of oxygen to increase the migration of MDA-MB-231 breast cancer cells, in both serum-depleted and serum-supplemented conditions. When cells were serum-deprived overnight, cells migrated optimally at $1 \% \mathrm{O}_{2}$ (see Figure 2B). Cell migration decreased at lower or higher oxygen concentrations. Subsequently, the assay was performed without starvation. The availability of serum influenced the optimal oxygen percentage profoundly. Figure $2 \mathrm{C}$ shows 
that in the presence of serum cells favored lower oxygen percentages for optimal cell migration $\left(0.1 \% \mathrm{O}_{2}\right)$.
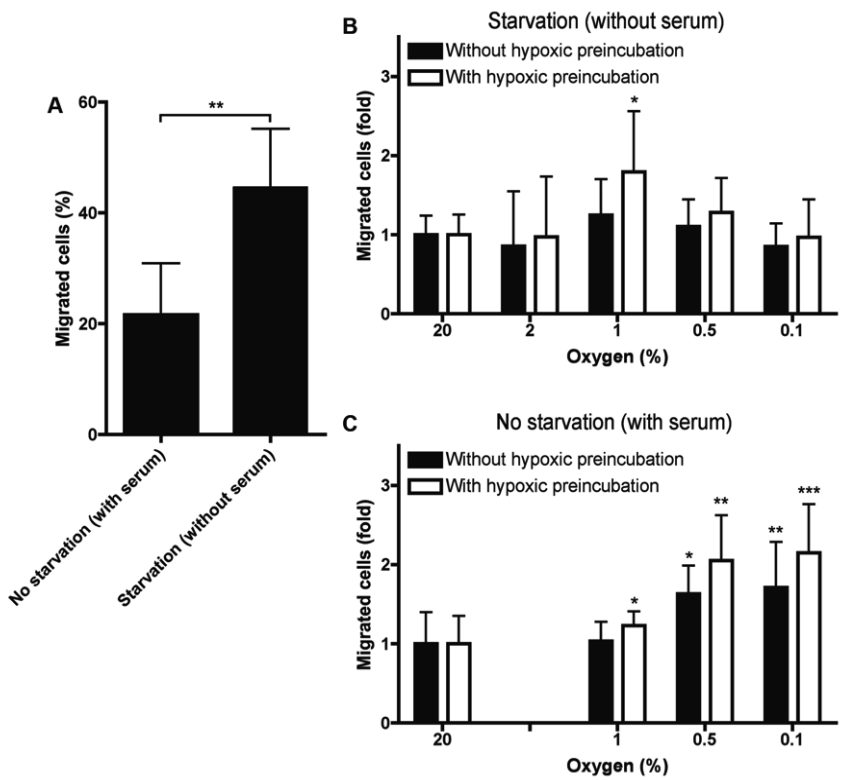

Figure 2. Serum starvation and hypoxia increase cell migration in transwell assays. (A) Effect of the addition of serum on the migration of MDA-MB-231 cells in a transwell assay during 24 hours. Effect of exposure to hypoxia on migration of MDA-MB-231 cells in a transwell assay under (B) serum-depleted or (C) serum-supplemented conditions, where cells were seeded in the transwell assays and then put in the hypoxic chamber for 24 hours (black bars) or cells received a 24 hour preincubation under the hypoxic conditions indicated on the x-axis and seeded in the transwell assays under hypoxia (white bars). Results are from two representative experiments with three replicates each. Asterisks indicate statistical significance of knockdown compared to the corresponding negative control.

\section{Effect of knockdown of PERK, ATF4 and LAMP3 on cell migration in transwell assay during hypoxia}

Next, the effect of knockdown of PERK, ATF4 and LAMP3 on cell migration during hypoxia using the transwell assay was studied. First, we examined whether PERK, ATF4 and LAMP3 expression was induced by $1 \% \mathrm{O}_{2}$ (see Figure 3A). Expression of these UPR components showed a moderate induction. Next, to ensure that any effects of knockdown on the migratory capacity during hypoxia were not due to reduced survival of the cells, a series of colony-forming assays was performed first. No significant effect of hypoxia $\left(\begin{array}{ll}1 \% & \mathrm{O}_{2}\end{array}\right)$ on colony-forming ability of knockdown cells was found in the timeframe in which assays are performed (see Figure 3B). Figure 3C shows that transfection with the siRNAs used successfully diminished expression of the mRNA of PERK, ATF4 and LAMP3. In addition, knockdown of PERK and 
ATF4 reduced the expression of their downstream targets (that is ATF4 and LAMP3) after serum starvation (see Figure 3D). Subsequently, transwell assays were performed. First, cell migration through the porous membrane was studied at $1 \% \mathrm{O}_{2}$ under serum-starved conditions. The most profound effect of knockdown on cell migration was induced when cells were preincubated under hypoxic conditions prior to the assay, which itself was also performed under hypoxia (see Figure 3E). Hypoxia without preincubation showed a diminished migration of cells for all knockdowns tested, but the effect was less profound than with the preincubated cells. Performing the assay in normoxic conditions led to a non-significant decrease in cell migration and only for some of the knockdowns tested. In addition, the cell migration after knockdown in a transwell assay at $0.1 \% \mathrm{O}_{2}$, without serum starvation was also studied (see Figure $3 \mathrm{~F}$ ). Here, effects similar to the assay at $1 \% \mathrm{O}_{2}$ were found, albeit less prominent.
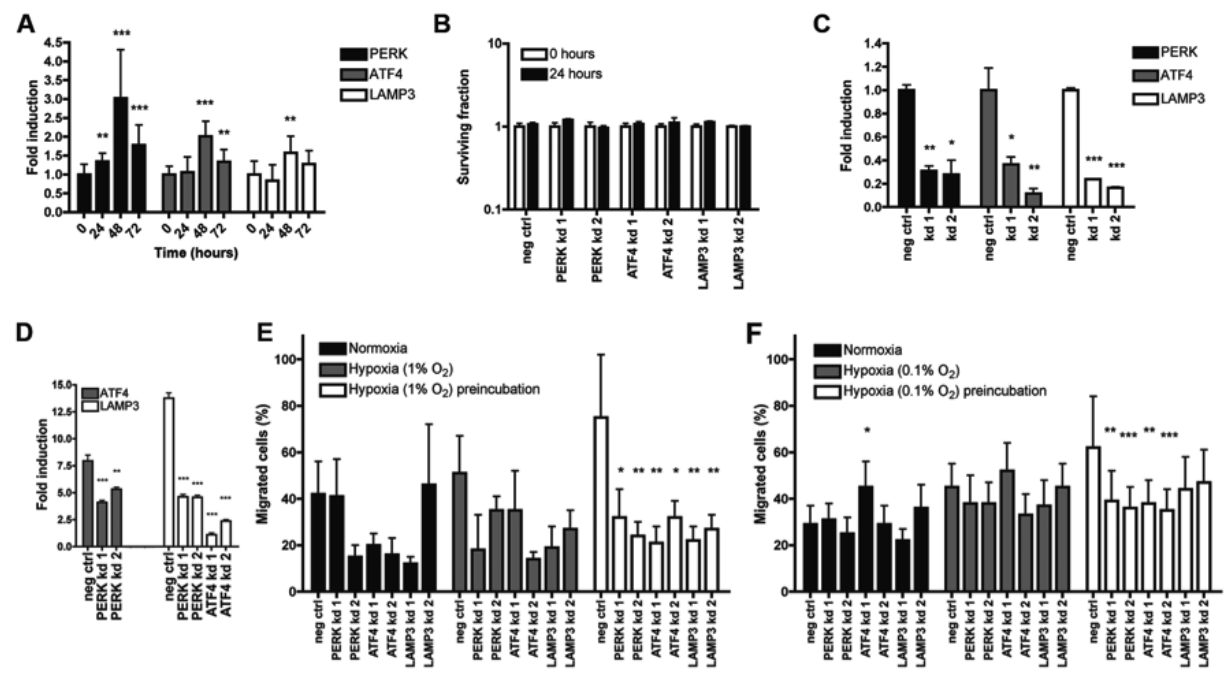

Figure 3. Knockdown of PERK, ATF4 and LAMP3 reduces cell migration under hypoxic conditions in transwell assays. (A) mRNA expression of PERK, ATF4 and LAMP3 after exposure of MDA-MB-231 cells to $1 \% \mathrm{O}_{2}$ for the time indicated on the $\mathrm{x}$-axis. (B) Clonogenic survival of MDA-MB-231 cells transiently transfected with siRNAs directed against PERK, ATF4 or LAMP3 after exposure to $1 \% \mathrm{O}_{2}$ for a 24-hour period. (C) mRNA expression of PERK, ATF4 and LAMP3 in MDA-MB-231 cells after transient transfection with siRNAs directed against the corresponding genes. (D) mRNA expression of ATF4 and LAMP3 in MDA-MB-231 cells, transfected with siRNAs directed against PERK and ATF4, after serum starvation for 24 hours. (E) Effect of hypoxia $\left(1 \% \mathrm{O}_{2}\right)$ in combination with transient knockdown of PERK, ATF4 or LAMP3 in MDA-MB-231 cells on cell migration in a transwell assay under serum-starved conditions. (F) Effect of hypoxia $\left(0.1 \% \mathrm{O}_{2}\right)$ in combination with transient knockdown of PERK, ATF4 or LAMP3 in MDA-MB-231 cells on cell migration in a transwell assay under serumsupplemented conditions. Preincubated cells were exposed to hypoxic conditions 16 hours prior to the start of the assay. Assays were carried out under normoxic or hypoxic conditions during 24 
hours. The preincubated assays were also performed under hypoxia. Results are from two representative experiments with three replicates each. Asterisks indicate statistical significance of knockdown compared to the corresponding negative control. ATF4, activating transcription factor 4; LAMP3, lysosomal-associated membrane protein 3; PERK, PKR-like endoplasmic reticulum kinase; siRNA, small interfering RNA.

\section{Migration of MDA-MB-231 breast cancer cells in a gap closure assay under hypoxic conditions}

To confirm and extend the data from the transwell assay, similar experiments were performed using a gap closure assay, which does not require serum deprivation. First, the effect of exposure to hypoxia on the migration of MDAMB-231 breast cancer cells was studied. Figure 4 shows the percentage of the gap that the cells filled in a 16-hour period. Compared to normoxic conditions, $1 \% \mathrm{O}_{2}$ showed the largest percentage of gap closure. $0.5 \% \mathrm{O}_{2}$ revealed a moderate but still significant effect. Exposure to even lower oxygen concentrations, that is $0.1 \% \mathrm{O}_{2}$, did not reveal an increase in gap closure speed compared to normoxia.

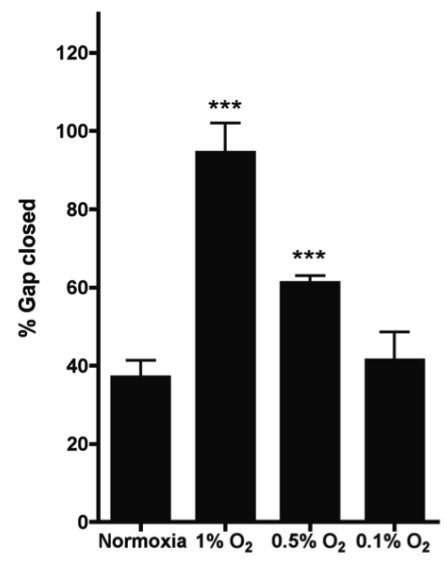

Figure 4. Hypoxia has a profound effect on cell migration in a gap closure assay. Shown is the percentage of the gap that is closed after 16 hours. Results are from two representative experiments with two replicates each. Asterisks indicate statistical significance compared to the normoxic control.

\section{Effect of knockdown of PERK, ATF4 and LAMP3 on cell migration during hypoxia in a gap closure assay}

As $1 \% \mathrm{O}_{2}$ was found to be the optimal level of hypoxia for cells to migrate, subsequent gap closure experiments were performed at this oxygen level. Figure 5 shows the effect of knockdown of PERK, ATF4 and LAMP3 on migration of MDA-MB-231 cells. Under normoxic conditions no significant difference between cells transfected with a negative control and cells transfected with siRNA against PERK, ATF4 or LAMP3 could be demonstrated (see Figure 5A, $5 \mathrm{C}$ and $5 \mathrm{E})$. In contrast, when the assay was performed under $1 \% \mathrm{O}_{2}$ a considerable effect was observed (see Figure 5B, 5D and 5F). Knockdown of 
PERK, ATF4 or LAMP3 led to a substantial decrease in the speed at which cells close the created gap (see also Additional file 1).
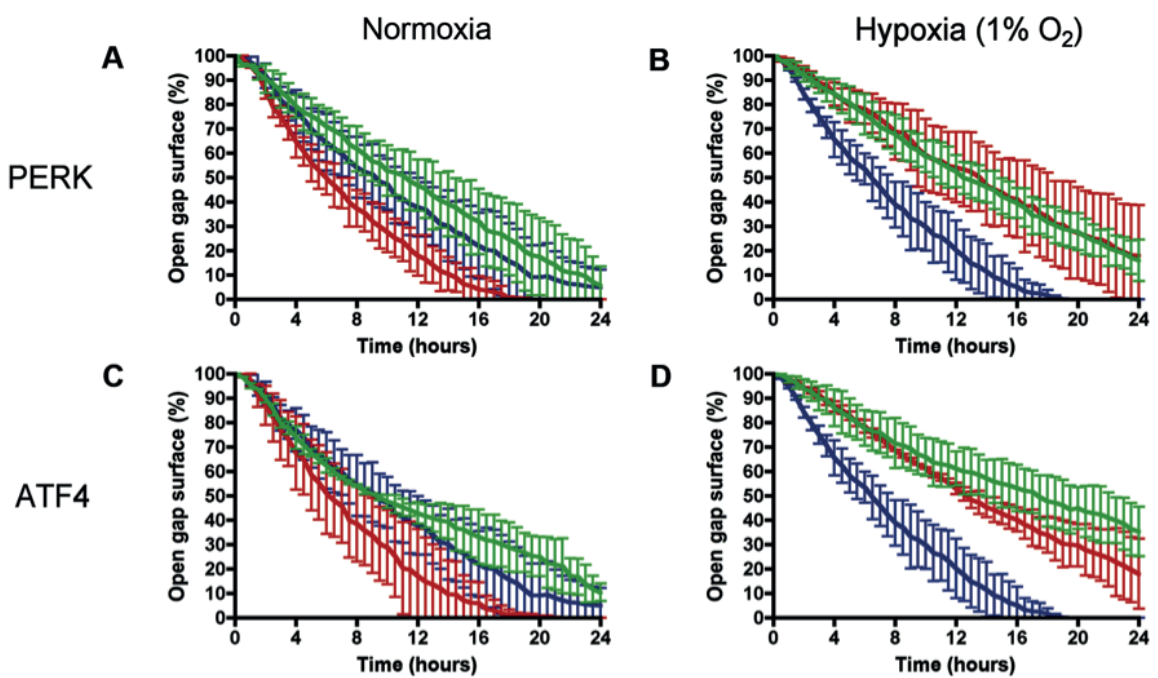

D
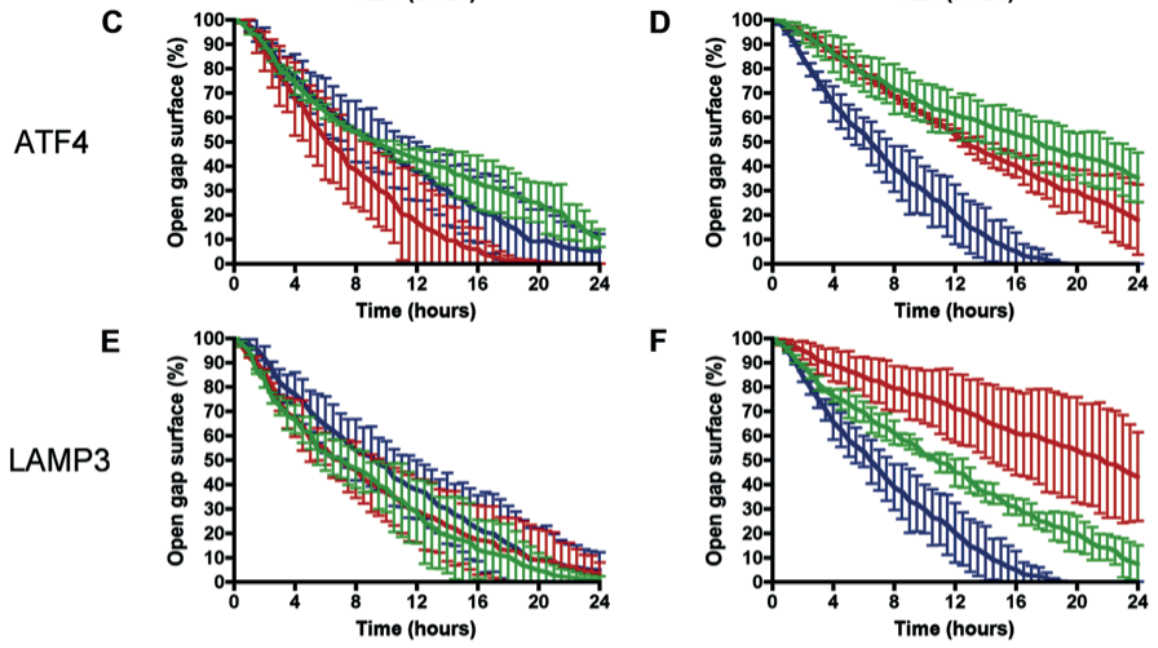

$\mathbf{F}$

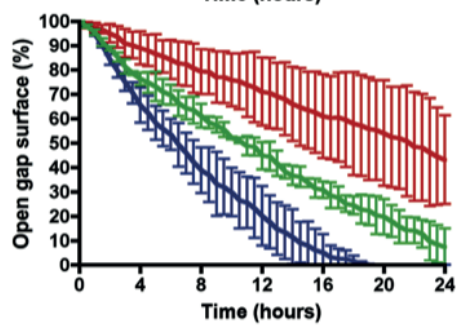

- Negative Control - Knockdown 1 -Knockdown 2

Figure 5. Knockdown of PERK, ATF4 and LAMP3 reduces cell migration under hypoxic conditions in gap closure assays. (A-F) Effect of hypoxia $\left(1 \% \mathrm{O}_{2}\right)$ in combination with transient knockdown of PERK, ATF4 or LAMP3 in MDA-MB-231 cells on cell migration in a gap closure assay. Results are from two representative experiments. ATF4, activating transcription factor 4; LAMP3, lysosomal-associated membrane protein 3; PERK, PKR-like endoplasmic reticulum kinase.

\section{Importance of the tumor microenvironment for migration of MDA-MB- 231 cells}

All assays used so far required an artificial induction of hypoxic conditions. To study the effect of hypoxia on migration with endogenous hypoxia, multicellular tumor spheroids were employed. Beyond a certain diameter, tumor spheroids will develop a core consisting of hypoxic cells (see Figure 6A). Expression of PERK, ATF4 and LAMP3 was found to be higher in cells grown as a monolayer than cells grown in a spheroid (see Figure 6B). To directly 
compare the potential to migrate of a standard two-dimensional monolayer and three-dimensional spheroids both transwell and gap closure assays were performed. Directly before the start of the assays, spheroids were disintegrated by standard trypsinization into a single cell suspension, which was used as the input for the assays. In both assays the cells initially cultured as spheroids showed an increased capacity to migrate compared to the cells grown as a monolayer (see Figure 6C and 6D). Thus, once cells have experienced a simplified, transient tumor microenvironment, their migratory capacity increases.

A

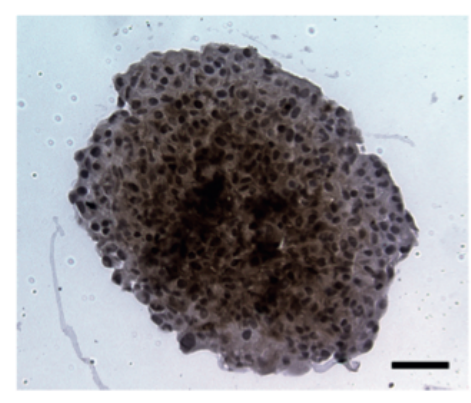

B

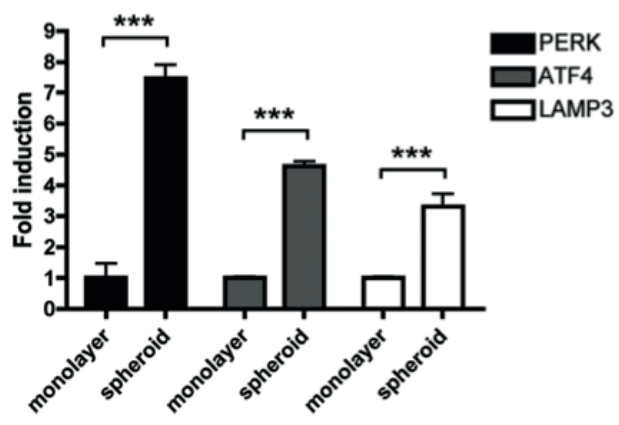

C

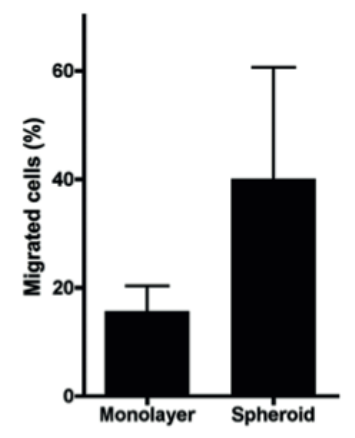

D

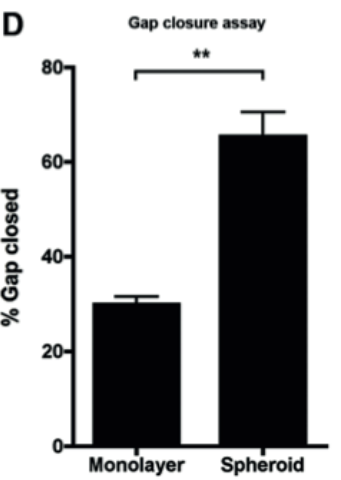

Figure 6. Cells derived from tumor spheroids are more migratory than monolayer cells. (A) MDA-MB-231 spheroid stained against the hypoxia marker pimonidazole. Bar is $100 \mu \mathrm{m}$, original magnification is $200 \mathrm{x}$. (B) mRNA expression of PERK, ATF4 and LAMP3 in MDAMB-231 monolayers compared to cells grown as spheroids. Migration of monolayer cells compared to cell initially grown as a spheroid in a transwell assay (C) during 24 hours and a gap closure assay (D) during 16 hours in standard cell culture medium. Spheroids were disintegrated into a single-cell suspension prior to the start of the assay. Results are from two representative experiments with three replicates each. ATF4, activating transcription factor 4; LAMP3, lysosomal-associated membrane protein 3; PERK, PKR-like endoplasmic reticulum kinase. 


\section{Effect of LAMP3 knockdown on collagen invasion of MDA-MB-231 spheroids}

Next, the ability of spheroids generated from cells with a stable knockdown of LAMP3 to invade a collagen matrix was studied. Figure 7A shows that stable knockdown of LAMP3 attenuated the mRNA expression of LAMP3. After 4 days of growth, both control and knockdown spheroids were of similar size, indicating that there is no difference in proliferation between these cells when grown as a spheroid (see Figure 7B). MDA-MB-231 negative control spheroids were found to invade the collagen with string-like protrusions (see Additional file 2). Stable knockdown of LAMP3 reduced these invasive filaments to some extent (see Figure 7C and Additional file 2). The effect of LAMP3 knockdown on invasion of the spheroids into collagen was quantified by measuring the surface of collagen invaded by the spheroids. The surface of the invasive zone was found to be smaller in the knockdown spheroids (see Figure 7D). The diminished invasion of LAMP3 knockdown spheroids was validated further by generating spheroids of a mixed origin. Control cells were labeled with CellTracker Green and LAMP3 knockdown cells were labeled with CellTracker Orange. Subsequently, mixed spheroids in a 1:1 ratio were generated. Invasion of these spheroids in collagen demonstrated the enhanced ability of the control cells to deeply invade the collagen compared to the LAMP3 knockdown cells (see Figure 7E). This effect was quantified by analyzing the green and red signal present within the spheroid body and the invasive zone (see Figure 7F). The invasive zone was divided into four circular zones with increasing distance from the spheroid body. Analysis of the signal present within each zone revealed that the green signal was more prevalent in the invasive zones than the red signal, indicating that the control cells invaded the collagen deeper than the LAMP3 knockdown cells.

\section{Discussion}

In this study, evidence is provided that UPR-induced LAMP3 can influence hypoxia-mediated cell migration of breast cancer cells. We provide evidence that apart from the established involvement of the HIF-pathway in the induction of cancer cell spread, the UPR is a second manner in which hypoxia is implicated in breast cancer cell migration.

A characteristic of the UPR is its maximum induction under conditions of severe hypoxia $\left(<0.2 \% \mathrm{O}_{2}\right)$ or anoxia (32). Indeed, LAMP3 as a UPR-induced factor was found to have its peak of induction under these conditions $(26,28)$. However, cell migration and invasion is often studied under conditions of more moderate hypoxia, around $1 \%$ oxygen (33-38), conditions which maximally in- 

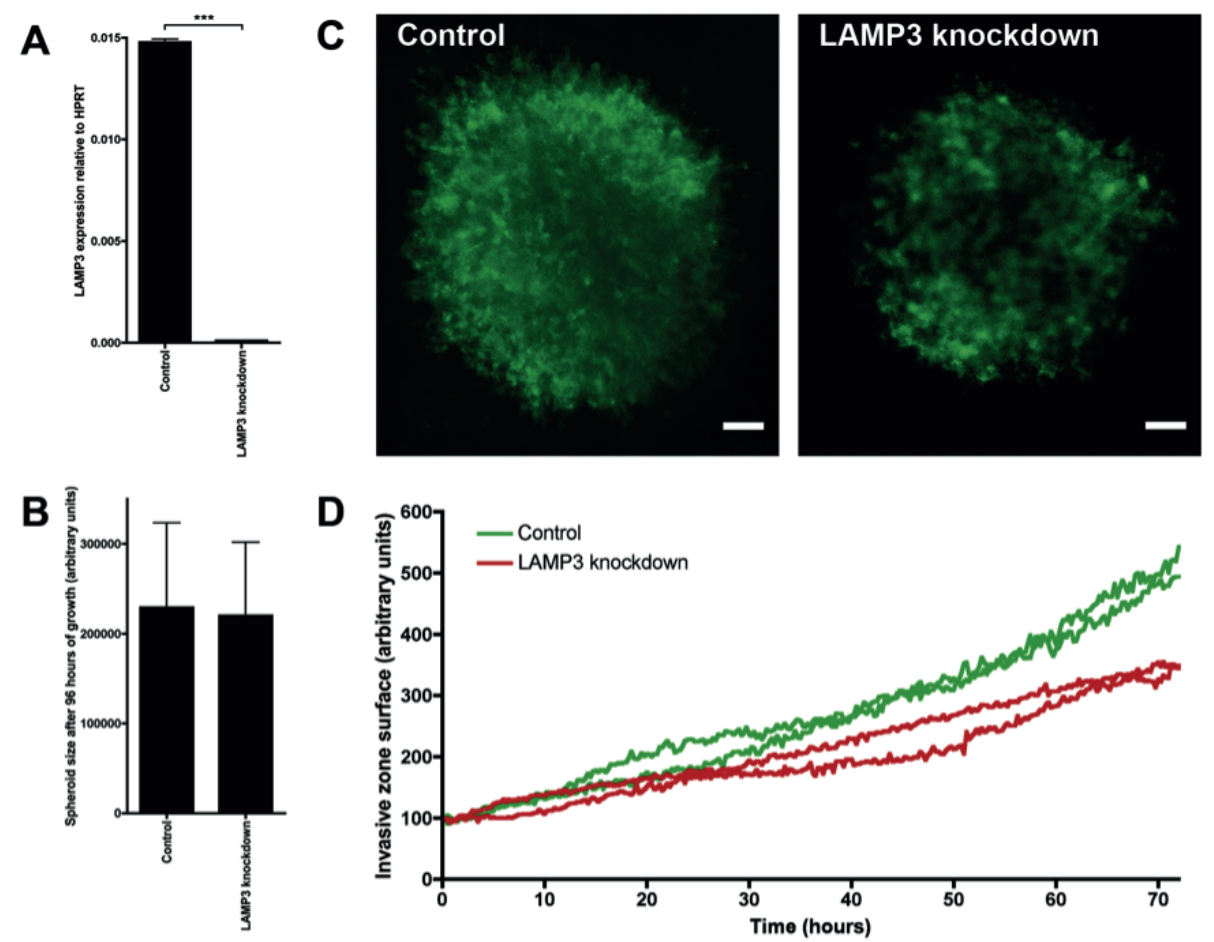

D
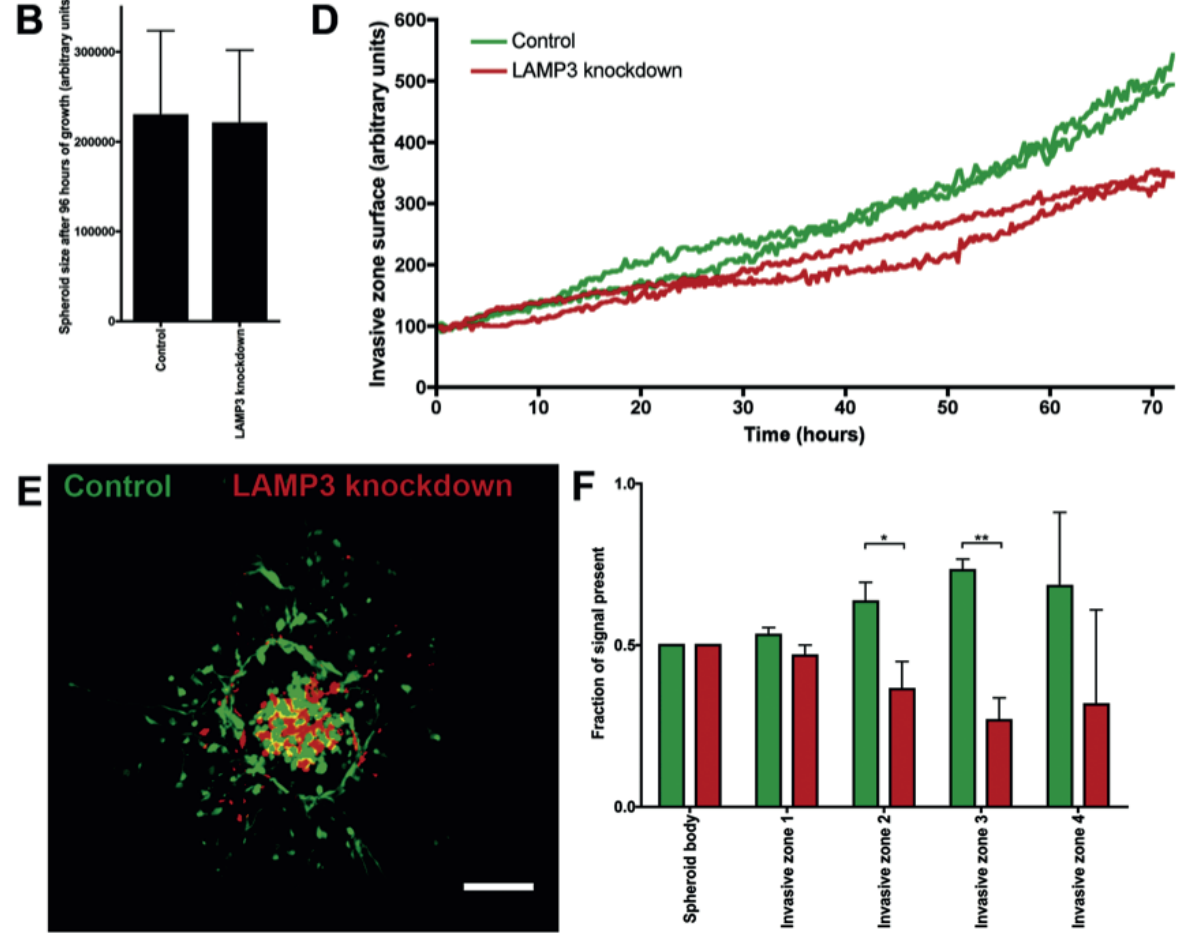

Figure 7. Knockdown of LAMP3 reduces invasion of spheroids into collagen. (A) Expression of LAMP3 mRNA in control cells versus LAMP3 knockdown cells. (B) Spheroid size of MDA-MB231 control and LAMP3 knockdown spheroids after 4 days of growth. Results are from two independent experiments with 32 replicates each. (C) F-actin staining of MDA-MB-231 spheroids of control and LAMP3 knockdown cells, after 6 days of invasion in collagen. Bar is $100 \mu \mathrm{m}$, original magnification is $50 \mathrm{x}$. (D) Surface of collagen invaded by MDA-MB-231 control and LAMP3 knockdown spheroids during 72 hours. (E) Collagen invasion of a mixed MDA-MB-231 spheroid after 6 days. Control cells were labeled with CellTracker Green and LAMP3 knockdown cells were labeled with CellTracker Orange. Control and LAMP3 knockdown cells were mixed in a 1:1 ratio. Bar is $100 \mu \mathrm{m}$, original magnification is $100 \mathrm{x}$. (F) Quantification of E. The total amount of green and red signal was analyzed in five different zones: the spheroid body and four consecutive invasive zones, $\mathrm{n}=5$. LAMP3, lysosomal-associated membrane protein 3 . 
duce HIF $1 \alpha$ expression (23). The current study shows that knockdown of PERK, ATF4 or LAMP3 in combination with hypoxic exposure to $1 \% \mathrm{O}_{2}$ led to a reduction in cell migration. If the UPR and its associated factors are maximally induced by anoxia, why are the largest effects observed at moderate levels of hypoxia? Several studies have shown that the UPR can indeed be induced by moderate hypoxia as well, but with different kinetics $(22,39,40)$. In this study assays were performed at $1 \% \mathrm{O}_{2}$ as stronger hypoxic conditions did not lead to a stimulation of cell migration. Possibly, at severe hypoxic conditions, cells apply the UPR more for cell survival (25) than migration.

In the transwell assays an intriguing effect of the addition of serum on the induction of cell migration by hypoxia was observed. Serum-starved cells migrated most profoundly at $1 \% \quad \mathrm{O}_{2}$, whereas serum-supplemented cells migrated best at $0.1 \% \mathrm{O}_{2}$. Serum dependency of cancer cell invasion has been observed before $(41,42)$. When MDA-MB-231 cells were serum depleted, no increase in invasion was found for a hypoxic incubation $\left(1.5 \% \mathrm{O}_{2}\right)(41)$. As addition of serum led to an increased invasion under hypoxia, it was suggested that serum might contain factors that increase invasion under hypoxic conditions (41). In a different study, the effect of hepatocyte growth factor (HGF) on tumor invasion was examined in U2-OS and SiHa cells (43). Mild hypoxia $\left(3 \% \mathrm{O}_{2}\right)$ was found to increase invasion by amplifying HGF signaling, thereby sensitizing cells to HGF stimulation (43). These and the current data indicate that the role of serum in cancer cell migration and invasion is more than just a chemoattractant and that growth factor signaling has a vast influence on the effects of hypoxia in migration and invasion assays. Trying to survive during hypoxia is of critical importance for cells. Depriving cells of serum may make survival even more difficult. Possibly, without serum and under severe hypoxic conditions $\left(0.1 \% \mathrm{O}_{2}\right)$ cells are not migrating as fast as under moderate hypoxia $\left(1 \% \mathrm{O}_{2}\right)$ because cell survival is more essential. When serum is present, the need for survival may become less critical even at $0.1 \% \mathrm{O}_{2}$, causing the increase in cell migration.

The importance of the tumor microenvironment during cell migration was emphasized when migration assays were performed with cells grown as monolayer and cells initially grown as spheroids. The latter were found to be more migratory than the former. In other words, cells that experienced a simplified microenvironment prior to the assay were more migratory, despite the fact that spheroids had to be disintegrated back to a single-cell suspension. This behavior was also observed previously with murine breast cancer cell lines in transwell invasion assays (44). As the spheroids used contain a central hypoxic core, the enhanced ability of spheroid cells to migrate or invade could be a consequence of hypoxia. This, however, remains to be established. 
With the evidence that LAMP3 is involved in hypoxia-induced cell migration, it needs to be elucidated which mechanism LAMP3 uses to cause the actual spread of cancer cells. LAMP3 protein under physiological conditions is localized within the lysosomal membrane (45). For LAMP1 and LAMP2 it has been previously established that their expression can relocalize to the plasma membrane in cancer cells (29). Cell lines with a stronger metastatic capacity showed an enhanced expression of LAMP1 and LAMP2 on the cell membrane (29). It is believed that LAMP surface expression provides a cancer cell with means to attach to selectins on endothelial cells and enhance their capacity to form metastases (30). A similar mechanism could be responsible for the role of LAMP3 in hypoxia-induced cell migration. LAMP3 was found to have the ability to relocalize to the plasma membrane upon influenza A virus infections in HeLa cells (46). Nevertheless, we have not been able to show LAMP3 expression on the cell surface in the MDA-MB-231 cells used, under either normoxic or hypoxic conditions. Immunohistochemically, in MDA-MB-231 cells we have only observed LAMP3 expression in the cytoplasm. An alternative explanation for the function of LAMP3 in cell migration is the link LAMP proteins have with autophagy (47). Autophagy has been previously suggested as a possible mechanism responsible for increased survival and increased metastasis of cancer cells $(48,49)$. Analysis of the autophagy marker LC3B expression in a large subset of breast tumors revealed that it is associated with metastasis and a worse outcome (50). However, Indelicato et al. found that chemically induced autophagy results in reduced invasion of MDA-MB-231 cells under both normoxic and hypoxic $\left(1 \% \mathrm{O}_{2}\right)$ conditions, whereas LC3B silenced cells showed a decreased invasion during hypoxic conditions (37). Thus, there is evidence that autophagy may function as a mechanism behind hypoxia-induced metastasis, but its precise role is far from clarified.

\section{Conclusions}

In conclusion, this study provides evidence that the UPR with LAMP3 is involved in the process of hypoxia-induced cell migration. In addition, growth factor signaling via the serum component of cell culture medium is a factor of vital importance in the migration of cells under conditions of both moderate and severe hypoxia. Furthermore, the tumor microenvironment, experienced by cells when grown as multicellular spheroids is of significance in the process of cell migration and invasion. The PERK/ATF4/LAMP3 arm of the UPR might function as a new target for therapy combating hypoxia-induced metastasis in breast cancer. 


\title{
Acknowledgements
}

\author{
Maurits en Anna de Kock Stichting.
}

\section{References}

1. Weigelt B, Peterse JL, van 't Veer LJ. Breast cancer metastasis: markers and models. Nat Rev Cancer. 2005;5:591-602.

2. Friedl P, Locker J, Sahai E, Segall JE. Classifying collective cancer cell invasion. Nat Cell Biol. 2012;14:777-83.

3. Hanahan D, Weinberg RA. Hallmarks of cancer: the next generation. Cell. 2011;144:64674.

4. Brown JM. Evidence for acutely hypoxic cells in mouse tumours, and a possible mechanism of reoxygenation. Br J Radiol. 1979;52:650-6.

5. Rademakers SE, Span PN, Kaanders JH, Sweep FC, van der Kogel AJ, Bussink J. Molecular aspects of tumour hypoxia. Mol Oncol. 2008;2:41-53.

6. Thomlinson RH, Gray LH. The histological structure of some human lung cancers and the possible implications for radiotherapy. Br J Cancer. 1955;9:539-49.

7. Brizel DM, Sibley GS, Prosnitz LR, Scher RL, Dewhirst MW. Tumor hypoxia adversely affects the prognosis of carcinoma of the head and neck. Int J Radiat Oncol Biol Phys. 1997;38:285-9.

8. Bussink J, Kaanders JH, van der Kogel AJ. Tumor hypoxia at the micro-regional level: clinical relevance and predictive value of exogenous and endogenous hypoxic cell markers. Radiother Oncol. 2003;67:3-15.

9. Hockel M, Schlenger K, Hockel S, Vaupel P. Hypoxic cervical cancers with low apoptotic index are highly aggressive. Cancer Res. 1999;59:4525-8.

10. Kaanders JH, Wijffels KI, Marres HA, Ljungkvist AS, Pop LA, van den Hoogen FJ, et al. Pimonidazole binding and tumor vascularity predict for treatment outcome in head and neck cancer. Cancer Res. 2002;62:7066-74.

11. Chia SK, Wykoff CC, Watson PH, Han C, Leek RD, Pastorek J, et al. Prognostic significance of a novel hypoxia-regulated marker, carbonic anhydrase IX, in invasive breast carcinoma. J Clin Oncol. 2001;19:3660-8.

12. Span PN, Bussink J, Manders P, Beex LV, Sweep CG. Carbonic anhydrase-9 expression levels and prognosis in human breast cancer: association with treatment outcome. Br J Cancer. 2003;89:271-6.

13. Hockel M, Schlenger K, Aral B, Mitze M, Schaffer U, Vaupel P. Association between tumor hypoxia and malignant progression in advanced cancer of the uterine cervix. Cancer Res. 1996;56:4509-15.

14. Nordsmark M, Overgaard M, Overgaard J. Pretreatment oxygenation predicts radiation response in advanced squamous cell carcinoma of the head and neck. Radiother Oncol. 1996;41:31-9. 
15. Sundfor K, Lyng H, Rofstad EK. Tumour hypoxia and vascular density as predictors of metastasis in squamous cell carcinoma of the uterine cervix. Br J Cancer. 1998;78:822-7.

16. Chan DA, Giaccia AJ. Hypoxia, gene expression, and metastasis. Cancer Metastasis Rev. 2007;26:333-9.

17. Chaudary N, Hill RP. Hypoxia and metastasis in breast cancer. Breast Dis. 2006;26:5564.

18. Gort EH, Groot AJ, van der Wall E, van Diest PJ, Vooijs MA. Hypoxic regulation of metastasis via hypoxia-inducible factors. Curr Mol Med. 2008;8:60-7.

19. Le QT, Denko NC, Giaccia AJ. Hypoxic gene expression and metastasis. Cancer Metastasis Rev. 2004;23:293-310.

20. Lunt SJ, Chaudary N, Hill RP. The tumor microenvironment and metastatic disease. Clin Exp Metastasis. 2009;26:19-34.

21. Feldman DE, Chauhan V, Koong AC. The unfolded protein response: a novel component of the hypoxic stress response in tumors. Mol Cancer Res. 2005;3:597-605.

22. Koumenis C, Naczki C, Koritzinsky M, Rastani S, Diehl A, Sonenberg N, et al. Regulation of protein synthesis by hypoxia via activation of the endoplasmic reticulum kinase PERK and phosphorylation of the translation initiation factor eIF2alpha. Mol Cell Biol. 2002;22:7405-16.

23. Koumenis C, Wouters BG. "Translating" tumor hypoxia: unfolded protein response (UPR)-dependent and UPR-independent pathways. Mol Cancer Res. 2006;4:423-36.

24. Wouters BG, Koritzinsky M. Hypoxia signalling through mTOR and the unfolded protein response in cancer. Nat Rev Cancer. 2008;8:851-64.

25. Rouschop KM, van den Beucken T, Dubois L, Niessen H, Bussink J, Savelkouls K, et al. The unfolded protein response protects human tumor cells during hypoxia through regulation of the autophagy genes MAP1LC3B and ATG5. J Clin Invest. 2010;120:127-41.

26. Mujcic H, Rzymski T, Rouschop KM, Koritzinsky M, Milani M, Harris AL, et al. Hypoxic activation of the unfolded protein response (UPR) induces expression of the metastasis-associated gene LAMP3. Radiother Oncol. 2009;92:450-9.

27. Ozaki K, Nagata M, Suzuki M, Fujiwara T, Ueda K, Miyoshi Y, et al. Isolation and characterization of a novel human lung-specific gene homologous to lysosomal membrane glycoproteins 1 and 2: significantly increased expression in cancers of various tissues. Cancer Res. 1998;58:3499-503.

28. Nagelkerke A, Mujcic H, Bussink J, Wouters BG, van Laarhoven HW, Sweep FC, et al. Hypoxic regulation and prognostic value of LAMP3 expression in breast cancer. Cancer. 2011;117:3670-81.

29. Saitoh O, Wang WC, Lotan R, Fukuda M. Differential glycosylation and cell surface expression of lysosomal membrane glycoproteins in sublines of a human colon cancer exhibiting distinct metastatic potentials. J Biol Chem. 1992;267:5700-11.

30. Sawada R, Lowe JB, Fukuda M. E-selectin-dependent adhesion efficiency of colonic carcinoma cells is increased by genetic manipulation of their cell surface lysosomal membrane glycoprotein-1 expression levels. J Biol Chem. 1993;268:12675-81.

31. Kanao H, Enomoto T, Kimura T, Fujita M, Nakashima R, Ueda Y, et al. Overexpression of LAMP3/TSC403/DC-LAMP promotes metastasis in uterine cervical cancer. Cancer Res. 2005;65:8640-5.

32. Mazure NM, Pouyssegur J. Hypoxia-induced autophagy: cell death or cell survival? Curr Opin Cell Biol. 2010;22:177-80. 
33. Canning MT, Postovit LM, Clarke SH, Graham CH. Oxygen-mediated regulation of gelatinase and tissue inhibitor of metalloproteinases-1 expression by invasive cells. Exp Cell Res. 2001;267:88-94.

34. Erler JT, Bennewith KL, Nicolau M, Dornhofer N, Kong C, Le QT, et al. Lysyl oxidase is essential for hypoxia-induced metastasis. Nature. 2006;440:1222-6.

35. Funasaka T, Yanagawa T, Hogan V, Raz A. Regulation of phosphoglucose isomerase/autocrine motility factor expression by hypoxia. FASEB J. 2005;19:1422-30.

36. Graham CH, Forsdike J, Fitzgerald CJ, Macdonald-Goodfellow S. Hypoxia-mediated stimulation of carcinoma cell invasiveness via upregulation of urokinase receptor expression. Int J Cancer. 1999;80:617-23.

37. Indelicato M, Pucci B, Schito L, Reali V, Aventaggiato M, Mazzarino MC, et al. Role of hypoxia and autophagy in MDA-MB-231 invasiveness. J Cell Physiol. 2010;223:359-68.

38. Postovit LM, Adams MA, Lash GE, Heaton JP, Graham CH. Oxygen-mediated regulation of tumor cell invasiveness. Involvement of a nitric oxide signaling pathway. J Biol Chem. 2002;277:35730-7.

39. Fels DR, Koumenis C. The PERK/eIF2alpha/ATF4 module of the UPR in hypoxia resistance and tumor growth. Cancer Biol Ther. 2006;5:723-8.

40. Koritzinsky M, Magagnin MG, van den Beucken T, Seigneuric R, Savelkouls K, Dostie J, et al. Gene expression during acute and prolonged hypoxia is regulated by distinct mechanisms of translational control. EMBO J. 2006;25:1114-25.

41. Munoz-Najar UM, Neurath KM, Vumbaca F, Claffey KP. Hypoxia stimulates breast carcinoma cell invasion through MT1-MMP and MMP-2 activation. Oncogene. 2006;25:2379-92.

42. Reshkin SJ, Bellizzi A, Albarani V, Guerra L, Tommasino M, Paradiso A, et al. Phosphoinositide 3-kinase is involved in the tumor-specific activation of human breast cancer cell $\mathrm{Na}(+) / \mathrm{H}(+)$ exchange, motility, and invasion induced by serum deprivation. $\mathrm{J}$ Biol Chem. 2000;275:5361-9.

43. Pennacchietti S, Michieli P, Galluzzo M, Mazzone M, Giordano S, Comoglio PM. Hypoxia promotes invasive growth by transcriptional activation of the met protooncogene. Cancer Cell. 2003;3:347-61.

44. Krohn A, Song YH, Muehlberg F, Droll L, Beckmann C, Alt E. CXCR4 receptor positive spheroid forming cells are responsible for tumor invasion in vitro. Cancer Lett. 2009;280:65-71.

45. de Saint-Vis B, Vincent J, Vandenabeele S, Vanbervliet B, Pin JJ, Ait-Yahia S, et al. A novel lysosome-associated membrane glycoprotein, DC-LAMP, induced upon DC maturation, is transiently expressed in MHC class II compartment. Immunity. 1998;9:325-36.

46. Zhou Z, Xue Q, Wan Y, Yang Y, Wang J, Hung T. Lysosome-associated membrane glycoprotein 3 is involved in influenza A virus replication in human lung epithelial (A549) cells. Virol J. 2011;8:384.

47. Eskelinen EL. Roles of LAMP-1 and LAMP-2 in lysosome biogenesis and autophagy. Mol Aspects Med. 2006;27:495-502.

48. Macintosh RL, Timpson P, Thorburn J, Anderson KI, Thorburn A, Ryan KM. Inhibition of autophagy impairs tumor cell invasion in an organotypic model. Cell Cycle. 2012;11:2022-9.

49. Vigneswaran N, Wu J, Song A, Annapragada A, Zacharias W. Hypoxia-induced autophagic response is associated with aggressive phenotype and elevated incidence of 
metastasis in orthotopic immunocompetent murine models of head and neck squamous cell carcinomas (HNSCC). Exp Mol Pathol. 2011;90:215-25.

50. Lazova R, Camp RL, Klump V, Siddiqui SF, Amaravadi RK, Pawelek JM. Punctate LC3B expression is a common feature of solid tumors and associated with proliferation, metastasis, and poor outcome. Clin Cancer Res. 2012;18:370-9. 



\section{CHAPTER 5}

Hypoxic Activation of the PERK/eIF $2 \alpha$ arm of the Unfolded Protein Response Promotes Metastasis through Induction of LAMP3

H. Mujcic

A. Nagelkerke

K.M.A. Rouschop

S. Chung

N. Chaudary

P.N. Span

R.P. Hill

M. Koritzinsky

B.G. Wouters

Submitted for publication 


\begin{abstract}
Conditions of poor oxygenation (hypoxia) are present in the many human tumors and in cervix cancer, and are associated with increased risk of metastasis and poor patient prognosis. Hypoxia is a potent activator of the PERK/eIF2a signaling pathway, a component of the unfolded protein response and an important mediator of hypoxia tolerance and tumor growth. To evaluate the importance of this pathway in metastasis, we constructed a series of isogenic and inducible cell lines to interfere with PERK signaling during hypoxia and used these in an orthotopic cervix cancer model of hypoxia-driven metastasis. We find that induced disruption of PERK signaling in established orthotopic xenografts results in complete inhibition of hypoxia-induced metastasis to the lymph nodes. Our data indicate this is due in part to a direct influence of this pathway on hypoxia tolerance, since its disruption markedly reduced cell survival to hypoxia in vitro and impaired primary tumor growth in vivo. However, we also find that the PERK/ATF4 target gene LAMP3, a metastasisassociated gene, is a key mediator of hypoxia driven lymph node metastasis. Silencing LAMP3 had no effect on hypoxia tolerance, but prevented lymph node metastasis in orthotopic xenografts and inhibited cell migration in vitro. Finally, we demonstrate that LAMP3 is regulated by both amplification, and by hypoxia in human cervix tumors. These data suggest that the poor prognosis of patients with hypoxic cervix cancer is due in part to PERK activation of LAMP3.
\end{abstract}




\section{Introduction}

The microenvironment of solid tumors is profoundly different from that of the normal tissues from which they derive. The high proliferation rate of tumor cells inevitably results in the development of poorly oxygenated (hypoxic) regions where oxygen and nutrient demand exceeds supply. Over the last two decades clinical studies have established a clear association between increased levels of tumor hypoxia and poor patient prognosis. The degree of hypoxia in tumors as measured by the Eppendorf probe has been found to be a prognostic factor for a variety of tumor types, including uterine cervix and head and neck carcinoma (1-3). Tumor hypoxia negatively impacts prognosis by conferring intrinsic resistance to both radio- and chemotherapy, and also induces biological changes that promote increased malignancy, including metastasis (4-6). Studies in both cervix carcinoma and soft tissue sarcoma have shown directly that patients with hypoxic tumors are more likely to fail therapy due to distant metastases $(4,5,7)$. Likewise, a recent study in prostate cancer has identified tumor hypoxia as an independent predictor of biochemical relapse, but only within the first 48 months of completing treatment, suggesting the presence of subclinical metastatic disease at time of treatment in patients with hypoxic tumors (8). Laboratory and animal models support a direct role for hypoxia in promoting metastasis. In vitro hypoxia exposure has been shown to potentiate experimental metastasis of several cancer cell lines when injected into mice (912). Moreover, increasing tumor hypoxia by subjecting tumor-bearing animals to periodically breathe low-oxygen gas enhances spontaneous metastasis in a number of metastatic xenograft models, including an orthotopic model of human cervical carcinoma (13-15). In this model, lymph node metastasis was increased in animals exposed to cyclic hypoxia.

Tumor cells respond to hypoxia through several known adaptive oxygensensitive signaling pathways. This includes activation of the hypoxia-inducible factor family of transcription factors (HIFs), which regulate the expression many genes involved in metabolism and angiogenesis (16). Hypoxia also acts as a potent activator of the unfolded protein response (UPR), an evolutionally conserved program that responds to endoplasmic reticulum (ER) stress (17-19). The UPR consist of 3 signaling pathways initiated by PKR-like ER kinase (PERK, also known as EIF2AK3), inositol-requiring enzyme 1 (IRE1), and activating transcription factor 6 (ATF6) which function as individual sensors of ER stress. Several studies have demonstrated that both PERK and IRE1 arms of the UPR are strongly activated by hypoxia and important for the tolerance of tumor cells to hypoxic stress (19-22). PERK activation leads to a rapid inhibition of protein synthesis during hypoxia through phosphorylation of the $\alpha$ 
subunit of eukaryotic translation initiation factor 2 (eIF2 $\alpha$ ) on Ser51 (18), which prevents the assembly of the ternary translation initiation complex eIF2-GTPtRNA/Met and inhibition of translation initiation. Paradoxically, eIF2a phosphorylation also results in selective translation of activating transcription factor 4 (ATF4) due to the presence of an unusual 5' UTR that contains multiple upstream open reading frames $(17,23,24)$. ATF4 initiates a widespread transcriptional response that mediates adaptation to ER stress, including ER protein chaperones, and genes involved in amino acid metabolism and resistance to oxidative stress (25). ATF4 promotes hypoxia tolerance directly by inducing LC3B (MAP1LC3B) that enables high rates of autophagy required to protect hypoxic cells from cell death (26). Finally, ATF4 also initiates a negative feedback loop by inducing growth arrest and DNA damage-inducible protein 34 (GADD34, also known as PPP1R15A), which promotes dephosphorylation of eIF2a and restoration of overall protein synthesis (27).

Several studies have demonstrated that HIF-1 activation can regulate pathways involved in metastasis $(28,29)$. Direct or indirect targets of HIF-1 include genes that regulate the epithelial and mesenchymal transition (EMT), matrix metalloproteinases (MMPs) and lysyl oxidase (LOX), which are involved in the establishment of the pre-metastatic niche (30-32). The relevance of UPR signaling in hypoxia-induced metastasis has not yet been examined. However, we recently showed that expression of a putative metastasis promoting gene, lysosomal-associated membrane protein 3 (LAMP3) was strongly induced by hypoxia in a PERK/ATF4 dependent and HIF independent manner (33). LAMP3 has been hypothesized as a potential mediator of metastasis and is overexpressed in several cancer types (34). Here, we have created a series of isogenic and inducible models and used these in an orthotopic model of cervical cancer to test the contribution of PERK and LAMP3 in hypoxia-induced metastasis.

\section{Materials and methods}

\section{Cell models and hypoxia exposure}

The ME180 (human cervix carcinoma) cell line with doxycycline inducible expression of the hamster GADD34 C-terminus (GADD34-C) (35) was created using the Flp-In T-Rex system according to the manufacturer's instructions (Invitrogen). ME180 cells were transfected with a pRetroSuper vector containing a short hairpin against LAMP3 to generate stable LAMP3 knockdown cells (shLAMP3) or with an empty vector (EV control). For anoxic exposure cells were transferred into a H85 HypOxystation hypoxic incubator (Hypoxgyen, USA). The composition of the atmosphere in the incubator consisted of $5 \% \mathrm{H}_{2}, 5 \% \mathrm{CO}_{2}, 0.0 \% \mathrm{O}_{2}$ and residual $\mathrm{N}_{2}$. 


\section{$R N A$ isolation and quantitative PCR analysis}

Total RNA isolation and quantitative RT-PCR was performed as previously described (33). Relative transcript abundance was determined using the standard curve method and normalized to $18 \mathrm{~S}$ rRNA expression.

\section{Western blot analysis}

Cell lysis and immunoblot analysis was performed as described previously (33). For the detection of phosphorylated eIF $2 \alpha$ cells were lysed in 20mM HEPES, $100 \mathrm{mM} \mathrm{KCl}, 5 \mathrm{mM}$ EDTA, $10 \%$ glycerol, $0.5 \%$ Triton-X, $0.005 \%$ SDS and $1 \mathrm{mM}$ DTT supplemented with Halt Phosphatase Inhibitor Cocktail (Thermo Scientific). See supplementary materials and methods for antibodies used.

\section{Spontaneous metastasis assay and cyclic hypoxia treatment}

Orthotopic implantations were performed as described previously (13). Expression of the GADD34-C transgene was induced 8 days after implantation by administration of doxycycline $(2 \mathrm{~g} / \mathrm{L}$ in $5 \%$ sucrose $)$ in the drinking water of the animals. The cyclic hypoxia treatment was started the following day (day 9) and repeated daily until 24 hours prior to sacrifice, as described previously (13). To identify viable hypoxic cells, animals were injected with the hypoxia marker drug EF5 [2-(2-nitro-1H- imidazole-1-yl)-N-(2,2,3,3,3-pentafluoropropyl) acetamide], obtained from Dr. Cameron Koch (University of Pennsylvania), 4 hours before tumor excision $(100 \mu \mathrm{mol} / \mathrm{kg}$ i.p.). All animal experiments were performed according to the regulations of the Canadian Council on Animal Care.

\section{Immunohistochemical staining and image analysis}

See supplementary materials and methods for the staining protocols. Images were analyzed using Definiens Tissue Studio software, which allows for semiautomatic histology image analysis. Briefly, the software was trained to identify viable tumor areas, necrotic areas, tumor stroma and empty areas within the scanned section. For human cervix carcinoma biopsies the average LAMP3 staining intensity within the tumor areas was measured as well as the LAMP3 positive area above a background threshold obtained from the average intensity of all patient sections. The product of average staining intensity and fractional labeled tumor area was calculated for each case to represent relative protein abundance. Two sections per case were stained and analyzed at different times.

\section{FISH analysis}

The LAMP3 containing clone RP11-1012H23 was selected from the Human UCSC Genome Browser assembly (Feb.2009 CRch37/hg19) and obtained from 
TCAG Genome Resource Facility (Toronto, Canada). Prior to experiments, the RP11-1012H23 probe was verified on normal blood metaphases to confirm its correct location on chromosome 3q27. The BAC probe was used along with centromeric probes CEP3 (labeled with SpG) and CEP7 (labeled with aqua) purchased from Abbott Molecular and utilized as internal controls. FISH was performed on paraffin embedded tissues - TMA's. See supplementary materials and methods for protocol. H\&E stained adjacent TMA sections were compared with FISH stained slides in order to properly identify tumor cells. 100 nonoverlapping, intact cells were scored for each case. Total LAMP3, CEP3 and CEP7 signal was determined for each case and subsequently the LAMP3 to CEP3 and LAMP3 to CEP7 ratio was calculated. A ratio of 1.5 or higher was considered an abnormal signal.

\section{Patients and oxygen measurements}

Biopsies were obtained from a previously described group of uterine cervix cancer patients enrolled in a single institutional prospective study (36). Written informed consent was obtained from each participant prior to study entry and the Research Ethics Board at the Princess Margaret Cancer Centre approved the trial. The clinical characteristics of the group of patients with LAMP3 protein expression (IHC) are found in supplementary table 1 . The first date of treatment in this group was 25 January 2000 and the last 25 April 2007. The median follow-up is 5.9 years (range 0.8 - 10.6).

\section{Statistical analysis}

Unless stated otherwise, Student t-test or one-way ANOVA with Bonferroni's post test was used to test significance of differences in numerical data. Twosided $p$-values of less than 0.05 were considered statistically significant.

\section{Results}

\section{Generation of an isogenic inducible PERK signaling defective cervical cancer xenograft model}

To address the functional importance of UPR signaling in hypoxia-induced metastasis, we introduced and validated a single flippase recombination target site together with a tetracycline repressor into the genome of the ME180 cervical carcinoma cell line. This approach allows rapid development of tetracycline/doxycycline inducible isogenic sublines with transgene expression from a single genomic integration. To test the functionality of our cell model, we inserted a doxycycline-regulated eGFP reporter gene into the flippase recombination target site. Addition of doxycycline resulted in strong induction of eGFP expression in vitro (figure 1A) and in vivo when administered continu- 
A

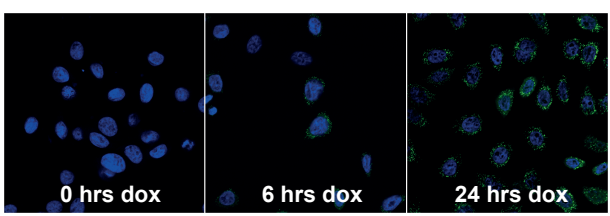

B

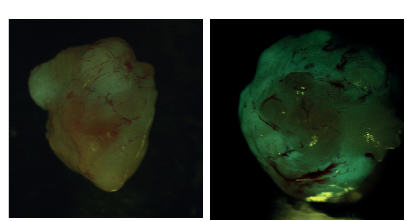

(-)dox

$(+)$ dox
C

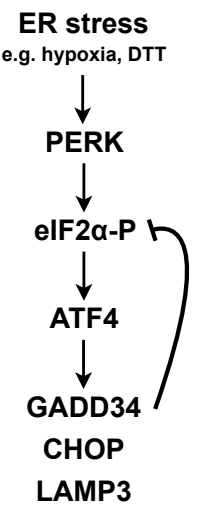

D

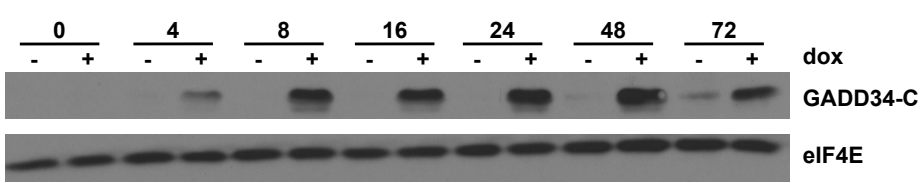

E

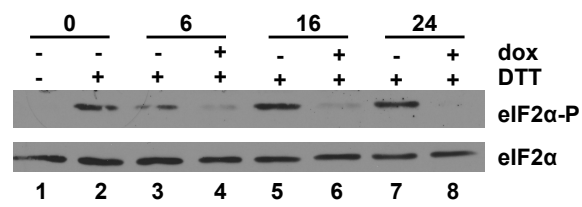

$\mathbf{F}$

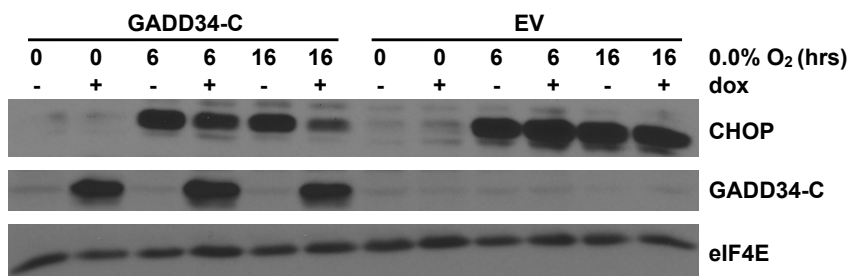

G

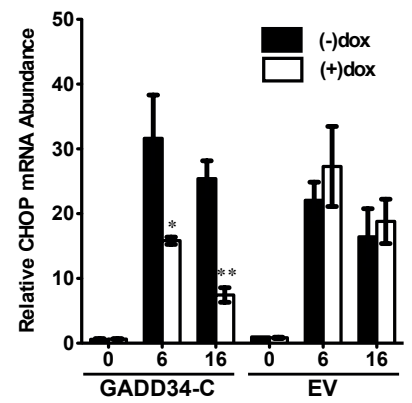

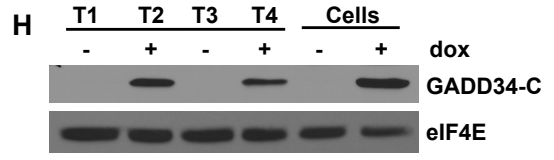

Figure 1. A doxycycline-regulated ME180 cervix carcinoma cell line with inducible expression of the GADD34 protein. A) EGFP fluorescence in ME180 cells expressing a doxycyclineinducible eGFP reporter gene. Shown are fluorescence microscopy images following 0, 24 and 48 hours of doxycycline incubation $(1 \mu \mathrm{g} / \mathrm{ml})$. B) EGFP expression in orthotopic xenografts established from cells in (A). Doxycycline was administered to tumor-bearing mice in water (2 $\mathrm{g} / \mathrm{L}$ ) for a total period of two weeks. EGFP expression was evaluated under a fluorescent stereomicroscope. C) The PERK/eIF2 $\alpha / \mathrm{ATF} 4$ arm of the UPR. D) Induction kinetics of 
doxycycline regulated expression of the hamster GADD34 C-terminus region in ME180GADD34-C cells. Levels of protein expression were measured by immunoblotting in cells grown in the presence or absence of doxycycline for the indicated periods of time. EIF4E was used as a loading control. E) DTT-induced phosphorylation of eIF2 $\alpha$ was assessed by immunoblotting in ME180-GADD34-C cells pre-exposed to $0,6,16$ or 24 hours of doxycycline. Total eIF2 $\alpha$ protein levels were used as loading control. F+G) ME180-GADD34-C and EV control (EV) cells were preincubated with doxycycline for 72 hours (+dox) or left untreated (-dox), and subsequently exposed to 0,6 or 16 hours of anoxia. CHOP protein (F) and mRNA (G) expression was measured by immunoblotting and qRT-PCR, respectively. Mean and SEM of three independent experiments is shown. (two-way ANOVA, $\mathrm{p}<0.05, * * \mathrm{p}<0.005$, (-)dox EV vs rest) H) GADD34 transgene protein expression was assessed in four different intramuscularly grown ME180GADD34-C derived xenografts (T1-T4) following a 7-day administration of doxycycline to the animals.

ously to animals for two weeks (figure 1B). Importantly, we confirmed that the potential of the ME180 cell line to spread to the local pelvic lymph nodes when grown orthotopically in the mouse uterine cervix was not altered by this genetic engineering (supplementary figure 1A-C). In addition, doxycycline treatment alone for two weeks had no effect on lymph node metastasis (supplementary figure 1D-F).

Next, we generated an ME180 subline that allows doxycycline-regulated expression of the highly conserved C-terminal region of the hamster GADD34 protein (referred to as ME180- GADD34-C). Overexpression of the C-terminus alone is more effective at inhibiting signaling through PERK/eIF2 $\alpha$ compared to the full-length protein (25). Using an antibody against the C-terminal region of the hamster GADD34 protein, we found that maximum induction of the transgene is reached after only 8 hours of exposure to doxycycline and persists for 48 hours (figure 1D). Dithiothreitol (DTT) is a highly potent ER stress inducing agent that functions to reduce protein disulfide bonds, causing accumulation of misfolded proteins and PERK-dependent inhibition of protein translation. Treatment of ME180-GADD34-C cells with DTT resulted in strong and rapid phosphorylation of eIF2 $\alpha$ (figure $1 \mathrm{E}$ lanes 2,3,5,7). However, eIF2 $\alpha$ phosphorylation was prevented in cells that had been exposed to doxycycline for 6,16 or 24 hours prior to DTT treatment to induce GADD34-C (figure 1E lanes 4,6,8). We tested the functionality of our expression system under conditions of hypoxic stress, by exposing ME180-GADD34-C and empty vector control cells to $0.0 \% \mathrm{O}_{2}$ and monitoring the expression of the ATF4 target gene CHOP. In doxycycline-free cells, we observed an early and strong induction of both CHOP protein (figure 1F) and mRNA (figure $1 \mathrm{G}$ ). However, CHOP expression was strongly inhibited in cells pre-incubated with doxycycline for 72 hours. Importantly, expression of the GADD34 transgene was also detectable in tumor xenografts at comparable levels to that of cell lines in vitro, in mice that received doxycycline for 7 days (figure $1 \mathrm{H}$ ). 


\section{Disruption of UPR signaling inhibits hypoxia-induced lymph node metastasis}

The metastatic potential of ME180 cells with intact versus defective PERK signaling, was tested by implanting ME180-GADD34-C xenografts orthotopically and allowing them to establish for eight days before expressing the GADD34 transgene with doxycycline. This approach eliminates confounding effects of the transgene on primary tumor establishment, which is influenced by PERK (20). Starting on day 9, tumor bearing mice were exposed daily to a cycling hypoxia regimen previously shown to increase lymph node metastasis in this model (13) (figure 2A). As observed previously, doxycyclinenaive tumors (with a functional PERK pathway) from hypoxia-treated animals were noticeably smaller compared to sham-treated mice (figure $2 \mathrm{~B}$; compare -dox sham and -dox hypoxia) $(13,37)$. Doxycycline induced disruption of UPR signaling also reduced primary tumor size (compare -dox and + dox sham), but adding doxycycline to the hypoxia group did not further affect tumor size.

These primary cervix tumors spread to the local pelvic lymph node chain, which consists of a total of eight lymph nodes, aligned in four pairs. We observed the previously described increase in the total number of colonized lymph nodes per animal following exposure to hypoxia treatment (figure 2C; compare -dox sham and -dox hypoxia). Importantly, inhibition of PERK signaling prevented the hypoxia-induced increase in metastasis to the lymph nodes (compare +dox sham and +dox hypoxia). In order to account for the location of the involved nodes, we assigned different weights to the four lymph node pairs based on their distance from the primary tumor and calculated a metastatic score for each animal. Pair one and pair two were given an equal weight because they are located at a similar distance from the primary tumor and colonization of pair one has been shown to be independent of the hypoxia treatment (24). Similar to the effect on the total number of metastatic nodes, disruption of PERK signaling significantly decreased the metastatic score in hypoxia treated animals, indicating diminished colonization of the more distant lymph node pairs (figure 2D). In fact, even in animals that were exposed to standard laboratory air only, doxycycline-mediated disruption of PERK signaling significantly reduced the metastatic score (compare -dox and +dox sham). Together these results indicate that in this animal model of cervical carcinoma the PERK/eIF $2 \alpha$ arm of the UPR is required for primary tumor growth as well as hypoxia-induced nodal metastasis. 
A

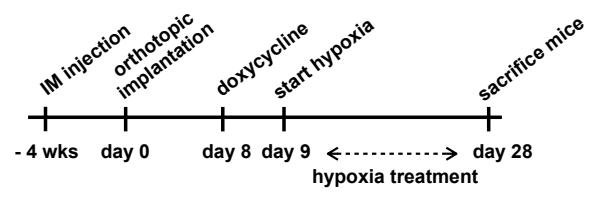

C

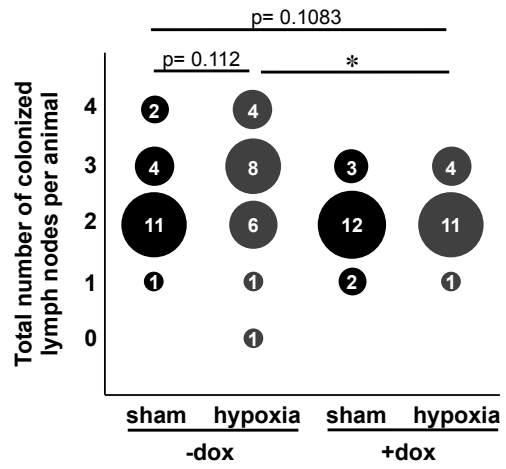

B

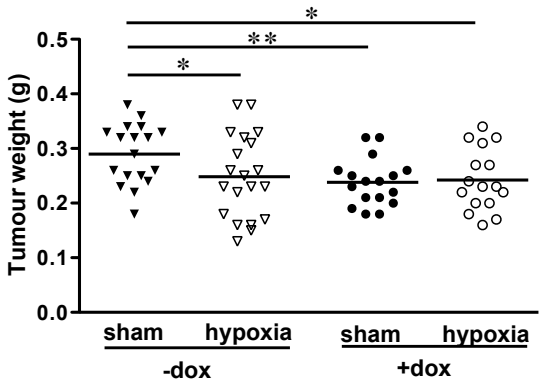

D

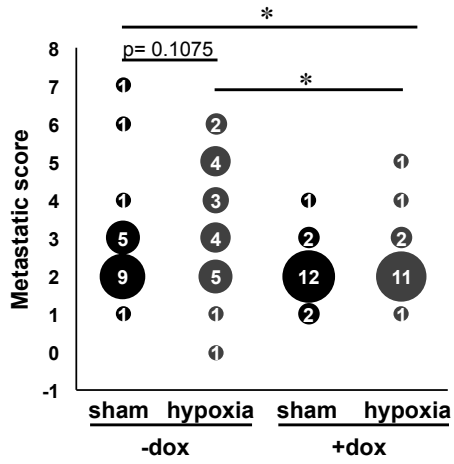

Figure 2. Inhibition of UPR signaling suppresses hypoxia-induced lymph node metastasis. A) Timeline metastasis assay. Cervical tumors were initiated by orthotopic implantation of fragments derived from several different intramuscular ME180-GADD34-C tumors. B) Size orthotopic xenografts. The cervix tumors were excised and weighted at the end of the experiment (day 28). Each symbol represents a tumor from one animal. Horizontal lines represent the mean values for each group. Animals carrying tumors 2 standard deviations above or below group mean were excluded from analysis because of positive correlation between primary tumor size and lymph node metastasis (13). (Unpaired Student t-test, one-tailed *p $<0.05, * * p<0.005$ ) C) On the yaxis is shown the total number of colonized lymph nodes in each animal (out of a total of eight). The size of the circle represents the number of animals (labeled in the center). D) On the y-axis is shown metastatic scores. The metastatic score for each animal was calculated using the formula: $(\mathrm{p} 1 * 1)+(\mathrm{p} 2 * 1)+(\mathrm{p} 3 * 2)+(\mathrm{p} 4 * 3)$ where $\mathrm{p} 1$ is the number of involved nodes for lymph node pair 1 , p2 is the number of involved nodes for lymph node pair 2 etc. The size of the circle represents the number of animals (labeled in the center). (Mann Whitney test, one-tailed $* \mathrm{p}<0.05$ ).

\section{UPR target gene LAMP3 promotes hypoxia-induced lymph node metastasis}

We recently demonstrated that LAMP3, a protein previously implicated in cervical cancer metastasis, is induced by hypoxia in a PERK/eIF2 $\alpha /$ ATF4 dependent manner (33). To assess the contribution of LAMP3 to lymph node metastasis, we stably expressed a shRNA to knockdown expression of LAMP3 in ME180 cells and showed that it fully abrogated the hypoxia-induced increase in mRNA and protein (supplementary figure 2 and figure 3A, respectively). Xenografts established from the LAMP3 knockdown cells also showed a 
marked reduction in LAMP3 protein expression compared to empty vector controls (figure 3B).

Mice with orthotopic ME180 empty vector control and LAMP3 knockdown xenografts were exposed to the hypoxia regimen and assessed for primary tumor growth and metastasis to the pelvic lymph nodes. As expected, both the LAMP3 knockdown and empty vector control tumors were considerably smaller in the hypoxia treatment group compared with sham-treated controls (figure 3C). In contrast to disruption of PERK signaling (figure 2), knockdown of LAMP3 resulted in a trend towards somewhat larger primary tumors in the sham treated group (figure 3C; compare EV and shLAMP3 sham). With respect to metastasis, the hypoxia treatment regimen resulted in an increase in metastasis in the animals bearing empty vector control tumors, as expected (figure 3D; compare EV sham and EV hypoxia). However, in mice with LAMP3 knockdown tumors, hypoxia treatment failed to increase metastasis and instead resulted in a trend towards fewer colonized nodes (compare shLAMP3 sham and shLAMP3 hypoxia). Thus, despite the fact that the shLAMP3 primary tumors were somewhat larger on average, they did not exhibit any measurable hypoxia-induced metastasis. A similar effect was observed when assessing metastatic score (figure 3E). The results from this experiment suggest that signaling through the UPR promotes hypoxia-mediated metastasis in part through induction of LAMP3. 
A

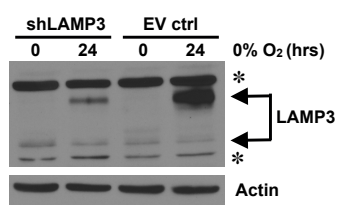

C

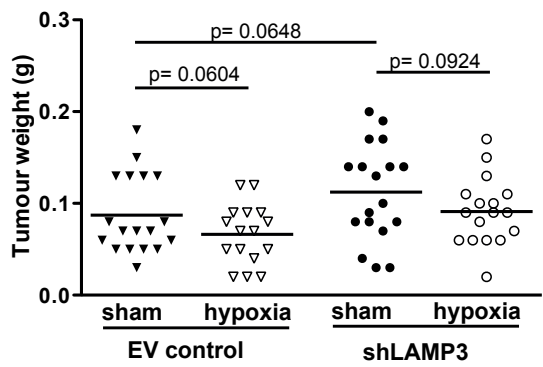

D

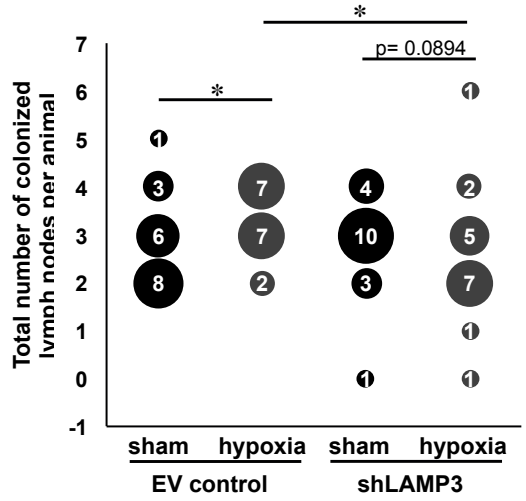

B

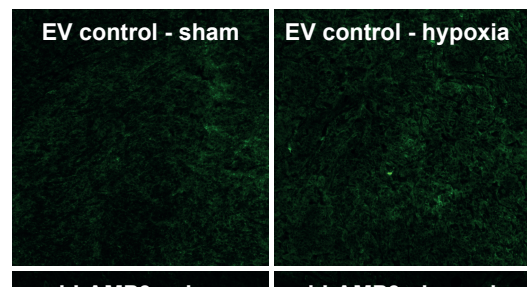

ShLAMP3 - sham

shLAMP3 - hypoxia

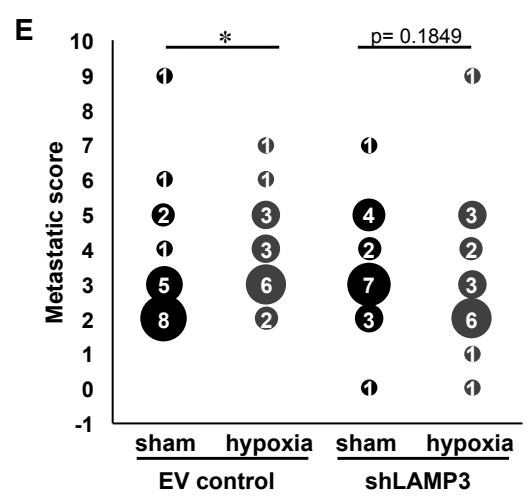

Figure 3. Knockdown of LAMP3 inhibits hypoxia-induced lymph node metastasis. A) LAMP3 protein levels in stable LAMP3 knockdown cells (shLAMP3) and empty vector control cells (EV control) exposed to 24 hours of anoxia. Asterisks indicate non-specific protein bands. B) LAMP3 protein expression was assessed by immunofluorescence staining in LAMP3 knockdown and empty vector control tumors. C) Size of the orthotopic tumors at the end of the experiment, 25 days post orthotopic implantation. Each symbol represents a tumor from one animal. Horizontal lines represent the mean values for each group. Animals carrying tumors $\leq 0.01$ grams and/or 2 standard deviations above or below group mean were excluded from analysis because of positive correlation between primary tumor size and lymph node metastasis (13). (Unpaired Student t-test, one-tailed) D) On the y-axis is shown the total number of colonized lymph nodes in each animal (out of a total of eight). The size of the circle represents the number of animals (labeled in the center). E) On the y-axis is shown metastatic scores. The metastatic score for each animal was calculated using the formula: $(\mathrm{p} 1 * 1)+(\mathrm{p} 2 * 1)+(\mathrm{p} 3 * 2)+(\mathrm{p} 4 * 3)$ where $\mathrm{p} 1$ is the number of involved nodes for lymph node pair 1, p2 is the number of involved nodes for lymph node pair 2 etc. The size of the circle represents the number of animals (labeled in the center). (Mann Whitney test, one-tailed $\left.{ }^{*} \mathrm{p}<0.05\right)$. 


\section{Activation of the PERK/eIF2 $\alpha$ arm of the UPR promotes hypoxia tolerance}

The potential mechanisms contributing to the defect in hypoxia-induced metastasis were investigated by characterizing the microenvironments of the orthotopic xenografts using immunohistochemistry (IHC) for blood vessel content and hypoxia. Although PERK signaling has been reported to regulate angiogenesis (21) we found no differences in vessel content or perfusion in the PERK signaling deficient tumors exposed to sham treatment or to hypoxia (figure 4A and supplementary figure 3). Several studies have shown that activation of the PERK/eIF2 $\alpha /$ ATF4 arm of the UPR increases hypoxia tolerance of cells and consequently promotes higher levels of tumor hypoxia $(20,26)$. The fact that the GADD34 tumors were smaller than controls is consistent with these observations (figure $2 \mathrm{~B}$; compare -dox and + dox sham). In order to directly test the contribution of PERK signaling on hypoxia tolerance we conducted clonogenic assays under hypoxia in dox treated and untreated cells in vitro. Figure 4B shows that ME180-GADD34-C cells are indeed significantly more sensitive to anoxia induced cell death following doxycycline. However, the fraction of hypoxic tumor cells as assessed by EF5 staining in vivo was not significantly different between tumors with intact versus inhibited PERK signaling (figure 4C). Thus, it is clear that although PERK deficient cells are more sensitive to hypoxia-induced cell death, differences in the proportion of viable hypoxic cells in the primary tumor cannot account alone for the loss of metastasis in the PERK signaling deficient group.

\section{LAMP3 influences migration of hypoxic cells}

Characterization of the microenvironment of sham and hypoxia treated tumors also demonstrated no measurable difference in angiogenesis in the control versus LAMP3 knockdown tumors (supplementary figure 4). LAMP3 deficient tumors did have a slightly larger hypoxic fraction compared to empty vector control tumors (supplementary figure 5A), although this finding can be accounted for based on a strong relationship between primary tumor size and hypoxic fraction (supplementary figure 5B). Unlike the PERK deficient cells, LAMP3 knockdown and empty vector controls showed a comparable sensitivity to hypoxia-induced cell death in in vitro as assessed by clonogenic survival (figure 4D). These data suggest that LAMP3 does not promote hypoxia-induced metastasis through regulation of angiogenesis and/or hypoxia tolerance.

The role of LAMP3 in hypoxia-induced cell migration and invasion was investigated by measuring cell migration under both normoxic $\left(21 \% \mathrm{O}_{2}\right)$ and hypoxic $\left(1 \% \mathrm{O}_{2}\right)$ conditions in LAMP3 deficient and empty vector control cells using in vitro transwell migration assay. The two cell lines showed similar migratory capacity during normoxia (figure 4E). However, hypoxia exposure significantly enhanced migration of empty vector control cells, whereas migra- 
A

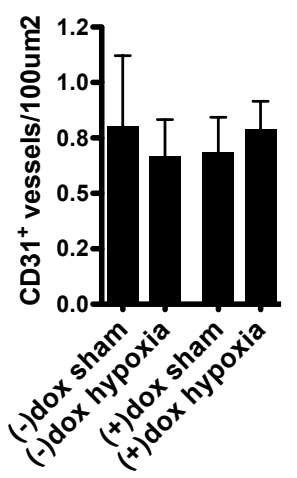

C

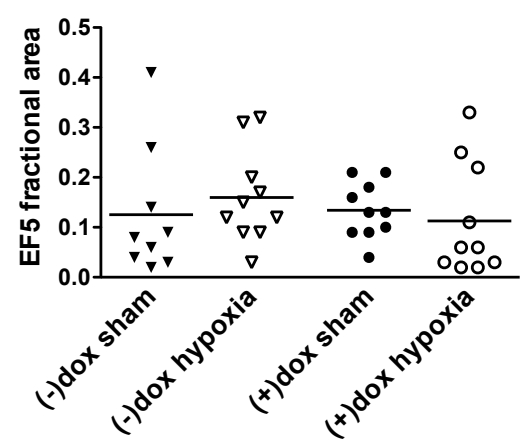

D

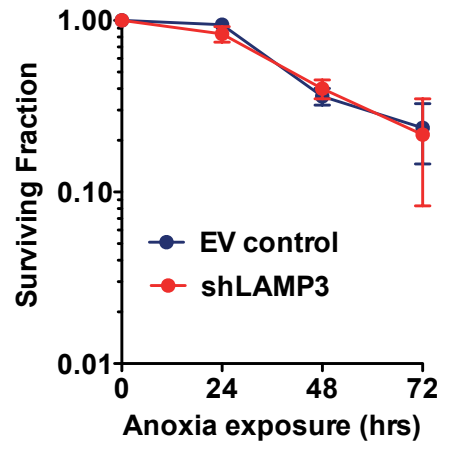

F

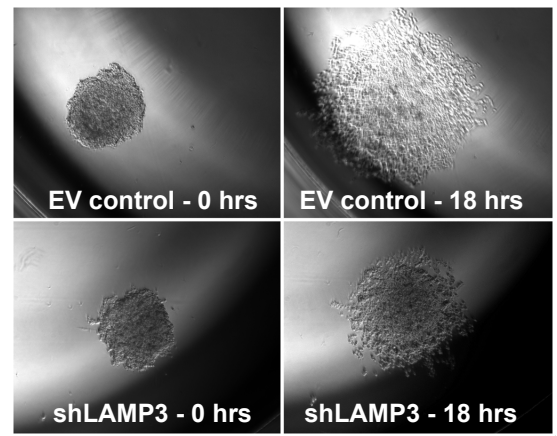

B
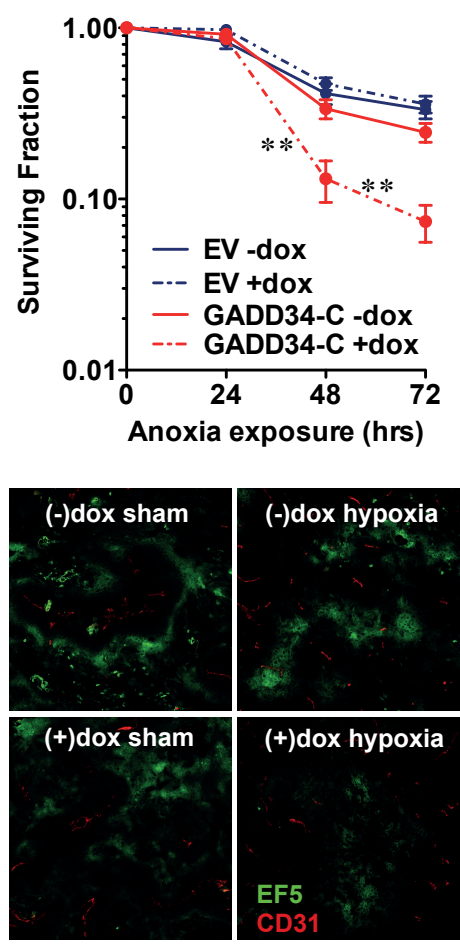

E
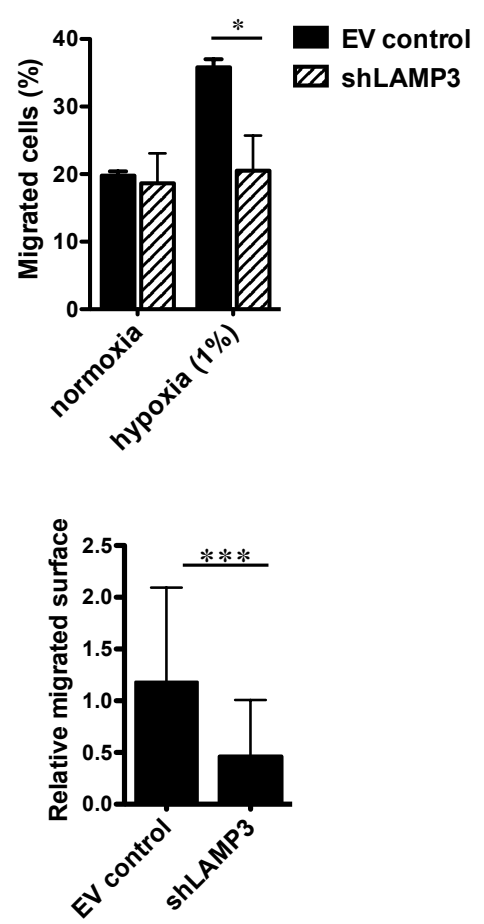
Figure 4. Activation of the PERK/eIF2 $\alpha$ arm of the UPR promotes hypoxia tolerance and cell migration and invasion through LAMP3. A) The microvessel density of ME180-GADD34-C orthotopic xenografts was evaluated by immunofluorescence staining (CD31). Bars represent the mean of ten tumors. Error bars depict SD. B) Clonogenic survival ME180-GADD34-C and empty vector control $(\mathrm{EV})$ cells after exposure to anoxia in the presence or absence of doxycycline. Mean and SEM of three independent experiments is shown. (one-way ANOVA, ${ }^{* *} \mathrm{p}<0.005$, ()dox EV vs rest) C) Fraction EF5 labeled tumor area (left) Horizontal lines represent the mean values for each group. Right: dual immunofluorescence labeling for hypoxia (EF5, green) and vessels (CD31, red). D) Clonogenic survival shLAMP3 and empty vector control cells in response to anoxic exposure. Mean and SEM of three independent experiments is shown. E) Transwell migration assay. Migration of shLAMP3 and empty vector control cells was monitored during both normoxic and hypoxic (1\% oxygen) conditions. Mean and SD of two independent experiments is shown. (two-way ANOVA *p < 0.05) F) 3D spheroid migration assay. Left: representative images of shLAMP3 and empty vector control spheroids. Right: The area covered by migrating cells during a period of 18 hours. Mean and SD of two independent experiments is shown. (Unpaired Student t-test $* * * \mathrm{p}<0.0001$ )

tion of the LAMP3 knockdown cells was unaffected. Cell motility was also evaluated in these cells using a 3D spheroid migration assay. Multicellular spheroid cultures grown in a $3 \mathrm{D}$ environment are characterized by a necrotic core surrounded by viable hypoxic cells and thus mimic some of the properties of cells grown in vivo. We observed that migration of cells out of the spheroids was strongly reduced by LAMP3 knockdown (figure 4F), reflecting impaired motility of the hypoxic LAMP3 deficient cells. Taken together, out results are consistent with a model where LAMP3 promotes metastasis during hypoxia by promoting cancer cell migration.

\section{LAMP3 expression correlates with the degree of hypoxia in human cervix tumors}

To evaluate the potential clinical relevance of these results we investigated whether hypoxia influences LAMP3 in patients with cervical cancer, where hypoxia has previously been shown to influence overall survival through metastasis $(5,7)$. LAMP3 expression was therefore determined in a set of cervical carcinoma patient samples obtained from clinical trials at the Princess Margaret Cancer Centre (Toronto) in which patient tumors had been assessed for hypoxia with oxygen needle electrodes prior to treatment. However, since cervical carcinoma is one of the cancer types where gene amplification of LAMP3 has been reported (38), we also first determined LAMP3 gene copy numbers using FISH analysis. This allowed us to distinguish between hypoxiainduced LAMP3 expression and enhanced LAMP3 expression associated with gene amplification. Similar to previously reported results in cervical cancer, elevated LAMP3 gene copy number was observed in $38 \%$ of all cases (figure 5A). A strong relationship was also observed between copy number alteration and both LAMP3 protein and mRNA expression levels (supplementary figure 
$6 \mathrm{~A}$ and $6 \mathrm{~B}$, respectively). No LAMP3 copy number aberrations were identified in normal cervix tissue (supplementary figure 6C).

A
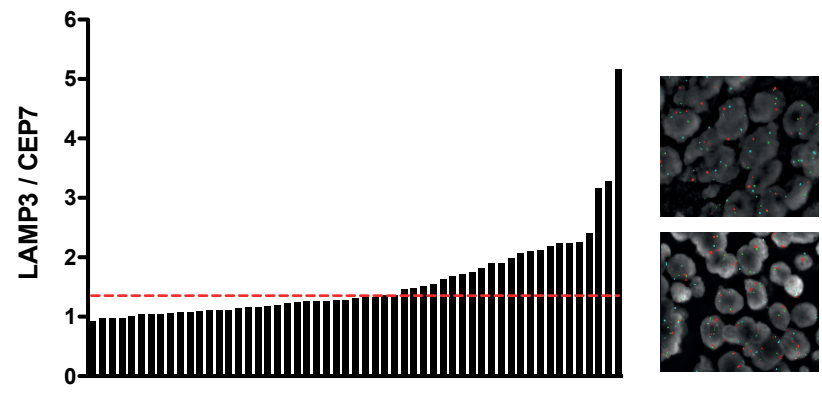

red $=$ LAMP3

aqua $=$ CEP7

green $=$ CEP3

B
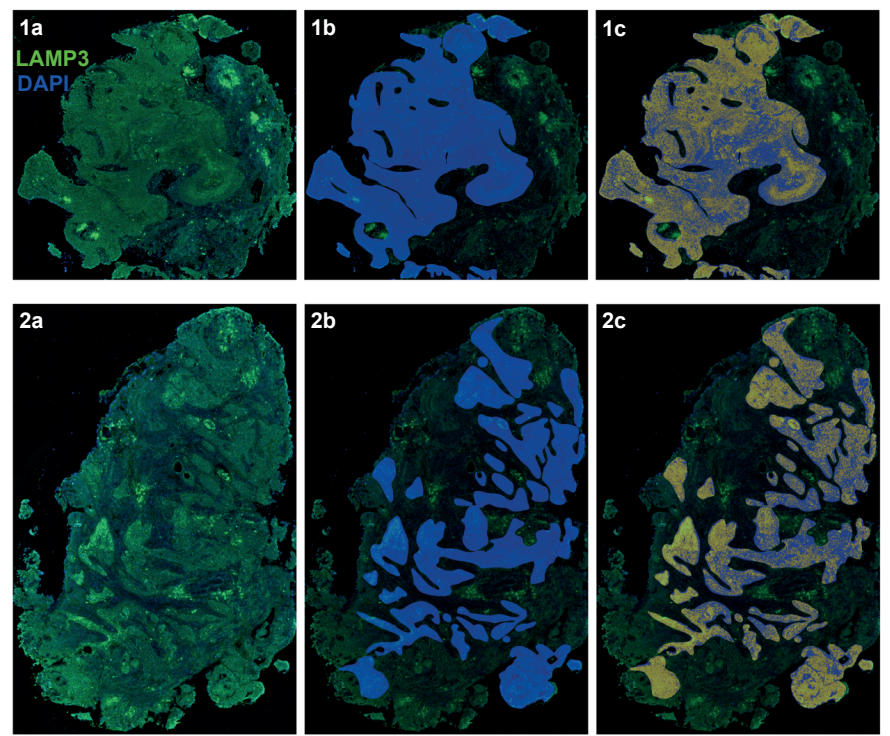

C
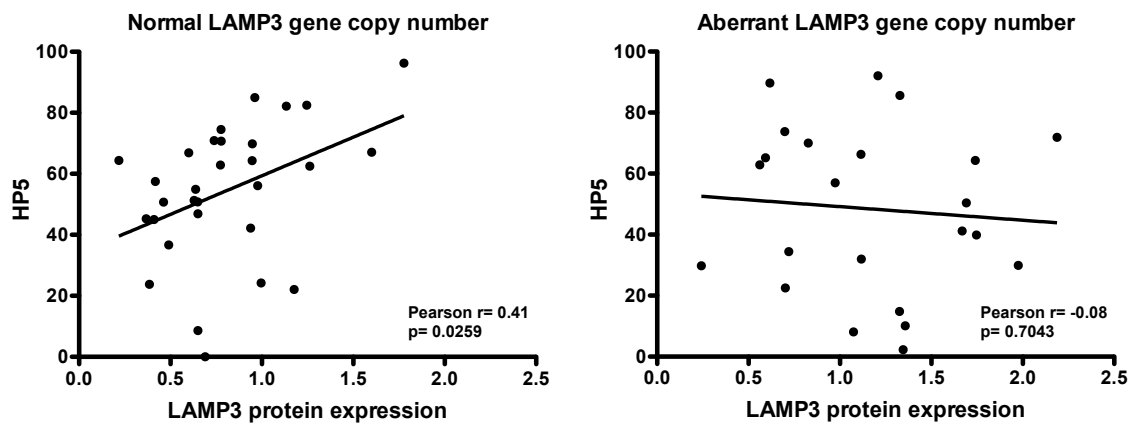

Figure 5. LAMP3 expression correlates with the degree of hypoxia in human cervix tumors. A) Left: waterfall plot of LAMP3/CEP7 ratios measured in human cervical cancer biopsies. Dashed line represents the cut-off between normal and aberrant LAMP3 gene copy numbers. Right: 
representative images of cases with normal (top) and amplified (bottom) LAMP3 copy numbers. LAMP3 = red signal, CEP7 = aqua, CEP3 = green. B) LAMP3 protein expression quantification exemplified in two human cervix tumors. Panels 1a and 2a: immunofluorescence staining of total biopsy sections for LAMP3 (green, unthresholded signal), overlaid with DAPI signal (blue); panels $1 \mathrm{~b}$ and $2 \mathrm{~b}$ : viable tumor areas within sections indicated in blue; panels $1 \mathrm{c}$ and $2 \mathrm{c}$ : LAMP3 (thresholded signal) within viable tumor areas. C) Scatter plots of HP5 values and LAMP3 expression in patients with normal (LAMP3/CEP7 $<1.5$ - left) and aberrant (LAMP3/CEP7 $\geq 1.5$ right) LAMP3 gene copy numbers. A straight line was fitted through the data. (Pearson correlation test)

Using quantitative immunofluorescence, LAMP3 protein expression was then measured within tumor areas (excluding stroma) of the biopsies (figure 5B). Tumor-infiltrating, LAMP3-positive, mature dendritic cells were also excluded from the analysis. As reported earlier (33), LAMP3 staining intensity was highly heterogeneous and the protein was found primarily on the cell membrane. Importantly, in patients with normal LAMP3 copy numbers a positive and significant association between hypoxia (HP5) and LAMP3 expression was observed (figure 5C and table 1) whereas no such correlation was seen in the amplified subset. These data indicate that LAMP3 expression in cervical cancer is induced through both genetic means as well as by hypoxia. A subgroup analysis showed a positive relationship between LAMP3 expression and clinical stage at diagnosis, but again only in patients with normal copy numbers (table 2) indicating that, like hypoxia, LAMP3 is associated with more advanced disease.

Table 1. Relationship LAMP3 expression and continuous clinical parameters

\begin{tabular}{lccccc}
\hline & \multicolumn{2}{c}{ LAMP3/CEP7 $<1.5$} & & \multicolumn{2}{c}{ LAMP3/CEP7 $\geq 1.5$} \\
\cline { 2 - 3 } \cline { 5 - 6 } \cline { 5 - 6 } & Spearman $r$ & $p$-value & & Spearman $r$ & $p$-value \\
\hline Age & 0.15 & 0.39 & & -0.29 & 0.2 \\
Tumour size & -0.075 & 0.67 & & -0.014 & 0.95 \\
Hemoglobin & -0.092 & 0.6 & & 0.13 & 0.62 \\
IFP & 0.15 & 0.39 & & -0.27 & 0.24 \\
HP5 & 0.39 & 0.024 & & -0.16 & 0.48 \\
\hline
\end{tabular}


Table 2. Relationship LAMP3 expression and categorical clinical parameters

\begin{tabular}{|c|c|c|c|c|c|c|c|c|c|c|}
\hline & \multicolumn{5}{|c|}{ LAMP3/CEP7 $<1.5$} & \multicolumn{5}{|c|}{ LAMP3/CEP7 $\geq 1.5$} \\
\hline & $\min$ & median & $\max$ & Wald & $p$-value & $\min$ & median & $\max$ & Wald & p-value \\
\hline \multicolumn{11}{|l|}{ FIGO stage } \\
\hline stage $1 \mathrm{~B}$ & 0.2199 & 0.6458 & 1.083 & & & 0.5674 & 0.7075 & 1.127 & & \\
\hline stage 2 & 0.3873 & 0.9562 & 1.617 & & & 0.2431 & 1.37 & 2.21 & & \\
\hline stage $3+$ & 0.6341 & 0.8736 & 1.795 & 0.177 & 0.0344 & 0.5988 & 0.9826 & 1.996 & 0.202 & 0.244 \\
\hline \multicolumn{11}{|l|}{ Grade } \\
\hline PD & 0.6053 & 0.8769 & 1.275 & & & 0.2431 & 0.9267 & 1.357 & & \\
\hline WD/MD & 0.2199 & 0.6567 & 1.795 & -0.0834 & 0.56 & 0.5674 & 1.338 & 2.21 & 0.345 & 0.195 \\
\hline \multicolumn{11}{|c|}{ Overall node } \\
\hline negative & 0.2199 & 0.7004 & 1.617 & & & 0.2431 & 1.127 & 2.21 & & \\
\hline positive & 0.3696 & 0.8769 & 1.795 & -0.0722 & 0.59 & 0.6219 & 1.221 & 1.766 & -0.0424 & 0.869 \\
\hline
\end{tabular}

\section{Discussion}

Using a xenograft model of hypoxia-driven metastatic cervix carcinoma and a human cervix cancer cell line with doxycycline-controlled expression of GADD34, we have demonstrated that the PERK/eIF2 $\alpha /$ ATF4 arm of the UPR promotes hypoxia-induced metastasis. Doxycycline-induced overexpression of the C-terminal region of the GADD34 protein, a negative regulator of PERK/eIF2 $\alpha /$ ATF4 signaling, resulted in complete inhibition of hypoxia-driven lymph node metastasis. More importantly, inhibition of UPR signaling significantly reduced nodal metastasis in animals that were not exposed to the in vivo hypoxia treatment. We have presented evidence for two different contributions of this pathway to hypoxia-induced metastasis. The first is through a direct influence on the tolerance of cells to hypoxia, since overexpression of GADD34 markedly reduced cell survival in cells exposed to hypoxia in vitro and also impaired tumor growth in vivo. These data are consistent with other reports demonstrating that the UPR pathway is an important mediator of hypoxia tolerance and tumor growth by affecting cellular processes that include autophagy, angiogenesis and $\mathrm{pH}$ regulation $(19-21,26$, 39). Tumor cells with a higher hypoxia tolerance, by definition, have a higher probability to escape the primary tumor and survive in an avascular metastatic site regardless of how or when they acquire other metastatic phenotypes. However, tolerance mechanisms cannot alone account for the PERK contribution to hypoxia-induced metastasis in our model. We did not observe significant differences in overall levels of hypoxia in the PERK signaling proficient and deficient tumors at the end of the hypoxia treatment schedule. Instead, our data indicate that PERK/eIF2a regulation of LAMP3 is a key driver of both the migratory phenotype and development of lymph node metastases in 
response to hypoxia. Silencing LAMP3 caused no reduction in hypoxia tolerance in vitro, hypoxic fraction in vivo, or primary tumor size, but did effectively inhibit hypoxia-induced metastasis in vivo and hypoxia-induced migration in two different in vitro models. Interestingly, knockdown of VEGF$\mathrm{C}$ signaling also achieves a reduction in hypoxia-induced metastasis in this model (37). Thus, it is clear that multiple pathways are likely contributing and required to observe increased metastasis in response to hypoxia.

LAMP3 and its functional role in cancer has not been investigated in much detail. LAMP3 and other LAMP family members are lysosomal membrane glycoproteins characterized by a long luminal domain containing multiple Oand N-linked glycosylation sites as well as several disulfide bonds, a transmembrane domain and a short cytoplasmic tail (40). Cell surface expression of LAMPs is often observed in cancer cells and has been shown to correlate with the metastatic ability of colon carcinoma cell lines (41). We identified LAMP3 as a hypoxia responsive gene regulated by PERK/eIF2 $\alpha$ signaling and showed that it is also found on the cell surface (33) We also showed that LAMP3 is overexpressed in breast cancer (33) and moreover that it is an independent prognostic factor for locoregional control in a subgroup of patients treated with radiotherapy (42). However, the biological function of LAMP3 in migration and metastasis in tumor cells is not understood. LAMP1 was shown to be required for proper formation of membrane ruffles and filopodia in migrating tumor cells (43) and it is possible that LAMP3 exerts a similar function in response to hypoxia. A role for LAMP3 in cell-cell adhesion has also been proposed since it is a highly glycosylated protein that is often localized to the cell surface of tumor cells $(40,44)$ and other LAMP family members have already been implicated in cell adhesion (45). By mediating binding to endothelial cells for example, LAMP3 might facilitate tumor cell extravasation.

Our findings are likely to translate into relevant mechanisms of poor prognosis in cervical cancer patients. Previous clinical studies have identified tumor hypoxia as an important predictor of metastasis in cervical cancer patients treated with surgery and/or radiotherapy $(5,7)$. This includes previously published results from an ongoing study assessing hypoxia in cervical cancer patients receiving radiotherapy at the Princess Margaret Cancer Centre in Toronto (7). In this study of 106 patients, hypoxia was shown to be a significant prognostic marker for overall survival in a multivariate model, and this effect was due primarily to differences in distant metastasis rather than local control. Here, we used biopsies from the same trial involving a similar group of cervix cancer patients. Our data show that in these patients, LAMP3 expression is regulated by both genetic gains/amplifications of LAMP3 and by tumor hypoxia. Similar to other studies in cervix cancer (38), approximately half of all patients showed copy number aberrations and this was associated with increased 
LAMP3 mRNA and protein expression. However, in the other half we found that hypoxia was strongly and significantly associated with LAMP3 expression. Although we did not have sufficient samples to investigate directly if LAMP3 expression was driving poor outcome in these patients, its direct association with hypoxia, which has been shown to drive poor outcome, strongly implicate LAMP 3 as a contributor to metastasis in these patients.

These data support accumulating evidence implicating ER stress responses as important contributors to aggressive hypoxic tumor biology $(19,26,39)$. This potential importance of ER stress responses in cancer has led to some attempts to identify and incorporate agents aimed at disrupting ER homeostasis either alone or in combination with conventional agents (26, 46-48). Our findings suggest that such agents are likely to be most effective when given in curative settings in combination with conventional therapy or with other agents that target well-oxygenated cells. This approach would produce synergy not only by targeting distinct populations of cells in the tumor, but also by targeting intrinsic mechanisms that enable the hypoxic cells to escape and colonize distant nodes or other organs.

\section{Acknowledgements}

The authors would like to thank Anthony Fyles, Michael Milosevic and Blaise Clarke for providing uterine cervix cancer TMA sections, and Trevor Do, Trudey Nicklee and Melanie Macasaet for advice and technical assistance on the immunohistochemical stainings in these and other tissue samples. We would also like to thank Olga Ludkovski for the FISH analysis, and Jenna Sykes for help with the statistical analysis. This work was financially supported by the Ontario Ministry of Health and Long Term Care (OMOHLTC), the Terry Fox New Frontiers Research Program (PPG09-020005 to BW and MK), the Ontario Institute for Cancer Research and Terry Fox Research Institute (Selective therapies program to $\mathrm{BW}$ ), the Canadian Institute for Health Research (CIHR grant 201592 to BW and MK and CIHR grant 102757 to RH), the Dutch Cancer Society (KWF grant UM 2008-4068 to BW), the transnationale Universiteit Limburg (TUL 30943099T to BW), the EU 7th framework program (METOXIA project 222741 to BW and MK) and the Terry Fox New Investigator awarded to MK The views expressed do not necessarily reflect those of the OMOHLT. 


\section{References}

1. Brizel DM, Sibley GS, Prosnitz LR, Scher RL, Dewhirst MW. Tumor hypoxia adversely affects the prognosis of carcinoma of the head and neck. International journal of radiation oncology, biology, physics. 1997;38:285-9.

2. Hockel M, Knoop C, Schlenger K, Vorndran B, Baussmann E, Mitze M, et al. Intratumoral pO2 predicts survival in advanced cancer of the uterine cervix. Radiother Oncol. 1993;26:45-50.

3. Nordsmark M, Overgaard J. A confirmatory prognostic study on oxygenation status and loco-regional control in advanced head and neck squamous cell carcinoma treated by radiation therapy. Radiother Oncol. 2000;57:39-43.

4. Brizel DM, Scully SP, Harrelson JM, Layfield LJ, Bean JM, Prosnitz LR, et al. Tumor oxygenation predicts for the likelihood of distant metastases in human soft tissue sarcoma. Cancer research. 1996;56:941-3.

5. Hockel M, Schlenger K, Aral B, Mitze M, Schaffer U, Vaupel P. Association between tumor hypoxia and malignant progression in advanced cancer of the uterine cervix. Cancer research. 1996;56:4509-15.

6. Pitson G, Fyles A, Milosevic M, Wylie J, Pintilie M, Hill R. Tumor size and oxygenation are independent predictors of nodal diseases in patients with cervix cancer. International journal of radiation oncology, biology, physics. 2001;51:699-703.

7. Fyles A, Milosevic M, Hedley D, Pintilie M, Levin W, Manchul L, et al. Tumor hypoxia has independent predictor impact only in patients with node-negative cervix cancer. J Clin Oncol. 2002;20:680-7.

8. Milosevic M, Warde P, Menard C, Chung P, Toi A, Ishkanian A, et al. Tumor hypoxia predicts biochemical failure following radiotherapy for clinically localized prostate cancer. Clin Cancer Res. 2012;18:2108-14.

9. Rofstad EK, Danielsen T. Hypoxia-induced metastasis of human melanoma cells: involvement of vascular endothelial growth factor-mediated angiogenesis. British journal of cancer. 1999;80:1697-707.

10. Stackpole CW, Groszek L, Kalbag SS. Benign-to-malignant B16 melanoma progression induced in two stages in vitro by exposure to hypoxia. Journal of the National Cancer Institute. 1994;86:361-7.

11. Young SD, Hill RP. Effects of reoxygenation on cells from hypoxic regions of solid tumors: anticancer drug sensitivity and metastatic potential. J Natl Cancer Inst. 1990;82:371-80.

12. Young SD, Marshall RS, Hill RP. Hypoxia induces DNA overreplication and enhances metastatic potential of murine tumor cells. Proceedings of the National Academy of Sciences of the United States of America. 1988;85:9533-7.

13. Cairns RA, Hill RP. Acute hypoxia enhances spontaneous lymph node metastasis in an orthotopic murine model of human cervical carcinoma. Cancer research. 2004;64:205461.

14. Cairns RA, Kalliomaki T, Hill RP. Acute (cyclic) hypoxia enhances spontaneous metastasis of KHT murine tumors. Cancer research. 2001;61:8903-8. 
15. Rofstad EK, Gaustad JV, Egeland TA, Mathiesen B, Galappathi K. Tumors exposed to acute cyclic hypoxic stress show enhanced angiogenesis, perfusion and metastatic dissemination. International journal of cancer. 2010;127:1535-46.

16. Harris AL. Hypoxia--a key regulatory factor in tumour growth. Nature reviews Cancer. 2002;2:38-47.

17. Blais JD, Filipenko V, Bi M, Harding HP, Ron D, Koumenis C, et al. Activating transcription factor 4 is translationally regulated by hypoxic stress. Molecular and cellular biology. 2004;24:7469-82.

18. Koumenis C, Naczki C, Koritzinsky M, Rastani S, Diehl A, Sonenberg N, et al. Regulation of protein synthesis by hypoxia via activation of the endoplasmic reticulum kinase PERK and phosphorylation of the translation initiation factor eIF2alpha. Molecular and cellular biology. 2002;22:7405-16.

19. Romero-Ramirez L, Cao H, Nelson D, Hammond E, Lee AH, Yoshida H, et al. XBP1 is essential for survival under hypoxic conditions and is required for tumor growth. Cancer research. 2004;64:5943-7.

20. Bi M, Naczki C, Koritzinsky M, Fels D, Blais J, Hu N, et al. ER stress-regulated translation increases tolerance to extreme hypoxia and promotes tumor growth. The EMBO journal. 2005;24:3470-81.

21. Blais JD, Addison CL, Edge R, Falls T, Zhao H, Wary K, et al. Perk-dependent translational regulation promotes tumor cell adaptation and angiogenesis in response to hypoxic stress. Molecular and cellular biology. 2006;26:9517-32.

22. Koritzinsky M, Rouschop KM, van den Beucken T, Magagnin MG, Savelkouls K, Lambin $\mathrm{P}$, et al. Phosphorylation of eIF2alpha is required for mRNA translation inhibition and survival during moderate hypoxia. Radiother Oncol. 2007;83:353-61.

23. Ameri K, Lewis CE, Raida M, Sowter H, Hai T, Harris AL. Anoxic induction of ATF-4 through HIF-1-independent pathways of protein stabilization in human cancer cells. Blood. 2004;103:1876-82.

24. Harding HP, Novoa I, Zhang Y, Zeng H, Wek R, Schapira M, et al. Regulated translation initiation controls stress-induced gene expression in mammalian cells. Molecular cell. 2000;6:1099-108.

25. Harding HP, Zhang Y, Zeng H, Novoa I, Lu PD, Calfon M, et al. An integrated stress response regulates amino acid metabolism and resistance to oxidative stress. Molecular cell. 2003;11:619-33.

26. Rouschop KM, van den Beucken T, Dubois L, Niessen H, Bussink J, Savelkouls K, et al. The unfolded protein response protects human tumor cells during hypoxia through regulation of the autophagy genes MAP1LC3B and ATG5. J Clin Invest. 2010;120:127-41.

27. Ma Y, Hendershot LM. Delineation of a negative feedback regulatory loop that controls protein translation during endoplasmic reticulum stress. J Biol Chem. 2003;278:34864-73.

28. Chan DA, Giaccia AJ. Hypoxia, gene expression, and metastasis. Cancer Metastasis Rev. 2007;26:333-9.

29. Lunt SJ, Chaudary N, Hill RP. The tumor microenvironment and metastatic disease. Clinical \& experimental metastasis. 2009;26:19-34.

30. Erler JT, Bennewith KL, Cox TR, Lang G, Bird D, Koong A, et al. Hypoxia-induced lysyl oxidase is a critical mediator of bone marrow cell recruitment to form the premetastatic niche. Cancer Cell. 2009;15:35-44. 
31. Yang MH, Wu MZ, Chiou SH, Chen PM, Chang SY, Liu CJ, et al. Direct regulation of TWIST by HIF-1alpha promotes metastasis. Nat Cell Biol. 2008;10:295-305.

32. Osinsky SP, Ganusevich, II, Bubnovskaya LN, Valkovskaya NV, Kovelskaya AV, Sergienko TK, et al. Hypoxia level and matrix metalloproteinases-2 and -9 activity in Lewis lung carcinoma: correlation with metastasis. Exp Oncol. 2005;27:202-5.

33. Mujcic H, Rzymski T, Rouschop KM, Koritzinsky M, Milani M, Harris AL, et al. Hypoxic activation of the unfolded protein response (UPR) induces expression of the metastasis-associated gene LAMP3. Radiother Oncol. 2009;92:450-9.

34. Kanao H, Enomoto T, Kimura T, Fujita M, Nakashima R, Ueda Y, et al. Overexpression of LAMP3/TSC403/DC-LAMP promotes metastasis in uterine cervical cancer. Cancer research. 2005;65:8640-5.

35. Novoa I, Zeng H, Harding HP, Ron D. Feedback inhibition of the unfolded protein response by GADD34-mediated dephosphorylation of eIF2alpha. The Journal of cell biology. 2001;153:1011-22.

36. Fyles A, Milosevic M, Pintilie M, Syed A, Levin W, Manchul L, et al. Long-term performance of interstial fluid pressure and hypoxia as prognostic factors in cervix cancer. Radiotherapy and oncology : journal of the European Society for Therapeutic Radiology and Oncology. 2006;80:132-7.

37. Wangsa D, Heselmeyer-Haddad K, Ried P, Eriksson E, Schaffer AA, Morrison LE, et al. Fluorescence in situ hybridization markers for prediction of cervical lymph node metastases. Am J Pathol. 2009;175:2637-45.

38. Cairns RA, Hill RP. A fluorescent orthotopic model of metastatic cervical carcinoma. Clinical \& experimental metastasis. 2004;21:275-81.

39. Chaudary N, Milosevic M, Hill RP. Suppression of vascular endothelial growth factor receptor 3 (VEGFR3) and vascular endothelial growth factor C (VEGFC) inhibits hypoxia-induced lymph node metastases in cervix cancer. Gynecologic oncology. 2011;123:393-400.

40. Rouschop KM, Dubois L, Keulers T, van den Beucken T, Lambin P, Bussink J, et al. PERK/eIF2 $\alpha$ signaling protects therapy resistant hypoxic cells through induction of glutathione synthesis and protection against ROS. Proceedings of the National Academy of Sciences of the United States of America. 2013:In press.

41. van den Beucken T, Ramaekers CH, Rouschop K, Koritzinsky M, Wouters BG. Deficient carbonic anhydrase 9 expression in UPR-impaired cells is associated with reduced survival in an acidic microenvironment. Radiother Oncol. 2009;92:437-42.

42. de Saint-Vis B, Vincent J, Vandenabeele S, Vanbervliet B, Pin JJ, Ait-Yahia S, et al. A novel lysosome-associated membrane glycoprotein, DC-LAMP, induced upon DC maturation, is transiently expressed in MHC class II compartment. Immunity. 1998;9:325-36.

43. Saitoh O, Wang WC, Lotan R, Fukuda M. Differential glycosylation and cell surface expression of lysosomal membrane glycoproteins in sublines of a human colon cancer exhibiting distinct metastatic potentials. The Journal of biological chemistry. 1992;267: 5700-11.

44. Nagelkerke A, Mujcic H, Bussink J, Wouters BG, van Laarhoven HW, Sweep FC, et al. Hypoxic regulation and prognostic value of LAMP3 expression in breast cancer. Cancer. 2011;117:3670-81. 
45. Garrigues J, Anderson J, Hellstrom KE, Hellstrom I. Anti-tumor antibody BR96 blocks cell migration and binds to a lysosomal membrane glycoprotein on cell surface microspikes and ruffled membranes. The Journal of cell biology. 1994;125:129-42.

46. Ozaki K, Nagata M, Suzuki M, Fujiwara T, Ueda K, Miyoshi Y, et al. Isolation and characterization of a novel human lung-specific gene homologous to lysosomal membrane glycoproteins 1 and 2: significantly increased expression in cancers of various tissues. Cancer research. 1998;58:3499-503.

47. Sawada R, Lowe JB, Fukuda M. E-selectin-dependent adhesion efficiency of colonic carcinoma cells is increased by genetic manipulation of their cell surface lysosomal membrane glycoprotein-1 expression levels. J Biol Chem. 1993;268:12675-81.

48. Feldman D. Irestatin, a potent inhibitor of IRE1 $\alpha$ and the unfolded protein response, is a hypoxia-selective cytotoxin and impairs tumor growth. Journal of Clinical Oncology, 2007 ASCO Annual Meeting Proceedings Part I. Vol 25, No. 18S (June 20 Supplement), 2007: 3514.

49. Davenport EL, Moore HE, Dunlop AS, Sharp SY, Workman P, Morgan GJ, et al. Heat shock protein inhibition is associated with activation of the unfolded protein response pathway in myeloma plasma cells. Blood. 2007;110:2641-9.

50. Obeng EA, Carlson LM, Gutman DM, Harrington WJ, Jr., Lee KP, Boise LH. Proteasome inhibitors induce a terminal unfolded protein response in multiple myeloma cells. Blood. 2006;107:4907-16. 


\title{
CHAPTER 6
}

\section{Hypoxic Regulation and Prognostic Value of LAMP3 Expression in Breast Cancer}

\author{
A. Nagelkerke \\ H. Mujcic \\ J. Bussink \\ B.G. Wouters \\ H.W.M. van Laarhoven \\ F.C.G.J. Sweep \\ P.N. Span
}

Cancer. 2011;(117):3670-3681. 


\begin{abstract}
Background and Purpose: LAMP3 is a newly described hypoxia regulated gene of potential interest in hypoxia-induced therapy resistance and metastasis. The prognostic value of LAMP3 in breast cancer was investigated.
\end{abstract}

Materials and Methods: Expression levels of LAMP3 in breast cancer cell lines and patient tissues were determined by real-time polymerase chain reaction and in a tissue microarray by immunohistochemistry. Immunofluorescent staining was used to evaluate the distribution of LAMP3 in tumor xenografts relative to pimonidazole. Kaplan-Meier analysis as well as multivariate Cox regression survival analyses were performed.

Results: LAMP3 was variably expressed in breast cancer cell lines and induced in an oxygen concentration-dependent manner. LAMP3 protein expression colocalized with hypoxic areas in breast cancer xenografts. LAMP3 mRNA was higher in breast tumors from patients with node-positive $(p=.019)$ and/or steroid hormone receptor-negative tumors $(\mathrm{p}<.001)$. Breast cancer patients with high LAMP3 mRNA levels had more locoregional recurrences $(\mathrm{p}=.032$ log-rank). This was limited to patients treated with lumpectomy and radiotherapy as primary treatment $(\mathrm{n}=53, \mathrm{p}=.009)$. No association with metastasis-free survival was found. In multivariate Cox regression analysis, LAMP3 remained as a statistically independent prognostic factor for locoregional recurrence (hazard ratio, 2.76; 95\% confidence interval, 1.01-7.5; $\mathrm{p}$ $=.048$ ) after correction for menopausal status, histologic grade, tumor size, nodal status, therapy, and steroid hormone receptor status. LAMP3 protein in breast cancer tissue proved also to be of prognostic relevance.

Conclusions: Evidence was provided for an association of LAMP3 with tumor cell hypoxia in breast cancer xenografts. In the current breast cancer cohorts, LAMP3 had independent prognostic value. 


\section{Introduction}

Lysosome-associated membrane protein 3 (LAMP3) was first identified in 1998 by two independent research groups. De Saint-Vis et al. named it DC-LAMP, a marker of mature dendritic cells (1) with a possible role in migration of dendritic cells from the periphery into lymph vessels (2), whereas Ozaki et al. described it as TSC403 with specific expression in the lung and overexpression in carcinomas of the breast, amongst others (3). Significant similarities of TSC403 with LAMP1 and LAMP2 were found (3). LAMPs are highly glycosylated type 1 integral membrane proteins, which reside in lysosomal membranes $(1,4)$. Their function is still largely unknown. In noncancerous cells, LAMP1 and LAMP2 are rarely expressed on the cell surface (5). However, in cancer cells their presence in the plasma membrane is frequently observed, with an increased incidence in more metastatic cell lines $(6,7)$. Experiments with overexpression of LAMP3 indicated similar characteristics for this protein: a strong association between LAMP3 and the promotion of metastatic potential was described both in vitro and in vivo (2). This suggests that LAMP3 expression might be related to metastasis. Indeed, high LAMP3 mRNA levels correlated significantly with poor prognosis in a small cohort of cervical cancers (2).

For several decades, hypoxia (oxygen deprivation) has been recognized as a hallmark of solid tumors. A low blood and oxygen supply to cancers complicates their (local) treatment. Hypoxia can decrease the effectiveness of both radiotherapy and chemotherapy and induce treatment resistance (8). Especially for radiotherapy, hypoxia poses problems, as oxygen is required for radiation to cause DNA damage (9). In addition, several studies have reported that less well-oxygenated tumors show a worse prognosis and a higher incidence of metastases compared with better oxygenated tumors (10-12). Hypoxia has therefore been linked to a more aggressive and metastatic tumor phenotype. Several hypoxia-regulated genes have been described that influence metastasis of tumors, including factors that enhance dissociation and migration of tumor cells (13). Recently, LAMP3 was shown to be regulated by hypoxia in a panel of tumor cells, via the unfolded protein response (UPR) (14). The UPR is a mechanism of adaptation to endoplasmic reticulum stress and has been demonstrated to contribute to hypoxic adaptation in tumors through multiple mechanisms (15). This adaptation may facilitate the survival of treatmentresistant hypoxic cells, leading to a poor prognosis of patients (16). Whether LAMP3 is associated with treatment resistance or metastasis in solid tumors is unknown. 
In this study, we investigated the correlation between hypoxia and LAMP3 expression in breast cancer xenografts and we assessed the prognostic value of LAMP3 mRNA and protein expression in breast cancer patients.

\section{Materials and Methods}

\section{Cell Culture}

MDA-MB-231 and SKBR-3 breast tumor cells were obtained from LGC Promochem (London, UK) and cultured at $37^{\circ} \mathrm{C}$ with $5 \% \mathrm{CO}_{2}$ in DMEM (Lonza, Biowhittaker, Walkersville, MD) supplemented with $10 \%(\mathrm{v} / \mathrm{v})$ heatinactivated fetal bovine serum (FBS), $10 \mathrm{U} / \mathrm{ml}$ penicillin, $10 \mu \mathrm{g} / \mathrm{ml}$ streptomycin, $2 \mathrm{mM}$ L-glutamine, $20 \mathrm{mM}$ Hepes (all from Invitrogen, Carlsbad, $\mathrm{CA}$ ), and $1 \mathrm{x}$ nonessential amino acids (NEAA, Promocell, Heidelberg, Germany). Cells were harvested and reseeded at 100\% confluence. cDNA from a panel of breast cancer cell lines $(n=16)$ was a gift from Dr. M. Schutte (Department of Medical Oncology, Josephine Nefkens Institute, Erasmus University Medical Center, Rotterdam, the Netherlands) $(17,18)$.

\section{Cell Culture in Hypoxic Conditions}

For culturing under hypoxic conditions, MDA-MB-231 cells were seeded at 300,000 cells per $10-\mathrm{cm}$ dish and were allowed to recover overnight. Hypoxia was induced using a H35 Hypoxystation (Don Whitley Scientific, Ltd, Shipley, UK), set at $0.5 \%, 0.2 \%$, or $0.1 \%$ oxygen. After incubation of up to 72 hours, cells were harvested.

\section{RNA Isolation}

RNA from hypoxic cultured cells was isolated using Norgen's total RNA purification kit (Norgen Biotek Corp, Thorold, Canada), according to the manufacturer's instructions with addition of an on-column DNase treatment. Isolated RNA was stored at $-80^{\circ} \mathrm{C}$ until further processing.

cDNA Synthesis and Quantitative Polymerase Chain Reactions ( $q P C R$ )

cDNA synthesis was performed by reverse transcribing $1 \mu \mathrm{g}$ of RNA using the Reverse Transcription System (Promega, Madison, WI) according to the manufacturer's instructions. The primers used for LAMP3 qPCR were FW: 5'TGAAAACAACCGATGTCCAA-3' and RV: 5'- TCAGACGAGCACTCATCCAC-3'.

mRNA expression was analyzed on a CFX96 real-time PCR detection system (Bio-Rad Laboratories Inc., Richmond, CA) using SYBR Green (Applied 
Biosystems, Foster City, CA). Hypoxanthine-guanine phosphoribosyl transferase (HPRT) was used as the reference gene, analyzed with a predeveloped assay (Applied Biosytems).

\section{Western Blot Analysis}

Cells were harvested in RIPA buffer ( $1 \%$ NP- $40,0.5 \%$ sodium desoxycholate and $0.1 \%$ sodium dodecylsulfate) to which phosphatase and protease inhibitors (Roche, Indianapolis, IN) were added. Protein concentrations were determined using the Pierce BCA assay (Thermo Fisher Scientific, Rockford, IL), after which $30 \mu \mathrm{g}$ of protein was fractionated on $12 \%$ Criterion XT Bis-Tris gels (Bio-Rad). After running, samples were transferred to PVDF membranes (Millipore Immobilon, Millipore, Bedford, MA) for 2 hours at $4^{\circ} \mathrm{C}$. After blocking with $4 \%$ nonfat dry milk (Bio-Rad), membranes were incubated overnight at $4{ }^{\circ} \mathrm{C}$ with rabbit-anti-human-LAMP3 $\operatorname{IgG}$ (AP1827a, $0.25 \mathrm{mg} / \mathrm{ml}$, Abgent, San Diego, CA) in a dilution of $1: 100$ or rabbit-anti-b-actin IgG (\#4970, Cell Signaling Technology, Beverly, MA) in a dilution of 1:1000, both diluted in 5\% (w/v) bovine serum albumin (Sigma-Aldrich, St. Louis, MO) in tris buffered saline (TBS) with $0.1 \%$ Tween-20 (w/v) (Sigma). Next, membranes were incubated for 1 hour at room temperature with horseradish peroxidase (HRP)-labeled goat-anti-rabbit immunoglobulin G (IgG; 1:2000, \#7074, Cell Signaling). Proteins were detected using chemiluminescent peroxidase substrate (Sigma) and imaged on a ChemiDoc XRSp imaging system (Bio-Rad).

\section{Growth of Breast Cancer Cell Xenografts}

Xenografts of breast cancer cells were grown on nu/nu BALB/c athymic mice, kept in a specific pathogen-free unit at the central animal facility of the Radboud University Nijmegen. All animal procedures were approved by the local ethics committee. In short, a cell suspension of MDA-MB-231 or SKBR-3 cells was diluted in Matrigel (BD Bioscience, Bedford, MA) 2:1 and injected subcutaneously (s.c.) into the flank of the mice. At an average tumor size of 8 $\mathrm{mm}$ to $9 \mathrm{~mm}$, mice were injected intraperitoneally (i.p.) with the hypoxic cell marker pimonidazole (1-[(2-hydroxy-3-piperi- dinyl)propyl]-2-nitroimidazole hydrochloride, Natural Pharmacia International Inc., Burlington, MA). One hour post-injection, mice were sacrificed, and tumors were harvested and immediately stored in liquid nitrogen until further processing.

\section{Immunohistochemistry}

Frozen 5 - $\mu \mathrm{m}$ tumor sections were fixed in acetone for 10 minutes at $4{ }^{\circ} \mathrm{C}$, after which they were rehydrated for 30 minutes in phosphate-buffered saline (PBS) pH 7.4 (Klinipath, Duiven, The Netherlands) and subjected to staining. All antibodies were dissolved in primary antibody diluent (PAD, AbD Serotec, 
Oxford, UK). Between all incubations, sections were rinsed 3 times in PBS. Sections were incubated overnight at $4^{\circ} \mathrm{C}$ with goat-anti-human-LAMP3 $\operatorname{IgG}$ (AF4087, $0.2 \mathrm{mg} / \mathrm{ml}$, R\&D Systems Inc., Minneapolis, MN) used in a dilution of 1:100. Subsequently, sections were treated with Cy3-conjugated donkey-antigoat IgG (705-166-147, $1.5 \mathrm{mg} / \mathrm{ml}$, Jackson ImmunoResearch Laboratories Inc., West Grove, PA) in a $1: 600$ dilution for 30 minutes at $37^{\circ} \mathrm{C}$ as the secondary antibody. Vessels were visualized by incubating sections with undiluted 9F1 supernatant, a rat monoclonal anti-body to mouse endothelium (Department of Pathology, Radboud University Nijmegen Medical Centre, RUNMC) for 45 minutes at $37^{\circ} \mathrm{C}$. Then, sections were incubated with rabbit-anti-pimonidazole (J.A. Raleigh) diluted $1: 1000$ for 30 minutes at $37^{\circ} \mathrm{C}$. Finally, sections were incubated with Alexa-Fluor-647-conjugated chicken-anti-rat IgG (A21472, 2 $\mathrm{mg} / \mathrm{ml}$, Invitrogen) diluted 1:100 and Alexa-Fluor-488-conjugated donkey-antirabbit $\operatorname{IgG}\left(\mathrm{A} 21206,2 \mathrm{mg} / \mathrm{ml}\right.$, Invitrogen) diluted $1: 600$ for 60 minutes at $37^{\circ} \mathrm{C}$. Nuclei were visualized using Hoechst $33342(1 \mathrm{mg} / \mathrm{ml})$ 1:3000 for 5 minutes. Slides were mounted in Fluorostab (ICN Pharmaceuticals, Inc., Zoetermeer, The Netherlands).

\section{Tissue Microarray (TMA) of BreastCancer Patients}

For the TMA construction, formalin-fixed paraffin-embedded (FFPE) tumor sections were marked on hematoxylin and eosin-stained slides of the primary tumors by a pathologist. TMAs were constructed with a tissue arrayer using a 2mm-diameter punch (Beecher Instruments, Silver Spring, MD). Staining for LAMP3 was performed as described in the next section and scored blinded for outcome semi-quantitatively as being either absent/low or present/high.

\section{Immunohistochemical Assessment of LAMP3 in FFPE Sections}

FFPE sections were dewaxed in Histosafe (Adamas Instruments BV, Leersum, The Netherlands) and rehydrated in graded alcohols. Antigen retrieval was performed by boiling sections in $10 \mathrm{mM}$ citrate buffer $\mathrm{pH} 6.0$ (Dako, Glostrup, Denmark) for 30 minutes after which endogenous peroxidase was blocked for 10 minutes using $3 \% \mathrm{H}_{2} \mathrm{O}_{2}$ in methanol. Sections were incubated for 30 minutes with 5\% normal donkey serum (Jackson) in PAD and subsequently incubated overnight at $4^{\circ} \mathrm{C}$ with goat-anti-human-LAMP3 (R\&D Systems), diluted 1:100 in PAD. Next, sections were incubated for 60 minutes with Biotin-conjugated donkey-anti-goat IgG (705-066-147, $1.5 \mathrm{mg} / \mathrm{ml}$, Jackson) diluted 1:200 in PBS, after which they were incubated for 30 minutes with avidin-biotin complex reagent (Vector Laboratories, Inc., Burlingame, CA). After rinsing with deionized water, sections were incubated with diaminobenzidine (Invitrogen) for 10 minutes. Next, sections were rinsed with tap water and counterstained with hematoxylin (Klinipath) for 1 minute, after which they were dehydrated and mounted in mounting medium (Klinipath). 


\section{Microscopy}

All images were acquired using IP-lab imaging software (Scanalytics Inc., Fairfax, VA) in combination with a Leica DM 6000 (fluorescence) microscope.

\section{Patients}

Coded tumor tissues were used in accordance with the Code of Conduct of the Federation of Medical Scientific Societies in The Netherlands (Code for Proper Secondary Use of Human Tissue in the Netherlands, http:// www.fmwv.nl). The study adhered to all relevant institutional and national guidelines, and was reported according to REMARK guidelines (19).

A series of 183 patients with unilateral, resectable breast cancers who had undergone resection of their primary tumors between November 1987 and December 1997 were selected based on the availability of RNA in the tumor bank of the Department of Laboratory Medicine of the RUNMC (20). This bank contains material from breast cancer patients of 7 different hospitals of the Comprehensive Cancer Centre East in The Netherlands. The inclusion and exclusion criteria have been described earlier (20). Postoperative radiotherapy was given to the breast after an incomplete resection or after breast-conserving treatment, or parasternal when the tumor was medially localized. Axillary irradiation was given in the case of positive lymph nodes.

A TMA was constructed from FFPE tissues as described above from another cohort of 61 breast cancer patients who had undergone lumpectomy and radiotherapy as primary treatment of their tumors between 1991 and 1996 at the Rijnstate Hospital, Arnhem, The Netherlands. These patients had no involved axillary lymph nodes and received no systemic adjuvant therapy, as was the practice at the time. Other clinicopathologic characteristics (steroid hormone receptor status, tumor size, and histologic grade) were essentially similar to those of the cohort from which RNA was extracted.

\section{Statistical Analysis}

Statistical analyses were carried out using SPSS 16.0 software (SPSS Benelux BV, Gorinchem, The Netherlands). Normality of data distribution was tested by Kolmogorov-Smirnov testing. An analysis of variance (ANOVA) with post-hoc Tukey's honestly significant difference (HSD) testing was used to assess the effect of hypoxia on LAMP3 mRNA levels. Nonparametric Mann-Whitney U tests or Kruskall-Wallis tests were used to assess differences in LAMP3 mRNA levels between categories of patients. Locoregional control (defined as the time from surgery until diagnosis of locoregional recurrent disease), disease-free survival (DFS) time (defined as the time from surgery until diagnosis of 
recurrent disease), metastasis-free survival (defined as the time between date of surgery and diagnosis of a distant metastasis), and overall survival (OS) time (defined as the time between date of surgery and death by any cause) were used as follow-up end points. Survival curves were generated using the KaplanMeier method. Equality of survival distributions was tested using log-rank testing and Cox univariate and multivariate regression analyses. Variables were selected for the multivariate survival analyses by backward stepwise selection, with removal testing based on the probability of the likelihood-ratio statistic, at a $\mathrm{p}>.10$. Two-sided $\mathrm{p}$-values $<.05$ were considered to be statistically significant.

\section{Results}

\section{Expression of LAMP3 in breast cancer cell lines}

We first measured the expression of LAMP3 mRNA in a panel of 16 different breast cancer cell lines under standard (normoxic) culturing conditions (Fig. 1). Three cell lines (SUM44PE, MPE600, and ZR75-30) displayed no measurable LAMP3 mRNA expression. In the other breast cell lines, levels varied $>100$ fold between SKBR-3 and MDA-MB-361, with OCUB-F cells exhibiting even higher LAMP3 levels. No association between LAMP3 expression and cancer subtype, or ER, PR, or HER2 expression was found (Fig. 1).

\section{Expression of LAMP3 in breast cancer cells under hypoxic conditions}

In MDA-MB-231 cells, which show moderate basal LAMP3 mRNA expression levels, LAMP3 was strongly induced under hypoxic conditions in an oxygendependent manner (Fig. 2A). The highest induction (i.e., 4-fold) was observed after 48 hours of incubation under severe hypoxic conditions $\left(0.1 \% \mathrm{O}_{2}, \mathrm{p}=\right.$ .003). An incubation of 72 hours at $0.1 \% \mathrm{O}_{2}$ led to a reduction in LAMP3 expression compared with 48 hours. At $0.2 \% \mathrm{O}_{2}$ there was a 2-fold increase overall as a maximum, whereas at $0.5 \% \mathrm{O}_{2}$ no statistically significant change was seen. Thus, the level of LAMP3 mRNA induction is dependent on the level of hypoxia, with severe hypoxia leading to a stronger induction of LAMP3 mRNA than moderate hypoxia. This dependency is consistent with the known oxygen dependency of UPR activation (21). Protein expression was found to be induced in a similar manner (Fig. 2B). 


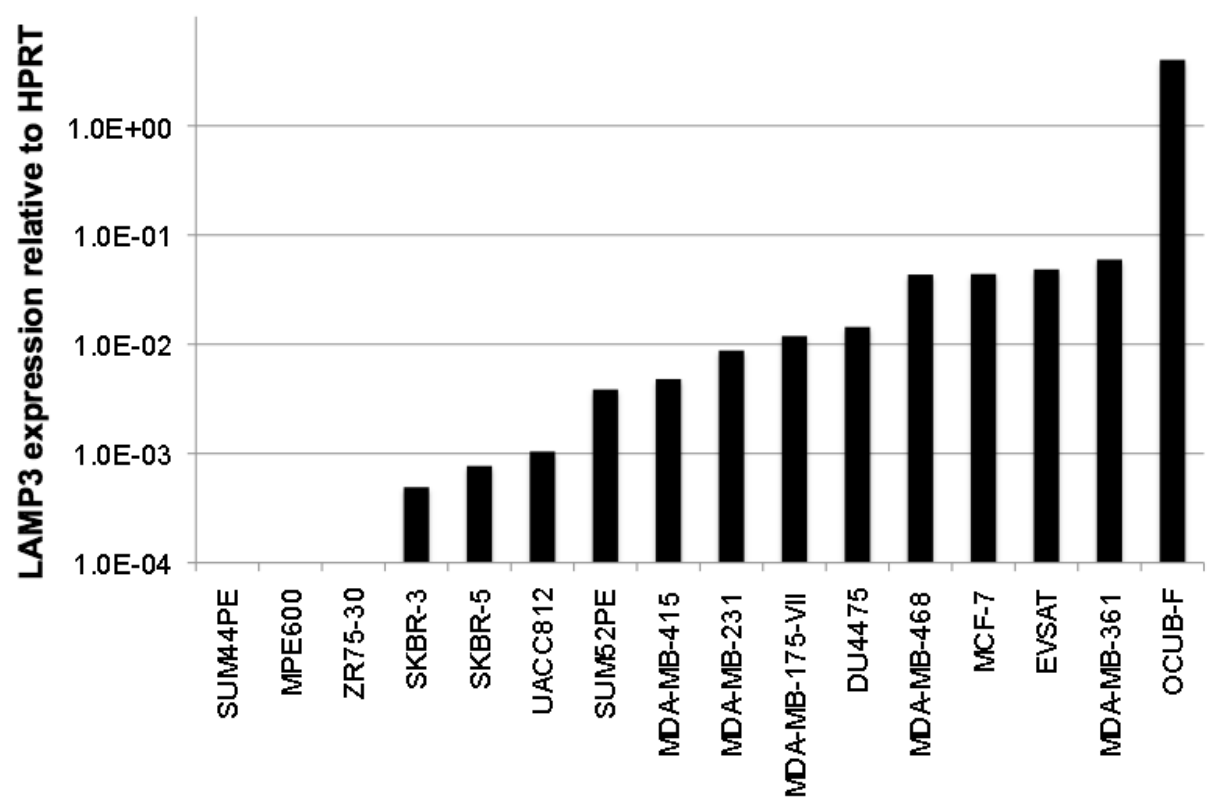

\begin{tabular}{llllllllllllllllllllll}
\hline subtype & $\mathrm{L}$ & $\mathrm{L}$ & $\mathrm{L}$ & $\mathrm{E}$ & $\mathrm{L}$ & $\mathrm{L}$ & $\mathrm{L}$ & $\mathrm{L}$ & $\mathrm{N}$ & $\mathrm{L}$ & $\mathrm{O}$ & $\mathrm{B}$ & $\mathrm{L}$ & $\mathrm{E}$ & $\mathrm{L}$ & $\mathrm{L}$ \\
\hline $\mathrm{ER}$ & + & + & + & - & - & - & + & + & - & + & - & - & + & - & + & - \\
$\mathrm{PR}$ & + & - & - & - & - & + & - & - & - & - & - & - & + & - & + & - \\
HER2 & - & - & ++ & ++ & ++ & ++ & - & - & - & - & - & - & - & ++ & ++ & ++ \\
\hline
\end{tabular}

Figure 1. LAMP3 mRNA expression in a panel of breast cancer cell lines is shown. Gene expression levels are shown relative to phosphoribosyl transferase (HPRT). L indicates luminal; E, ERBB2; N, normal-like; B, basal-like; O, other subtype; -, not detectable; +, expressed; ++, overexpressed (18). 


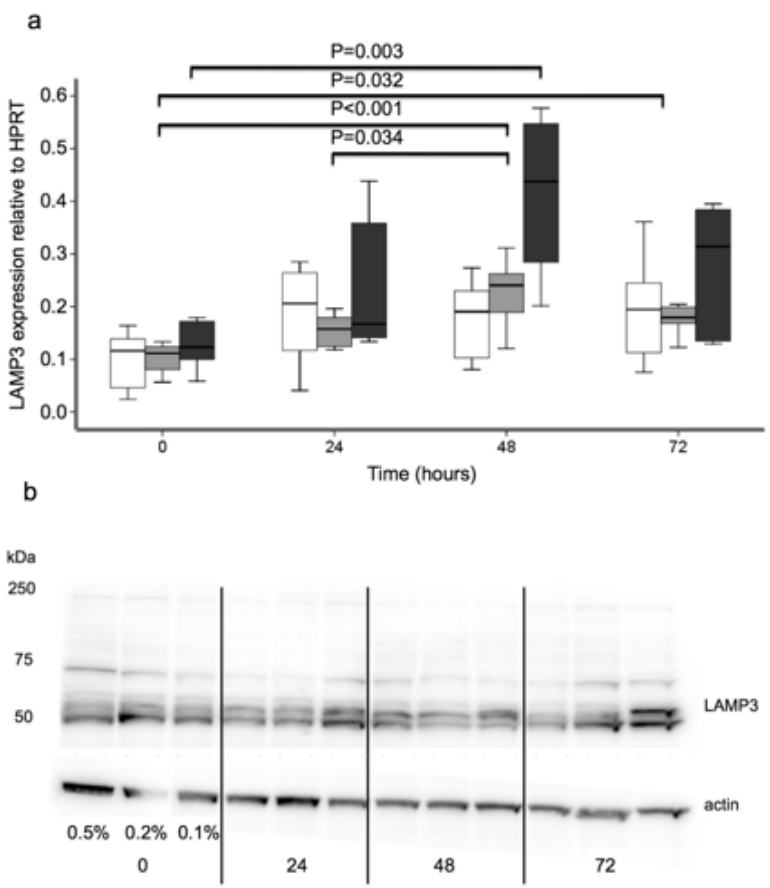

Figure 2. Induction of LAMP3 in MDA-MB-231 cells under hypoxic conditions is shown. mRNA expression (A) was found to be dependent on the level of hypoxia (0.1 [dark gray], 0.2 [gray], or 0.5 [white] $\% \mathrm{O}_{2}$ ). Gene expression levels are shown relative to phosphoribosyl transferase (HPRT). Data $(n=6)$ are presented as box-and-whisker plots with median values, 25 and 75 percentiles, and minimal and maximal values. A similar effect was observed for protein expression (B). The multiple bands are distinct forms of LAMP3 carrying different glycosylations.

\section{Colocalization of LAMP3 with hypoxic areas in breast cancer xenografts}

Next, xenografts of SKBR-3 (low endogenous expression) and MDA-MB-231 breast cancer cells were established in immunodeficient mice. After subcutaneous injection of the hypoxic cell marker pimonidazole, mice were sacrificed and xenografted tumors were stained for LAMP3 and hypoxia. In agreement with our in vitro expression data, we found only limited staining of the SKBR-3 tumors for LAMP3 in normoxic areas (Fig. 3A-C). Simultaneous staining for LAMP3 and pimonidazole revealed a regional colocalization of intense LAMP3 staining with areas of severe hypoxia, distant from perfused blood vessels (Fig. 3D). A hematoxylin and eosin staining showed the epithelial cell origin of this breast cancer xenograft and LAMP3 expressing cells (Fig. $3 \mathrm{E})$. The MDA-MB-231 xenografted tumors were well oxygenated and did not show hypoxic areas or LAMP3 expression (results not shown). 

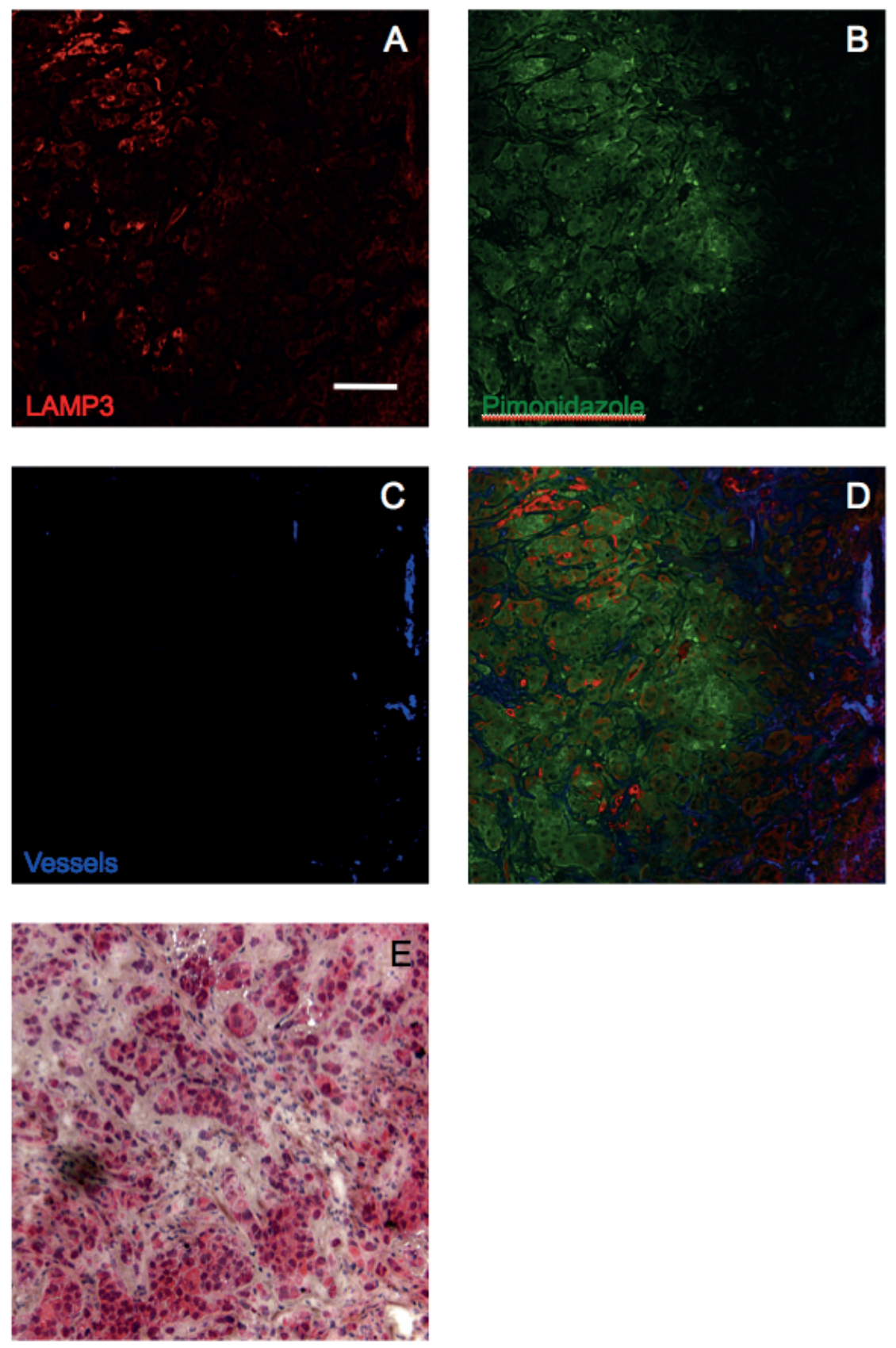

Figure 3. Single-field pseudo-colored immunofluorescent images of an SKBR-3 xenograft at 100x magnification show (A) LAMP3 (red), (B) pimonidazole binding (green), and (C) vessels (white) and nuclei (blue). Panel D shows the superimposed image of LAMP3, pimo and vessels, and panel $\mathrm{E}$ shows the hematoxylin and eosin staining of an adjacent tumor section. Yellow arrows indicate vessels. Bar $=200 \mu \mathrm{m}$. 


\section{LAMP3 mRNA expression in breast cancer}

LAMP3/HPRT mRNA values were assessed in 183 human invasive breast cancer tissues and were found to be log-normally distributed with a $>100$-fold variation in values, similar to the range in the breast cancer cell lines. There was no association between LAMP3 and menopausal status, type of surgery, histologic grade, or tumor size (pT, Table 1). However, LAMP3 was significantly higher in node-positive patients $(\mathrm{p}=.019$, Kruskal-Wallis, Fig. $4 \mathrm{~A})$, steroid hormone receptor-negative tumors $(\mathrm{p}<.001$, Mann-Whitney $\mathrm{U}$, Fig. 4B), patients receiving radiotherapy as part of their primary treatment $(\mathrm{p}=$ $.022)$, and patients receiving adjuvant systemic chemotherapy $(\mathrm{p}=.050)$. Thus, LAMP3 is associated with poor prognosis characteristics (node positive, steroid hormone receptor negative) and therefore with more aggressive treatment (radiotherapy, chemotherapy).
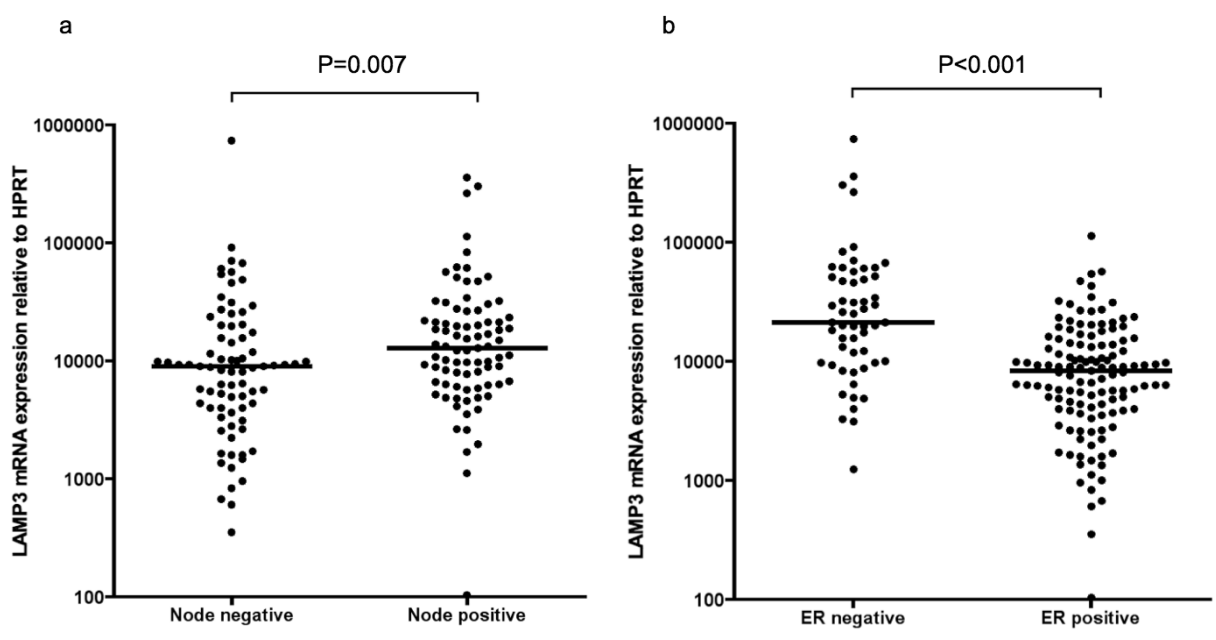

Figure 4. Differences in LAMP3/phosphoribosyl transferase (HPRT) values in (A) patients with 0,1 to 3 , or $\geq 4$ positive lymph nodes $(\mathrm{p}=.019)$ and $(\mathrm{B})$ ER-negative and ER-positive $(\mathrm{p}<.001)$ tumors are shown. Horizontal bars represent median values. Open symbols represent outliers above the range of the chosen y-axis.

\section{Prognostic value of LAMP3 mRNA expression}

Patients were dichotomized based on LAMP3 levels in their primary tumor and evaluated for response parameters. Patients with higher levels of LAMP3 $(\mathrm{n}=$ 99) had more locoregional recurrences than those with low LAMP3 mRNA levels $(\mathrm{n}=84), \mathrm{p}=.032$ log-rank (Fig. 5A). In Cox regression analysis, this amounted to a hazard ratio (HR) of 2.85 (95\% CI, 1.05-7.8). There was no association with distant metastasis-free or overall survival. In exploratory subgroup analyses, we found that the association of LAMP3 with locoregional 
Table 1. LAMP3 mRNA levels per clinicopathologic subgroup

\begin{tabular}{|c|c|c|c|c|}
\hline & $N=183$ & Median & Interquartile Range & p-value \\
\hline Menopausal status & & & & $0.196^{a}$ \\
\hline Pre & 48 & 10,825 & 21,005 & \\
\hline Post & 135 & 9883 & 15,524 & \\
\hline Histologic grade & & & & $0.082^{a}$ \\
\hline $\mathrm{I} / \mathrm{II}$ & 70 & 9430 & 14,898 & \\
\hline III & 65 & 13,998 & 23,164 & \\
\hline Size & & & & $0.533^{b}$ \\
\hline pT1 & 45 & 9409 & 15,340 & \\
\hline рT2 & 115 & 9986 & 16,148 & \\
\hline pT3 & 16 & 16,973 & 25,150 & \\
\hline pT4 & 6 & 7772 & 10,803 & \\
\hline Nodal status & & & & $0.019^{a}$ \\
\hline 0 & 78 & 9017 & 14,348 & \\
\hline $1-3$ & 57 & 13,998 & 18,262 & \\
\hline$\geq 4$ & 26 & 10,129 & 15,667 & \\
\hline Surgery & & & & $0.904^{a}$ \\
\hline Lumpectomy & 55 & 9884 & 16,389 & \\
\hline Mastectomy & 128 & 9889 & 16,440 & \\
\hline Radiotherapy & & & & $0.022^{a}$ \\
\hline No & 49 & 7292 & 11,895 & \\
\hline Yes & 134 & 10,688 & 17,814 & \\
\hline Adjuvant therapy & & & & $0.195^{a}$ \\
\hline None & 82 & 9017 & 15,967 & \\
\hline Endocrine & 67 & 10,670 & 15,070 & \\
\hline Chemo & 24 & 14,104 & 25,642 & \\
\hline Both & 10 & 15,317 & 15,200 & \\
\hline ER & & & & $<0.001^{a}$ \\
\hline Negative & 55 & 21,499 & 42,924 & \\
\hline Positive & 126 & 8336 & 10,630 & \\
\hline PR & & & & $<0.001^{a}$ \\
\hline Negative & 71 & 15,751 & 28,429 & \\
\hline Positive & 111 & 8932 & 12,471 & \\
\hline
\end{tabular}

${ }^{\text {a }}$ Mann-Whitney U test

${ }^{\mathrm{b}}$ Kruskall-Wallis test 


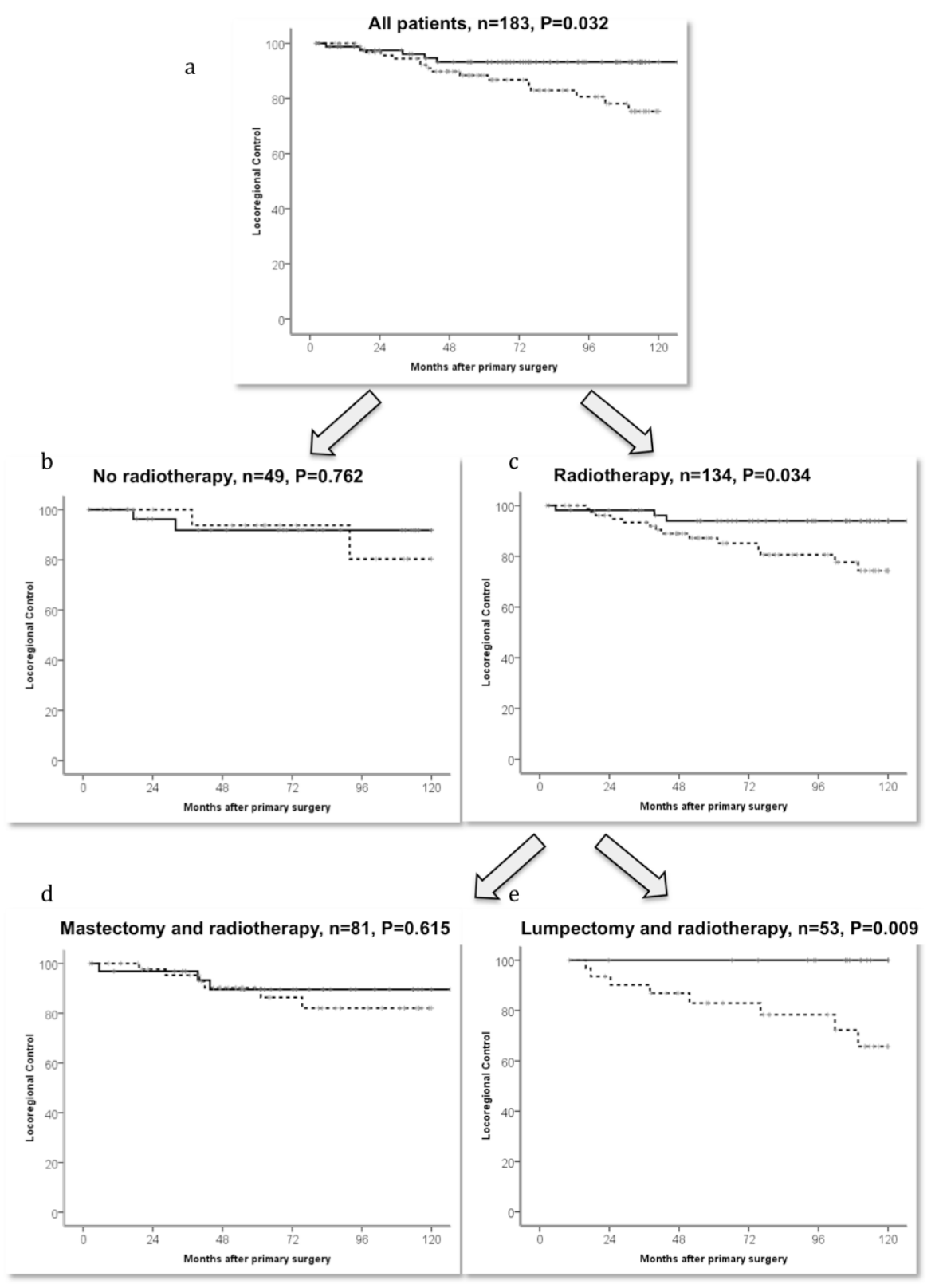

Figure 5. Prognostic value of LAMP 3 mRNA levels are shown. (A) Patients with high LAMP3 mRNA levels (dashed line) in their primary tumor experienced more locoregional recurrences $(\mathrm{p}=.032$, log-rank). (B) There is no association with locoregional control in patients who had no radiotherapy $(\mathrm{n}=49, \mathrm{p}=.762)$, but $(\mathrm{C})$ only in patients who had received radiotherapy $(\mathrm{n}=134, \mathrm{p}=.034)$. (D) LAMP3 was not prognostic if radiotherapy was part of a modified radical mastectomy procedure $(n=81, \mathrm{p}=.615)$, but $(\mathrm{E})$ only as part of a breastconserving lumpectomy $(\mathrm{n}=53, \mathrm{p}=.009)$. 
control was limited to patients who had received radiotherapy as part of their primary treatment. In patients who had not received radiotherapy, LAMP3 showed no association with locoregional control $(\mathrm{n}=49, \mathrm{p}=.762$, Fig. 5B), whereas in patients who had received radiotherapy, a significant association was found $(\mathrm{n}=134, \mathrm{p}=.034$, Fig. $5 \mathrm{C})$. Within the patient cohort that had received radiotherapy, no association of LAMP3 with locoregional control was found if this was part of a modified radical mastectomy procedure $(n=81, p=.615$, Fig. 5D). LAMP3 was significantly associated with locoregional control but only in those patients who received radiotherapy as part of a breast-conserving lumpectomy $(\mathrm{n}=53, \mathrm{p}=.009$, Fig. 5E).

In multivariate Cox regression analysis, only LAMP3 remained as an independent prognostic factor for locoregional recurrence $(\mathrm{HR}=2.76,95 \% \mathrm{CI}$, $1.01-7.5, \mathrm{p}=.048$ ) after correction for menopausal status, histologic grade, tumor size, nodal status, therapy, and steroid hormone receptor status (Table 2).

Table 2. Uni- and Multivariate Cox Regression Survival Analyses for Locoregional Control

\begin{tabular}{|c|c|c|c|c|c|c|}
\hline & \multicolumn{3}{|c|}{ Univariate } & \multicolumn{3}{|c|}{ Multivariate } \\
\hline & HR & $95 \% \mathrm{Cl}$ & p-value & HR & $95 \% \mathrm{Cl}$ & p-value \\
\hline Menopausal status & & & 0.827 & & & 0.942 \\
\hline Post vs pre & 0.827 & $0.320-2.134$ & & 0.964 & $0.360-2.579$ & \\
\hline Histologic grade & & & 0.459 & & & 0.598 \\
\hline III vs I/II & 1.433 & $0.553-3.718$ & & 1.622 & $0.605-4.352$ & \\
\hline Size & & & 0.571 & & & 0.368 \\
\hline pT2 vs pT1 & 1.905 & $0.630-5.768$ & & 1.989 & $0.640-6.185$ & \\
\hline pT3 vs pT1 & 0.974 & $0.108-8.746$ & & 1.125 & $0.118-10.74$ & \\
\hline pT4 vs pT1 & 2.783 & $0.309-25.07$ & & 6.663 & $0.646-68.72$ & \\
\hline Nodal status & & & 0.596 & & & 0.669 \\
\hline $1-3$ vs 0 & 1.531 & $0.621-3.771$ & & 1.414 & $0.104-19.283$ & \\
\hline$\geq 4$ vs 0 & 0.906 & $0.194-4.227$ & & 0.523 & $0.027-10.197$ & \\
\hline Surgery & & & 0.766 & & & 0.545 \\
\hline Mastectomy vs lumpectomy & 0.873 & $0.360-2.117$ & & 0.761 & $0.314-1.845$ & \\
\hline Radiotherapy & & & 0.561 & & & 0.718 \\
\hline Yes vs no & 1.381 & $0.465-4.108$ & & 0.826 & $0.215-3.172$ & \\
\hline Adjuvant therapy & & & 0.462 & & & 0.952 \\
\hline Endocrine vs none & 1.173 & $0.465-2.956$ & & 1.384 & $0.546-3.506$ & \\
\hline Chemo vs none & 1.311 & $0.353-4.868$ & & 1.196 & $0.319-4.477$ & \\
\hline Both vs none & $-\mathrm{a}$ & - & & & & \\
\hline ER & & & 0.497 & & & 0.641 \\
\hline Positive vs negative & 0.726 & $0.293-1.798$ & & 1.371 & $0.364-5.155$ & \\
\hline PR & & & 0.488 & & & 0.699 \\
\hline Positive vs negative & 0.736 & $0.310-1.749$ & & 0.833 & $0.329-2.107$ & \\
\hline LAMP3 & & & 0.028 & & & 0.048 \\
\hline High vs low & 2.853 & $1.044-7.792$ & & 2.758 & $1.010-7.534$ & \\
\hline
\end{tabular}

HR, hazard ratio; CI, confidence interval. ${ }^{\mathrm{a}}$ Too few events. 


\section{Immunohistochemical validation of prognostic value of LAMP3 mRNA}

We set out to validate the data on LAMP3 mRNA as being prognostic in breast cancer patients who were treated with lumpectomy and radiotherapy on the protein level. For this, LAMP3 protein was semi-quantitatively scored in TMA of a series of FFPE sections of breast cancer patients that were only treated with lumpectomy and radiotherapy. These patients received no adjuvant systemic therapy, making it possible to distinguish a prognostic from a predictive value of LAMP3 in these patients. Of the 61 patients, $21(34 \%)$ had low or absent levels of LAMP3 protein (Fig. 6A), and 40 (66\%) had high levels (Fig. 6B) of LAMP3 protein in their tumor. Despite the clear difference in the number of events between these subgroups ( 1 versus 8 in the LAMP3 low and high cohort, respectively), the power was too low to obtain a significant difference in locoregional control $(\mathrm{p}=.121)$. These 2 categories of patients did, however, differ significantly in both disease-free survival (DFS) $(\mathrm{p}=.024$, Fig. $6 \mathrm{C})$ and overall survival (OS) time $(\mathrm{p}=.019$, Fig. $6 \mathrm{D})$, confirming the prognostic value of LAMP3 mRNA levels in this patient group on the protein level.

\section{Discussion}

In this study, the occurrence and prognostic relevance of LAMP3 in breast cancer was evaluated. We present evidence indicating that LAMP3 mRNA levels are elevated in aggressive ER-negative breast tumors and in tumors that have already spread to the axillary lymph nodes. Patients with high LAMP3 mRNA levels also have more locoregional recurrences than those with low levels, a phenomenon that remains after correction for menopausal status, tumor size, histologic grade, nodal status, steroid hormone receptor status, adjuvant therapy, and radiotherapy. The prognostic value of LAMP3 for locoregional control is limited to patients treated with breast-conserving lumpectomy and radiotherapy. The prognostic value of LAMP3 mRNA is also seen for LAMP3 protein as assessed by immunohistochemistry.

In 2004, Treileux et al. examined the potential prognostic role of LAMP3 in breast cancer tissue, using a semi-quantitative immunohistochemical analysis (22) They found that the presence of mature LAMP3+ dendritic cells (DC) within clusters of lymphocytes at the margin of the tumor correlated with lymph node involvement and tumor grade, although no association with prognosis was found. Our immunohistochemical data indicate that tumor hypoxia is also an important regulator of LAMP3 in the epithelial cancer cells. LAMP3 expression in breast cancer xenografts colocalizes with tumor cell hypoxia as revealed by pimonidazole labeling. Together with our immunohistochemical data on actual breast tumors, this indicates that lymphocyte infiltration, which reportedly has 
a
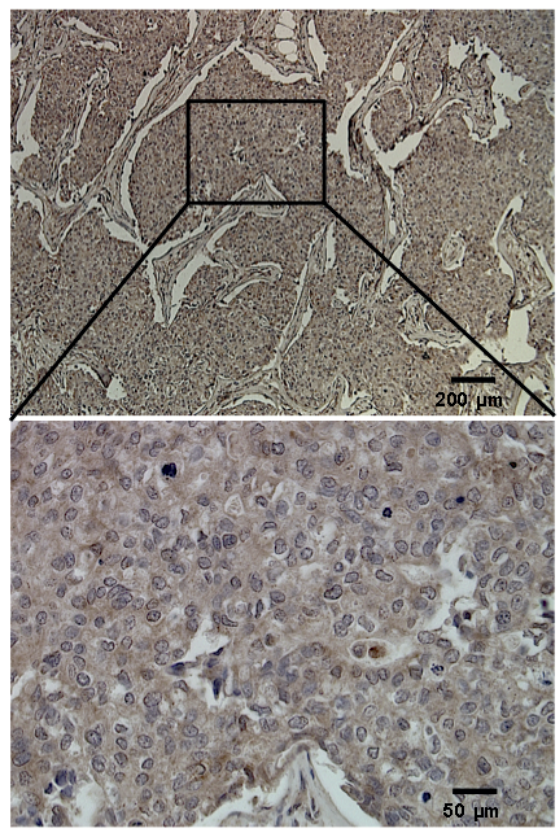

C

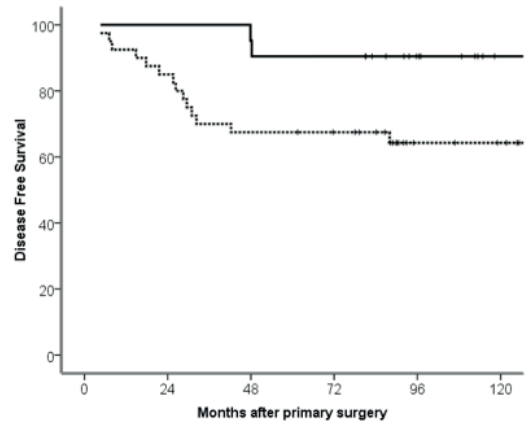

b
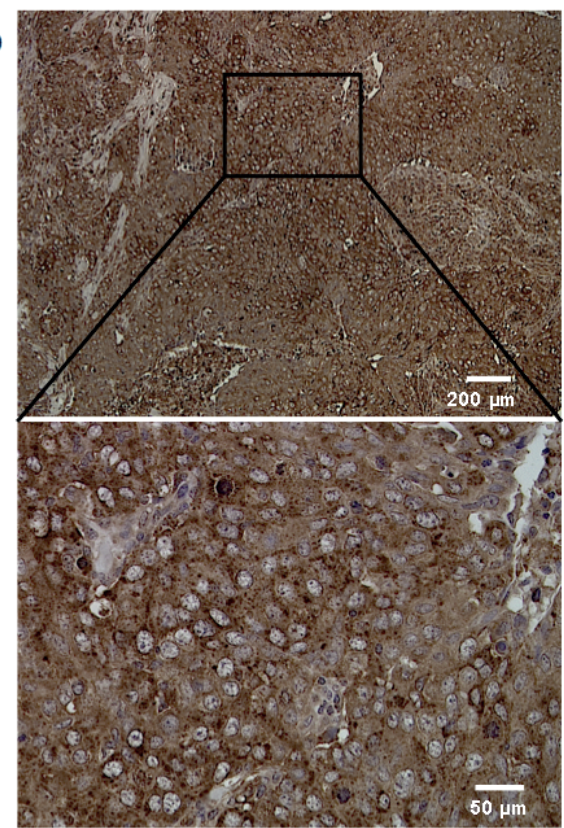

d

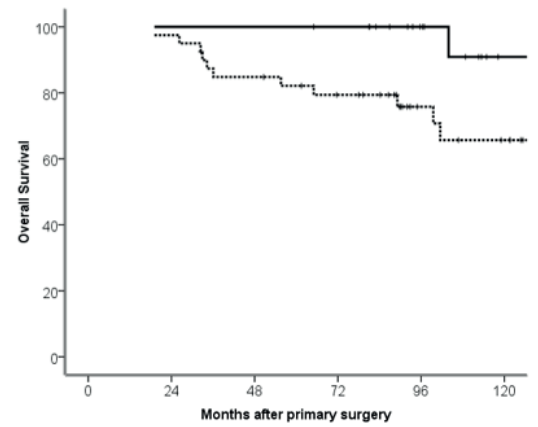

Figure 6. Validation of the prognostic value of LAMP3 mRNA via immunohistochemical staining of LAMP3 protein on a tissue microarray of formalin-fixed paraffin-embedded breast cancer tissues $(n=61)$ is shown. Panel A shows a typical example of a tumor with low/absent levels of LAMP3 protein expression at 100x and 400x magnification. Panel B shows a typical example of a tumor with high levels of LAMP3 protein at 100x and 400x magnification. Patients with high levels of LAMP3 protein (dashed line, $n=40,66 \%$ ) have a worse (C) disease-free survival (DFS, $p=.024)$ and (D) overall survival (OS, $p=.019)$ compared with patients with low LAMP3 protein levels (solid line, $\mathrm{n}=21,34 \%$ ).

different effects on prognosis in breast cancer depending on ER status (23), is unlikely to be the sole cause of the association of LAMP3 mRNA with prognosis we report here. Rather, the tumor epithelial cells themselves aberrantly express LAMP3, with consequences for locoregional control. 
LAMPs have previously been implicated in cancer (24-26); especially in relation to the metastatic potential of tumors they may serve important functions (7, 27, 28). LAMPs are characterized by high and complex levels of glycosylation $(4,29)$. They are the main carriers of sialyl-Le ${ }^{\mathrm{x}}$ (sialylated Lewis $\mathrm{x}$ antigen), which is amplified in carcinoma cells (30). Via these carbohydrates, tumor cells are able to connect with E-selectins, adhere to endothelial cells, and form metastases, suggesting that LAMPs play a role in the metastasis of certain solid tumors (31-33). Indeed, overexpression of LAMP3 in cervical cancer cells used for xenografts led to an enhancement of formation of metastasis (2). Our observation that mRNA levels are significantly higher in breast cancer patients with positive axillary lymph nodes would indicate that LAMP3 might also serve a role in metastasis of breast cancers. Other studies have demonstrated that tumor hypoxia is also associated with a more malignant phenotype and a higher prevalence of metastasis (10-12).

Although a direct link between hypoxia, LAMP3, and metastasis has not yet been explored, hypoxia was found to increase the expression of LAMPassociated sialyl-Le $\mathrm{e}^{\mathrm{x}}$ at the surface of colon cancer cells (34). This leads to increased adhesion to endothelial E-selectin and potentially could provide a mechanism for hypoxia-meditated metastasis. We did not find an association between LAMP3 mRNA expression in breast cancer and distant metastasis-free survival in our breast cancer cohort. However, it is possible that protein localization and/or glycosylation patterns of the protein may be relevant for its association with metastasis.

Interestingly, unlike most other hypoxia targets, LAMP3 induction occurs independently of the master hypoxia transcription factor hypoxia inducible factor $1 \alpha($ HIF $1 \alpha)$ (14). Consistent with previous reports, we found that LAMP3 induction was dependent on the level of hypoxia, with severe hypoxia being most effective. This is consistent with the reported dependency of UPR activation in response to hypoxia. The UPR is induced potently and rapidly under conditions of severe hypoxia but requires oxygen levels well below those required for most HIF1 target genes (21). As such, LAMP3 may serve as a unique biomarker for the presence of UPR activation under conditions of severe hypoxia in human tumors. This is interesting in the context of our intriguing finding that LAMP3 is specifically related to locoregional control in patients treated with breast-conserving lumpectomy and radiotherapy. We speculate that high levels of LAMP3 and UPR activation may indicate the presence of substantial numbers of radiation-resistant hypoxic cells in these tumors. As such, LAMP3 may be a particularly useful marker of the radiation-resistant fraction of the tumor. There have been intense efforts made at identifying endogenous markers of tumor hypoxia $(35,36)$ although most of these studies have focused on HIF target genes such as carbonic anhydrase 9 (CA9), glucose transporters (GLUT-1,4), and vascular endothelial growth factor (VEGF). 
Although clearly important, these hypoxia targets are activated at moderate oxygen concentrations ( $1 \%$ to $2 \%$ oxygen), which may not be sufficient to cause radiation resistance. Tumor cells become maximally radiation resistant only below $0.1 \%$ oxygen, levels that are well below those required to activate HIF. The UPR, and LAMP3, may thus provide a more accurate surrogate of oxygenation levels associated with clinical resistance to radiotherapy. Our results suggest that the prognostic value of LAMP3 in breast cancer is due to its induction by severe hypoxia, the consequential association with radiotherapy resistance, and lack of locoregional control.

In conclusion, LAMP3 is expressed to highly variable levels within a large panel of breast cancer cell lines and breast cancer patient samples. In addition, LAMP3 is strongly induced by hypoxia both in vitro and in vivo. The correlation between LAMP3 mRNA expression and nodal spread strengthens the concept of a function of LAMP3 in (hypoxia-mediated) metastasis formation in (breast) cancer. Furthermore, the identification of LAMP3 as an independent prognostic factor for locoregional recurrence supports the notion that LAMP3 may be a biomarker for hypoxia-mediated treatment resistance.

\section{References}

1. de Saint-Vis B, Vincent J, Vandenabeele S, Vanbervliet B, Pin JJ, Ait-Yahia S, et al. A novel lysosome-associated membrane glycoprotein, DC-LAMP, induced upon DC maturation, is transiently expressed in MHC class II compartment. Immunity. 1998;9:325-36.

2. Kanao H, Enomoto T, Kimura T, Fujita M, Nakashima R, Ueda Y, et al. Overexpression of LAMP3/TSC403/DC-LAMP promotes metastasis in uterine cervical cancer. Cancer Res. 2005;65:8640-5.

3. Ozaki K, Nagata M, Suzuki M, Fujiwara T, Ueda K, Miyoshi Y, et al. Isolation and characterization of a novel human lung-specific gene homologous to lysosomal membrane glycoproteins 1 and 2: significantly increased expression in cancers of various tissues. Cancer Res. 1998;58:3499-503.

4. Fukuda M. Lysosomal membrane glycoproteins. Structure, biosynthesis, and intracellular trafficking. J Biol Chem. 1991;266:21327-30.

5. Fukuda M. Biogenesis of the lysosomal membrane. Subcell Biochem. 1994;22:199-230.

6. Carlsson SR, Fukuda M. The lysosomal membrane glycoprotein lamp-1 is transported to lysosomes by two alternative pathways. Arch Biochem Biophys. 1992;296:630-9.

7. Saitoh O, Wang WC, Lotan R, Fukuda M. Differential glycosylation and cell surface expression of lysosomal membrane glycoproteins in sublines of a human colon cancer exhibiting distinct metastatic potentials. J Biol Chem. 1992;267:5700-11.

8. Brown JM, Giaccia AJ. The unique physiology of solid tumors: opportunities (and problems) for cancer therapy. Cancer Res. 1998;58:1408-16.

9. Hall EJ. Molecular biology in radiation therapy: the potential impact of recombinant technology on clinical practice. Int J Radiat Oncol Biol Phys. 1994;30:1019-28. 
10. Fyles AW, Milosevic M, Wong R, Kavanagh MC, Pintilie M, Sun A, et al. Oxygenation predicts radiation response and survival in patients with cervix cancer. Radiother Oncol. 1998;48:149-56.

11. Hockel M, Schlenger K, Aral B, Mitze M, Schaffer U, Vaupel P. Association between tumor hypoxia and malignant progression in advanced cancer of the uterine cervix. Cancer Res. 1996;56:4509-15.

12. Sundfor K, Lyng H, Rofstad EK. Tumour hypoxia and vascular density as predictors of metastasis in squamous cell carcinoma of the uterine cervix. Br J Cancer. 1998;78:822-7.

13. Chan DA, Giaccia AJ. Hypoxia, gene expression, and metastasis. Cancer Metastasis Rev. 2007;26:333-9.

14. Mujcic H, Rzymski T, Rouschop KM, Koritzinsky M, Milani M, Harris AL, et al. Hypoxic activation of the unfolded protein response (UPR) induces expression of the metastasis-associated gene LAMP3. Radiother Oncol. 2009;92:450-9.

15. Wouters BG, Koritzinsky M. Hypoxia signaling through mTOR and the unfolded protein response in cancer. Nat Rev Cancer. 2008;8:851-64.

16. Rouschop KM, van den Beucken T, Dubois L, Niessen H, Bussink J, Savelkouls K, et al. The unfolded protein response protects human tumor cells during hypoxia through regulation of the autophagy genes MAP1LC3B and ATG5. J Clin Invest. 2010;120:127-41.

17. Hollestelle A, Elstrodt F, Nagel JH, Kallemeijn WW, Schutte M. Phosphatidylinositol-3$\mathrm{OH}$ kinase or RAS pathway mutations in human breast cancer cell lines. Mol Cancer Res. 2007;5:195-201.

18. Hollestelle A, Nagel JH, Smid M, Lam S, Elstrodt F, Wasielewski M, et al. Distinct gene mutation profiles among luminal-type and basal-type breast cancer cell lines. Breast Cancer Res Treat. 2009;121:53-64.

19. McShane LM, Altman DG, Sauerbrei W, Taube SE, Gion M, Clark GM. Reporting recommendations for tumor marker prognostic studies (REMARK). J Natl Cancer Inst. 2005;97:1180-4.

20. Span PN, Waanders E, Manders P, Heuvel JJ, Foekens JA, Watson MA, et al. Mammaglobin is associated with low-grade, steroid receptor-positive breast tumors from postmenopausal patients, and has independent prognostic value for relapse-free survival time. J Clin Oncol. 2004;22:691-8.

21. Koritzinsky M, Magagnin MG, van den Beucken T, Seigneuric R, Savelkouls K, Dostie J, et al. Gene expression during acute and prolonged hypoxia is regulated by distinct mechanisms of translational control. EMBO J. 2006;25:1114-25.

22. Treilleux I, Blay JY, Bendriss-Vermare N, Ray-Coquard I, Bachelot T, Guastalla JP, et al. Dendritic cell infiltration and prognosis of early stage breast cancer. Clin Cancer Res. 2004;10:7466-74.

23. Calabro A, Beissbarth T, Kuner R, Stojanov M, Benner A, Asslaber M, et al. Effects of infiltrating lymphocytes and estrogen receptor on gene expression and prognosis in breast cancer. Breast Cancer Res Treat. 2009;116:69-77.

24. Chen JW, Murphy TL, Willingham MC, Pastan I, August JT. Identification of two lysosomal membrane glycoproteins. J Cell Biol. 1985;101:85-95.

25. Feizi T. Demonstration by monoclonal antibodies that carbohydrate structures of glycoproteins and glycolipids are onco-developmental antigens. Nature. 1985;314:53-7.

26. Fukuda M. Cell surface glycoconjugates as onco-differentiation markers in hematopoietic cells. Biochim Biophys Acta. 1985;780:119-50. 
27. Heffernan M, Yousefi S, Dennis JW. Molecular characterization of P2B/LAMP-1, a major protein target of a metastasis-associated oligosaccharide structure. Cancer Res. 1989;49:6077-84.

28. Laferte S, Dennis JW. Purification of two glycoproteins expressing beta 1-6 branched Asn-linked oligosaccharides from metastatic tumour cells. Biochem J. 1989;259:569-76.

29. Hunziker W, Geuze HJ. Intracellular trafficking of lysosomal membrane proteins. Bioessays. 1996;18:379-89.

30. Sawada R, Lowe JB, Fukuda M. E-selectin-dependent adhesion efficiency of colonic carcinoma cells is increased by genetic manipulation of their cell surface lysosomal membrane glycoprotein-1 expression levels. J Biol Chem. 1993;268:12675-81.

31. Kannagi R. Carbohydrate antigen sialyl Lewis a--its pathophysiological significance and induction mechanism in cancer progression. Chang Gung Med J. 2007;30:189-209.

32. Kannan K, Stewart RM, Bounds W, Carlsson SR, Fukuda M, Betzing KW, et al. Lysosome-associated membrane proteins h-LAMP1 (CD107a) and h-LAMP2 (CD107b) are activation-dependent cell surface glycoproteins in human peripheral blood mononuclear cells which mediate cell adhesion to vascular endothelium. Cell Immunol. 1996;171:10-9.

33. Takada A, Ohmori K, Takahashi N, Tsuyuoka K, Yago A, Zenita K, et al. Adhesion of human cancer cells to vascular endothelium mediated by a carbohydrate antigen, sialyl Lewis A. Biochem Biophys Res Commun. 1991;179:713-9.

34. Koike T, Kimura N, Miyazaki K, Yabuta T, Kumamoto K, Takenoshita S, et al. Hypoxia induces adhesion molecules on cancer cells: A missing link between Warburg effect and induction of selectin-ligand carbohydrates. Proc Natl Acad Sci U S A. 2004;101:8132-7.

35. Bussink J, Kaanders JH, van der Kogel AJ. Tumor hypoxia at the micro-regional level: clinical relevance and predictive value of exogenous and endogenous hypoxic cell markers. Radiother Oncol. 2003;67:3-15.

36. Rademakers SE, Span PN, Kaanders JH, Sweep FC, van der Kogel AJ, Bussink J. Molecular aspects of tumour hypoxia. Mol Oncol. 2008;2:41-53. 



\section{CHAPTER 7}

\section{Summary and General Discussion}




\section{Summary}

Clinical studies in several cancer types have established a strong association between hypoxia and the risk of metastasis (1-3). In addition, extensive evidence from experimental studies supports a role for hypoxia in driving metastasis (4-7). However, the signaling events that promote a pro-metastatic phenotype during conditions of hypoxia are not well understood. This thesis describes the contribution of the unfolded protein response (UPR) to hypoxiaregulated metastasis, and its importance in human cancer.

In an ongoing screen for novel hypoxia-regulated genes, we employed microarray technology to assess transcriptional changes of genes during hypoxia, and identified lysosomal associated membrane protein 3 (LAMP3), a gene previously implicated in metastasis (8). In the study described in Chapter 3 we demonstrated that LAMP3 expression is induced by severe hypoxia in multiple cancer cell lines, including cervix, breast and colon carcinoma. We showed that unlike most other hypoxia-induced metastasis genes identified to date, LAMP3 is not regulated by HIF1, but instead is induced by the UPR in a PERK, eIF2 $\alpha$, and ATF4-dependent manner. We also showed that the gene is overexpressed in breast cancer, and is induced in tumors treated with the antiangiogenic drug bortezomib (Avastin). This is consistent with induction of hypoxia and the UPR in these tumors following therapeutic targeting of blood vessels. The results presented in Chapter 3 suggested that LAMP3 may contribute to hypoxia-induced metastasis.

To examine the importance of UPR and LAMP3 induction by hypoxia in metastasis, we assessed their role in hypoxia-mediated cell migration and invasion in breast cancer (Chapter 4). Using two different in vitro cell migration assays we were able to show that siRNA-mediated knockdown of PERK, ATF4 or LAMP3 significantly reduced the migratory capacity of breast cancer cells during hypoxia. This effect was not due to reduced cell survival during hypoxia following the knockdown. As expected, we did not observe differences in cell migration when the assays were performed under normoxic conditions. As a second in vitro model of tumor hypoxia we used multicellular spheroid cultures established from breast cancer cell lines. Multicellular tumor spheroids are characterized by a necrotic core that is surrounded by hypoxic cells. We validated the presence of hypoxic cells within the core of the spheroids by IHC staining of the exogenous hypoxia marker pimonidazole, and we observed UPR and LAMP3 activation in cells grown in spheroids, but not in (normoxic) monolayer cells. Moreover, tumor cells derived from disaggregated spheroids were more migratory compared to cells grown in monolayers. To investigate 
whether LAMP3 also affects cell invasion, we generated spheroids from stable LAMP3 knockdown cells and tested their ability to invade matrices of collagen, the most abundant protein in the extracellular matrix. LAMP3 knockdown did not affect the growth of the spheroids, but it did significantly impair collagen invasion. We also generated mixed spheroids by combining LAMP3 knockdown and control cells, each labeled with a different fluorescent dye, and tracked their invasion into collagen. In line with our previous results, the LAMP3 knockdown cells within the spheroids showed a diminished collagen invasion capacity compared to the control cells. In conclusion, our data from the study described in Chapter 4 suggest that the UPR as well as LAMP3 promote cell migration and invasion during conditions of hypoxia.

In Chapter 5 we directly assessed the importance of hypoxic activation of the UPR and LAMP3 in metastasis using an animal model of hypoxia-induced metastatic cervix carcinoma. In this model, primary tumors established in the mouse cervix from the human ME180 cervix cancer cell line spontaneously metastasize to the regional pelvic lymph node chain (9). Previous work with this model has shown that subjecting tumor-bearing animals to cyclic hypoxia conditions quantitatively increases the frequency of nodal involvement (4), making this a highly suitable model for studying the molecular mechanisms of hypoxia-driven metastasis. We generated an isogenic ME180 subline that allows doxycycline-inducible disruption of UPR signaling through the PERK/eIF2 $\alpha /$ ATF4-arm. The use of an inducible model allowed us to uncouple any possible involvement of the UPR in metastasis from its known role in primary tumor establishment (10). We found that disruption of UPR signaling in established tumors resulted in complete inhibition of hypoxia-driven lymph node metastasis. More importantly, inhibition of UPR signaling significantly reduced nodal metastasis even in animals that were not exposed to the additional in vivo hypoxia treatment.

We next investigated different mechanisms through which UPR signaling contributes to hypoxia-induces metastasis. Previous reports have demonstrated that the UPR pathway is an important mediator of hypoxia tolerance and tumor growth by affecting cellular processes that include autophagy, angiogenesis, $\mathrm{pH}$ regulation and the elimination of reactive oxygen species (10-15). We found that UPR deficient ME180 cells were more sensitive to hypoxia-induced cell death in vitro and disruption of UPR signaling also impaired tumor growth in vivo. However, tolerance mechanisms cannot alone account for the PERK/eIF2 $\alpha /$ ATF4 contribution to hypoxia-induced metastasis in our model. Instead, our data indicate that LAMP3 is a key mediator of hypoxia driven lymph node metastasis downstream of UPR activation. Silencing LAMP3 expression significantly inhibited lymph node metastasis in response to hypoxia, but did not affect hypoxia tolerance or tumor growth. In agreement with our 
study described in Chapter 4, we instead found evidence for a role of LAMP3 in regulating hypoxia-induced cell migration in this model.

Next, we investigated whether the relationship between hypoxia and LAMP3 also exists in human cervix tumors, one of the cancer types in which a direct association between tumor hypoxia and metastasis has been identified (1, 16)(Chapter 5). LAMP3 expression was determined in a set of cervical carcinoma patient samples obtained from clinical trials at the Princess Margaret Cancer Centre, Toronto, in which tumors were assessed for tumor hypoxia with oxygen needle electrodes prior to treatment. However, since cervical carcinoma is one of the cancer types where gene amplification of LAMP3 has been reported (17), we also first determined LAMP3 gene copy numbers using FISH analysis. This allowed us to distinguish between hypoxia-induced LAMP3 expression and enhanced LAMP3 expression associated with gene amplification. Similar to previously reported results in cervical cancer, elevated LAMP3 gene copy number was observed in $38 \%$ of all cases. Importantly, in patients with normal LAMP3 copy numbers a positive and significant association between hypoxia (HP5) and LAMP3 expression was observed whereas no such correlation was seen in the amplified subset. These data indicate that LAMP3 expression in cervical cancer is induced through both genetic means (amplification) as well as by hypoxia (UPR mediated induction), and suggest that the poor prognosis of patients with hypoxic cervix cancer is due in part to PERK/eIF2 $\alpha /$ ATF4 activation of LAMP3 and increased metastatic capacity.

We extended our LAMP3 expression analysis described in Chapter 5 to breast cancer patients (Chapter 6). We found that LAMP3 mRNA levels are elevated in steroid hormone receptor-negative breast tumors and in tumors from nodepositive patients, suggesting that LAMP3 is associated with more aggressive disease. Moreover, we showed that LAMP3 is an independent negative prognostic factor for locoregional control in patients treated with breastconserving lumpectomy and radiotherapy. Since hypoxia has been shown to be prognostic for local control in radiotherapy-treated head and neck cancers (18, 19), our findings suggest that LAMP3 could potentially serve as an endogenous marker of hypoxia-induced radiation resistance in breast cancer.

\section{General Discussion and Future Perspectives}

\section{Hypoxia tolerance versus hypoxia-induced changes in phenotype}

Our work in this thesis emphasizes two distinct mechanisms through which hypoxia-induced signaling pathways, and specifically UPR signaling, facilitate metastasis. First, cellular responses to hypoxia promote adaptation and cell 
survival during conditions of low oxygen, increasing the overall chance of hypoxic tumor cells to metastasize. Tumor cells that are best equipped to survive in hypoxia will, by definition have a higher probability to seed distant metastases. Second, changes in gene expression that occur in response to hypoxia can directly affect the metastatic behavior of tumor cells. This is exemplified by the PERK/eIF $2 \alpha$-mediated increase in LAMP3 expression during hypoxia. LAMP3 enhances the migratory and invasive properties of hypoxic cells (chapter 4 and chapter 5, figures 4E-F), without affecting tolerance (chapter 5, figure 4D).

In chapter 5 of this thesis we demonstrated that disruption of PERK/eIF2 $\alpha$ signaling decreased cell survival during hypoxia in vitro (figure 4B) and inhibited tumor growth (figure 2B). These findings are in agreement with previous studies reporting the importance of PERK signaling in mediating hypoxia tolerance. Hypoxic activation of PERK promotes tolerance by preventing further accumulation of unfolded proteins in the ER through inhibition of protein translation $(10,20,21)$, as well as by stimulating autophagy (13) and protecting cells from oxidative stress (15). The decreased metastatic efficiency of cells with defective PERK/eIF2 $\alpha$ signaling that was observed in chapter 5 (figure 2) is therefore due at least in part to a direct influence of the UPR pathway on hypoxia tolerance. Although our work argues that hypoxia tolerance is an important determinant of metastatic efficiency, its relative importance in hypoxia-regulated metastasis still remains undefined. It is likely that its contribution is dependent on the hypoxic fraction of the tumor as well as the metastasis-promoting genes that are expressed within the tumor, which itself can be tumor-specific.

\section{Acute versus chronic hypoxia}

The cells within a tumor are exposed to a wide range of oxygen concentrations, which originate from both diffusion-limited (chronic) and perfusion-limited (acute) hypoxia. We still have a poor understanding of which subpopulations of hypoxic cells are responsible for the seeding of metastases. Several studies have assessed the importance of acute versus chronic hypoxia in metastasis through dynamically changing the oxygen content of inhalation gas in tumor-bearing animals, and demonstrated that acute/cyclic hypoxia may be more relevant for metastasis than hypoxia arising due to limited diffusion from perfused vessels $(4,5,22)$. The cellular pathways that are activated in response to hypoxia respond differently to hypoxic severity and duration. Stabilization of HIFs occurs at a broad range of oxygen concentrations and maximal activation is observed at relatively moderate hypoxia $\left(1-2 \% \mathrm{O}_{2}\right)$. Activation of the UPR, however, requires more severe hypoxia $\left(<0.02 \% \mathrm{O}_{2}\right.$ for maximum induction), which would be expected upon acute disruption of blood perfusion. A recent study demonstrated a critical role for the PERK/eIF2 $\alpha$-arm of the UPR in 
promoting the survival of cycling hypoxic cells through its ability to upregulate glutathione synthesis for protection against reactive oxygen species that are generated during reoxygenation (15). In contrast, HIF signaling was not required for cell survival under these conditions (15). In Chapter 5 of this thesis we provide evidence for a direct involvement of UPR signaling in cyclic hypoxia-induced metastasis using a genetic model. It should be noted, however, that activation of the UPR can also occur during more moderate hypoxia, albeit more slowly (20). We did not directly compare the contributions of HIF and UPR signaling in our experiments, but it will be important to evaluate their relative importance in hypoxia-driven metastasis during either acute or chronic exposures. It is likely, that the underlying molecular mechanisms, and thus therapeutic targets, will differ between these pathways and thus the relative importance of each is an important question. Experiments are currently underway in our institute to test the impact of knocking down HIF $1 \alpha$ on hypoxia-induced metastasis using the same animal model of human cervix carcinoma that was used for our studies in chapter 5. Similarly, we have recently developed a hypoxia lineage-tracing technology that will allow clear delineation of the involvement of these two pathways in metastasis (see below).

\section{IRE1 and ATF6}

The focus of this thesis has been on the PERK/eIF $2 \alpha$-arm of the UPR. However, the UPR consists of two additional signaling arms, which are mediated by IRE1 and ATF6 that are also activated during ER stress. IRE1 is an ER transmembrane protein with both kinase and endoribonuclease (RNAse) activity. Upon activation, IRE1 catalyzes the mRNA splicing and activation of its only known substrate XBP1 (23). This spliced XBP1 variant is a transcription factor that regulates the expression of genes involved in protein folding, such as chaperones, and protein degradation (24). Just as for PERK/eIF2 $\alpha$, signaling through IRE1/XBP1 has been reported to promote hypoxia tolerance and tumor growth (12). It is therefore possible that the metastatic ability of hypoxic tumor cells is also influenced by phenotypic changes induced by IRE1. However, a recent study using an IRE1-specific inhibitor showed that signaling through IRE1/XBP1 is not important for cell survival during conditions of acute ER stress (25). Instead, cells depend on IRE1/XBP1 for ER expansion, to ensure efficient production and secretion of proteins $(25,26)$. Since hypoxic cells constitute a phenotypically diverse set of cells, it is possible that different subsets of (severely) hypoxic cells show a different dependency on the IRE1 and PERK arm of the UPR. Activation of PERK may be more relevant in acutely hypoxic cells to rapidly limit energycostly protein translation, whereas IRE1 signaling is mainly concerned with restoration of ER capacity and therefore recovery from prolonged ER stress. 
ATF6, the third UPR signaling arm, is a transcription factor whose target genes include XBP1, as well as genes required for protein folding, secretion, and degradation. However, the phenotypic changes associated with ATF6 activation remain poorly characterized. It is important to note that since both IRE1 and ATF6 are transcriptional pathways, their pool of target genes potentially also includes metastasis-promoting genes. Going forward, it will be of great interest to assess the contribution of both IRE1 and ATF6 to hypoxia-mediated metastasis, as this may uncover additional novel mechanisms used by tumor cells to metastasize.

\section{LAMP3, hypoxia and metastasis}

In this thesis we have identified LAMP3 as an important regulator of UPRmediated metastasis. In chapters 4 and 5 we shed some light on its metastasisenhancing functions by demonstrating its involvement in cell migration and invasion. However, the biological function of LAMP3 in these processes remains to be elucidated. The LAMP3 family member LAMP1 was shown to be required for proper formation of membrane ruffles and filopodia in migrating tumor cells (27) and it is possible that LAMP3 exerts a similar function in response to hypoxia. In fact, closer examination of the collagen invasion patterns of LAMP3 knockdown and control spheroids (chapter 5, figure 7) reveals that control spheroids invade the collagen with string-like protrusions, whereas these are largely absent in LAMP3-knockdown spheroids (figure 1). Labeling of LAMP3 to track its subcellular localization in migrating cells, combined with genetic models (e.g. LAMP3 knockdown and overexpression), will further characterize the role of LAMP3 in cell motility and invasion.
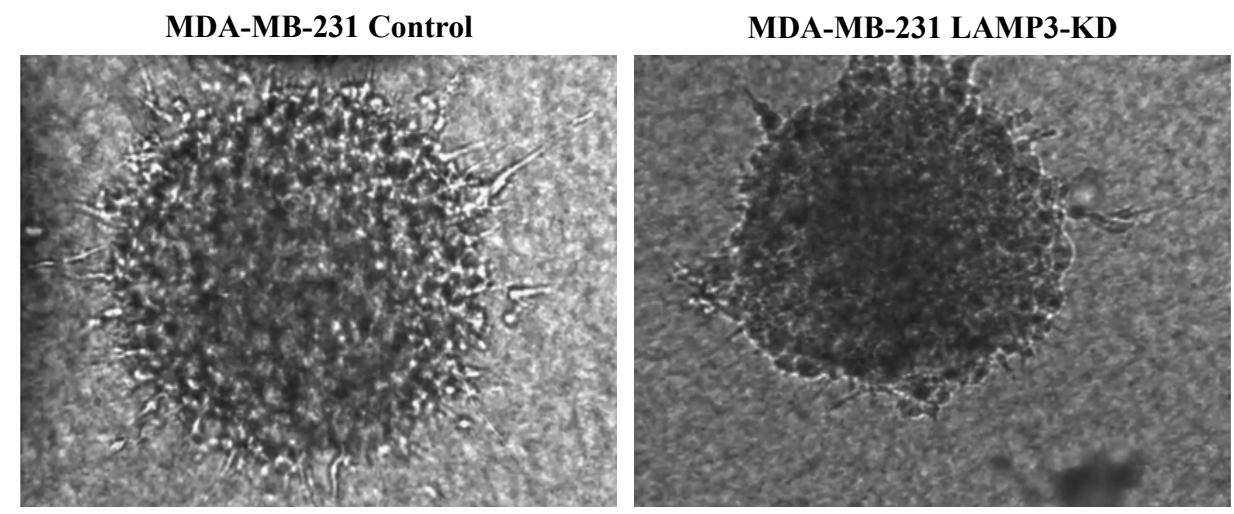

Figure 1. 3D collagen spheroid invasion assay. Spheroids were established from MDA-MB-231 breast cancer cells expressing either a control vector (left) or a short hairpin directed against LAMP3 (LAMP3-KD; right) and allowed to invade into collagen. Images show spheroids after 6 days of invasion. 
A role for LAMP3 in cell-cell adhesion and extravasation has also been suggested, based on the fact that LAMP3 is a highly glycosylated protein that could potentially mediate tumor cell binding to endothelial cells and platelets via cell surface selectins $(28,29)$. We have continued to investigate the role of LAMP3 in the various steps of the metastatic cascade using the experimental metastasis (tail-vein) assay, which allows assessment of the final steps in metastasis, including extravasation. In this assay, tumor cells are injected intravenously into the lateral tail vein of mice, and the number of pulmonary metastases is counted after 2-6 weeks. We established a highly sensitive RealTime PCR assay for quantification of human tumor cells within murine lungs, using primers directed against human Alu repeat sequences. With this method we are able to detect 1 human tumor cell for every $\sim 115,000$ murine lung cells. Due to its high sensitivity, this method can detect small changes in the number of tumor cells in the lungs and therefore allows quantitative assessment of individual steps in metastasis, including extravasation, early survival of solitary cells at the metastatic site and metastatic growth.

To investigate the involvement of LAMP3 in extravasation, we intravenously injected mice with either ME180 control or LAMP3-knockdown cells previously exposed in vitro to 16 hours of anoxia to activate the UPR and induce upregulation of LAMP3 expression, or left untreated. Lungs were harvested 24 hours or 10 days post injection to evaluate tumor cell extravasation, and overall survival and growth at the metastatic site, respectively. At 24 post-injection we detected less human cells in the lungs of animals injected with LAMP3 deficient cells compared to those injected with control cells (figure 2). Most tumor cells are expected to have exited the bloodstream by 24 hours post injection (30); therefore data from this preliminary experiment suggest that LAMP3 indeed promotes extravasation of tumor cells. However, this finding will need to be confirmed by histological analysis of lung sections as well as additional in vitro cell-cell adhesion experiments. Similarly, LAMP3 knockdown significantly reduced metastatic burden at 10 days post-injection, which is most likely a reflection of the diminished extravasation of LAMP3 knockdown cells. Incorporation of additional time points ( $>10$ days) will be necessary to evaluate the contribution of LAMP3 to initial and continued metastatic growth. Furthermore, preexposure of the cells to anoxia increased the number of both LAMP3 knockdown and control cells detected at 24 post-injection, which supports the idea that transient changes in gene expression in response to (primary) tumor hypoxia are sufficient to drive metastatic behavior.

In this thesis we provide evidence from two separate studies that suggests that LAMP3 can potentially serve as an endogenous marker of tumor hypoxia. In the first such study (Chapter 5), we identified a direct relationship between LAMP3 expression and oxygen tension in human cervix tumors. In breast cancer 

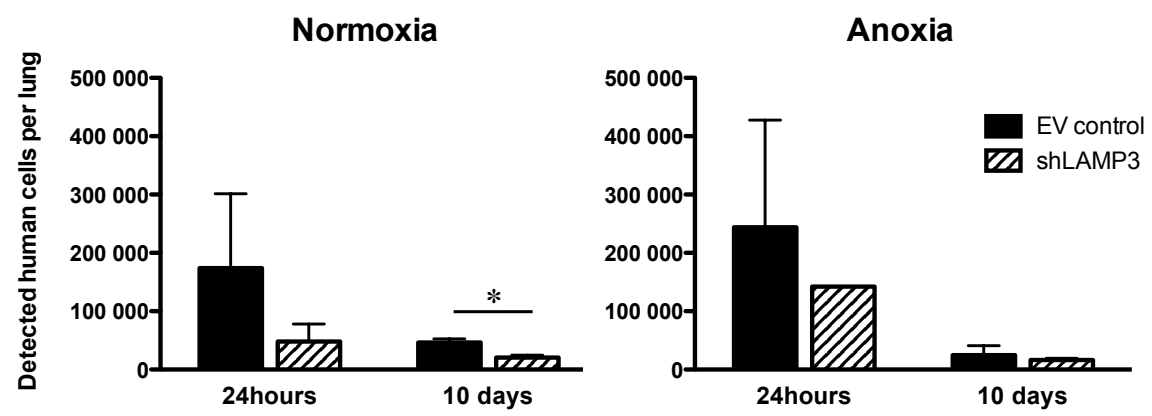

Figure 2. Quantitative analysis of experimental metastasis. ME180 control and LAMP3 knockdown cells $\left(10^{6}\right)$ were injected into the tail-vein of mice and the number of human tumor cells per lung was quantified either 24 hours or 10 days post-injection using RT-qPCR. Cells were exposed to 16 hours of anoxia prior to injection (right; anoxia) or left untreated (left; normoxia). Bars represent averages from 2 animals, and error bars depict SD. ${ }^{*} \mathrm{p}<0.05$

(Chapter 6), we showed that LAMP3 is an independent prognostic factor for locoregional control in patients treated with radiotherapy where hypoxia is known to be important. However, the value of LAMP3 as a marker of hypoxia may be limited by the fact that the LAMP3 gene is often amplified in cervical carcinoma (17), including the patient cohort in our study, and possibly also other cancers $(31,32)$. The reported clinical association between tumor hypoxia and metastasis in cervical cancer implies that LAMP3 could also potentially distinguish between less and more metastatic cervix cancers. However, it still remains to be determined whether LAMP3 directly drives malignancy in human tumors.

\section{Hypoxia lineage-tracing}

Clinical studies have provided robust evidence for an association between tumor hypoxia and increased risk of distant metastasis in several cancer types, including cervix, prostate and soft tissue sarcoma (1-3,33). Experimental data support a role for hypoxia in metastasis (reviewed in chapter 2). However, the underlying mechanisms driving the association between hypoxia and metastasis remain unclear. This is due in part to the fact that all clinical and pre-clinical data (including that presented in this thesis) are correlative in nature, and therefore do not prove that hypoxic cells themselves are directly responsible for seeding metastases. Instead, hypoxia could simply be a manifestation of rapidly growing, aggressive disease. Furthermore, if hypoxia is indeed significantly contributing to metastatic behavior of cells, this could occur in either a direct way by altering cell intrinsic properties, or in an indirect way by influencing other cells in the tumor through paracrine signals (for example by secretion of VEGF). Our understanding of hypoxia-induced metastasis is further complicated by the vast diversity of hypoxic subpopulations in tumors. As 
mentioned earlier, different subsets of hypoxic cells activate distinct oxygensensitive pathways, which can mediate very different cellular responses to hypoxia. It is yet to be determined which subpopulation is most important for metastasis.

A more direct demonstration that hypoxia can influence metastatic capacity directly requires tools to follow the fate of individual cells. One approach to prove the direct involvement of hypoxia in metastasis is through lineage-tracing of specific populations of hypoxic cells. Cell lineage-tracing experiments have been extensively used in developmental biology and stem cell research to map the fate of specific cell populations of interest - primarily putative stem cells. We have recently developed our own hypoxia lineage-tracing technology to genetically label different subpopulations of hypoxic tumor cells based on their activation of distinct hypoxia-response pathways, and track their contribution to the development of metastases. This system allows us to create a set of isogenic cell lines in which the expression of a fluorescent reporter gene can be activated in only defined cell populations. Activation of the reporter gene is irreversible and therefore all labeled cells will pass on the expression of the reporter gene to their progeny. The first step is to create "lineage reporter" lines through genetic integration of a construct containing the fluorescent reporter gene mCherry. This reporter is initially silent due to the presence of a LoxP flanked transcription stop sequence (Lox-Stop-Lox) that can be excised by a Cre recombinase (figure 3). Once these lineage reporter lines are generated and validated, derivate lines are created that contain integration of a second optical reporter (GFP) as well as a modified Cre enzyme (CreERT2) that is active only in the presence of tamoxifen. An internal ribosome entry site (IRES) is used to allow expression of both GFP and CreERT2 from the same promoter. This second construct provides both conditional and temporal control over the activity of the reporter gene: conditional expression of Cre is engineered using selected promoters that are active only under conditions of interest, whereas temporal control over the activation of Cre is achieved through tamoxifen administration.

To determine the contribution of specific subsets of hypoxic cells that activate either the HIF or UPR pathways to metastasis, we propose creation of three sublines that use three different promoters to drive expression of the GFP-IRESCreERT2 construct (figure 3). The first such line will constitutively express GFP and CreERT2 (LRC line), which is achieved using the CMV promoter. Conditional expression in HIF expressing cells (LRH line) is achieved using a promoter containing 5 copies of the hypoxia response element (HRE) (34). We have already synthesized the 5xHRE-EGFP-IRES-CreERT2 lentiviral vector and demonstrated strong induction by hypoxia (figure 4). We will use a fragment of the UPR responsive gene GRP78, which contains 3 copies of the 
ER stress response element (ERSE) to attain conditional expression of GFPIRES-CreERT2 in UPR activated cells (LRU line) (35).

a)

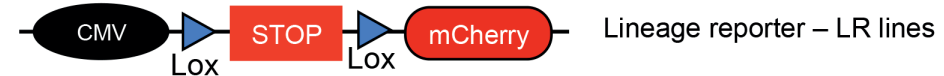

b)

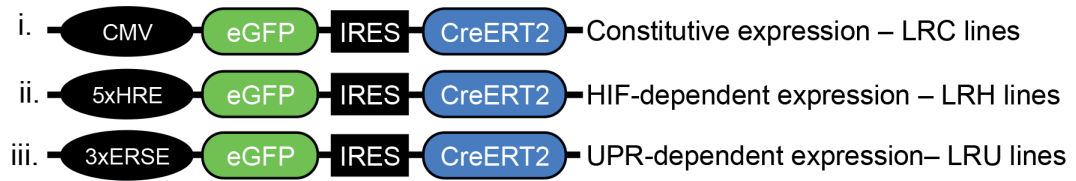

c)

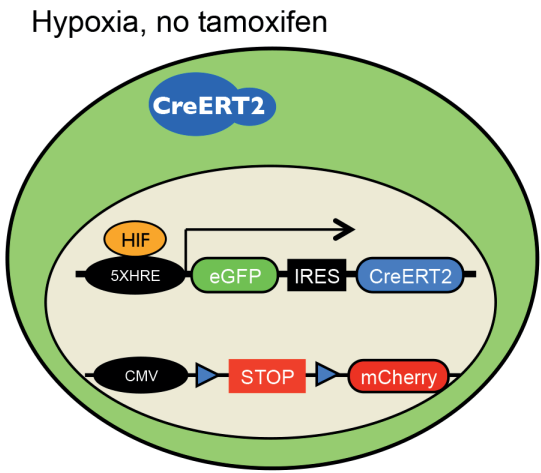

Hypoxia, with tamoxifen

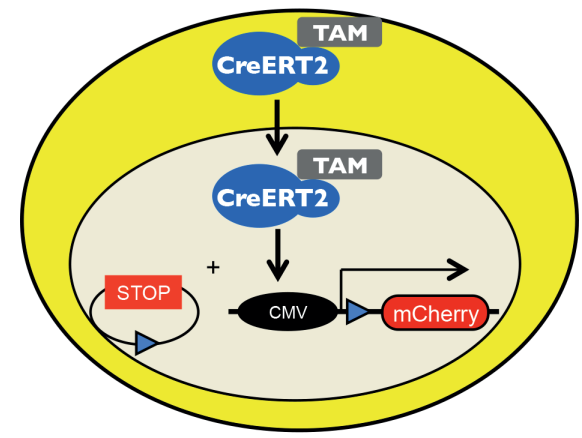

Figure 3. Hypoxia lineage-tracing system. (A) The generation of hypoxia lineage-tracing cell lines first involves the creation of lineage reporter (LR) lines containing the red fluorescent reporter gene mCherry preceded by a synthetic STOP cassette surrounded by loxP sites. (B) Subsequently, three derivate lines are created to express eGFP and CreERT2 from i) a constitutive promoter, ii) HIF dependent promoter, and iii) UPR dependent reporter. (C) An example of lineage tracing to track HIF expressing cells. Left: during hypoxia and without tamoxifen, HIF induces expression of GFP and inactive Cre. Right: in the presence of tamoxifen, Cre is activated by translocation to the nucleus and excises the STOP casette leading to permanent mCherry expression.

This set of isogenic cell lines will be derived from the ME180 cervix carcinoma cell line, which we will subsequently use to establish orthotopic tumors in the mouse cervix to monitor the development of lymph node metastases as described in chapter 5 . Animals will receive tamoxifen continuously during the initial metastasis-free period (first 9 days post implantation) to activate mCherry expression in the primary tumor. The number of mCherry expressing cells in the primary tumor as well as in the nodal metastases will be determined 2 weeks later, after metastasis has occurred. If hypoxia directly stimulates metastases through either the HIF or UPR pathways, we should observe a higher frequency of mCherry positive cells in the metastases compared with that in the corresponding matched primary tumor. 
5xHRE-eGFP-IRES-CreERT2

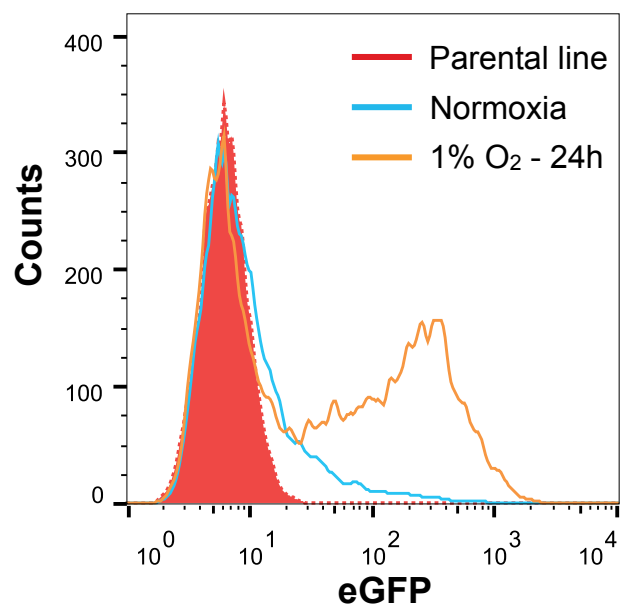

Figure 4. Validation of conditional GFP expression. The 5XHRE-eGFPIRES-CreERT2 construct depicted in figure 1b-ii, which enables HIF dependent expression of GFP and CreERT2, was synthesized and transferred to a lentiviral vector. Recipient cells were infected with resulting lentivirus and subsequently exposed to hypoxia $\left(1 \% \mathrm{O}_{2}\right)$ for 24 hours to activate the HIF-responsive promoter. Infected cells show strong hypoxic induction of GFP.

\section{Concluding Remarks}

Given the fact that hypoxia can greatly influence metastatic behavior of cells, targeting hypoxic cells is a viable therapeutic strategy to prevent development of metastases. Hypoxia-targeting drugs would be most effective in combination with radiotherapy and chemotherapy, which target well-oxygenated cells within the tumor, including those ones with a high metastatic propensity. Our results presented in this thesis suggest that a potential approach to prevent metastasis of hypoxic cells is through targeting of the PERK/eIF2 $\alpha$-arm of the UPR. This could be achieved using agents that inhibit PERK/eIF2 $\alpha$ pathway components (e.g. PERK inhibitors), or agents that target its downstream effector pathways such as autophagy, but potentially also LAMP3. Due to its cell surface location, LAMP3 would be a suitable therapeutic target for metastatic cells. Given the fact that LAMP3 is often amplified in cancer, targeting LAMP3 may also eliminate non-hypoxic tumor cells. The potential importance of ER stress in cancer has led to the development of novel anti-cancer agents aimed at disrupting ER homeostasis (36-38). It will be important to evaluate the therapeutic effect of these agents in combination with conventional therapies on metastasis, in patients both with and without occult metastases at the time of treatment.

\section{References}

1. Fyles A, Milosevic M, Hedley D, Pintilie M, Levin W, Manchul L, et al. Tumor hypoxia has independent predictor impact only in patients with node-negative cervix cancer. J Clin Oncol. 2002;20:680-7. 
2. Milosevic M, Warde P, Menard C, Chung P, Toi A, Ishkanian A, et al. Tumor hypoxia predicts biochemical failure following radiotherapy for clinically localized prostate cancer. Clin Cancer Res. 2012;18:2108-14.

3. Sundfor K, Lyng H, Rofstad EK. Tumour hypoxia and vascular density as predictors of metastasis in squamous cell carcinoma of the uterine cervix. British journal of cancer. 1998;78:822-7.

4. Cairns RA, Hill RP. Acute hypoxia enhances spontaneous lymph node metastasis in an orthotopic murine model of human cervical carcinoma. Cancer research. 2004;64:205461.

5. Cairns RA, Kalliomaki T, Hill RP. Acute (cyclic) hypoxia enhances spontaneous metastasis of KHT murine tumors. Cancer research. 2001;61:8903-8.

6. Rofstad EK, Gaustad JV, Egeland TA, Mathiesen B, Galappathi K. Tumors exposed to acute cyclic hypoxic stress show enhanced angiogenesis, perfusion and metastatic dissemination. International journal of cancer. 2010;127:1535-46.

7. Young SD, Marshall RS, Hill RP. Hypoxia induces DNA overreplication and enhances metastatic potential of murine tumor cells. Proceedings of the National Academy of Sciences of the United States of America. 1988;85:9533-7.

8. Kanao H, Enomoto T, Kimura T, Fujita M, Nakashima R, Ueda Y, et al. Overexpression of LAMP3/TSC403/DC-LAMP promotes metastasis in uterine cervical cancer. Cancer research. 2005;65:8640-5.

9. Cairns RA, Hill RP. A fluorescent orthotopic model of metastatic cervical carcinoma. Clinical \& experimental metastasis. 2004;21:275-81.

10. Bi M, Naczki C, Koritzinsky M, Fels D, Blais J, Hu N, et al. ER stress-regulated translation increases tolerance to extreme hypoxia and promotes tumor growth. The EMBO journal. 2005;24:3470-81.

11. Blais JD, Addison CL, Edge R, Falls T, Zhao H, Wary K, et al. Perk-dependent translational regulation promotes tumor cell adaptation and angiogenesis in response to hypoxic stress. Molecular and cellular biology. 2006;26:9517-32.

12. Romero-Ramirez L, Cao H, Nelson D, Hammond E, Lee AH, Yoshida H, et al. XBP1 is essential for survival under hypoxic conditions and is required for tumor growth. Cancer research. 2004;64:5943-7.

13. Rouschop KM, van den Beucken T, Dubois L, Niessen H, Bussink J, Savelkouls K, et al. The unfolded protein response protects human tumor cells during hypoxia through regulation of the autophagy genes MAP1LC3B and ATG5. J Clin Invest. 2010;120:127-41.

14. van den Beucken T, Ramaekers CH, Rouschop K, Koritzinsky M, Wouters BG. Deficient carbonic anhydrase 9 expression in UPR-impaired cells is associated with reduced survival in an acidic microenvironment. Radiother Oncol. 2009;92:437-42.

15. Rouschop KM, Dubois LJ, Keulers TG, van den Beucken T, Lambin P, Bussink J, et al. PERK/eIF2alpha signaling protects therapy resistant hypoxic cells through induction of glutathione synthesis and protection against ROS. Proceedings of the National Academy of Sciences of the United States of America. 2013;110:4622-7.

16. Hockel M, Schlenger K, Aral B, Mitze M, Schaffer U, Vaupel P. Association between tumor hypoxia and malignant progression in advanced cancer of the uterine cervix. Cancer research. 1996;56:4509-15. 
17. Wangsa D, Heselmeyer-Haddad K, Ried P, Eriksson E, Schaffer AA, Morrison LE, et al. Fluorescence in situ hybridization markers for prediction of cervical lymph node metastases. Am J Pathol. 2009;175:2637-45.

18. Nordsmark M, Overgaard J. A confirmatory prognostic study on oxygenation status and loco-regional control in advanced head and neck squamous cell carcinoma treated by radiation therapy. Radiother Oncol. 2000;57:39-43.

19. Nordsmark M, Overgaard J. Tumor hypoxia is independent of hemoglobin and prognostic for loco-regional tumor control after primary radiotherapy in advanced head and neck cancer. Acta Oncol. 2004;43:396-403.

20. Koritzinsky M, Rouschop KM, van den Beucken T, Magagnin MG, Savelkouls K, Lambin P, et al. Phosphorylation of eIF2alpha is required for mRNA translation inhibition and survival during moderate hypoxia. Radiother Oncol. 2007;83:353-61.

21. Koumenis C, Naczki C, Koritzinsky M, Rastani S, Diehl A, Sonenberg N, et al. Regulation of protein synthesis by hypoxia via activation of the endoplasmic reticulum kinase PERK and phosphorylation of the translation initiation factor eIF2alpha. Molecular and cellular biology. 2002;22:7405-16.

22. Rofstad EK, Galappathi K, Mathiesen B, Ruud EB. Fluctuating and diffusion-limited hypoxia in hypoxia-induced metastasis. Clinical cancer research : an official journal of the American Association for Cancer Research. 2007;13:1971-8.

23. Calfon M, Zeng H, Urano F, Till JH, Hubbard SR, Harding HP, et al. IRE1 couples endoplasmic reticulum load to secretory capacity by processing the XBP-1 mRNA. Nature. 2002;415:92-6.

24. Ron D, Walter P. Signal integration in the endoplasmic reticulum unfolded protein response. Nat Rev Mol Cell Biol. 2007;8:519-29.

25. Cross BC, Bond PJ, Sadowski PG, Jha BK, Zak J, Goodman JM, et al. The molecular basis for selective inhibition of unconventional mRNA splicing by an IRE1-binding small molecule. Proceedings of the National Academy of Sciences of the United States of America. 2012;109:E869-78.

26. Lee AH, Chu GC, Iwakoshi NN, Glimcher LH. XBP-1 is required for biogenesis of cellular secretory machinery of exocrine glands. The EMBO journal. 2005;24:4368-80.

27. Garrigues J, Anderson J, Hellstrom KE, Hellstrom I. Anti-tumor antibody BR96 blocks cell migration and binds to a lysosomal membrane glycoprotein on cell surface microspikes and ruffled membranes. The Journal of cell biology. 1994;125:129-42.

28. de Saint-Vis B, Vincent J, Vandenabeele S, Vanbervliet B, Pin JJ, Ait-Yahia S, et al. A novel lysosome-associated membrane glycoprotein, DC-LAMP, induced upon DC maturation, is transiently expressed in MHC class II compartment. Immunity. 1998;9:325-36.

29. Ozaki K, Nagata M, Suzuki M, Fujiwara T, Ueda K, Miyoshi Y, et al. Isolation and characterization of a novel human lung-specific gene homologous to lysosomal membrane glycoproteins 1 and 2: significantly increased expression in cancers of various tissues. Cancer research. 1998;58:3499-503.

30. Cameron MD, Schmidt EE, Kerkvliet N, Nadkarni KV, Morris VL, Groom AC, et al. Temporal progression of metastasis in lung: cell survival, dormancy, and location dependence of metastatic inefficiency. Cancer research. 2000;60:2541-6.

31. Bockmuhl U, Schwendel A, Dietel M, Petersen I. Distinct patterns of chromosomal alterations in high- and low-grade head and neck squamous cell carcinomas. Cancer research. 1996;56:5325-9. 
32. Sugita M, Tanaka N, Davidson S, Sekiya S, Varella-Garcia M, West J, et al. Molecular definition of a small amplification domain within 3q26 in tumors of cervix, ovary, and lung. Cancer Genet Cytogenet. 2000;117:9-18.

33. Brizel DM, Scully SP, Harrelson JM, Layfield LJ, Bean JM, Prosnitz LR, et al. Tumor oxygenation predicts for the likelihood of distant metastases in human soft tissue sarcoma. Cancer research. 1996;56:941-3.

34. Shibata T, Giaccia AJ, Brown JM. Hypoxia-inducible regulation of a prodrug-activating enzyme for tumor-specific gene therapy. Neoplasia. 2002;4:40-8.

35. Yamamoto K, Yoshida H, Kokame K, Kaufman RJ, Mori K. Differential contributions of ATF6 and XBP1 to the activation of endoplasmic reticulum stress-responsive cis-acting elements ERSE, UPRE and ERSE-II. Journal of biochemistry. 2004;136:343-50.

36. Davenport EL, Moore HE, Dunlop AS, Sharp SY, Workman P, Morgan GJ, et al. Heat shock protein inhibition is associated with activation of the unfolded protein response pathway in myeloma plasma cells. Blood. 2007;110:2641-9.

37. Feldman D. Irestatin, a potent inhibitor of IRE1 $\alpha$ and the unfolded protein response, is a hypoxia-selective cytotoxin and impairs tumor growth. Journal of Clinical Oncology, 2007 ASCO Annual Meeting Proceedings Part I. Vol 25, No. 18S (June 20 Supplement), 2007: 3514.

38. Obeng EA, Carlson LM, Gutman DM, Harrington WJ, Jr., Lee KP, Boise LH. Proteasome inhibitors induce a terminal unfolded protein response in multiple myeloma cells. Blood. 2006;107:4907-16. 



\section{Samenvatting}

Klinische studies in verscheidene soorten kanker hebben een sterke associatie aangetoond tussen hypoxie en het risico op uitzaaiing van kanker (metastasering) (1-3). Er bestaat bovendien een overvloed aan bewijs verkregen uit experimentele studies voor een rol van hypoxie bij metastasering (4-7). Echter, de signaaloverdrachten die plaatsvinden binnen kankercellen en die metastasering bevorderen tijdens hypoxie zijn op dit moment nog niet goed bekend. Dit proefschrift beschrijft hoe de signaaloverdrachten die via het unfolded protein response (UPR) plaatsvinden, bijdragen aan hypoxiegereguleerde metastasering, en ook het algemene belang van het UPR in kanker.

Tijdens onze voortdurende zoektocht naar nieuwe hypoxie-gereguleerde genen hebben we microarray technologie toegepast om transcriptionele veranderingen tijdens hypoxie in kaart te brengen, en daarbij hebben we lysosomal associated membrane protein 3 (LAMP3) ontdekt, een gen dat al eens eerder met metastasering in verband is gebracht (8). In de studie die beschreven staat in Hoofdstuk 3 van dit proefschrift hebben we gedemonstreerd dat de gen expressie van LAMP3 wordt geïnduceerd door strenge hypoxie in meerdere kanker cellijnen, inclusief baarmoederhals (cervix), borst en dikkedarmkanker. We hebben laten zien dat in tegenstelling tot de meeste andere hypoxiegeïnduceerde genen die in verband zijn gebracht met metastasering tot nu toe, LAMP3 niet wordt gereguleerd door HIF1, maar geïnduceerd wordt door het UPR op een PERK, eIF2 $\alpha$, en ATF4-afhankelijke wijze. We hebben ook overexpressie van LAMP3 in borstkanker vastgesteld, en laten zien dat dit gen geïnduceerd wordt in tumoren die behandeld zijn met het anti-angiogenese geneesmiddel bortezomib (Avastin). Dit is consistent met de inductie van hypoxie en het UPR in deze tumoren na het therapeutisch beschadigen van het tumorvaatbed. De resultaten gepresenteerd in Hoofdstuk 3 suggereren dat LAMP3 mogelijk betrokken is bij hypoxie-gereguleerde metastasering.

Om de bijdrage van UPR en LAMP3 inductie door hypoxie tot metastasering te bepalen, hebben we hun rol bij hypoxie-gemedieerde cel migratie en invasie in borstkanker onderzocht (Hoofdstuk 4). Door middel van twee verschillende in vitro cel migratie assays hebben we kunnen aantonen dat siRNA-gemedieerde knockdown van PERK, ATF4 of LAMP3 aanzienlijk de migratiecapaciteit van borstkankercellen verminderde tijdens hypoxie. Dit effect was niet het resultaat van verminderde overleving van cellen tijdens hypoxie na de knockdown. Zoals verwacht hebben we geen enkele verschil in cel migratie gezien toen de assays werden uitgevoerd onder normoxie. Als een tweede in vitro model van tumor hypoxie hebben we multicellulaire sferoïde culturen afkomstig van borstkanker cellijnen tot stand gebracht. Multicellulaire sferoïden hebben een necrotische 
kern die omgeven wordt door hypoxische cellen. We hebben de aanwezigheid van hypoxische cellen in de kern van de sferoïden aangetoond door middel van immunohistochemische kleuring van de exogene hypoxie marker pimonidazole, en we hebben de activatie van het UPR en LAMP3 in de cellen in de sferoïden geobserveerd, maar niet in (normoxische) monolaag cellen. Bovendien, de kankercellen afkomstig van disaggregeerde sferoïden migreerden sneller vergeleken met cellen die in monolagen groeiden. Om te onderzoeken of LAMP3 ook invloed heeft op cel invasie hebben we sferoïden van stabiele LAMP3 knockdown cellen gegenereerd en hun vermogen getest tot infiltratie van collageen matrices, het meest voorkomende eiwit in de extracellulaire matrix. Knockdown van LAMP3 had geen effect op de groei van de sferoïden, maar het had wel aanzienlijk de collageen infiltratie vertraagd. We hebben ook gemengde sferoïden gegenereerd door LAMP3 knockdown en controle cellen te combineren, elk gelabeld met een ander fluorescente kleur, en hun collageen infiltratie gevolgd. In overeenstemming met onze eerdere resultaten hadden de LAMP3 knockdown cellen in de gemengde sferoïden een verminderde capaciteit tot collageen infiltratie vergeleken met de controle cellen. Samenvattend, onze resultaten vanuit de studie beschreven in Hoofdstuk 4 suggereren dat zowel het UPR als LAMP3 cel migratie en invasie bevorderen tijdens hypoxie.

In Hoofdstuk 5 hebben we direct de bijdrage van de hypoxische activering van het UPR en LAMP3 tot metastasering getest door middel van een diermodel van hypoxie-geïnduceerde metastatische cervixkanker. In dit model vindt spontane metastasering plaats van de primaire tumoren die gegenereerd worden van de humane ME180 cervixkanker cellijn in de cervix van muizen, naar de regionale lymfeklieren in het bekken (9). Eerder onderzoek met dit model heeft aangetoond dat wanneer de muizen die deze tumoren dragen worden blootgesteld aan cyclische hypoxie, de metastasering naar de lymfeklieren toeneemt (4), waardoor dit model erg geschikt is om de moleculaire mechanismes van hypoxie-gereguleerde metastasering te bestuderen. We hebben een isogene ME180 sub cellijn gegenereerd waarin doxycyclinegeïnduceerde verstoring van UPR signaaloverdracht via de PERK/eIF2 $\alpha /$ ATF4tak plaats kan vinden. Het gebruik van een induceerbaar model heeft ons in staat gesteld om een mogelijk betrokkenheid van het UPR in metastasering los te koppelen van zijn welbekende rol in primaire tumorvorming (10). We hebben ontdekt dat verstoring van UPR-gemedieerde signaaloverdracht in bestaande tumoren resulteert in een complete inhibitie van hypoxie-gereguleerde lymfeklieren metastasering. Wat nog belangrijker is, is dat inhibitie van UPRgemedieerde signaaloverdracht aanzienlijk uitzaaiing naar de lymfeklieren verminderde, zelfs in dieren die niet waren blootgesteld aan de additionele in vivo hypoxie behandeling. 
Vervolgens hebben we de verschillende mechanismes onderzocht door middel van welke signaaloverdracht via het UPR bijdraagt aan hypoxie-gereguleerde metastasering. Eerdere onderzoeken hebben aangetoond dat het UPR een belangrijke bijdrage levert aan hypoxie tolerantie en tumorgroei doordat het verscheidene cellulaire processen beïnvloedt zoals autofagie, angiogenese, $\mathrm{pH}$ regulatie en de eliminatie van reactieve zuurstofverbindingen (ROS, reactive oxygen species) (10-15). We hebben ontdekt dat UPR deficiënte ME180 cellen gevoeliger zijn voor hypoxie-geïnduceerde celdood in vitro en verstoring van UPR signaaltransductie belemmerde ook de tumorgroei in vivo. Echter, tolerantie mechanismen alleen kunnen niet de bijdrage van PERK/eIF2 $\alpha /$ ATF4 tot hypoxie-gereguleerde metastasering verklaren in ons model. In plaats daarvan wijzen onze resultaten erop dat LAMP3 een fundamentele bijdrage levert aan hypoxie-gereguleerde lymfeklieren metastasering volgend op UPR activatie. Het uitschakelen van LAMP3 expressie verhinderde aanzienlijk hypoxie-gestuurde uitzaaiing naar de lymfeklieren, maar had geen effect op hypoxie tolerantie or tumorgroei. In overeenstemming met onze studie beschreven in Hoofdstuk 4, hebben we in plaats daarvan bewijs gevonden voor een rol van LAMP3 in hypoxie-gereguleerde cel migratie in dit model.

We hebben vervolgens onderzocht of de relatie tussen hypoxie en LAMP3 ook bestaat in humane cervix tumoren, een van de kankersoorten waarin een directe associatie tussen tumor hypoxie en metastasering is gevonden $(1,16)$ (Hoofdstuk 5). LAMP3 expressie werd bepaald in een set van cervixkanker biopten verkregen uit klinische studies in de Princess Margaret Cancer Centre, Toronto, waarin de mate van tumor hypoxie voorafgaande aan de behandeling is gemeten met behulp van zuurstof naald elektrodes. Echter, omdat cervixkanker een van de kankersoorten is waarin amplificatie van het LAMP3 gen is gevonden (17), hebben we eerst het aantal kopieën van het LAMP3 gen bepaald met behulp van een FISH analyse. Hierdoor waren we in staat om onderscheid te maken tussen hypoxie-gereguleerde LAMP3 expressie en verhoogde LAMP3 expressie als gevolg van genetische amplificatie. Overeenkomstig met eerdere cervixkanker studies, hebben we in $38 \%$ van alle patiënten een verhoogd aantal kopieën van het LAMP3 gen geobserveerd. Wat nog belangrijker is, is dat er in patiënten met een normaal aantal LAMP3 kopieën een positieve en statistisch significante associatie tussen hypoxie (HP5) en LAMP3 expressie aanwezig was, terwijl er niet zo een correlatie werd gevonden in de patiënten die een amplificatie van het LAMP3 gen hebben. Deze resultaten duiden erop dat LAMP3 expressie in cervixkanker abnormaal is door zowel een genetisch mechanisme (amplificatie) als ook hypoxie (UPR-gemedieerde inductie), en suggereren dat de slechte prognose van patiënten met hypoxische cervix tumoren mede wordt veroorzaakt door PERK/eIF2 $\alpha /$ ATF4 activatie van LAMP3 en verhoogde capaciteit tot metastasering. 
We hebben ons LAMP3 expressie analyse beschreven in Hoofdstuk 5 uitgebreid naar borstkanker patiënten (Hoofdstuk 6). We hebben ontdekt dat LAMP3 mRNA expressie verhoogd is in steroid hormoon receptor-negatieve borsttumoren en in tumoren afkomstig van lymfeklier-positieve patiënten, wat suggereert dat LAMP3 expressie geassocieerd is met agressievere tumoren. Bovendien hebben we laten zien dat LAMP3 een afhankelijke negatieve prognostische factor is voor locoregionale controle in patiënten die een borstsparende operatie (lumpectomie) en radiotherapie hebben ondergaan. Aangezien hypoxie ook prognostisch is voor lokale controle in radiotherapiebehandelde hoofd- en halstumoren $(18,19)$, suggereren onze bevindingen dat LAMP3 ook een potentiële endogene marker is voor hypoxie-geïnduceerde radioresistentie in borstkanker.

\section{References}

1. Fyles A, Milosevic M, Hedley D, Pintilie M, Levin W, Manchul L, et al. Tumor hypoxia has independent predictor impact only in patients with node-negative cervix cancer. J Clin Oncol. 2002;20:680-7.

2. Milosevic M, Warde P, Menard C, Chung P, Toi A, Ishkanian A, et al. Tumor hypoxia predicts biochemical failure following radiotherapy for clinically localized prostate cancer. Clin Cancer Res. 2012;18:2108-14.

3. Sundfor K, Lyng H, Rofstad EK. Tumour hypoxia and vascular density as predictors of metastasis in squamous cell carcinoma of the uterine cervix. British journal of cancer. 1998;78:822-7.

4. Cairns RA, Hill RP. Acute hypoxia enhances spontaneous lymph node metastasis in an orthotopic murine model of human cervical carcinoma. Cancer research. 2004;64:205461.

5. Cairns RA, Kalliomaki T, Hill RP. Acute (cyclic) hypoxia enhances spontaneous metastasis of KHT murine tumors. Cancer research. 2001;61:8903-8.

6. Rofstad EK, Gaustad JV, Egeland TA, Mathiesen B, Galappathi K. Tumors exposed to acute cyclic hypoxic stress show enhanced angiogenesis, perfusion and metastatic dissemination. International journal of cancer. 2010;127:1535-46.

7. Young SD, Marshall RS, Hill RP. Hypoxia induces DNA overreplication and enhances metastatic potential of murine tumor cells. Proceedings of the National Academy of Sciences of the United States of America. 1988;85:9533-7.

8. Kanao H, Enomoto T, Kimura T, Fujita M, Nakashima R, Ueda Y, et al. Overexpression of LAMP3/TSC403/DC-LAMP promotes metastasis in uterine cervical cancer. Cancer research. 2005;65:8640-5.

9. Cairns RA, Hill RP. A fluorescent orthotopic model of metastatic cervical carcinoma. Clinical \& experimental metastasis. 2004;21:275-81.

10. Bi M, Naczki C, Koritzinsky M, Fels D, Blais J, Hu N, et al. ER stress-regulated translation increases tolerance to extreme hypoxia and promotes tumor growth. The EMBO journal. 2005;24:3470-81. 
11. Blais JD, Addison CL, Edge R, Falls T, Zhao H, Wary K, et al. Perk-dependent translational regulation promotes tumor cell adaptation and angiogenesis in response to hypoxic stress. Molecular and cellular biology. 2006;26:9517-32.

12. Romero-Ramirez L, Cao H, Nelson D, Hammond E, Lee AH, Yoshida H, et al. XBP1 is essential for survival under hypoxic conditions and is required for tumor growth. Cancer research. 2004;64:5943-7.

13. Rouschop KM, Dubois LJ, Keulers TG, van den Beucken T, Lambin P, Bussink J, et al. PERK/eIF2alpha signaling protects therapy resistant hypoxic cells through induction of glutathione synthesis and protection against ROS. Proceedings of the National Academy of Sciences of the United States of America. 2013;110:4622-7.

14. Rouschop KM, van den Beucken T, Dubois L, Niessen H, Bussink J, Savelkouls K, et al. The unfolded protein response protects human tumor cells during hypoxia through regulation of the autophagy genes MAP1LC3B and ATG5. J Clin Invest. 2010;120:127-41.

15. van den Beucken T, Ramaekers CH, Rouschop K, Koritzinsky M, Wouters BG. Deficient carbonic anhydrase 9 expression in UPR-impaired cells is associated with reduced survival in an acidic microenvironment. Radiother Oncol. 2009;92:437-42.

16. Hockel M, Schlenger K, Aral B, Mitze M, Schaffer U, Vaupel P. Association between tumor hypoxia and malignant progression in advanced cancer of the uterine cervix. Cancer research. 1996;56:4509-15.

17. Wangsa D, Heselmeyer-Haddad K, Ried P, Eriksson E, Schaffer AA, Morrison LE, et al. Fluorescence in situ hybridization markers for prediction of cervical lymph node metastases. Am J Pathol. 2009;175:2637-45.

18. Nordsmark M, Overgaard J. A confirmatory prognostic study on oxygenation status and loco-regional control in advanced head and neck squamous cell carcinoma treated by radiation therapy. Radiother Oncol. 2000;57:39-43.

19. Nordsmark M, Overgaard J. Tumor hypoxia is independent of hemoglobin and prognostic for loco-regional tumor control after primary radiotherapy in advanced head and neck cancer. Acta Oncol. 2004;43:396-403. 



\section{Acknowledgments}

I would like to thank my supervisors/promotores Brad Wouters and Philippe Lambin, and my co-supervisors/copromotores Marianne Kortizinsky and Kasper Rouschop for their ongoing guidance and support, and the unique opportunity to work on my research project in Toronto.

I would also like to thank all my colleagues in the Maastro lab in Maastricht, and the Wouters lab in Toronto for all their support and great company over the past few years.

Members of my assessment committee, Prof. dr. Frans Ramaekers, Dr. Jan Bussink, Prof. dr. Rob Coppes and Prof. dr. Marc Vooijs, thank you for your interest in my research and for taking the time to read my thesis.

During my PhD studies I have had the opportunity to collaborate with many highly regarded researchers in the hypoxia field, and I would especially like to thank Prof. dr. Richard Hill, Prof. dr. Adrian Harris and Dr. Paul Span, for their valuable contribution to my research. 



\section{Curriculum Vitae}

Full Name: $\quad$ Hilda Mujcic

Date of Birth: $\quad 27$ June 1984

Education:

- PhD, Jul. 2008 - May 2013

${ }^{1}$ Ontario Cancer Institute/Princess Margaret Cancer Centre, Toronto, Canada ${ }^{2}$ Maastricht Radiation Oncology (Maastro) Lab, Maastricht University, The Netherlands

- MSc in Molecular Life Sciences, specialization: Clinical Molecular Sciences, Maastricht University, The Netherlands, 2006 - 2008

- BSc in Molecular Life Sciences, Maastricht University, The Netherlands, $2003-2006$ 



\section{List of Publications}

Mujcic H, Nagelkerke A, Rouschop K, Chung S, Chaudary N, Span PN, Hill RP, Koritzinsky M, Wouters BG. Hypoxic Activation of the PERK/eIF2 $\alpha$ arm of the Unfolded Protein Response Promotes Metastasis through Induction of LAMP3. Under Review.

Mujcic H, Hill RP, Koritzinsky M, Wouters BG. Hypoxia Signaling and the Metastatic Phenotype. In Preparation.

Chaudary N, Mujcic H, Wouters BG and Hill RP. Hypoxia and Metastasis in an Orthotopic Cervix Cancer Xenograft Model. Radiother Oncol. (In press)

Nagelkerke A, Bussink J, Mujcic H, Wouters BG, Lehmann S, Sweep FC, Span PN. Hypoxia stimulates migration of breast cancer cells via the PERK/ATF4/LAMP3-arm of the unfolded protein response. Breast cancer research : BCR. 2013;15:R2.

Nagelkerke A, Mujcic H, Bussink J, Wouters BG, van Laarhoven HW, Sweep FC, Span PN. Hypoxic regulation and prognostic value of LAMP3 expression in breast cancer. Cancer. 2011;117:3670-81.

Rouschop KM, van den Beucken T, Dubois L, Niessen H, Bussink J, Savelkouls K, Keulers T, Mujcic H, Landuyt W et al. The unfolded protein response protects human tumor cells during hypoxia through regulation of the autophagy genes MAP1LC3B and ATG5. J Clin Invest. 2010;120:127-41.

Mujcic H, Rzymski T, Rouschop KM, Koritzinsky M, Milani M, Harris AL, Wouters BG. Hypoxic activation of the unfolded protein response (UPR) induces expression of the metastasis-associated gene LAMP3. Radiother Oncol. 2009;92:450-9.

van den Beucken T, Koritzinsky M, Niessen H, Dubois L, Savelkouls K, Mujcic $\underline{\mathrm{H}}$, Jutten B, Kopacek J, Pastorekova S et al. Hypoxia-induced expression of carbonic anhydrase 9 is dependent on the unfolded protein response. The Journal of biological chemistry. 2009;284:24204-12.

Xanthoulea S, Gijbels MJ, van der Made I, Mujcic H, Thelen M, Vergouwe $\mathrm{MN}$, Ambagts MH, Hofker MH, de Winther MP. P55 tumour necrosis factor receptor in bone marrow-derived cells promotes atherosclerosis development in low-density lipoprotein receptor knock-out mice. Cardiovasc Res. 2008;80:30918. 